Tesis Doctoral

\title{
EL PAPEL DEL CATALIZADOR USADO DE CRAQUEO CATALÍTICO (FCC) COMO MATERIAL PUZOLÁNICO EN EL PROCESO DE CORROSIÓN DE ARMADURAS DE HORMIGÓN
}

\author{
Autor \\ Emilio Manuel Zornoza Gómez
}

Directores

Jordi Payá Bernabéu

Pedro Garcés Terradillos

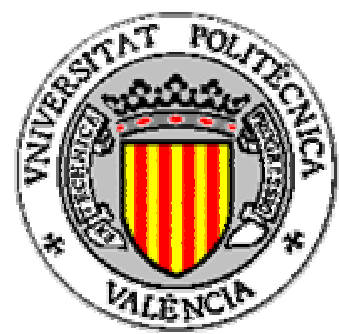

Valencia 2007 



\section{UNIVERSIDAD POLITÉCNICA DE VALENCIA}

\section{Departamento de Ingeniería de la Construcción y Proyectos de Ingeniería Civil}

\section{$\underline{\text { Tesis Doctoral }}$}

\section{EL PAPEL DEL CATALIZADOR USADO DE CRAQUEO CATALÍTICO (FCC) COMO MATERIAL PUZOLÁNICO EN EL PROCESO DE CORROSIÓN DE ARMADURAS DE HORMIGÓN}

Presentada por: D. Emilio M. Zornoza Gómez

Para la obtención del

Grado de Doctor por la Universidad Politécnica de Valencia

Dirigida por: Prof. Dr. D. Jordi Payá Bernabeu

Prof. Dr. D. Pedro Garcés Terradillos

Tribunal Calificador:

Presidente: Dr.

Secretario: Dr.

Vocales: Dr.

Dr.

Dr.

Calificación: 



\section{AGRADECIMIENTOS}

Este documento se ha podido realizar gracias al trabajo conjunto de muchas personas a las que debo un sincero y profundo agradecimiento.

En primer lugar quisiera agradecer al Ministerio de Educación y Ciencia la concesión de la beca FPU (AP20023421) en cuyo amparo he podido realizar este trabajo con el que optar al grado de doctor.

Para mi ha sido una satisfacción personal y un honor el poder haber sido instruido por dos profesionales geniales cuyo rigor $\mathrm{y}$ conocimiento científico sólo es superado por su valía humana. Me refiero a mis directores de tesis Jordi Payá Bernabéu y Pedro Garcés Terradillos. Gracias.

Mis compañeros de laboratorio no sólo han contribuido con su ayuda en muchas de las tareas aquí recogidas sino que han plagado de risas y buenos momentos los cuatro años que he dedicado a la realización de este trabajo. Sin ellos todo habría sido mucho más difícil. Gracias.

Mi familia, entre los que destaco a mi hermano Juande y a mis padres, Ezequiel y $\mathrm{M}^{\mathrm{a}}$ Dolores, son los cimientos de vida y a ellos se lo debo todo. Gracias.

Mi esposa Rosa lo es todo para mí, es mi presente y mi futuro, y sin ella hacer todo esto no tendría sentido. Gracias de todo corazón. 



\section{RESUMEN DE LA TESIS}

\section{INTRODUCCIÓN}

El principal problema que afecta a la vida útil de las estructuras de hormigón armado es la corrosión de las armaduras. Uno de los riesgos más importantes para dicha corrosión es la carbonatación del recubrimiento de hormigón, la cual produce una reducción del $\mathrm{pH}$ de la disolución intersticial y, consecuentemente, la despasivación de los aceros de refuerzo. El otro proceso que supone un gran riesgo para la corrosión de las armaduras lo constituye el ingreso de iones cloruro. Cuando una cantidad suficientemente alta de cloruros alcanza la superficie del acero se produce una ruptura local de las condiciones de pasivación del acero que hace que aumente significativamente la velocidad de corrosión de las armaduras. Por estas razones, la investigación en nuevos conglomerantes que favorezcan la resistencia a la corrosión de las armaduras es un campo de interés para la ingeniería civil.

El catalizador de craqueo catalítico (FCC) es un material de base silicoaluminosa y estructura zeolítica que se usa en las refinerías de petróleo. Cuando el FCC pierde sus propiedades catalíticas, se debe reemplazar por nuevo catalizador. El residuo de catalizador desactivado se desecha y se trata como un residuo inerte. En los últimos años, algunos investigadores han estudiado las propiedades de este residuo como material puzolánico, usándolo como adición a morteros y hormigones. En dichos estudios se ha comprobado que el FCC mejora las propiedades mecánicas de los morteros y hormigones debido a una densificación de la matriz cementicia causada por la reacción puzolánica. No obstante, existe una carencia en el conocimiento de cómo la incorporación de este residuo puede afectar a la corrosión de las armaduras de hormigón frente a los clásicos ataques por dióxido de carbono y cloruros. 


\section{OBJETIVO}

Este trabajo se ha llevado a cabo para estudiar el papel del FCC en el proceso de corrosión de las armaduras de hormigón, cuando se emplea como sustitución parcial del cemento, sometiendo probetas de mortero con FCC a ambientes agresivos $\left(\mathrm{CO}_{2} \mathrm{y} \mathrm{Cl}^{-}\right)$. Para ello se ha dividido el trabajo en diferentes etapas que abarcaban ambos tipos de ambientes (carbonatación y cloruros) y el efecto de estas condiciones agresivas en la matriz cementante y la corrosión de las armaduras.

\section{RESULTADOS}

\section{Efecto de la carbonatación en la matriz cementante de cemento/FCC}

Se realizaron ensayos de carbonatación acelerada de morteros con distintos niveles de sustitución de cemento por FCC y varias relaciones agua/material cementante $(\mathrm{a} / \mathrm{mc})$. En los mismos se pudo comprobar que el consumo de parte de la reserva alcalina de los morteros debido a la reacción puzolánica del FCC, puede ser un factor que acelere el proceso de carbonatación de los recubrimientos de hormigón. No obstante, este fenómeno sólo se puso de manifiesto para relaciones $\mathrm{a} / \mathrm{mc}$ elevadas. Para relaciones $\mathrm{a} / \mathrm{mc}$ inferiores a 0,5 , la incorporación de FCC en cantidades de hasta el 15\% con respecto al peso de cemento, no ofrecía diferencias significativas en cuanto a la velocidad de carbonatación de los morteros. En estos ensayos también se pudo comprobar que la sustitución de cemento por FCC producía una densificación de la microestructrura de la matriz cementante.

Efecto de la carbonatación en la corrosión de armaduras embebidas en morteros de cemento/FCC

En los ensayos de medida de la velocidad de corrosión de aceros en condiciones de carbonatación se observó que la incorporación de hasta un $15 \%$ de FCC no afectaba de forma significativa a la corrosión de los aceros cuando se mantenían relaciones $\mathrm{a} / \mathrm{mc}$ por debajo de 0,5 . Por encima de este valor, el periodo de iniciación de la corrosión era más corto para los aceros que se encontraban embebidos en los morteros con FCC. No obstante, los valores de velocidad de corrosión que se obtuvieron para los aceros de 
los morteros que no incorporaban FCC, una vez que se despasivaban, eran similares a los que ofrecían los análogos con FCC. Esto hace que, si bien la corrosión se iniciaría antes para los morteros con FCC, la vida útil de estructuras que incorporaran en su hormigón FCC sólo sería ligeramente más corta (la diferencia entre los periodos de iniciación de ambos recubrimientos, con y sin FCC). Para relaciones $\mathrm{a} / \mathrm{mc}$ bajas, no se observaron diferencias entre los aceros embebidos en morteros con FCC y los de los morteros sin FCC.

Efecto del ingreso de cloruros en la matriz cementante de morteros de cemento/FCC

Se pudo comprobar que la mayor proporción de aluminatos que ofrece el FCC produce una mayor capacidad de fijación de cloruros en la matriz cementante de los morteros que incorporan dicho producto. Esto hace que el coeficiente difusión de cloruros en estado no estacionario de los morteros con FCC sea menor que el de los morteros sin FCC. Además la densificación de la estructura debida a la reacción puzolánica, también produce un descenso de los coeficientes de difusión de cloruros en estado estacionario con respecto a los morteros que no incorporan FCC. Todo esto apunta a que los morteros con FCC ofrecen una mayor resistencia al ingreso de cloruros que los morteros sin FCC.

Efecto del ingreso de cloruros en la velocidad de corrosión de aceros embebidos en morteros de cemento/FCC

La mayor resistencia al ingreso de cloruros de los morteros con FCC que se ha comentado anteriormente, produce que la velocidad de corrosión de los aceros embebidos en morteros con FCC sea inferior a la ofrecida en los morteros sin FCC. Esto hace que el umbral de cloruros de los morteros con FCC se sitúe en valores cercanos al $2 \%$ con respecto al peso de cemento lo que supone una mejora muy importante respecto a los márgenes de seguridad que se fijan en la instrucción de hormigón EHE, donde se fija como límite máximo de cloruros el $0,4 \%$ respecto al peso de cemento. 


\section{CONCLUSIONES}

Adicionalmente a las mejoras de las propiedades mecánicas que ofrece el FCC se ha podido comprobar que dicho residuo no empeora la corrosión de las armaduras frente a un ataque por carbonatación usando relaciones a/mc bajas, y que mejora muy significativamente la corrosión de las armaduras ante un ataque por cloruros. 


\section{RESUM DE LA TESI}

\section{INTRODUCCIÓ}

El principal problema que afecta la vida útil de les estructures de formigó armat és la corrosió de les armadures. Un dels riscos més importants per aquesta corrosió és la carbonatació del recobriment de formigó, la qual produeix una reducció del $\mathrm{pH}$ de la dissolució intersticial i, conseqüentment, la despassivació dels acers de reforç. L'altre procés que suposa un gran risc per a la corrosió de les armadures està constituït per l'ingrés de ions clorur. Quan una quantitat suficientment alta de clorurs arriba a la superfície de l'acer, es produeix una ruptura local de les condicions de passivació de l'acer que fa que aumente significativament la velocitat de corrosió de les armadures. Per aquestes raons, la investigació en nous conglomerants que afavoreixen la resistència a la corrosió de les armadures és un camp d'interés per l'enginyeria civil.

El catalitzador de craqueig catalític (FCC) és un material de base silicoaluminosa i estructura zeolítica que s'usa en les refineries de petroli. Quan l'FCC perd les seues propietats catalítiques, s'ha de substituir per nou catalitzador. El residu de catalitzador desactivat s'elimina i es tracta com a residu inert. En els últims anys, alguns investigadors han estudiat les propietats d'aquest residu com a material puzolànic com a addició en morters y formigons. En aquests estudis s'ha comprovat que l'FCC millora les propietats mecàniques dels morters i formigons degut a una densificació de la matriu cementícia que està causada per la reacció puzolànica. No obstant, existeix una carència en el coneixement de com la incorporació d'aquest residu pot afectar la corrosió de les armadures de formigó davant els clàssics atacs per diòxide de carboni i clorurs.

\section{OBJECTIU}

En aquest treball s'ha estudiat el paper del FCC en el procés de corrosió de les armadures de formigó, quan s'usa com a substitució parcial de cement. Les provetes de morter amb FCC s'han sotmès a ambients agressius $\left(\mathrm{CO}_{2} \mathrm{i} \mathrm{Cl}^{-}\right)$. Per això s'ha dividit el treball en diferents etapes abarcant les dues classes d'ambients (carbonatació i 
clorurs) i l'efecte d'aquestes condicions agressives en la matriu cementant i la corrosió de les armadures.

\section{RESULTATS}

\section{$\underline{\text { Efecte de la carbonatació en la matriu cementant de cement/FCC }}$}

S'han realitzat proves de carbonatació accelerada de morters amb distints nivells de substitució de cement per FCC i varies relacions aigua/material cementant $(\mathrm{a} / \mathrm{mc})$. En aquestos s'ha pogut comprovar que el consum de part de la reserva alcalina dels morters degut a la reacció puzolànica del $\mathrm{FCC}$, pot ser un factor que accelere el procés de carbonatació dels recobriments de formigó. No obstant, aquest fenomen solament s'ha posat de manifest per a relacions a/mc altes. Per a relacions a/mc per davall de 0,5, la incorporació de FCC en quantitats fins al $15 \%$ respecte de la massa de cement, no oferia diferències significatives de velocitat de carbonatació. En aquestes proves també es va poder comprovar que la substitució de cement per FCC produïa una densificació de la microestructura de la matriu cementant.

Efecte de la carbonatació en la corrosió d'armadures embegudes en morters de cement/FCC

En les proves de mesura de la velocitat de corrosió d'acers en condicions de carbonatació es va observar que la incorporació de fins un $15 \%$ d'FCC no afectava de forma significativa la corrosió dels acers quan es mantenien relacions a/mc per davall de 0,5 . Per damunt d'aquest valor, el període d'iniciació de la corrosió era més curt per als acers que es trobaven embeguts en els morters amb FCC. No obstant, els valors de velocitat de corrosió que es van obtenir per als acers dels morters que no portaven FCC, després de la despassivació, eren pareguts als que oferien els que sí portaven FCC. Això fa que, si bé la corrosió començaria abans per als morters amb FCC, la vida útil d'estructures amb FCC solament seria lleugerament més curta (la diferència entre els períodes de iniciació de cadascun dels recobriments). Per a relacions $\mathrm{a} / \mathrm{mc}$ baixes, no es van observar diferències entre els acers embeguts en morters amb FCC i els dels morters sense FCC. 
Efecte de l'ingrés de clorurs en la matriu cementant de morters de cement/FCC

Es va comprovar que la major proporció de aluminats que ofereix l'FCC produeix una major capacitat de fixació de clorurs en la matriu cementant dels morters que incorporen FCC. Això fa que el coeficient de difusió de clorurs en estat no estacionari dels morters amb FCC siga menor que el dels morters sense FCC. A més, la densificació de l'estructura deguda a la reacció puzolànica, també produeix un descens dels coeficients de difusió de clorurs en estat estacionari respecte als morters que no incorporen FCC. Tot això apunta a que els morters amb FCC ofereixen una major resistència a l'ingrés de clorurs que el morters sense FCC.

Efecte de l'ingrés de clorurs en la velocitat de corrosió d'acers embeguts en morters de cement/FCC

La major resistència a l'ingrés de clorurs dels morters amb FCC que s'ha comentat abans, fa que la velocitat de corrosió dels acers embeguts en morters amb FCC siga menor a l'oferida pels morters sense FCC. Això fa que l'umbral de clorurs dels morters amb FCC es situe en valors prop al $2 \%$ respecte a la massa de cement, el que suposa una millora molt important respecte dels marges de seguretat de la instrucció de formigó EHE, on es fixa com a límit màxim de clorurs el $0,4 \%$ respecte del pes de cement.

\section{CONCLUSIONS}

Addicionalment a les millores de les propietats mecàniques que ofereix l'FCC s'ha pogut comprovar que aquest residu no empitjora la corrosió de les armadures davant un atac per carbonatació usant relacions $\mathrm{a} / \mathrm{mc}$ baixes, $\mathrm{i}$ que millora de forma molt significativa la corrosió de les armadures davant un atac per clorurs. 



\section{SUMMARY OF THE THESIS}

The main problem affecting the life of reinforced concrete structures is reinforcement corrosion. One of the most important risks for corrosion is the carbonation of concrete cover, which produces a reduction of $\mathrm{pH}$ of the pore solution and, consequently, the depassivation of reinforcing steels. The other process leading to high risk of reinforcement corrosion is chloride ingress. When a sufficient amount of chlorides reaches the steel surface, a local breakdown of the passive conditions of the steel takes place, and that produces a significative increase in corrosion rate of steels. For these reasons, research on new binders that enhance the corrosion resistance of reinforcements is a matter of interest in civil engineering.

Catalytic cracking catalyst (FCC) is an aluminosilicate-based material with zeolitic structure that is used in petrol refineries. When FCC losses its pozzolanic activity, it has to be substituted by new catalyst. During last years, some researchers have investigated the properties of this waste as a pozzolanic material, using it as an admixture for mortars and concretes. In these researchs it has been observed that FCC improves mechanical properties of mortars and concretes due to the densification of the cementitious matrix produced by the pozzolanic reaction. However, there is a lack of the knowledge on how the addition of this material can affect the corrosion of steel reinforcements under the classic attacks by carbon dioxide and chlorides.

\section{OBJECTIVE}

In this work it has been studied the role of FCC on the corrosion process of reinforcing steel, when it is used as cement replacement. Mortar and paste specimens have been subjected to aggressive environments $\left(\mathrm{CO}_{2}\right.$ and $\left.\mathrm{Cl}^{-}\right)$. The experimental work has been divided in different stages depending on the aggressive ambient and its effect on the cementing matrix and on the corrosion of reinforcing steel. 


\section{RESULTS}

Influence of carbonation on the cementitious matrix of cement/FCC mortars

Accelerated carbonation tests have been performed in mortars with different level of cement substitution by FCC and different water/binder ratios $(\mathrm{w} / \mathrm{b})$. These tests showed that the presence of FCC produces high decrease in the alkaline reserve of mortars due to the pozzolanic reaction, thus producing higher carbonation rates of mortar cover. However, this phenomenon was only observed for mortars with high $w / b$ ratio. For w/b ratios lower than 0.5 , the presence of FCC in quantities up to $15 \%$ by cement mass, did not offer significative differences in the carbonation rate of mortars. These tests also revealed that cement substitution by FCC produced a densification of the cementing matrix.

Influence of carbonation on the corrosion of reinforcements embedded in cement/FCC mortars

In corrosion rate tests of steels embedded in mortars under carbonation, it was observed that the incorporation of FCC in quantities up to $15 \%$ did not affect significantly the corrosion rate of steels when the $\mathrm{w} / \mathrm{b}$ ratio of the mortar was lower than 0.5 . For higher $\mathrm{w} / \mathrm{b}$ ratios, the initiation period was shorter for that steels embedded in mortars with FCC. Nevertheless, corrosion rate values obtained for steels embedded in mortars without FCC, once they were depassivated, were similar to that offered by steels embedded in mortars with FCC. This means that the corrosion process would start earlier in mortars with FCC, but the life of structures incorporating FCC will only be slightly shorter (the difference between initiation periods of both concretes, with and without FCC). For low w/b ratio, no differences were observed between steels embedded in mortars with and without FCC. 
Influence of chloride ingress on the cementitious matrix of cement/FCC mortars

The higher proportion of aluminates that FCC contains produces an improvement in the chloride binding capacity of the cementitious matrix of mortars with FCC. Therefore, the non-steady state chloride diffusion coefficient of mortars with FCC is lower than that presented by mortars without FCC. Additionally, the densification of the structure due to the pozzolanic reaction also produces a decrease of steady state chloride diffusion coefficients presented by mortars containing FCC. It is concluded that mortars with FCC offer higher chloride ingress resistance than mortars without FCC.

Influence of chloride ingress on the corrosion rate of steels embedded in cement/FCC mortars

The higher chloride ingress resistance of mortars with FCC produces lower corrosion rate levels of steels embedded in these mortars. Then, an increase in the chlorides threshold (up to $2 \%$ of chloride content by cement mass) is observed for mortars with FCC. This is a significant improvement respect to the maximum level of chlorides allowed by the Spanish Concrete Technical Code, which is fixed at $0.4 \%$.

\section{CONCLUSIONS}

In addition to the enhancement of the mechanical properties that FCC offers, it has been observed that this pozzolan does not worsen the corrosion level of steel reinforcement under carbonation attack for low w/b ratio, and a significant improvement in the corrosion behaviour of reinforcements has been observed under chloride ingress attack for steels embedded in mortars incorporating FCC. 



\section{ÍNDICE DE CONTENIDO}

1 Introducción........................................................................2

1.1 Los cementos y la pasta de cemento ................................29

1.1.1 Tipos de cemento y la reacción de hidratación ................29

1.1.2 Porosidad y procesos de transporte .................................31

1.1.2.1 Relación a/c y curado ..................................................

1.1.2.2 Porosidad, permeabilidad y percolación ....................34

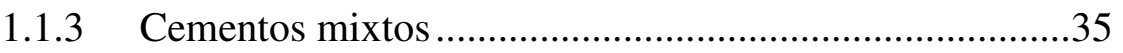

1.1.3.1 Materiales puzolánicos ..............................................35

1.1.3.2 Propiedades de los cementos mixtos ........................37

1.2 Procesos de transporte en el hormigón..................................38

1.2.1 Composición de la disolución intersticial y contenido

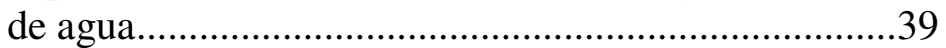

1.2.1.1 Composición de la disolución de los poros ................40

1.2.1.2 Contenido de agua y procesos de transporte .............40

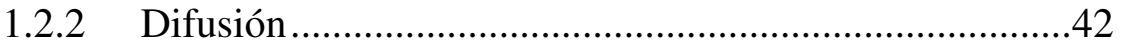

1.2.2.1 Difusión estacionaria...............................................43

1.2.2.2 Difusión no estacionaria............................................43

1.2.2.3 Difusión y fijación....................................................44

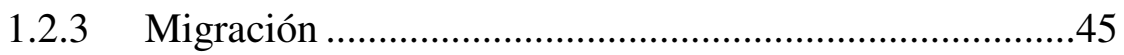


1.2.3.1 Transporte de iones en disolución ............................45

1.2.3.2 Transporte de iones en el hormigón .........................46

1.2.3.3 Resistividad del hormigón......................................48

1.3 Mecanismos de corrosión de armaduras ............................48

1.3.1 Iniciación y propagación de la corrosión ........................49

1.3.1.1 Fase de iniciación ...................................................49

1.3.1.2 Fase de propagación ..............................................50

1.3.2 Velocidad de corrosión..................................................51

1.3.3 Consecuencias ...........................................................52

1.4 Corrosión inducida por carbonatación ................................54

1.4.1 La carbonatación del hormigón......................................54

1.4.1.1 Penetración de la carbonatación ................................55

1.4.1.2 Factores que influyen en la velocidad de carbonatación ........................................................56

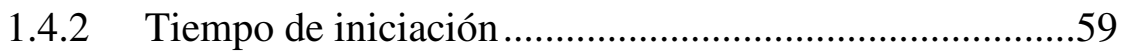

1.4.3 Velocidad de corrosión..................................................61

1.5 Corrosión inducida por cloruros ........................................62

1.5.1 Corrosión por picaduras ................................................64

1.5.2 Iniciación de la Corrosión ...........................................65

1.5.2.1 Umbral de cloruros ...............................................66

1.5.2.2 Penetración de cloruros ........................................... 70 
1.5.2.3 Coeficiente de difusión aparente .............................72

1.5.3 Velocidad de corrosión...................................................74

1.6 El residuo de catalizador de craqueo catalítico (FCC)

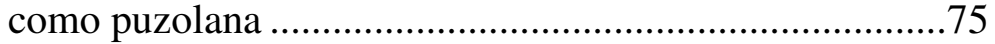

1.6.1 Propiedades físicas y químicas del FCC ........................77

1.6.2 Propiedades de morteros y hormigones frescos con

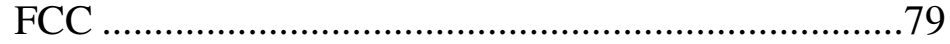

1.6.3 Propiedades de morteros y hormigones endurecidos

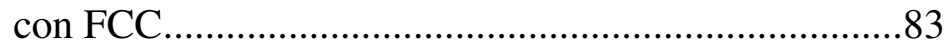

1.6.4 Durabilidad de hormigones y morteros con FCC............91

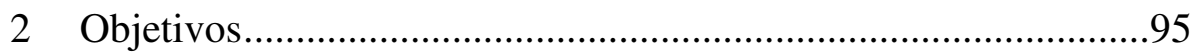

3 Efecto de la carbonatación en la matriz cementante de los morteros mixtos de cemento-FCC

3.1 Análisis mediante termogravimentría de pastas

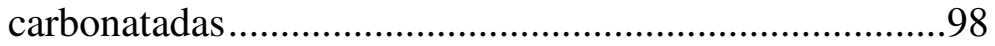

3.1.1 Diseño de la experiencias ..............................................98

3.1.2 Análisis de las pastas de cal ......................................103

3.1.2.1 Antes de la carbonatación ....................................104

3.1.2.2 Después de la carbonatación ..................................110

3.1.3 Análisis de las pastas de cemento ...............................114

3.1.3.1 Antes de la carbonatación ......................................114

3.1.3.2 Después de la carbonatación ...................................120

3.2 Análisis mediante difracción de rayos $\mathrm{X}$ de pastas

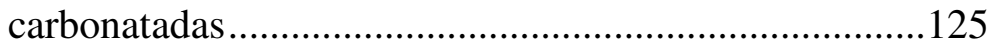




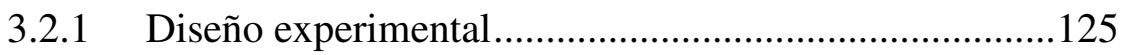

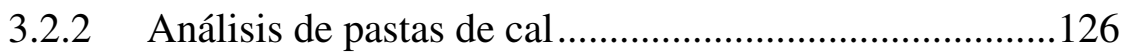

3.2.2.1 Antes de la carbonatación .....................................126

3.2.2.2 Después de la carbonatación ...................................128

3.2.3 Análisis de las pastas de cemento ...............................129

3.2.3.1 Antes de la carbonatación .....................................130

3.2.3.2 Después de la carbonatación .................................132

3.3 Análisis mediante microscopía electrónica de barrido de pastas carbonatadas ...................................................134

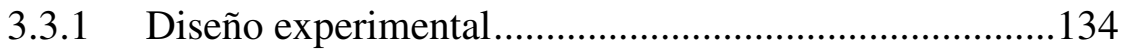

3.3.2 Análisis de pastas de cal ..............................................135

3.3.2.1 Antes de la carbonatación ......................................135

3.3.2.2 Después de la carbonatación .................................138

3.3.3 Análisis de pastas de cemento .....................................140

3.3.3.1 Antes de la carbonatación .....................................140

3.3.3.2 Después de la carbonatación ...................................144

3.4 Caracterización de la estructura porosa de morteros

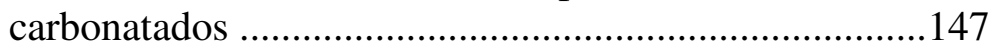

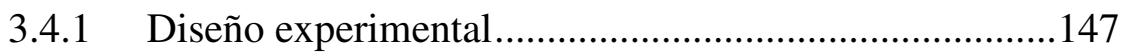

3.4.2 Resultados de las porosimetrías de los morteros...........148

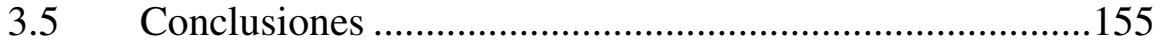


4 Cinética de carbonatación de morteros mixtos de cementoFCC

4.1 Diseño experimental

4.2 Cinética de carbonatación de morteros

4.3 Efecto de la carbonatación en las propiedades mecánicas de los morteros

4.4 Conclusiones

5 Estudio de la velocidad de corrosión de aceros embebidos en morteros mixtos de cemento-FCC sometidos a un ataque por carbonatación

5.1 Diseño experimental

5.1.1 Materiales usados y elaboración de probetas

5.1.2 Conservación de las probetas

5.1.3 Medida de la velocidad de corrosión

5.2 Influencia de la relación a/mc 188

5.3 Influencia del porcentaje de sustitución de FCC.

5.4 Influencia de la humedad relativa del medio de conservación

5.5 Efecto de la carbonatación de los morteros

5.6 Conclusiones

6 Efecto de la carbonatación en morteros ternarios de cementoFCC-ceniza volante reforzados con acero

6.1 Diseño experimental 202

6.1.1 Materiales y elaboración de las probetas..... 202 
6.1.2 Ensayos de velocidad de carbonatación de morteros ....204

6.1.3 Ensayos de velocidad de corrosión de aceros ...............205

6.2 Velocidad de carbonatación de morteros de cemento-

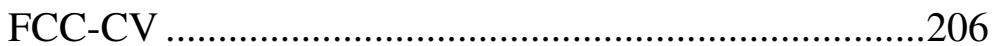

6.3 Velocidad de corrosión de aceros embebidos en morteros de cemento-FCC-CV carbonatados ................211

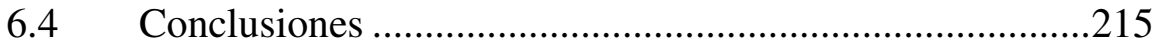

7 Efecto del ataque por cloruros en la matriz cementante de los morteros mixtos de cemento-FCC

7.1 Diseño de las experiencias .............................................218

7.2 Análisis termogravimétrico de las pastas de cementoFCC

7.3 Influencia de los cloruros en la propiedades mecánicas de morteros de cemento-FCC

7.4 Conclusiones

8 Cinética de ingreso de cloruros en morteros mixtos de cemento-FCC

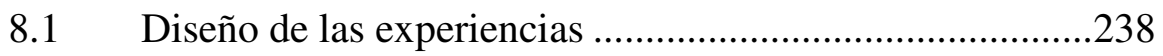

8.2 Cálculo de los coeficientes de difusión de cloruros ..........242

8.3 Caracterización de la red de poros .................................251

8.4 Medidas de resistividad de los morteros ..........................255

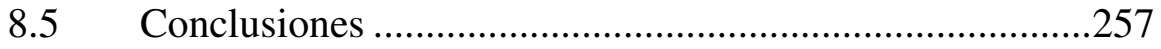

9 Estudio de la velocidad de corrosión de aceros embebidos en morteros mixtos de cemento-FCC sometidos a un ataque por cloruros externos 


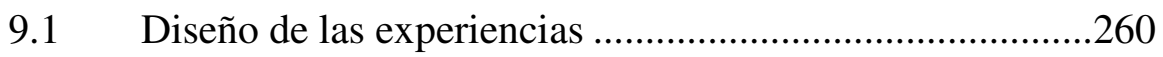

9.2 Influencia del porcentaje de sustitución de FCC...............261

9.3 Influencia de la relación a/mc .........................................264

9.4 Influencia de un ataque por carbonatación posterior al

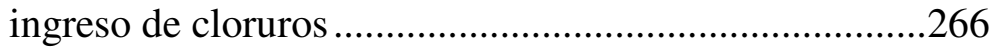

9.5 Comprobación de medidas electroquímicas......................268

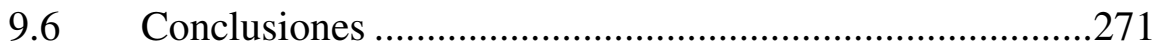

10 Estudio de la velocidad de corrosión de aceros embebidos en morteros mixtos de cemento-FCC sometidos a un ataque por cloruros internos

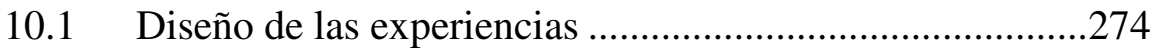

10.2 Influencia del nivel de cloruros introducidos en

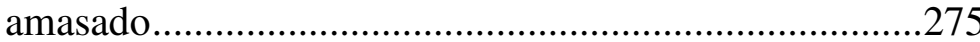

10.3 Comprobación de las medidas electroquímicas ................279

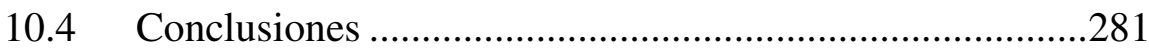

11 Efecto del ataque por cloruros en morteros ternarios de cemento-FCC-ceniza volante reforzados con acero ...................283

11.1 Análisis termogravimétrico de pastas de cemento-FCC-

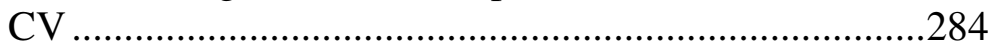

11.1.1 Diseño de las experiencias ........................................284

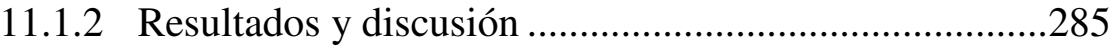

11.2 Cinética de ingreso de cloruros en morteros de cemento-FCC-CV .......................................................293

11.2.1 Diseño de las experiencias ..........................................293 
11.2.2 Resultados y discusión 294

11.3 Corrosión de aceros en morteros de cemento-FCC-CV sometidos a un ataque por cloruros externos .................298

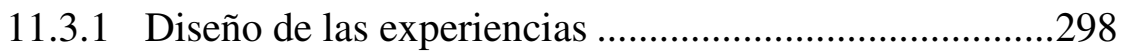

11.3.2 Resultados y discusión ................................................299

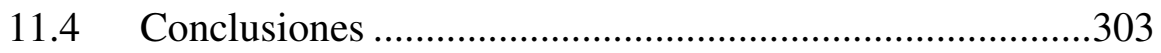

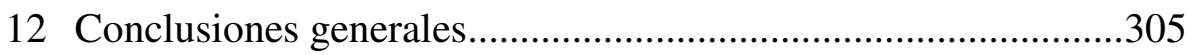

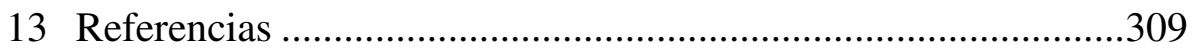




\section{Introducción}

Durante dos milenios, el hormigón preparado por los romanos usando cal, puzolana y áridos ha sobrevivido a los elementos, dando prueba de su durabilidad. Nos han llegado desde entonces prestigiosos trabajos de hormigón: edificios como el Panteón en Roma, cuya estructura actual fue completada en el año 125 d.C. y también estructuras en ambientes marinos han sobrevivido durante dos mil años. Esto demuestra claramente que el hormigón puede ser tan durable como la piedra natural, cuando no estén presentes causas específicas de degradación, como los ácidos o sulfatos, ciclos de hielo-deshielo, o áridos reactivos.

Hoy en día, gracias al progreso realizado durante las últimas décadas en el desarrollo de la química del cemento y en la tecnología del hormigón, incluso estas causas de deterioro pueden ser combatidas de forma efectiva. Con una apropiada selección de materiales, y una preparación y ejecución cuidadosa y adecuadamente controlada, es posible obtener estructuras de hormigón que perdurarán en el tiempo, bajo una amplia variedad de condiciones de servicio. 
El caso del hormigón armado es de alguna forma diferente. Estas estructuras no son eternas, o casi eternas, como se suponía hasta los años 70. En su lugar, su vida de servicio se limita precisamente por la corrosión de las armaduras. De hecho, el hormigón ofrece el entorno ideal para proteger el acero embebido debido a su alcalinidad. $\mathrm{Si}$ el diseño de una estructura, la elección de materiales, la composición de la mezcla, la colocación, compactación y curado se llevan a cabo de acuerdo a las normativas actuales, entonces el hormigón es capaz, bajo la mayoría de condiciones ambientales, de ofrecer protección más allá de los 50 años típicos requeridos de vida de servicio en muchas estructuras ordinarias, al menos en regiones de clima suave. De hecho, los casos de corrosión que han sido identificados en muchas estructuras en periodos mucho menores a los mencionados, pueden, casi siempre, ser atribuidos a fallos en el cumplimiento de las normativas o errores triviales en la manufactura del hormigón. Sin embargo, bajo condiciones de alta agresividad (generalmente relacionados con la presencia de cloruros), incluso el hormigón que ha sido preparado y ejecutado correctamente puede perder sus propiedades protectoras y permitir la corrosión de las armaduras antes de que hayan transcurrido 50 años, a veces con graves consecuencias.

Por lo tanto el problema de la corrosión en estructuras de hormigón armado es muy real y se le debe dar una consideración especial. De hecho, sólo desde principios de los 80 se ha aumentado de forma significativa la actividad investigadora en torno a este problema. Desde entonces, se han establecido los principales aspectos fisiológicos relacionados con el comportamiento del acero en el hormigón, tales como la naturaleza de la disolución intersticial presente en el hormigón endurecido, la electroquímica del acero en este medio, el mecanismo de protección del acero por una capa de óxido, etc. En cuanto a los aspectos patológicos, la investigación ha explicado la fenomenología y los mecanismos de corrosión, ha establecido la condiciones que dan lugar a la misma, las leyes que gobiernan su evolución, y ha desarrollado técnicas para su diagnóstico y control. En particular, se ha mostrado que las únicas circunstancias que dan lugar a la corrosión son aquellas que conducen simultáneamente a la despasivación (debido a la carbonatación o los cloruros), la presencia de oxígeno y la presencia de cierta humedad. 
Las estructuras de hormigón armado forman una parte importante de nuestra infraestructura. La combinación de la elevada resistencia a compresión del hormigón y las altas propiedades a tracción de la armadura de acero, da un material compuesto ideal, el cual ofrece, comparado con otros materiales, un amplio abanico de aplicaciones en la ingeniería de estructuras. Edificios, losas, vigas, puentes, pilares, tanques y tuberías, son estructuras típicas que se pueden realizar con hormigón armado.

Estudiando la historia del hormigón armado se encuentran pocos casos donde una estructura haya fallado debido a cargas mecánicas que no se hayan considerado en la fase de diseño. Las normativas técnicas ofrecen suficiente información a la hora de dar una guía al ingeniero civil para diseñar una estructura adecuada para soportar todas las cargas mecánicas. Rara vez se encuentran fallos de las estructuras debidos a sobrecargas, pero se conoce un alto número de estructuras en las que la corrosión de la armadura ha conducido a fallos prematuros y reparaciones costosas. Por ello, la corrosión de las armaduras en estructuras es ahora un aspecto que figura en el mantenimiento de edificios ya construidos y que ha provocado cierto número de colapsos estructurales.

\subsection{Los cementos y la pasta de cemento}

El hormigón es un material compuesto por combinación de áridos y el producto de la reacción del cemento y el agua de amasado, es decir, la pasta de cemento porosa. La estructura y composición de la pasta de cemento determina la durabilidad y el comportamiento a largo plazo del hormigón. El hormigón se refuerza normalmente con barras de acero. La protección que el hormigón ofrece a los aceros embebidos y, de forma más general, su capacidad para soportar los distintos tipos de degradación, también depende de su estructura.

\subsubsection{Tipos de cemento y la reacción de hidratación}

Los cementos son finos polvos minerales que, cuando se mezclan con agua, forman una pasta que fragua y se endurece debido a reacciones de hidratación. El cemento Portland es la base para los cementos más comúnmente usados. Se produce moliendo el clínker, el 
cual se obtiene mediante la calcinación y fusión las materias primas, una mezcla adecuada de caliza y arcilla, junto con algún componente adicional para el ajuste composicional del crudo que se va a realizar. Sus componentes principales son los silicatos tricálcicos y bicálcicos $\left(\mathrm{C}_{3} \mathrm{~S}\right.$ y $\mathrm{C}_{2} \mathrm{~S}$, respectivamente), el aluminato y el ferroaluminato de calcio $\left(\mathrm{C}_{3} \mathrm{~A}\right.$ y $\mathrm{C}_{4} \mathrm{AF}$, respectivamente). También se añade yeso $(\mathrm{CS})$ al clínker antes de molerlo, para controlar la velocidad de hidratación de los aluminatos, y regular así el tiempo de fraguado.

En presencia de agua, los componentes del cemento Portland forman productos hidratados coloidales y cristalinos de muy baja solubilidad. Los aluminatos reaccionan primero, y son los principales responsables del fraguado, es decir, la solidificación de la pasta de cemento. La hidratación del $\mathrm{C}_{3} \mathrm{~A}$ y del $\mathrm{C}_{4} \mathrm{AF}$, en presencia de yeso, da lugar principalmente a sulfoaluminatos hidratados de calcio. El endurecimiento de la pasta de cemento, es decir, el desarrollo de resistencia que sigue a la solidificación, está gobernada por la hidratación de los silicatos. La hidratación del $\mathrm{C}_{3} \mathrm{~S}$ y del $\mathrm{C}_{2} \mathrm{~S}$ da lugar a silicatos hidratados de calcio formando un gel rígido que se indica como CSH. Está compuesto de partículas extremadamente pequeñas con una estructura laminar que tienden a aglomerarse en formaciones de unas pocas micras de tamaño, caracterizadas por espacios interlaminares de pequeñas dimensiones $(<2 \mathrm{~nm})$ y por una gran área superficial (100-700 m²/g). La Figura 1 muestra un modelo propuesto para describir esta estructura. Debido a la gran área superficial, el $\mathrm{CSH}$ puede dar una resistencia considerable a la pasta de cemento. $\mathrm{Su}$ composición química no está bien definida ya que la relación entre los óxidos de silicio y calcio puede variar según el grado de hidratación, la relación agua/cemento $(\mathrm{a} / \mathrm{c})$ y la temperatura (por ejemplo la relación $\mathrm{C} / \mathrm{S}$ puede pasar de 1,5 a 2). Sin embargo, una vez completada la hidratación, tiende a corresponderse a la fórmula $\mathrm{C}_{3} \mathrm{~S}_{2} \mathrm{H}_{3}$ que se usa normalmente en cálculos estequiométricos. El CSH representa aproximadamente el 50-60\% del volumen de la pasta de cemento completamente hidratada.

La hidratación de los silicatos de calcio también produce cristales hexagonales de hidróxido de calcio $\left(\mathrm{Ca}(\mathrm{OH})_{2}\right.$, portlandita). Éstos tienen dimensiones del orden de unas pocas micras y ocupan entre el 20 y el $25 \%$ del volumen de sólidos. No contribuyen a la 
resistencia de la pasta de cemento. Sin embargo, el $\mathrm{Ca}(\mathrm{OH})_{2}$, así como el $\mathrm{NaOH}$ y el $\mathrm{KOH}$ que están presentes en pequeñas cantidades, son muy importantes en relación con la protección de las armaduras, porque dotan de un $\mathrm{pH}$ alcalino de hasta 13,5 a la disolución de los poros.

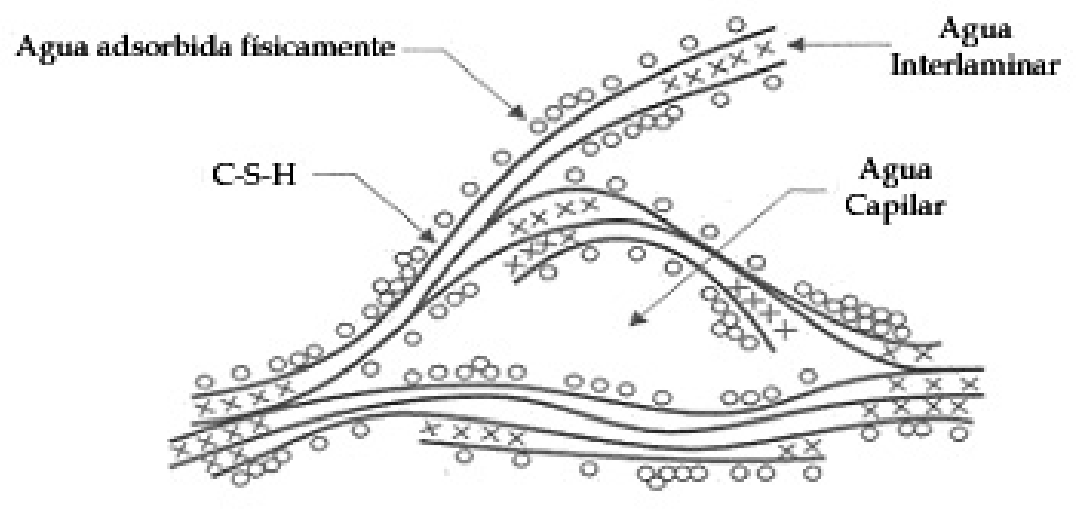

Figura 1. Modelo Ferman-Sereda para CSH [2].

Las reacciones de hidratación de los silicatos tricálcicos y bicálcicos se pueden ilustrar de la siguiente forma:

Ecuación 1

Ecuación 2

$$
\begin{gathered}
2 \mathrm{C}_{3} \mathrm{~S}+6 \mathrm{H} \rightarrow \mathrm{C}_{3} \mathrm{~S}_{2} \mathrm{H}_{3}+3 \mathrm{Ca}(\mathrm{OH})_{2} \\
2 \mathrm{C}_{2} \mathrm{~S}+4 \mathrm{H} \rightarrow \mathrm{C}_{3} \mathrm{~S}_{2} \mathrm{H}_{3}+\mathrm{Ca}(\mathrm{OH})_{2}
\end{gathered}
$$

\subsubsection{Porosidad y procesos de transporte}

La pasta de cemento formada por las reacciones de hidratación siempre contiene poros de distinto tamaño interconectados, como se muestra en la Figura 2. Los poros se pueden dividir en macroporos, poros capilares y poros de gel. El espaciado interlaminar en el CSH (poros de gel) tiene un volumen igual a aproximadamente el $28 \%$ del volumen de gel y dimensiones que van desde unas pocas fracciones de $\mathrm{nm}$ a varios nm. Éstos no afectan a la durabilidad del hormigón y su 
protección a la armadura porque son demasiado pequeños para permitir un transporte significativo de especies químicas agresivas. Los poros capilares son los huecos no rellenados por los productos sólidos de hidratación de la pasta de cemento endurecida. Tienen dimensiones que van desde los 10 hasta $\operatorname{los} 50 \mathrm{~nm}$ si la pasta de cemento está bien hidratada y se usan relaciones a/c bajas. No obstante, pueden alcanzar hasta las 3-5 $\mu \mathrm{m}$ si el hormigón se prepara usando altas relaciones $\mathrm{a} / \mathrm{c}$ o si no está bien hidratado. Los poros mayores de dimensiones de hasta pocos $\mathrm{mm}$ son el resultado del aire atrapado durante el amasado y no eliminados mediante la compactación del hormigón fresco. También se puede introducir intencionadamente burbujas de aire con diámetros de aproximadamente $0,05-1 \mathrm{~mm}$ en la pasta de cemento por medio de aditivos aireantes, de forma que se produzca cierta resistencia a los ciclos de hielo-deshielo. Tanto los poros capilares como los de aire atrapado son relevantes para la durabilidad del hormigón y la protección de las armaduras.

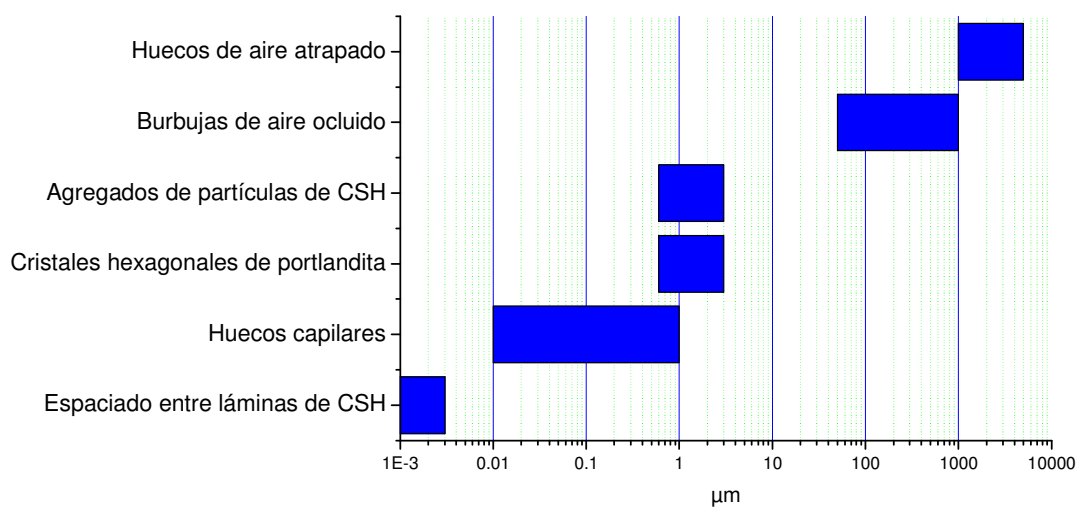

Figura 2. Intervalo dimensional de sólidos y poros en pasta de cemento hidratada [3].

\subsubsection{Relación a/c y curado}

Si la pasta de cemento se mantiene húmeda (curado), la hidratación tiene lugar y el volumen de poros capilares decrece y llegará a un mínimo cuando la hidratación del cemento se haya 
completado. No obstante, el volumen de poros capilares tras la completa hidratación será mayor cuanto mayor sea la distancia inicial entre las partículas de cemento, parámetro que está determinado por la cantidad de agua de amasado. La Figura 3 muestra que la distribución de tamaños de poro, medida por porosimetría de intrusión de mercurio, depende de la relación a/c y del curado. Conforme disminuye la relación a/c o aumenta el tiempo de curado, se observa una reducción de la porosidad. Ésta se debe principalmente a la reducción de los poros de mayor tamaño que han sido rellenados o han sido conectados únicamente por poros de gel de CSH.
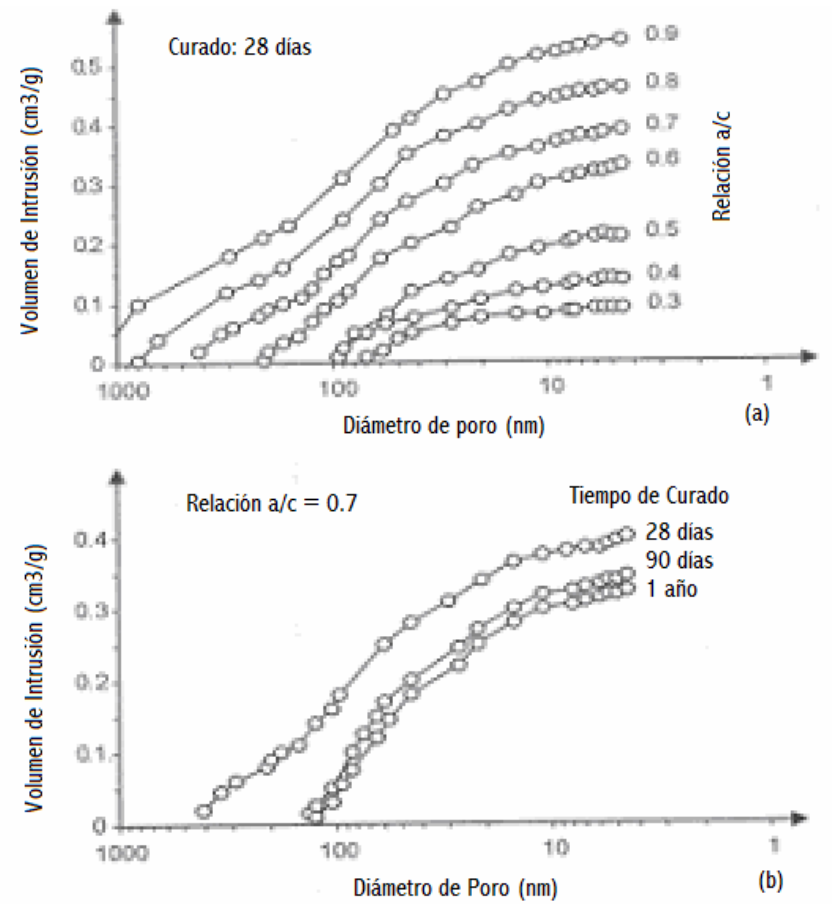

Figura 3. Influencia de la relación a/c $(a)$ y curado $(b)$ en la distribución de tamaños de poro en pastas de cemento hidratadas [3].

Cuando se considera el hormigón en lugar de la pasta de cemento, la relación a/c y el grado de hidratación permanecen como factores principales para determinar la porosidad capilar. No obstante, el hormigón es más complejo debido a la presencia de áridos y la zona 
de transición entre el árido y la matriz cementante, donde la estructura de la pasta de cemento de cemento tiende a ser más porosa $[2,3]$.

\subsubsection{Porosidad, permeabilidad y percolación}

Para la determinación de la resistencia a la degradación del hormigón y su papel en la protección del acero embebido, no sólo se debería considerar la porosidad capilar total (es decir, el porcentaje de volumen ocupado por los capilares) sino también el tamaño y la interconexión de los poros capilares. La Figura 4 muestra la relación entre las propiedades de transporte de la pasta de cemento (expresadas como coeficiente de permeabilidad de agua) y la resistencia a compresión como función de la relación a/c y del grado de hidratación [7].

El descenso en la porosidad capilar aumenta la resistencia mecánica de la pasta de cemento y reduce la permeabilidad de la pasta de cemento hidratada (Figura 4). Se debería hacer una distinción entre los poros capilares de mayores dimensiones (es decir, $>50 \mathrm{~nm}$ ), o macroporos, y los poros de menores dimensiones, o microporos [3]. La reducción en la porosidad resultante tanto de los macro- como de los micro- juega un papel esencial para aumentar la resistencia mecánica.

Por otro lado, la influencia de la porosidad en los procesos de transporte no se puede explicar simplemente por el volumen de poros, sino que tiene que tenerse en cuenta el concepto de conectividad o grado de continuidad del sistema de poros. Con porosidades elevadas el sistema de poros capilares intercontectados se extiende desde la superficie del hormigón hasta el seno del mismo. Si la permeabilidad es alta (Figura 4), los procesos de transporte como, por ejemplo, la succión capilar de agua con cloruros, pueden tener lugar rápidamente. Con porosidad decreciente, el sistema de poros capilar pierde su conectividad, y de esta forma los procesos de transporte pasan a estar controlados por los pequeños poros de gel. Como resultado, el agua y los cloruros penetrarán sólo una pequeña profundidad en el hormigón. Esta influencia de la estructura (geometría) en las propiedades de transporte se puede describir con la teoría de la percolación [8]: por debajo de una porosidad crítica, $p_{c}$ (umbral de percolación), el sistema 
de poros capilares no está interconectado (sólo existen clusters finitos); por encima de $p_{c}$ el sistema de poros capilares es continuo (clusters infinitos). La teoría de la percolación se ha usado para diseñar experimentos numéricos y se ha aplicado a procesos de transporte en pastas y morteros de cemento [9].
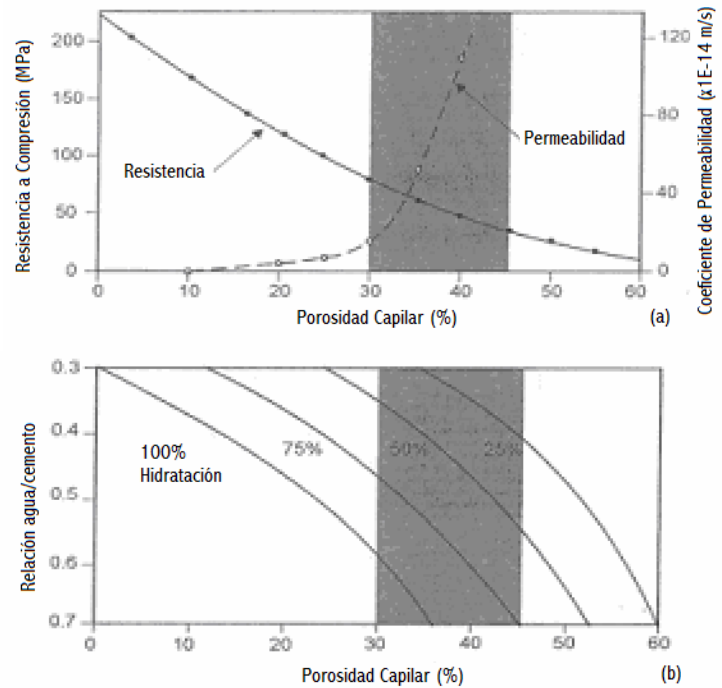

Figura 4. Influencia de la porosidad capilar en la resistencia y permeabilidad de la pasta de cemento $(a)$. La porosidad capilar se deriva de la relación a/c y el grado de hidratación (b) (Powers [7] a partir de [3]).

\subsubsection{Cementos mixtos}

Actualmente los cementos mixtos se usan habitualmente. Éstos se obtienen mediante la molienda o mezclado de cemento Portland con sustancias minerales particulares. Entre éstos, aquéllos con la adición de materiales puzolánicos o escorias de alto horno molidas son de interés particular en relación a la durabilidad del hormigón armado.

\subsubsection{Materiales puzolánicos}

Los materiales puzolánicos pueden ser o bien naturales, como algunas cenizas volcánicas o también tierras de diatomeas, o artificiales, como la ceniza volante y el humo de sílice [2]. Son 
principalmente materiales silíceos vítreos que pueden contener compuestos aluminosos pero que tienen un bajo contenido en calcio. No tienen propiedades ligantes por ellos mismos cuando se mezclan con agua, pero las adquieren en presencia de cal (hidróxido cálcico), dando lugar a productos de hidratación similares a los del cemento Portland.

La reacción entre los materiales puzolánicos, el hidróxido cálcico y el agua se conoce como reacción puzolánica:

Ecuación 3

$$
\text { Puzolana }+ \text { Agua }+\mathrm{Ca}(\mathrm{OH})_{2} \rightarrow \mathrm{C}-\mathrm{S}-\mathrm{H}
$$

En cementos que contienen adiciones puzolánicas, la cal necesitada para la reacción puzolánica la ofrece la hidratación del cemento Portland. La pasta de cemento endurecida (comparada con la obtenida con cemento Portland ordinario) tiene un menor contenido en cal y un mayor contenido en $\mathrm{CSH}$. En algunos casos, la puzolana contiene otros componentes reactivos, fundamentalmente alúmina, que puede modificar la naturaleza de los productos puzolánicos, formándose aluminatos cálcicos y silicoaluminatos cálcicos hidratados (CAH y CASH, respectivamente). La cantidad de adición puzolánica al cemento Portland generalmente oscila entre un 5 y un $40 \%$ de contenido total de cemento. A este respecto se debería considerar cuanta cantidad de cal se produce en la hidratación del cemento Portland, ya que cualquier exceso de adición puzolánica no reaccionará y como consecuencia se comportará como una adición inerte.

a) Puzolana natural. Este es un material sedimentario, normalmente de origen piroclástico, que se deriva de los sedimentos de erupciones volcánicas que producen depósitos incoherentes o depósitos compactos que se han transformado químicamente con el tiempo (como la puzolana italiana, que fue usada por los romanos). Los materiales puzolánicos pueden además tener otros orígenes, como la tierra de diatomeas que se compone del esqueleto silíceo de microorganismos. La actividad puzolánica de estos materiales está relacionada con su componente silícea en estado vítreo y con su finura. También existen puzolanas que se obtienen por 
calcinación de sustancias naturales, como es el caso del metacaolín o la ceniza de cáscara de arroz [10-13].

b) Ceniza volante. La ceniza volante ( $\mathrm{CV}$, también llamada ceniza de fuel pulverizada, PFA) es un subproducto de la combustión del polvo de carbón en centrales termoeléctricas. Consta de partículas muy finas y de forma esférica (tamaño entre 1-100 $\mu \mathrm{m}$ y área superficial específica entre 300-600 $\mathrm{m}^{2} / \mathrm{kg}$ ) que se recogen de los gases de las chimeneas con filtros electrostáticos o mecánicos. Su composición depende del tipo de carbón del que se obtiene; la $\mathrm{CV}$ más común es principalmente silícea. Debido a la alta temperatura a la que se forma y su subsiguiente rápido enfriamiento, se consigue una estructura principalmente amorfa (vítrea) y por tanto reactiva.

c) Humo de sílice. El humo de sílice (HS) es un subproducto de la manufactura de silicio y de aleaciones de ferrosilicio. Consta de un polvo extremadamente fino de sílice amorfa. El tamaño medio de una partícula es aproximadamente 100 veces menor que las de cemento Portland y su área superficial específica es enorme: $13.000-30.000 \mathrm{~m}^{2} / \mathrm{kg}$ comparada con la de cementos Portland ordinarios $\left(300-400 \mathrm{~m}^{2} / \mathrm{kg}\right)$. El humo de sílice muestra una elevada actividad puzolánica y es también un filler muy efectivo. Por estas razones, la adición de humo de sílice al cemento Portland puede conducir a una pasta de cemento de muy baja porosidad, aumentando la resistencia y disminuyendo la permeabilidad. Se adiciona normalmente en una proporción del 5 al $10 \%$ y se combina con el uso de superplastificantes para mantener una adecuada trabajabilidad del hormigón fresco.

\subsubsection{Propiedades de los cementos mixtos}

La pasta de cemento obtenida con cementos mixtos difiere considerablemente de la obtenida con cemento Portland. La hidratación de los materiales puzolánicos consume cal y de esta forma se reduce su cantidad respecto a la pasta de cemento obtenida con cemento Portland. En la Figura 5 se esquematizan las microestructuras de pastas de cemento endurecidas fabricadas con cemento Portland y 
con cementos mixtos. Se puede observar que la adición de CV conduce a la formación de productos de hidratación muy finos que conducen a un refinamiento de los poros. Consecuentemente, se puede obtener un aumento en la resistencia a la penetración de agentes agresivos. Sin embargo, las reacciones de los materiales puzolánicos son más lentas que la hidratación del cemento Portland; por lo que este efecto sólo se conseguirá si el curado húmedo del hormigón es lo suficientemente prolongado.

(a)

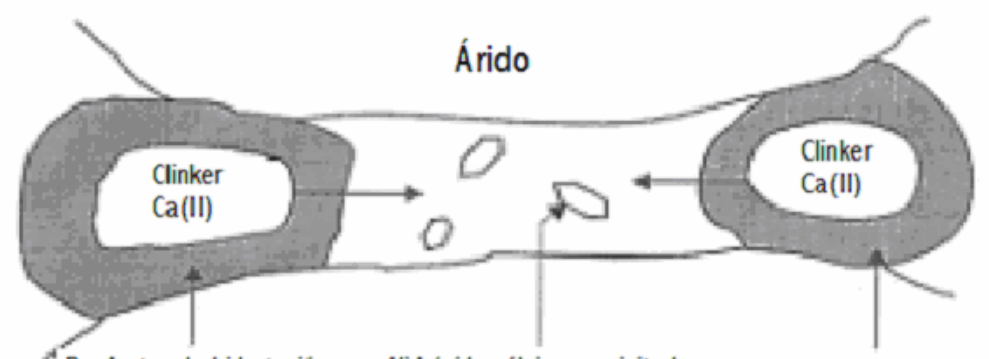

Productos de hidratación del cemento Portland

Hidróxido cálcico precipitado (sin reacción puzolánica)
Productos de hidratación del cemento Portland

(b)

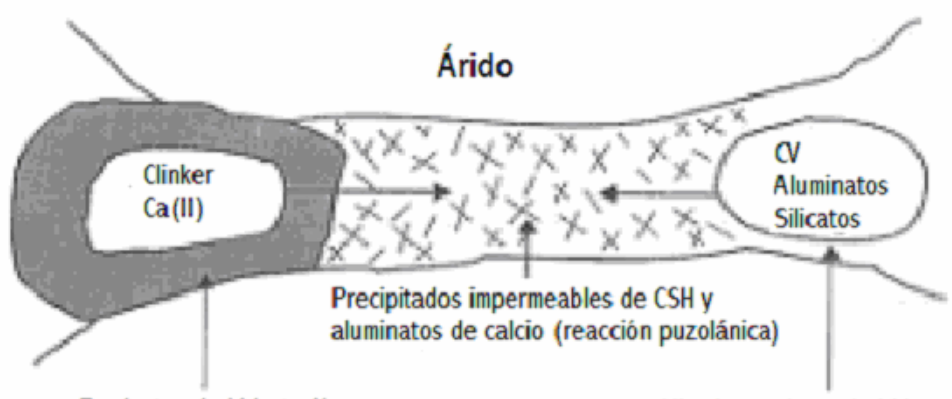

Productos de hidratación del cemento Portland

Ningún producto de hidratación de las cenizas volantes

Figura 5. Microestructura de pastas hidratadas de cemento Portland (a) y de cementos con adición de ceniza volante $(b)$ [6].

\subsection{Procesos de transporte en el hormigón}

A través de los poros del hormigón pueden penetrar gases (como el nitrógeno, oxígeno y $\mathrm{CO}_{2}$ presentes en la atmósfera) y sustancias líquidas (como agua, en la que se disuelven varios iones). 
El término permeabilidad indica, en general, la propiedad del hormigón para permitir el ingreso de estas sustancias. La permeabilidad del hormigón no sólo es importante para estructuras y elementos que retengan agua (tuberías, canales o tanques), sino que es un factor decisivo en la durabilidad del hormigón armado. Los fenómenos que conducen a la degradación del hormigón armado dependen de los procesos que permiten el transporte de agua, dióxido de carbono, iones cloruro, oxígeno, iones sulfato y corrientes eléctricas en el hormigón.

El movimiento de fluidos e iones a través del hormigón puede tener lugar de acuerdo a cuatro mecanismos básicos: succión capilar, debida a la acción capilar dentro de los capilares de la pasta de cemento; permeación, debido a los gradientes de presión; difusión, debido a los gradientes de concentración; y migración, debido a los gradientes de potencial eléctrico [15-17]. La cinética de transporte depende del mecanismo, de las propiedades del hormigón (como su porosidad y la presencia de fisuras), de la capacidad de fijación, por parte de la pasta de cemento, de las sustancias que se transportan, así como de las condiciones medioambientales existentes en la superficie del hormigón (microclima) y de sus variaciones en el tiempo.

Debido a que el líquido presente en los poros tiene una importante influencia tanto en el transporte de varias especies agresivas como en los fenómenos de degradación que pueden tener lugar en el hormigón, es necesario atender a la composición de la disolución de los poros y a las formas físicas del agua en el hormigón en función de las condiciones medioambientales.

\subsubsection{Composición de la disolución intersticial y contenido de agua}

Una determinada cantidad de agua está contenida en los poros de la pasta de cemento hidratada. La cantidad real de agua en los poros del hormigón, es decir, el contenido de humedad, depende de la humedad del ambiente circundante. En el líquido de los poros se encuentran disueltos varios iones producidos por la hidratación del cemento, por lo que en realidad es una disolución acuosa bastante concentrada. 


\subsubsection{Composición de la disolución de los poros}

La composición química de la disolución en los poros de la pasta de cemento hidratada depende de la composición del hormigón; principalmente del tipo de cemento, pero también de las condiciones de exposición, por ejemplo, cambia debido a la carbonatación o penetración de sales.

La hidratación del cemento produce una disolución que consta principalmente de $\mathrm{NaOH}$ y $\mathrm{KOH}$. Dependiendo de la composición del cemento, el $\mathrm{pH}$ de la disolución de los poros puede oscilar entre 13 y 14. Cuando el hormigón sufre la carbonatación, el pH de la disolución de los poros decrece hasta alcanzar valores que se aproximan a la neutralidad $(\mathrm{pH} \approx 9)$ como consecuencia de la drástica reducción en la concentración de iones hidroxilo.

En hormigones no carbonatados y libres de iones, la concentración de iones hidroxilo $\left(\mathrm{OH}^{-}\right)$varía desde $0,1 \mathrm{M}$ hasta $0,9 \mathrm{M}$, debido a la presencia de $\mathrm{NaOH}$ y $\mathrm{KOH}$ (este último más predominante en cemento Portland). Otros iones, como el $\mathrm{Ca}^{2+}$ y el $\mathrm{SO}_{4}{ }^{2-}$, se encuentran presentes sólo en muy bajas concentraciones. La adición de escoria de alto horno o ceniza volante produce una moderada reducción de la concentración iónica, y por tanto del $\mathrm{pH}$. A partir de las concentraciones de los iones hidroxilo se pueden calcular valores de $\mathrm{pH}$ de 13,4-13,9 para el cemento Portland, y valores de $\mathrm{pH}$ de 13,013,5 para los cementos mixtos. La adición de humo de sílice en mayores porcentajes puede conducir a un descenso del $\mathrm{pH}$ a valores por debajo de $13[18,19]$.

La penetración o adición de sales con cloruro cambia la composición química de la disolución de los poros, dependiendo también del tipo de sal (como cloruro sódico o cloruro cálcico). Por ejemplo, el cloruro de sodio aumenta la concentración de $\mathrm{OH}^{-}$(y por tanto el $\mathrm{pH}$ ), mientras que el cloruro de calcio disminuye el $\mathrm{pH}$ [20].

\subsubsection{Contenido de agua y procesos de transporte}

Para el hormigón expuesto a la atmósfera bajo condiciones de equilibrio y en ausencia de mojado, el contenido de agua se puede 
relacionar con la humedad relativa del ambiente, como se muestra en la Figura 6. Con respecto a los poros capilares, el agua se adsorbe primero en su superficie y luego, según aumenta la humedad relativa, el agua condensa y rellena los poros, comenzando por los menores y moviéndose a aquéllos de mayor tamaño.

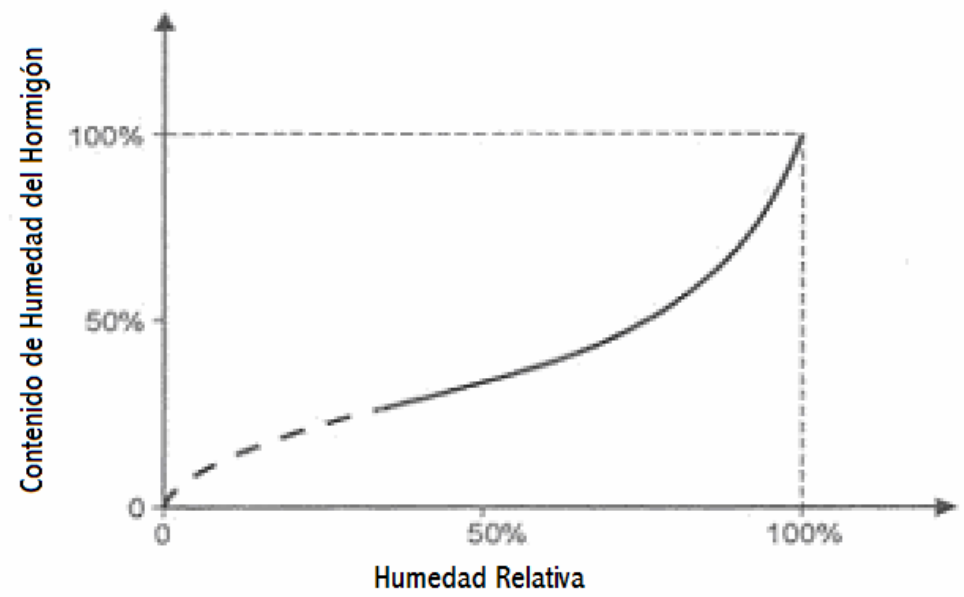

Figura 6. Representación esquemática del contenido de agua libre en los poros del hormigón en función de la humedad relativa del ambiente, en condiciones de equilibrio [15].

En la Figura 7 se representan gráficamente los poros capilares mediante cavidades esféricas conectadas por cilindros capilares estrechos cuyos tamaños se consideran estadísticamente distribuidos (sólo se representan los poros accesibles, es decir los poros conectados entre ellos y con el medio externo). De acuerdo con este diagrama, dentro del hormigón que está expuesto a una atmósfera con una determinada humedad relativa, los poros cuyos diámetros están por debajo de un valor determinado resulta que están rellenos de agua, mientras que aquellos con diámetros por encima de este valor están rellenos de aire. 


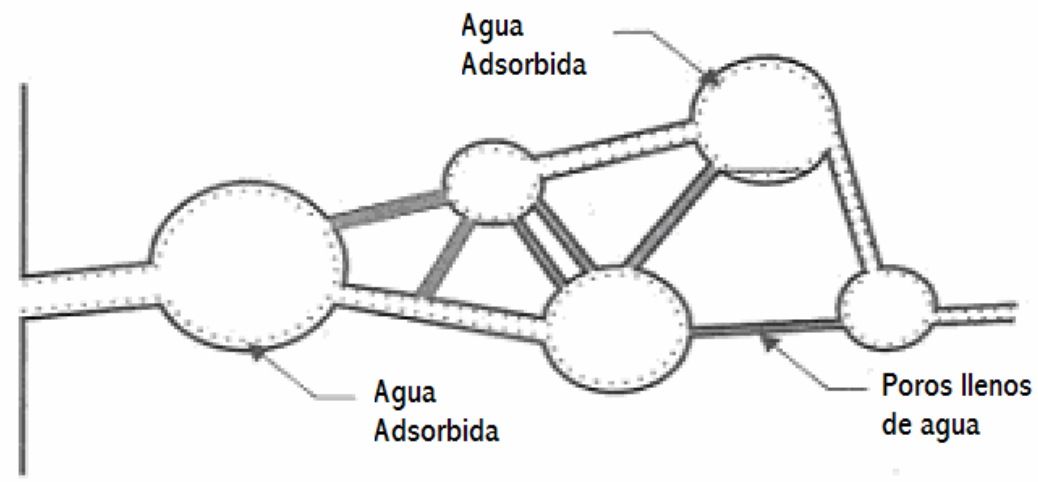

Figura 7. Representación del agua presente en los poros capilares en el hormigón en equilibrio con una atmósfera no saturada [15].

La presencia de poros rellenos de agua que están interconectados con otros tiene una marcada influencia en las cinéticas de los procesos de transporte. Ello dificulta aquellos procesos que tienen lugar más fácilmente en fase gaseosa, como la difusión de oxígeno y dióxido de carbono. Por otro lado, facilita los procesos que tienen lugar en disolución acuosa, como la difusión de cloruros, o iones en general.

\subsubsection{Difusión}

La penetración de especies agresivas en el hormigón con frecuencia ocurre por difusión, esto es, por el efecto de un gradiente de concentración. $\mathrm{El} \mathrm{O}_{2}$, el $\mathrm{CO}_{2}$, el $\mathrm{Cl}^{-} \mathrm{o}$ el $\mathrm{SO}_{4}{ }^{2-}$ se mueven a través de los poros desde la superficie, donde están presentes en mayores concentraciones, hacia zonas internas donde su concentración es menor. Los gases difunden mucho más rápidamente a través de los poros abiertos que a través de los que están saturados de agua (la difusión de gases en agua es 4-5 órdenes de magnitud más lenta que en aire). Por otro lado, los iones cloruro o sulfato sólo difunden cuando están disueltos en el agua de los poros; la difusión es más efectiva en poros saturados que en los parcialmente saturados. 


\subsubsection{Difusión estacionaria}

Bajo condiciones de transferencia de masa estacionarias (unidireccional y constante), la primera ley de Fick describe el fenómeno de la difusión:

\section{Ecuación 4}

$$
F=-D \frac{d C}{d x}
$$

donde: $F$ es el flujo $\left(\mathrm{kg} / \mathrm{m}^{2} \mathrm{~s}\right), C$ es la concentración de las especies que difunden presentes a una distancia $x$ de la superficie. $D$ es el coeficiente de difusión, expresado en $\mathrm{m}^{2} / \mathrm{s}$, el cual depende de las especies que difunden, de las características del hormigón y de las condiciones medioambientales. Este coeficiente puede cambiar en función de la posición y el tiempo, siguiendo variaciones en la estructura de los poros (como los debidos a la hidratación de la pasta de cemento), o de la humedad externa (y por tanto del grado de saturación de los poros) o la temperatura.

Los valores para el coeficiente de difusión efectivo de estado estacionario pueden variar desde $10^{-14}$ hasta $10^{-11} \mathrm{~m}^{2} / \mathrm{s}$ para hormigones con distintos cementos y relaciones a/c [21,22].

\subsubsection{Difusión no estacionaria}

Como la difusión rara vez alcanza condiciones estacionarias en estructuras de hormigón, el flujo depende del tiempo $t$ y está gobernado por la segunda ley de Fick:

$$
\text { Ecuación } 5 \quad \frac{\partial C}{\partial t}=D \frac{\partial^{2} C}{\partial x^{2}}
$$

Esta ecuación se usa normalmente integrada bajo la suposición de que la concentración del ion que difunde, medida en la superficie del hormigón, es constante en el tiempo y es igual a $C_{s}\left(C=C_{s}\right.$ para $x$ $=0$ y para cualquier $t$ ), de que el coeficiente de difusión $D$ no varía con el tiempo, de que el hormigón es homogéneo, por lo que $D$ no varía a través del espesor del hormigón, y de que inicialmente no 
contiene cloruros $(C=0$ para $x>0$ y $t=0)$. La solución entonces obtenida es:

\section{Ecuación 6}

$$
\frac{C(x, t)}{C_{s}}=1-\operatorname{erf}\left(\frac{x}{2 \sqrt{D t}}\right)
$$

donde:

Ecuación 7

$$
\operatorname{erf}(z)=\frac{2}{\sqrt{\pi}} \int_{0}^{z} e^{-t^{2}} d t
$$

es la función error ${ }^{1}$.

Esta ecuación se utiliza a menudo para describir matemáticamente los perfiles de concentración de cloruros experimentales encontrados en ensayos de laboratorio no estacionarios o a partir de estructuras de campo.

Los valores obtenidos para los coeficientes de difusión aparentes de cloruros en estado no estacionario pueden variar entre $10^{-13}$ y $10^{-11} \mathrm{~m}^{2} / \mathrm{s}$ para hormigones con distintos ligantes y relaciones a/c $[2,23]$. En los países nórdicos se ha normalizado un ensayo para la determinación del coeficiente de difusión no estacionario [24].

\subsubsection{Difusión y fijación}

Las especies que difunden en el hormigón se pueden fijar hasta cierto punto a componentes de la matriz de cemento, por ejemplo, los cloruros se unen a las fases de aluminato o son adsorbidos en el CSH; el dióxido de carbono reacciona con los componentes alcalinos, en particular con el $\mathrm{Ca}(\mathrm{OH})_{2}$. El consumo gradual de estos compuestos

${ }^{1}$ Los valores de la función error han sido tabulados. Por otro lado, también se puede calcular mediante la distribución estándar normal ( $N$, también tabulada), considerando que:

$$
\operatorname{erf}(z)=2 N(z \sqrt{2})-1 \quad N(z \sqrt{2})=\frac{1}{\sqrt{2 \pi}} \int_{-\infty}^{z \sqrt{2}} e^{\frac{t^{2}}{2}} d t
$$


modifica las condiciones de difusión, las cuales no pueden seguir siendo descritas por la segunda ley de Fick sino que requieren un factor de corrección.

Para la penetración de cloruros en particular, a menudo se considera la concentración total de especies que difunden y los efectos de las reacciones químicas en el hormigón son ignorados. En efecto, es difícil estimar el factor de corrección. De hecho, la capacidad de fijación de la pasta de cemento es función de varios parámetros, tales como la concentración local de una sustancia dada y la temperatura. También dependerá de la composición química del hormigón y por tanto de sus variaciones (por ejemplo, la capacidad de fijación de cloruros se reduce considerablemente en el hormigón carbonatado) [16]. La fijación de especies que difunden es importante a la hora de determinar experimentalmente el coeficiente de difusión. De hecho, mientras que la capacidad de fijación del hormigón no se haya agotado, el flujo neto de material parecerá menor, y el coeficiente será subestimado. Por lo tanto, cuando no se aplica un factor corrector en la evaluación de la concentración de un compuesto que difunde, el coeficiente de difusión que se obtiene de este modo es "aparente" y depende del tiempo. Sin embargo, se ha demostrado [25] que incluso en presencia de compuestos ligantes, los cloruros se mueven hacia el interior del hormigón como si la difusión determinara la velocidad de penetración. Como una primera aproximación, la fijación por tanto puede ser despreciada en el cálculo y el coeficiente de difusión se denomina aparente. Dado que la penetración de cloruros en estructuras de hormigón es esencialmente un proceso no estacionario, los ensayos se deberían realizar en condiciones no estacionarias, o se debería tener en cuenta el efecto de la fijación.

\subsubsection{Migración}

\subsubsection{Transporte de iones en disolución}

El transporte de iones dentro de una disolución bajo un campo eléctrico se denomina migración. La velocidad de movimiento de los iones es proporcional a la intensidad del campo eléctrico y a la carga y tamaño de los iones. Es posible hacer una comparación entre los diferentes iones en función de su movilidad $u$. El protón y el hidroxilo 
son los iones que muestran las mayores movilidades debido a su interacción con el agua como disolvente.

La movilidad iónica $u_{\mathrm{i}}$ (que describe el movimiento del ion bajo un campo eléctrico) está directamente relacionada con el coeficiente de difusión $D_{\mathrm{i}}$ (que describe el movimiento bajo un gradiente de concentración) mediante [26]:

\section{Ecuación 8}

$$
D_{i}=\frac{R T u_{i}}{z_{i} F}
$$

donde: $R$ es la constante de los gases $(\mathrm{J} / \mathrm{mol} \cdot \mathrm{K}), T$ es la temperatura $(\mathrm{K}), F$ es la constante de Faraday $(96490 \mathrm{C} / \mathrm{mol})$ y $z_{\mathrm{i}}$ es la valencia del ion $i$.

La contribución de un determinado ion (i) a la corriente total que fluye $I_{\text {tot }}$ se denomina número de transferencia o número de transporte $t_{\mathrm{i}}$, el cual aumenta con la concentración $c_{\mathrm{i}} \mathrm{y}$ con la movilidad $u_{\mathrm{i}}$ del ion (siendo constante la de otros iones $(j)$ ):

\section{Ecuación 9}

$$
t_{i}=\frac{I_{i}}{I_{\text {tot }}}=\frac{c_{i} u_{i} z_{i}}{\sum\left(c_{j} u_{j} z_{j}\right)}
$$

Cabe destacar que la temperatura tiene un efecto muy pronunciado en la migración iónica (y por tanto en el flujo de corriente y resistividad).

\subsubsection{Transporte de iones en el hormigón}

Los principios que se aplican a las disoluciones acuosas son, básicamente, también válidos para el hormigón, porque el transporte de corriente eléctrica se debe al movimiento de iones en el sistema de poros rellenos de agua. Los iones positivos $\left(\mathrm{Na}^{+}, \mathrm{K}^{+}, \mathrm{Ca}^{2+}\right)$ migran en la dirección de la corriente; los negativos $\left(\mathrm{OH}^{-}, \mathrm{SO}_{4}{ }^{2-}, \mathrm{Cl}^{-}\right)$en la dirección opuesta.

Aplicando el concepto de números de transporte (Ecuación 9) al hormigón, se puede demostrar que para el hormigón libre de 
cloruros, asumiendo que la disolución de los poros contiene $0,5 \mathrm{M}$ de $\mathrm{NaOH}$, los números de transporte para el $\mathrm{OH}^{-}$y el $\mathrm{Na}^{+}$son 0,8 y 0,2 , respectivamente. Para el hormigón contaminado por sales de cloruro, asumiendo que la disolución de los poros contiene $0,5 \mathrm{M}$ de $\mathrm{NaOH}$ y $0,5 \mathrm{M}$ de $\mathrm{NaCl}$, los números de transporte del $\mathrm{OH}^{-}$, el $\mathrm{Na}^{+}$y el $\mathrm{Cl}^{-}$son $0,52,0,20$ y 0,28 , respectivamente.

A diferencia de lo que ocurre en el seno de una disolución, los iones no son capaces de moverse por la ruta más corta, sino que tienen que encontrar el camino a lo largo de los estrechos y tortuosos poros capilares. Por ello la distancia real (es decir, desde la superficie del hormigón hasta la armadura) es mucho mayor que la distancia geométrica. Además, los iones sólo se pueden transportar a través de los poros interconectados que estén rellenos de agua. Por tanto, la velocidad de migración (y difusión) en el hormigón está gobernada por el volumen y la geometría de los poros y su distribución. Por esta razón la migración de iones (y la difusión), incluso en materiales basados en cemento saturados de agua (pasta de cemento, mortero, hormigón), es 2-3 órdenes de magnitud inferior comparada con las disoluciones. Esta drástica influencia del volumen de poros se puede modelar usando la teoría de la percolación [27].

El flujo de corriente eléctrica por la migración de iones en el hormigón es importante para las técnicas de rehabilitación electroquímicas como la extracción de cloruros, pero también para los procesos de corrosión (macrocélulas).

La migración de iones en el hormigón se puede ensayar como una medida de su resistencia a la penetración de cloruros usando ensayos de migración, de los que existen varias versiones. Algunos de estos ensayos miden la migración no estacionaria, expresada como la profundidad de penetración de cloruros en un espécimen en un campo eléctrico $[28,29]$. Otros métodos aplican un campo eléctrico a través de un espécimen hasta que se detecta un flujo de cloruros estacionario en la célula de baja concentración de cloruros [30]. 


\subsubsection{Resistividad del hormigón}

La resistividad del hormigón es un parámetro importante usado para describir, por ejemplo, el grado de saturación de agua, la resistencia a la penetración de cloruros o la velocidad de corrosión. La resistividad del hormigón puede tener valores que van desde unas pocas decenas hasta varios miles de $\Omega \cdot \mathrm{cm}$ en función del contenido de agua del hormigón (humedad relativa), el tipo de cemento usado (cemento Portland o mixto), la relación a/c, la presencia de cloruros o si el hormigón se encuentra carbonatado. A edades tempranas, la resistividad del hormigón es baja y tiene lugar un considerable aumento debido a la hidratación del cemento. Todos estos factores pueden ser racionalizados en base a la migración de iones a través de la porosa y tortuosa microestructura del hormigón: una elevada humedad relativa aumenta la cantidad de poros rellenos de agua (disminuye la resistividad), la relación a/c y el tipo de cemento determina el volumen de poros y la distribución de tamaños de poro (menos poros pero más anchos con cemento Portland sólo; más poros pero más finos y menos interconectados con escoria de alto horno y ceniza volante); los iones cloruro aumentan la conductividad de la disolución de los poros y la carbonatación la disminuye. Una mayor resistividad viene acompañada por una menor velocidad de corrosión [31].

\subsection{Mecanismos de corrosión de armaduras}

Durante la hidratación del cemento se obtiene una disolución en los poros altamente alcalina ( $\mathrm{pH}$ entre 13 y 14), principalmente de hidróxidos de sodio y potasio. En este ambiente, los compuestos termodinámicamente estables del hierro son óxidos y oxihidróxidos de hierro. Por tanto, para un acero de refuerzo ordinario embebido en el hormigón alcalino se forma espontáneamente una fina capa protectora de óxido (la capa pasivante). Esta capa pasivante sólo tiene unos nanómetros de espesor y está compuesta de óxidos de hierro más o menos hidratados con un grado variable de $\mathrm{Fe}^{2+}$ y $\mathrm{Fe}^{3+}$ [34]. La acción protectora de la capa pasivante es inmune al daño mecánico de la superficie del acero. Sin embargo, puede ser destruida mediante la carbonatación del hormigón o mediante la presencia de iones cloruro. El acero de refuerzo estaría entonces despasivado. 


\subsubsection{Iniciación y propagación de la corrosión}

La vida de servicio de las estructuras de hormigón armado puede dividirse en dos fases distintas (Figura 8). La primera fase es la iniciación de la corrosión, en la cual la armadura está pasivada pero los fenómenos que pueden conducir a la pérdida de pasividad, como la carbonatación o la penetración de cloruros en el recubrimiento de hormigón, tienen lugar. La segunda fase, la propagación de la corrosión, comienza cuando el acero se despasiva y finaliza cuando se alcanza un estado límite más allá del cual la consecuencias de la corrosión no pueden ser toleradas [35].

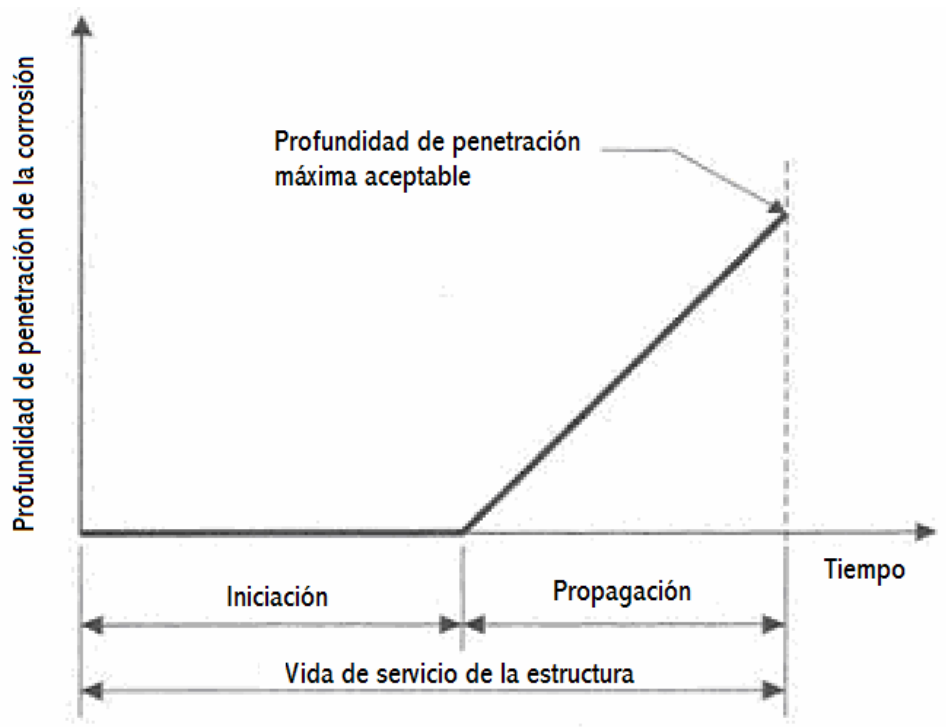

Figura 8. Periodos de iniciación y propagación para la corrosión en una estructura de hormigón armado (modelo de Tuutti) [35].

\subsubsection{Fase de iniciación}

Durante la fase de iniciación, las sustancias agresivas $\left(\mathrm{CO}_{2}\right.$, cloruros) que pueden despasivar el acero penetran desde la superficie hacia el seno del hormigón:

a) Carbonatación: comenzando en la superficie del hormigón y moviéndose gradualmente hacia zonas interiores, la alcalinidad 
del hormigón puede ser neutralizada por el dióxido de carbono de la atmósfera, de forma que el $\mathrm{pH}$ del líquido de los poros del hormigón disminuye a un valor alrededor de 9 donde la película pasivante ya no es estable.

b) Iones cloruro del medio pueden penetrar en el hormigón y alcanzar la armadura; si su concentración sobre la superficie del refuerzo alcanza un valor crítico, la capa protectora puede ser localmente destruida.

La duración de la fase de iniciación depende del espesor de recubrimiento y de la velocidad de penetración de los agentes agresivos así como de la concentración necesaria para despasivar el acero. La influencia del recubrimiento de hormigón es obvia y los códigos de diseño definen espesores de recubrimiento de acuerdo a la clase de exposición esperada. La velocidad de ingreso de los agentes agresivos depende de la calidad del hormigón de recubrimiento (porosidad, permeabilidad) y de las condiciones microclimáticas (mojado, secado) sobre la superficie del hormigón.

\subsubsection{Fase de propagación}

La destrucción de la capa protectora es un prerrequisito necesario para la iniciación de la corrosión. Una vez que se ha destruido la capa, la corrosión sólo tendrá lugar si están presentes el agua y el oxígeno en la superficie de la armadura. La velocidad de corrosión determina el tiempo que tarda la estructura en alcanzar un estado inaceptable (Figura 8) pero se debería tener en cuenta que esta velocidad puede variar considerablemente dependiendo de la temperatura y la humedad.

La carbonatación del hormigón conduce a la completa disolución de la capa protectora. Los cloruros, por su parte, causan la destrucción localizada, a menos que estén presentes en cantidades muy elevadas. Por tanto:

a) La corrosión inducida por carbonatación puede tener lugar en toda la superficie del acero en contacto con el hormigón carbonatado (corrosión generalizada). 
b) La corrosión por cloruros es localizada (corrosión por picaduras), con ataques penetrantes de área limitada (picaduras) rodeadas de áreas no corroídas. Sólo cuando están presentes niveles muy altos de cloruros (o disminuye el $\mathrm{pH}$ ) puede ser destruida la capa pasivante en grandes extensiones de la armadura y la corrosión será de naturaleza generalizada.

Si la despasivación debido a la carbonatación o los cloruros tiene lugar sólo en una parte de la armadura, se puede desarrollar una macropila entre las barras corroídas y las que están todavía pasivas (y conectadas eléctricamente a las anteriores). Esto puede aumentar la velocidad del ataque sobre la armadura que ya estaba corroída.

En estructuras afectadas por campos eléctricos, las armaduras pueden sufrir en algunas zonas la formación de corrientes vagabundas. La capa pasivante puede destruirse en la zona de salida de la corriente vagabunda.

En el acero de alta resistencia usado en hormigón pretensado (pero no en el acero de refuerzo corriente) bajo condiciones ambientales de carga mecánica, metalúrgicas y electroquímicas muy específicas, puede tener lugar la fragilización por hidrógeno, que puede ocasionar una rotura frágil del material $[36,37]$.

\subsubsection{Velocidad de corrosión}

La velocidad de corrosión normalmente se expresa como la velocidad de penetración y se mide en $\mu \mathrm{m} / \mathrm{año}$. Con frecuencia, especialmente en ensayos de laboratorio, se expresa en unidades electroquímicas, como $\mathrm{mA} / \mathrm{m}^{2}$ ó $\mu \mathrm{A} / \mathrm{cm}^{2}$. En el caso del acero, 1 $\mathrm{mA} / \mathrm{m}^{2}$ ó $10 \mu \mathrm{A} / \mathrm{cm}^{2}$ se corresponde con una pérdida de masa de aproximadamente $90 \mathrm{~g} / \mathrm{m}^{2}$.año y una velocidad de penetración de aproximadamente $11,7 \mu \mathrm{m} / \mathrm{año}$.

La velocidad de corrosión se puede considerar despreciable si está por debajo de $0,1 \mu \mathrm{A} / \mathrm{cm}^{2}$, baja entre 0,1 y $0,2 \mu \mathrm{A} / \mathrm{cm}^{2}$, moderada entre 0,2 y $0,5 \mu \mathrm{A} / \mathrm{cm}^{2}$, intermedia entre 0,5 y $1 \mu \mathrm{A} / \mathrm{cm}^{2}$, alta entre $1 \mathrm{y}$ $10 \mu \mathrm{A} / \mathrm{cm}^{2}$ y muy alta por encima de $10 \mu \mathrm{A} / \mathrm{cm}^{2}$ (Figura 9). 


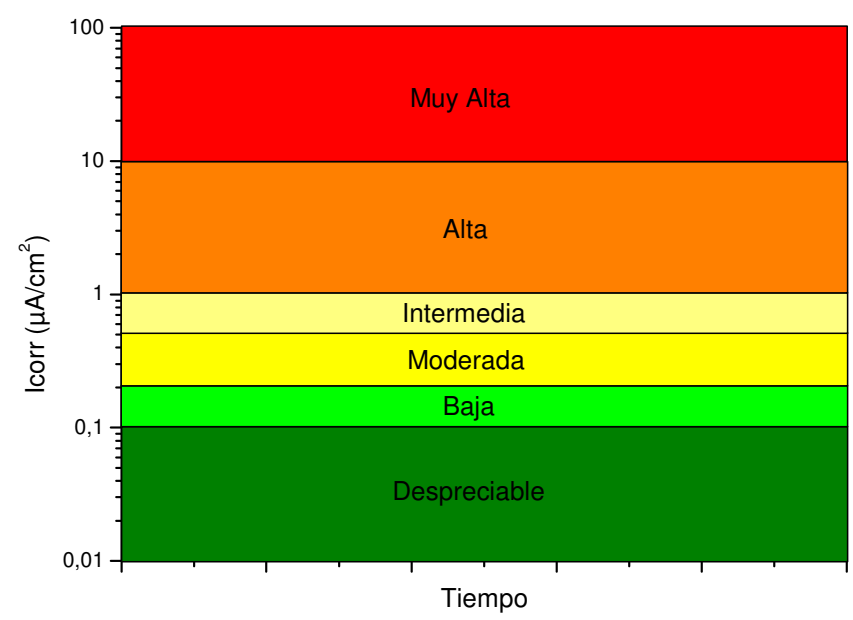

Figura 9. Diagrama de clasificación de la velocidad de corrosión.

\subsubsection{Consecuencias}

Las consecuencias de la corrosión de las armaduras de acero no implican sólo a la capacidad de dar un servicio de la estructura o sus condiciones externas, sino que también pueden afectar a su rendimiento estructural, y por tanto su seguridad.

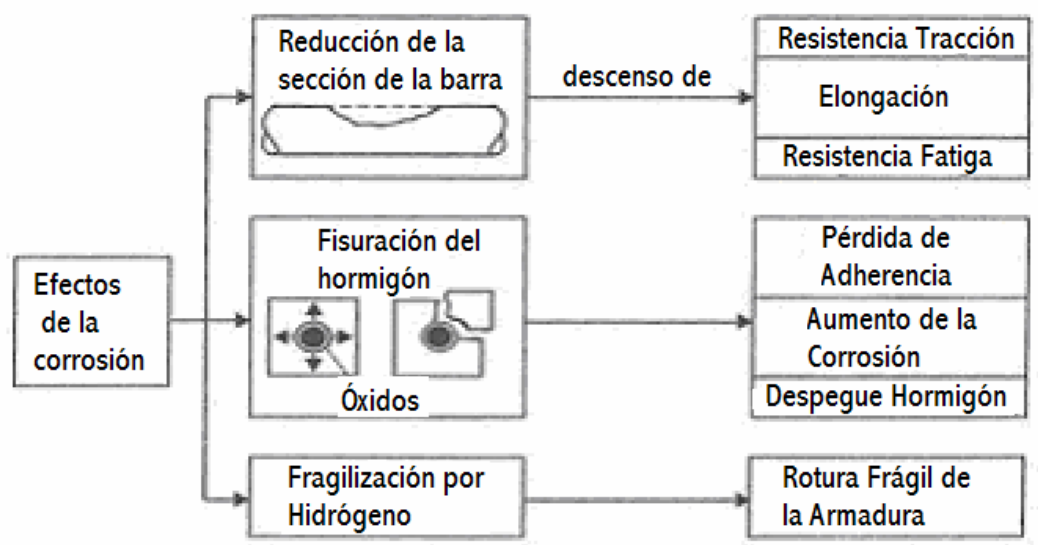

Figura 10. Consecuencias estructurales de la corrosión de estructuras de hormigón armado [15]. 
Las principales consecuencias del ataque por corrosión se muestran en la Figura 10. La corrosión normalmente se observa por las manchas de óxido que aparecen en la superficie externa del hormigón, o por el daño al recubrimiento de hormigón producido por la expansión de los productos de corrosión. Estos productos, de hecho, ocupan un volumen muy superior al del acero original. El volumen de los productos de corrosión puede ser desde 2 hasta 6 veces mayor que el del hierro del que se derivan, dependiendo de su composición y del grado de hidratación. Por ejemplo, los volúmenes de los óxidos $\mathrm{Fe}_{3} \mathrm{O}_{4}$, $\mathrm{Fe}(\mathrm{OH})_{2}, \mathrm{Fe}(\mathrm{OH})_{3}, \mathrm{Fe}(\mathrm{OH})_{3} \cdot 3 \mathrm{H}_{2} \mathrm{O}$ son, respectivamente, 2, 3, 4 y 6 veces mayores que el del hierro. En general, el volumen de los productos de corrosión, mezcla de estos óxidos, se puede considerar 34 veces mayor que el del hierro.
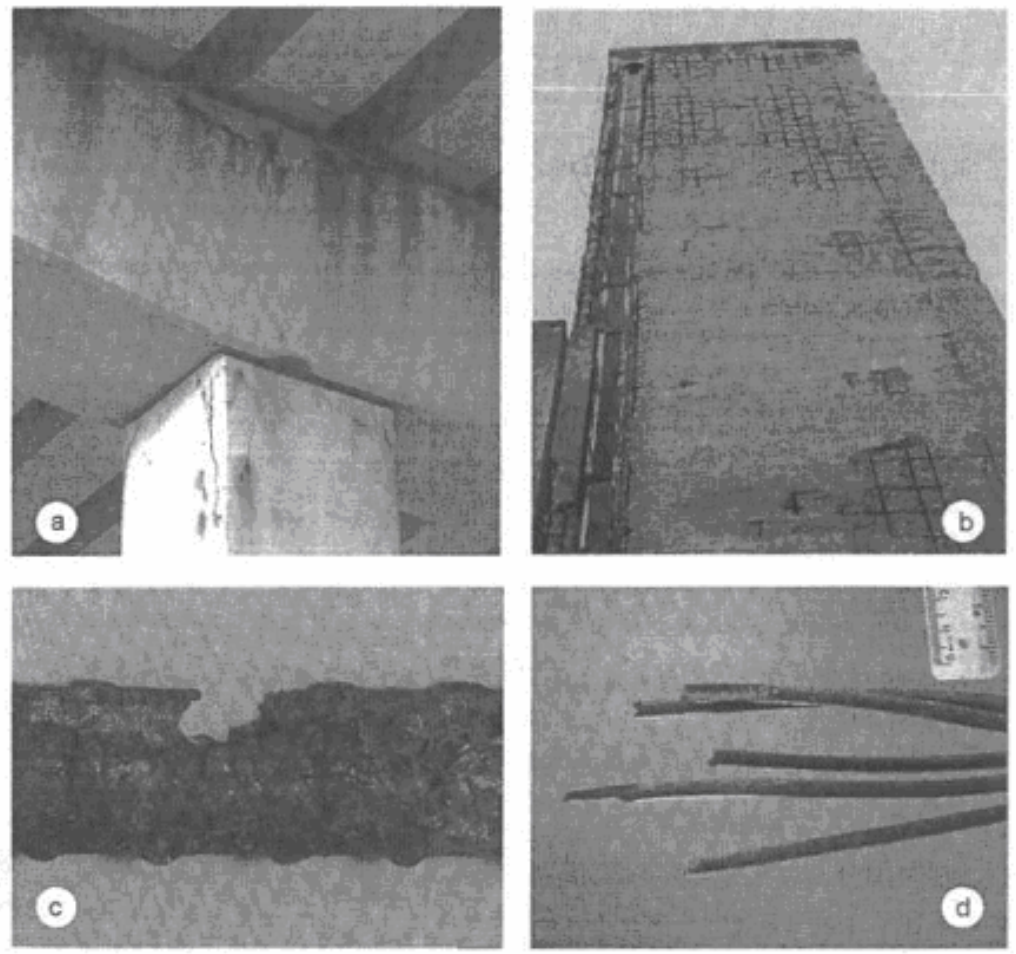

Figura 11. Ejemplos de las consecuencias de la corrosión del acero en el hormigón: $a$ ) fisuración de pilar y viga; $b$ ) escamas y delaminación del recubrimiento de hormigón; $c$ ) reducción de la sección de la barra debido a corrosión por picadura; $d$ ) rotura frágil de tendones pretensados debido a fragilización por hidrógeno. 
Consecuentemente, los productos de corrosión pueden producir presiones radiales que generan fisuras en el recubrimiento de hormigón (Figura 11a), desprendimientos en áreas localizadas, o delaminaciones completas (Figura 11b). También puede ocurrir una reducción de la adherencia entre la armadura y el hormigón.

En caso de corrosiones localizadas, la sección de la armadura se puede reducir significativamente (Figura 11c) y por tanto la capacidad de carga y su resistencia de fatiga. Finalmente, bajo condiciones muy especiales que conducen a la fragilización por hidrógeno de aceros de alta resistencia, pueden tener lugar roturas frágiles de algunos tipos de aceros pretensados (Figura 11d).

\subsection{Corrosión inducida por carbonatación}

\subsubsection{La carbonatación del hormigón}

En ambientes húmedos, el dióxido de carbono presente en el aire forma una disolución acuosa ácida que puede reaccionar con la pasta de cemento hidratado y tiende a neutralizar la alcalinidad del hormigón (este proceso se conoce como carbonatación). También otros ácidos presentes en la atmósfera, como el $\mathrm{SO}_{2}$, pueden neutralizar la alcalinidad del hormigón, pero su efecto se limita normalmente a la superficie del hormigón.

Los constituyentes alcalinos del hormigón están presentes en el líquido de los poros (principalmente como hidróxidos de sodio y potasio) pero también en los productos de hidratación sólidos, como $\mathrm{Ca}(\mathrm{OH})_{2}$ o CSH. El hidróxido de calcio es el hidrato en la pasta de cemento que reacciona más rápidamente con el $\mathrm{CO}_{2}$. La reacción, que tiene lugar en disolución acuosa, se puede describir como:

\section{Ecuación 10}

$$
\mathrm{CO}_{2}+\mathrm{Ca}(\mathrm{OH})_{2} \longrightarrow \mathrm{CaCO}_{3}+\mathrm{H}_{2} \mathrm{O}
$$

Ésta es la reacción de mayor interés, especialmente para el hormigón preparado con cemento Portland. No obstante también es posible la carbonatación del CSH cuando se agota el $\mathrm{Ca}(\mathrm{OH})_{2}$, hecho que puede tener lugar por la misma carbonatación en sí o por la reacción puzolánica en el hormigón hecho con cemento mixto. 
La carbonatación no causa ningún daño al hormigón por sí misma, aunque puede ocasionar que haya retracción en el hormigón. De hecho, en el caso del hormigón obtenido con cemento Portland, puede incluso reducir la porosidad y conducir a un incremento de la resistencia. Sin embargo, la carbonatación tiene importantes efectos en la corrosión del acero embebido. La primera consecuencia es que el $\mathrm{pH}$ de la disolución de los poros cae de su valor normal de $\mathrm{pH}$ 13-14, a valores que se aproximan a la neutralidad. Una segunda consecuencia de la carbonatación es que los cloruros fijados en forma de cloroaluminato de calcio hidratado (ver sección 1.5.2.1) y el fijado a otras fases hidratadas pueden ser liberados, haciendo la disolución de los poros incluso más agresiva [35-39].

\subsubsection{Penetración de la carbonatación}

La reacción de carbonatación comienza en la superficie externa y penetra dentro del hormigón produciendo un frente de bajo $\mathrm{pH}$. La medida de la profundidad de carbonatación se suele llevar a cabo pulverizando una disolución alcohólica de fenolftaleína en una cara recién fracturada. Las áreas donde el $\mathrm{pH}$ es mayor que 9 toman un color rosado típico de la fenolftaleína en ambientes básicos, mientras que el color de las áreas carbonatadas permanece invariable.

La velocidad de carbonatación disminuye con el tiempo, ya que el $\mathrm{CO}_{2}$ tiene que difundir a través de los poros de la capa exterior ya carbonatada. La penetración de la carbonatación en función del tiempo se puede describir como:

$$
\text { Ecuación } 11 \quad d=V_{\mathrm{CO} 2} \cdot t^{1 / n}
$$

donde $d$ es la profundidad de carbonatación (mm) y $t$ es el tiempo (años). Con frecuencia el exponente $n$ es aproximadamente igual a 2 $\mathrm{y}$, por lo tanto, se puede considerar una tendencia parabólica: $d=V_{\mathrm{CO} 2} \cdot t^{1 / 2}$. El coeficiente de carbonatación $V_{\mathrm{CO} 2}\left(\mathrm{~mm} / \mathrm{año}{ }^{1 / 2}\right)$ se puede tomar como una medida de la velocidad de penetración de la carbonatación para un hormigón y unas condiciones ambientales determinadas. En el hormigón denso y/o húmedo, sin embargo, la reducción de la velocidad de carbonatación con el tiempo es mayor que la descrita por la fórmula parabólica, de forma que $n>2$; en 
hormigones muy impermeables la velocidad de carbonatación tiende a ser despreciable tras un determinado tiempo.

\subsubsection{Factores que influyen en la velocidad de carbonatación}

La velocidad de carbonatación depende tanto de factores medioambientales (humedad, temperatura, concentración de dióxido de carbono) como de factores relacionados con el hormigón (principalmente su alcalinidad y permeabilidad).

a) Humedad. La velocidad de carbonatación varía con la humedad del hormigón por dos razones. Primero, la difusión del dióxido de carbono en el hormigón está facilitada en los poros con aire, pero es muy lenta a través de los poros rellenos de agua (la difusión del $\mathrm{CO}_{2}$ en el agua es cuatro órdenes de magnitud más lenta que en el aire). La velocidad de difusión del $\mathrm{CO}_{2}$ disminuye consecuentemente con el aumento de la humedad del hormigón hasta que se minimiza cuando el hormigón está saturado en agua. Esto significa que cuando el hormigón está húmedo, el $\mathrm{CO}_{2}$ penetra muy lentamente en él. Por otro lado, la reacción de carbonatación tiene lugar sólo en la presencia de agua de forma que se convierte en despreciable cuando el hormigón está seco. La velocidad de carbonatación, y por tanto el valor de $V_{\mathrm{CO} 2}$, cambiará de un clima húmedo a un clima seco. Bajo condiciones de equilibrio con un ambiente de una humedad relativa constante, la velocidad de carbonatación puede correlacionarse con la humedad del medio como se muestra en la Figura 12 [40,41]. El intervalo de humedad relativa más crítico para fomentar la carbonatación es desde un 60 hasta $80 \%$. 


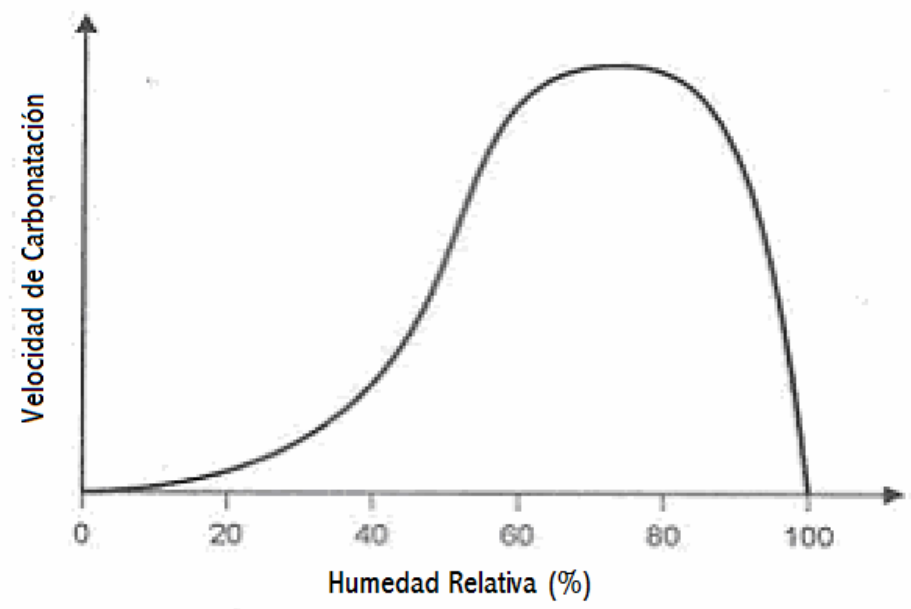

Figura 12. Representación esquemática de la velocidad de carbonatación del hormigón en función de la humedad relativa de medio, bajo condiciones de equilibrio [35].

b) Concentración de $\mathrm{CO}_{2}$. La concentración de dióxido de carbono en la atmósfera puede variar entre un $0,03 \%$ en medios rurales hasta más de un $0,1 \%$ en medio urbanos. Se pueden alcanzar concentraciones comparativamente altas bajo condiciones de exposición específicas, como en el interior de túneles de vehículos a motor. Según aumenta el contenido de $\mathrm{CO}_{2}$ en el aire, la velocidad de carbonatación aumenta. Los ensayos acelerados llevados a cabo en laboratorio para comparar la resistencia a la carbonatación en distintos tipos de hormigón muestran que, de forma indicativa, una semana de exposición a una atmósfera que contiene un $4 \%$ de $\mathrm{CO}_{2}$ causará la misma penetración de la carbonatación que un año de exposición en una atmósfera normal [42]. Algunos investigadores sugieren que con una alta concentración de $\mathrm{CO}_{2}$ la porosidad del hormigón carbonatado artificialmente es mayor que la obtenida por una exposición natural. Sin embargo, esto es controvertido, ya que otros estudios han mostrado que incluso con un $100 \% \mathrm{CO}_{2}$ con sobrepresión, se produce la misma microestructura que en carbonatación natural [43]. 


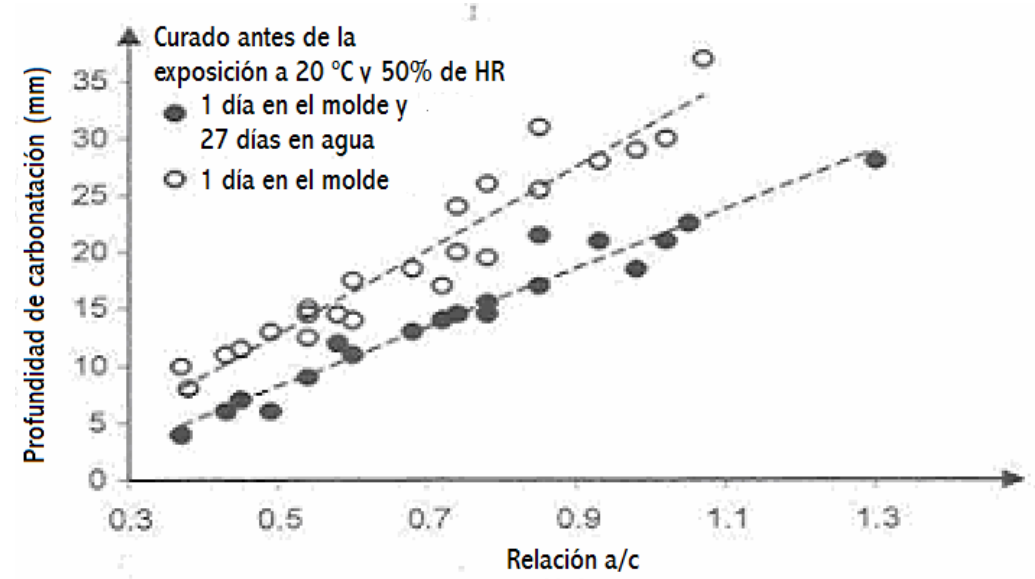

Figura 13. Influencia de la relación $a / c$ en la profundidad de carbonatación (hormigón de cemento Portland, 6 años, $20^{\circ}$ C, 50\% HR) [44].

c) Temperatura. A igualdad del resto de condiciones, especialmente la humedad, que es, en general, el parámetro más importante, un aumento de la temperatura elevará la velocidad de carbonatación.

d) Composición del hormigón. La permeabilidad del hormigón tiene una gran importancia en la difusión del dióxido de carbono y por tanto en la velocidad de carbonatación. Un descenso en la relación a/c ralentiza la penetración de la carbonatación como se muestra en la Figura 13, ya que disminuye la porosidad capilar de la pasta de cemento hidratada. No obstante, las ventajas de una menor relación a/c sólo se pueden conseguir si el hormigón se cura correctamente, ya que un pobre curado obstaculiza la hidratación de la pasta de cemento y conduce a una matriz de cemento más porosa. Se debería hacer hincapié en que un curado insuficiente afectará principalmente al hormigón de recubrimiento, es decir, la parte que está destinada a proteger la armadura. De hecho, la capa más externa del hormigón es la parte más susceptible de sufrir la evaporación del agua (empeorando el curado). 


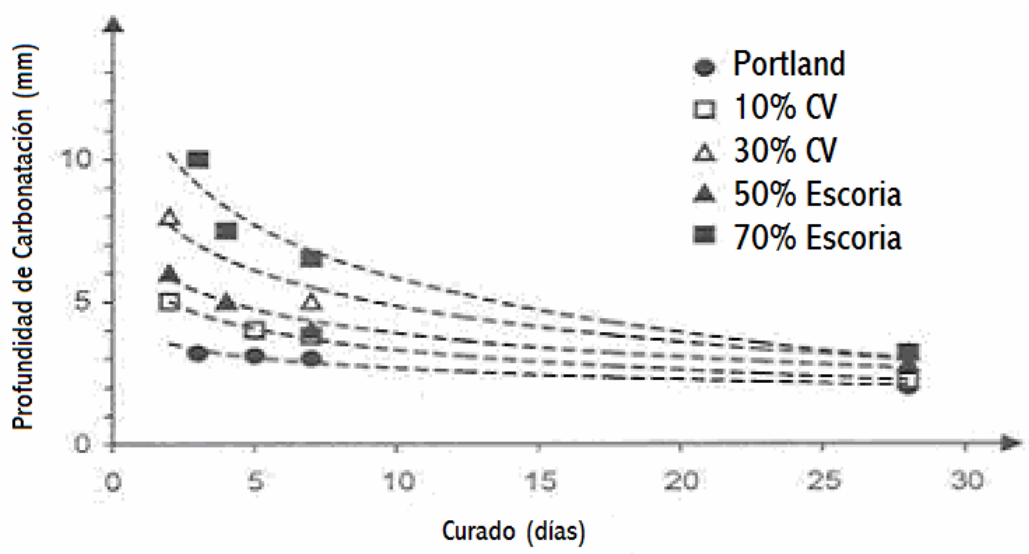

Figura 14. Influencia del curado en la profundidad de carbonatación para distintas pastas de cemento ( 6 meses, $0,03 \% \mathrm{CO}_{2}$ ) de cemento Portland y cementos mixtos con ceniza volante (PFA) y escorias de alto horno (GGBS) [44].

El tipo de cemento también influye en la velocidad de carbonatación. De hecho, la capacidad del hormigón para fijar $\mathrm{CO}_{2}$ es proporcional a la alcalinidad de su pasta de cemento. Para cementos mixtos, la hidratación de los materiales puzolánicos o la escoria conduce a un menor contenido de $\mathrm{Ca}(\mathrm{OH})_{2}$ en la pasta de cemento endurecida lo que puede aumentar la velocidad de carbonatación. No obstante, la relación a/c y el curado siguen siendo los factores más importantes. De hecho, la estructura más densa producida por la hidratación de los cementos mixtos puede ralentizar la difusión del $\mathrm{CO}_{2}$. En la Figura 14 se puede observar que la menor alcalinidad de los cementos con adiciones de ceniza volante o escoria de alto horno puede compensarse por la menor permeabilidad de sus pastas de cemento, si se curan apropiadamente.

\subsubsection{Tiempo de iniciación}

El tiempo para la iniciación de la corrosión inducida por carbonatación es el tiempo requerido para que el frente de carbonatación alcance una profundidad igual al espesor de recubrimiento. Depende de todos los factores mencionados anteriormente (que influyen en la velocidad de carbonatación) y del espesor de recubrimiento. $\mathrm{Si}$ se conoce la evolución de la 
carbonatación en el curso del tiempo y el espesor de recubrimiento, se puede estimar el tiempo de iniciación. Sin embargo, se debería considerar que el frente de carbonatación puede no ser uniforme a lo largo de la superficie del hormigón.

Con frecuencia se usa la fórmula parabólica para describir la penetración de la carbonatación:

$$
\text { Ecuación } 12 \quad d=V_{\mathrm{CO} 2} \cdot \sqrt{t}
$$

Ésta ofrece predicciones bastante exactas, aunque tiende a sobreestimar, al menos para tiempo largos, la penetración en caso de hormigones poco porosos de cemento Portland. Los valores de $V_{\mathrm{CO} 2}$ dependen de todos los factores discutidos anteriormente y por tanto cambia en función de las propiedades del hormigón y de las condiciones del medio. En la práctica, una predicción exacta de $V_{\mathrm{CO} 2}$, y por tanto del tiempo de despasivación del acero, es compleja, sobre todo porque este parámetro puede cambiar con el tiempo o distintas partes de una misma estructura.

Para estructuras existentes la profundidad de carbonatación de cualquier parte de la estructura se puede medir tras un periodo dado de tiempo y por tanto el valor de $V_{\mathrm{CO} 2}$ y su variación espacial se puede calcular. Asumiendo que las condiciones de exposición media no cambiarán en el futuro, estos valores de $V_{\mathrm{CO} 2}$ pueden utilizarse para extrapolar la profundidad de carbonatación a un tiempo más largo.

Los valores de $V_{\mathrm{CO} 2}$ encontrados para estructuras reales expuestas a la atmósfera pero protegidas de la lluvia, pueden oscilar entre 2 y $15 \mathrm{~mm} / \mathrm{añono}^{1 / 2}$. De forma indicativa: $2<V_{\mathrm{CO} 2}<6$ para hormigones de baja porosidad (esto es, bien compactado y curado, con baja relación a/c) cuyo contenido de cemento es superior a $350 \mathrm{~kg} / \mathrm{m}^{3}$; $6<V_{\mathrm{CO} 2}<9$ para hormigones de porosidad media; $V_{\mathrm{CO} 2}>9$ para hormigones altamente porosos con contenido de cemento por debajo de $250 \mathrm{~kg} / \mathrm{m}^{3}$. 


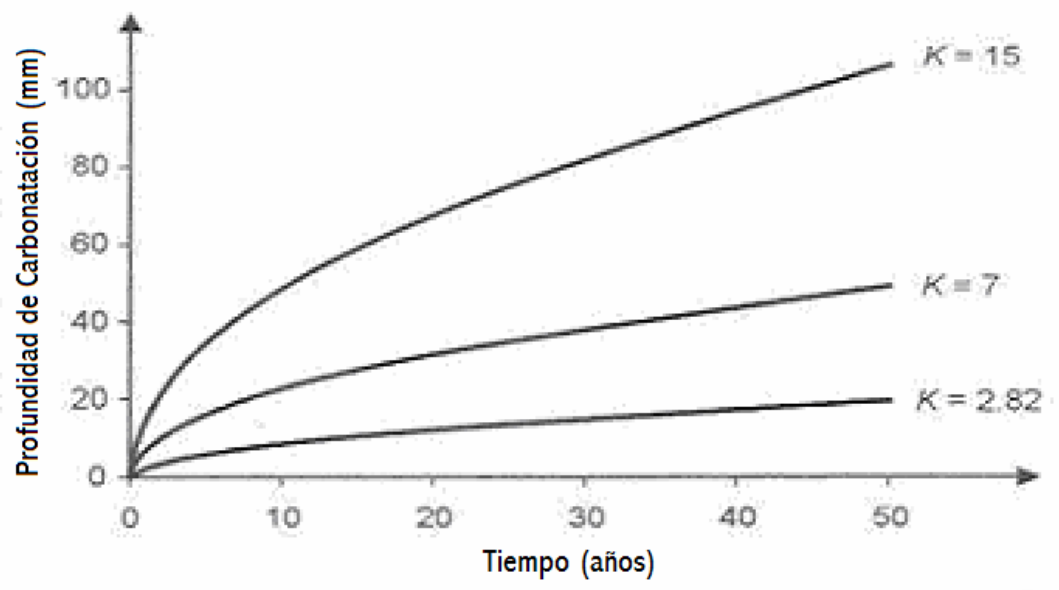

Figura 15. Profundidad de carbonatación, calculada por la función simplificada $s=V_{\mathrm{CO} 2} \cdot t^{1 / 2}$, en relación con el tiempo y con $V_{\mathrm{CO} 2}($ humedad relativa constante, sin mojado del hormigón).

\subsubsection{Velocidad de corrosión}

Una vez que el frente de carbonatación ha alcanzado la armadura, el acero se despasiva y puede tener lugar la corrosión si están presentes oxígeno y agua. Si se excluyen las condiciones de completa y permanente saturación del hormigón, siempre hay una cierta cantidad de oxígeno suficiente que alcanza la superficie del acero para permitir el proceso de corrosión. En este caso la velocidad de corrosión está gobernada por la resistividad del hormigón (es decir, la corrosión está bajo control óhmico).

El contenido de humedad es el principal factor en la determinación de la resistividad del hormigón carbonatado. En segundo lugar, la microestructura del hormigón y los factores que la determinan (tipo de cemento, relación a/c, curado, etc.) son también importantes para la velocidad de carbonatación y el tiempo de iniciación.

La velocidad de corrosión se puede considerar despreciable, excepto para humedades altas, o cuando la duración y frecuencia de los periodos de condensación de agua en la superficie del hormigón 
puedan causar variaciones en el contenido de humedad al nivel de las armaduras.

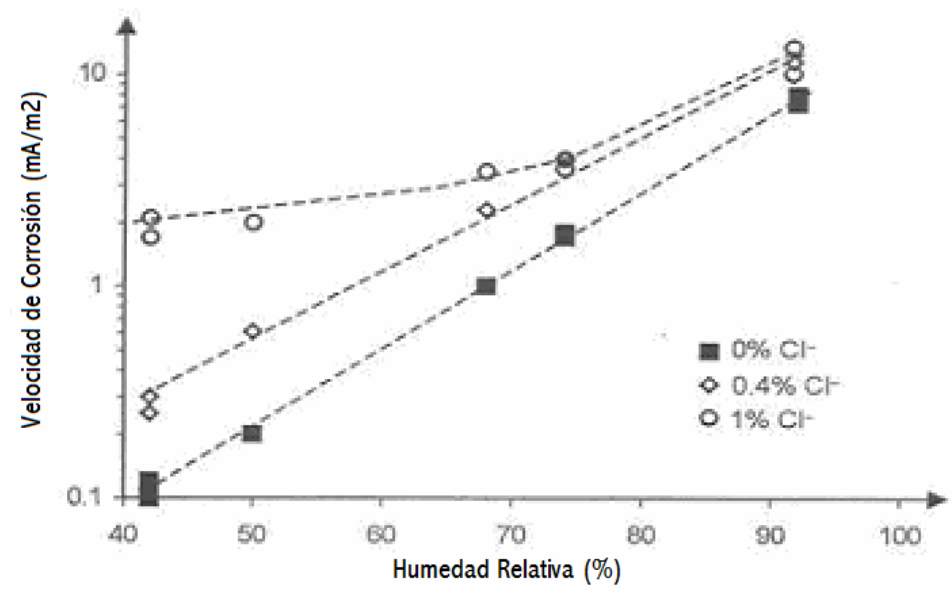

Figura 16. Relación entre la humedad relativa y la velocidad de corrosión en mortero carbonatado con y sin presencia de cloruros [45].

La situación es mucho más seria que la descrita anteriormente si existen cloruros presentes en el hormigón, incluso en cantidades tan pequeñas que por ellos mismos no darían lugar a corrosión. La presencia de una pequeña cantidad de cloruros en el hormigón puede ser debida al uso de materias primas (agua, áridos) que contengan estos iones o a la penetración de cloruros desde el medio exterior (agua de mar, sales de deshielo).

La Figura 16 muestra la velocidad de corrosión del acero en morteros carbonatados artificialmente en ausencia y en presencia de cloruros. Se puede observar claramente que la velocidad de corrosión será despreciable sólo en condiciones de humedad relativa externa inferior al $75 \%, 60 \%$ e incluso el $40 \%$ según el contenido de cloruros aumenta desde cero hasta $1 \%$ en peso de cemento.

\subsection{Corrosión inducida por cloruros}

La contaminación por cloruros del hormigón es causa frecuente de corrosión de las armaduras de acero. Los códigos de diseño modernos para estructuras de hormigón armado y pretensado 
imponen restricciones a la cantidad de cloruros que pueden ser introducidos a partir de las materias primas que contengan cantidades significativas de cloruros. De acuerdo con la norma europea EN 206, el máximo contenido en cloruros permitido es un $0,2-0,4 \%$ de iones cloruro por masa de material cementante para hormigón armado y un 0,1-0,2\% para hormigón pretensado. Con estas restricciones se considera que se eliminaría la corrosión debida a cloruros en el hormigón fresco. En algunas estructuras edificadas en el pasado, los cloruros se han añadido a la amasada de hormigón, inintencionadamente o deliberadamente, por medio del agua de amasado, los áridos (usando, por ejemplo, arena y grava drenada del mar sin lavarla con agua libre de cloruros) o aditivos (el cloruro de calcio, que ahora está prohibido, en el pasado fue el aditivo acelerador del fraguado más utilizado). Los contenidos de cloruro de los aditivos aceleradores en cantidades que oscilan entre el $0,5 \%$ hasta más allá del $2 \%$ en peso de cemento han provocado daños por corrosión muy importantes tras la carbonatación e incluso en condiciones alcalinas $[46,47]$.

La otra fuente principal de cloruros en el hormigón es la penetración desde el medio externo. Esto tiene lugar, por ejemplo, en ambientes marinos o en carreteras que transcurren por regiones donde se usan sales de deshielo (que contienen cloruros) en invierno.

La corrosión de la armadura en el hormigón no carbonatado sólo puede tener lugar una vez que el contenido de cloruros en el hormigón en contacto con la superficie del acero haya alcanzado un valor umbral. Este umbral depende de varios parámetros; sin embargo, el potencial electroquímico de la armadura, el cual está relacionado con la cantidad de oxígeno que puede alcanzar la superficie del acero, ejerce la mayor influencia. Niveles relativamente bajos de cloruros son suficientes para iniciar la corrosión en estructuras expuestas a la atmósfera, donde el oxígeno puede alcanzar fácilmente la armadura. Se necesitan valores mucho más altos de cloruros en estructuras sumergidas en agua de mar o en zonas donde el hormigón está saturado en agua, dado que el suministro de oxígeno está impedido y por tanto el potencial de la armadura es más bien bajo [48,49]. Sin embargo, incluso en estructuras expuestas a la atmósfera como cubiertas de puentes, se observa mucha dispersión en los valores 
"umbral". Se han establecido relaciones estadísticas en estudios de campo realizados sobre un gran número de estructuras, que expresan el porcentaje de estructuras que presentan corrosión en función del contenido de cloruro, como se muestra en la Figura 17 [50].

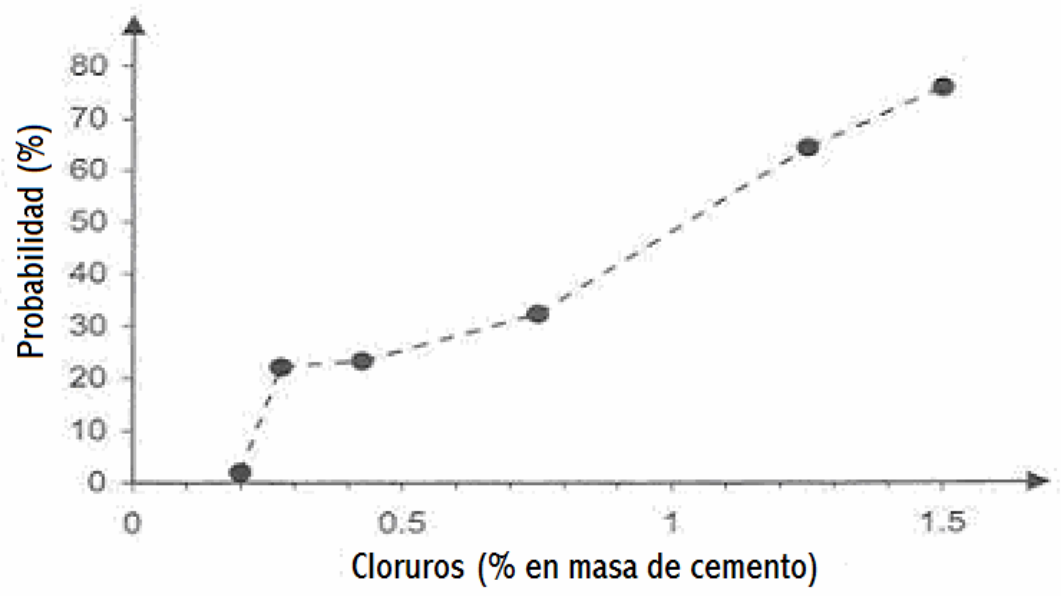

Figura 17. Relación entre el contenido de cloruro encontrado en cubiertas de puentes y el porcentaje de armaduras que presentan corrosión [50].

\subsubsection{Corrosión por picaduras}

Los cloruros conducen a una rotura local de la película de óxidos protectora de la armadura en el hormigón alcalino, de forma que tiene lugar un posterior ataque por corrosión localizada. Las zonas que ya no están protegidas por la película pasivante actúan como ánodos (zonas activas) con respecto a las zonas todavía pasivas de los alrededores donde tiene lugar la reacción catódica de reducción del oxígeno. La morfología del ataque es la típica de una picadura que se muestra en la Figura 18. Si la armadura es alcanzada por niveles muy elevados de cloruros, el ataque puede realizarse sobre grandes zonas, de forma que la morfología de picadura puede ser menos evidente. El mecanismo, sin embargo, es el mismo.

Como se muestra en la Figura 18, una vez que se ha iniciado la corrosión, se produce un ambiente muy agresivo dentro de las picaduras. De hecho, la corriente que fluye de las zonas anódicas hacia las zonas catódicas circundantes consigue aumentar el contenido 
de cloruro (los cloruros, al ser iones cargados negativamente, migran hacia la región anódica) y reduce la alcalinidad (la acidez se produce por la hidrólisis de los productos de corrosión dentro de las picaduras). Por otro lado, la corriente refuerza la capa protectora de la superficie pasiva ya que tiende a eliminar los cloruros, mientras que la reacción catódica produce alcalinidad. Por consiguiente, se establece tanto el comportamiento anódico de las zonas activas como el comportamiento catódico de las zonas pasivas. La corrosión se acelera entonces (mecanismo autocatalítico de la picadura) y puede alcanzar velocidades de penetración muy elevadas (hasta $1 \mathrm{~mm} / \mathrm{año}$ ) que puede conducir rápidamente a una importante reducción en la sección de las barras de refuerzo.

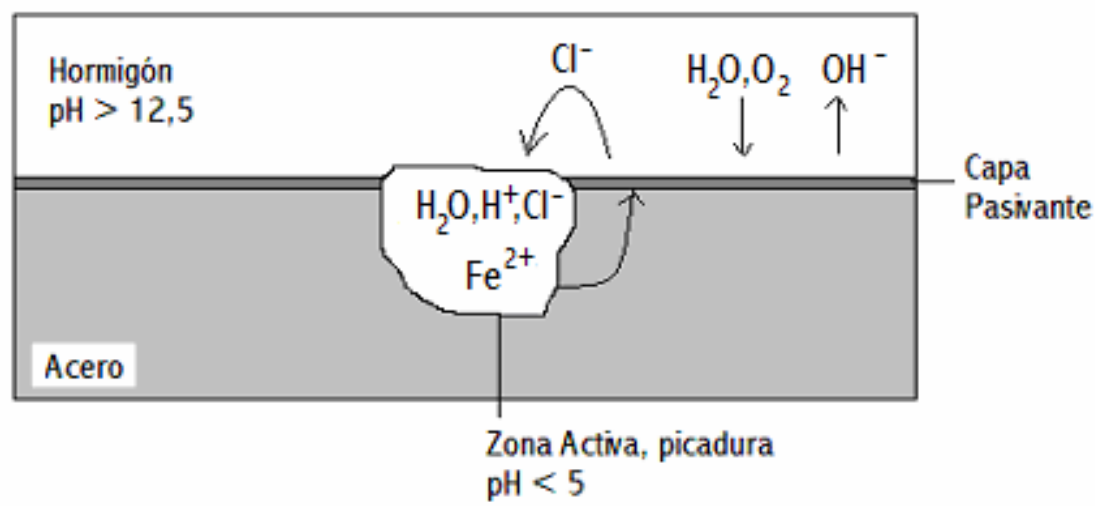

Figura 18. Representación esquemática de corrosión del acero por picadura en el hormigón.

\subsubsection{Iniciación de la Corrosión}

La iniciación de la corrosión por picaduras tiene lugar cuando el contenido de cloruro sobre la superficie de la armadura alcanza un valor umbral (o contenido crítico de cloruros). Se requiere cierto tiempo desde la rotura de la película pasivante hasta la formación de la primera picadura, de acuerdo con el mecanismo de corrosión descrito anteriormente. El umbral de cloruros para una estructura específica se puede definir como el contenido de cloruros requeridos para alcanzar esta condición de corrosión. 
Cuando los cloruros proceden del medio exterior, el tiempo de iniciación de la corrosión dependerá de la velocidad de penetración de los iones cloruro a través del recubrimiento de hormigón. El conocimiento tanto del umbral de cloruros como de la cinética de penetración de los cloruros en el hormigón es esencial para la determinación del tiempo de iniciación de la corrosión de estructuras de hormigón armado expuestas a ambientes con cloruros. A este respecto, la influencia de varios parámetros relacionados tanto con el hormigón (como el tipo de cemento, la relación a/c, el contenido de humedad, etc.) como con el medio (como la concentración de cloruros, la temperatura, etc.) debe de considerarse.

\subsubsection{Umbral de cloruros}

El umbral de cloruros para la iniciación de una corrosión por picaduras para una estructura dada depende de numerosos factores [16,51,52]. Los factores más importantes que se han identificado son el pH del hormigón, es decir, la concentración de iones hidroxilo en la disolución de los poros, el potencial del acero y la presencia de huecos en la interfase acero/hormigón.

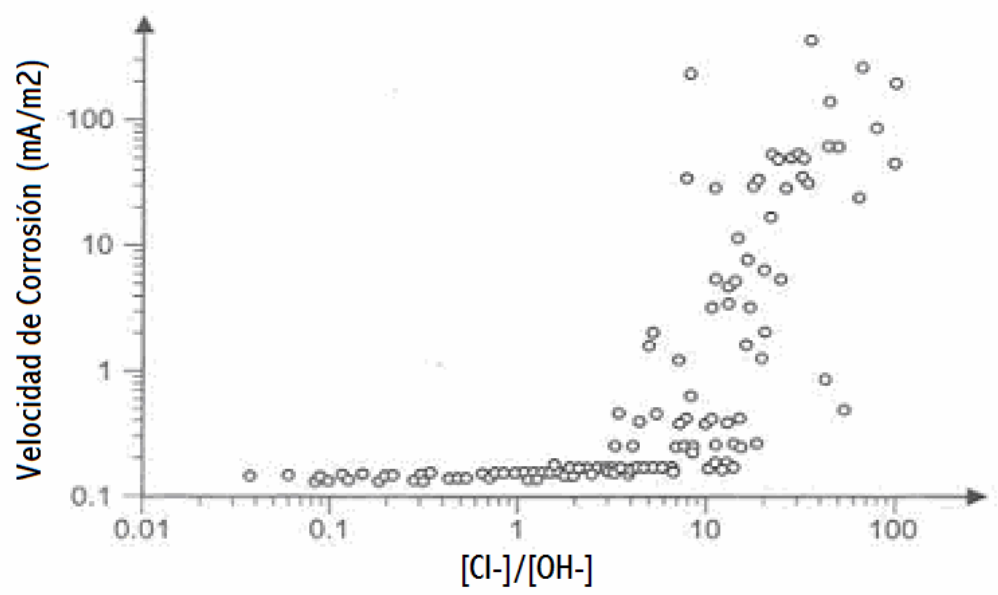

Figura 19. Ejemplo de relación entre la relación molar del $\mathrm{Cl}^{-}$y el $\mathrm{OH}^{-}$en la disolución de los poros y la velocidad de corrosión del acero [53,54].

La concentración de iones hidroxilo en la disolución de los poros depende principalmente del tipo de cemento y de las adiciones. 
Se sugirió que la corrosión por picaduras podría tener lugar sólo por encima de cierta relación crítica entre los cloruros y los iones hidroxilo [55]. Por ejemplo, la Figura 19 muestra que el riesgo de una corrosión significativa aumenta según la relación $\left[\mathrm{Cl}^{-}\right] /\left[\mathrm{OH}^{-}\right]$en la disolución de los poros si se supera un cierto valor [53,54]. Aunque algunos autores han confirmado la dependencia de la iniciación de la corrosión con la relación $\left[\mathrm{Cl}^{-}\right] /\left[\mathrm{OH}^{-}\right]$, se encontró una gran variabilidad para el valor umbral [52].

La gran variabilidad del umbral de $\left[\mathrm{Cl}^{-}\right] /\left[\mathrm{OH}^{-}\right]$es, primero de todo, una consecuencia de la naturaleza estocástica de la iniciación de la corrosión por picaduras; parece que el umbral de cloruros sólo se puede definir en una base estadística.

El potencial electroquímico del acero, el cual está fuertemente relacionado con la disponibilidad de oxígeno sobre la superficie del acero y por tanto con el contenido de humedad del hormigón, es un segundo factor que tiene una marcada influencia en el umbral de cloruros. De hecho, según el potencial del acero disminuye, el umbral de cloruros puede aumentar más de un orden de magnitud.

El umbral de cloruros ha resultado ser dependiente de la presencia de huecos macroscópicos en el hormigón cercano a la superficie del acero [56]. Los huecos que se pueden encontrar normalmente en estructuras reales debido a una pobre compactación pueden debilitar la capa de productos de hidratación del cemento depositados en la interfase acero/hormigón, y por tanto pueden favorecer la acidificación localizada que se requiere para la propagación sostenida de las picaduras. La presencia de huecos de aire, así como grietas o microfisuras, también pueden ofrecer una explicación para los inferiores valores de umbral de cloruros que se encuentran normalmente en estructuras reales comparados con los encontrados en (normalmente bien compactadas) probetas de laboratorio con materiales similares [57].

Otros factores, como la temperatura, la composición del cemento, la composición de la rugosidad superficial del acero de refuerzo, o la polarización con corrientes anódicas o catódicas pueden afectar el umbral de cloruros. 
Fijación de cloruros. El contenido de cloruros en el hormigón, y por tanto el umbral, se puede expresar de varias maneras, ya sea refiriéndose a la concentración de cloruros en la disolución de los poros (es decir, los cloruros libres) o bien refiriéndose al contenido total de cloruros en el hormigón, es decir, incluyendo los cloruros enlazados a los constituyentes de la pasta de cemento. Generalmente se piensa que sólo los iones cloruro disueltos en la disolución de los poros pueden provocar la corrosión por picaduras, mientras que no participan los que están químicamente enlazados a los constituyentes de la pasta de cemento, como los cloruros absorbidos en el gel CSH o ligados al aluminato tricálcico (como sal de Friedel, $3 \mathrm{CaO} \cdot \mathrm{Al}_{2} \mathrm{O}_{3} \cdot \mathrm{CaCl}_{2} \cdot 10 \mathrm{H}_{2} \mathrm{O}$ ) a través del mecanismo mostrado en la Ecuación 13 y la Ecuación 14. Sin embargo, un estudio reciente de los aspectos químicos de la fijación sugiere que también los cloruros ligados pueden jugar un papel en la iniciación de la corrosión. Glass y Buenfeld [52] afirman que una gran parte de los cloruros fijados se liberan en cuanto el $\mathrm{pH}$ cae por valores por debajo de 12 , lo que puede ocurrir localmente en huecos de la interfase acero/hormigón. Los cloruros fijados se disuelven y pueden posteriormente estar implicados en la iniciación de la corrosión.

Ecuación 13

Ecuación 14

$$
\mathrm{Ca}(\mathrm{OH})_{2}+2 \mathrm{NaCl} \rightarrow 2 \mathrm{NaOH}+\mathrm{CaCl}_{2}
$$

$$
\begin{aligned}
\mathrm{CaCl}_{2}+\mathrm{Ca}_{3} \mathrm{Al}_{2} \mathrm{O}_{6} & \cdot 8 \mathrm{H}_{2} \mathrm{O}+2 \mathrm{H}_{2} \mathrm{O} \rightarrow \\
& \rightarrow \mathrm{Ca}_{4} \mathrm{Al}_{2} \mathrm{O}_{6} \mathrm{Cl}_{2} \cdot 10 \mathrm{H}_{2} \mathrm{O}
\end{aligned}
$$

Se tienden a establecer unas condiciones de equilibrio entre los cloruros libres y los cloruros ligados, dependiendo de la composición del cemento y de su capacidad de fijación (Figura 20). Por lo tanto, es posible que la concentración de iones cloruro libres en la disolución de los poros de distintos hormigones varíe, incluso si el contenido total de cloruros es el mismo. La fijación en un cemento Portland ordinario depende del contenido de fase de aluminato tricálcico. Por ejemplo, el riesgo de corrosión de cementos Portland resistentes a sulfatos, los cuales están caracterizados por un bajo contenido en aluminato tricálcico, es mayor que en el cemento Portland normal, considerando un contenido total de cloruros igual. De forma similar, los cementos mixtos de escoria y ceniza volante tienen menores 
concentraciones de cloruros libres que el cemento Portland original, aunque su $\mathrm{pH}$ es ligeramente inferior. La absorción de los iones cloruro en el CSH puede ser más importante incluso que la fijación química, y esto podría explicar la mayor capacidad de fijación observada en cementos mixtos, los cuales tienden a formar una microestructura más fina de los productos de hidratación [16].

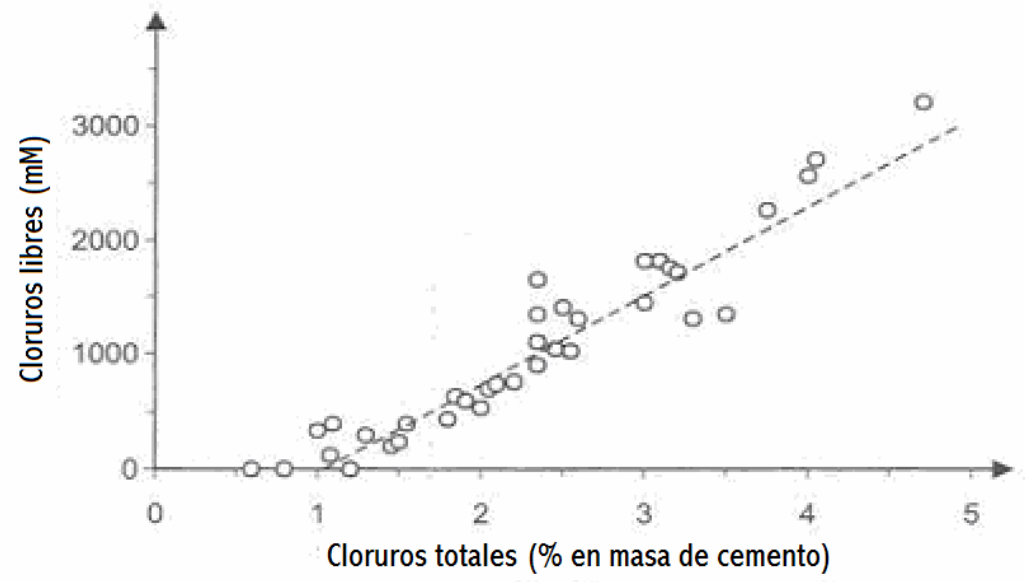

Figura 20. Relación entre el contenido de cloruros libres y totales encontrado en un hormigón de cemento Portland ordinario sometido a penetración de cloruros [53].

En la práctica, debido a que el contenido total de cloruros se puede medir mucho más fácilmente que la concentración de cloruros libres, el umbral de cloruros se expresa como contenido total crítico. El valor crítico se suele dar como un porcentaje de cloruros con respecto a la masa de cemento, ya que la cantidad de cloruros que se pueden tolerar aumenta según aumenta el contenido de cemento en el hormigón.

Estructuras expuestas a la atmósfera. En estructuras expuestas a la atmósfera, el oxígeno puede alcanzar fácilmente la superficie del acero a través de los poros rellenos de aire y el potencial electroquímico de la armadura se encuentra alrededor de 0 V SCE. En la práctica, el riesgo de corrosión en hormigón no carbonatado fabricado con cemento Portland normal (para el cual el $\mathrm{pH}>13$ ) se considera bajo para contenidos de cloruros por debajo del $0,4 \%$ en 
peso de cemento y alto para niveles por encima del $1 \%$. El valor umbral tiende a ser mayor en hormigones de baja permeabilidad. La influencia sobre el umbral de corrosión de los cementos mixtos con adiciones de puzolanas o escoria de alto horno es un tema controvertido. Existen evidencias de laboratorio de que el cemento de escoria de alto horno tiene un umbral superior para la iniciación de la corrosión [59]. Por otro lado, los datos de exposición marina sugieren que los umbrales con cementos de escoria o ceniza volante son similares o incluso inferiores que con cemento Portland [60]. Sin embargo, en el caso de grandes adiciones de humo de sílice, el umbral es significativamente menor debido al inferior $\mathrm{pH}$ de la disolución de los poros.

Para cementos resistentes a sulfatos con bajo contenido en $\mathrm{C}_{3} \mathrm{~A}$, el nivel crítico de cloruros para iniciar la corrosión puede estar entre los valores inferiores de los mencionados anteriormente, o en valores incluso por debajo de éstos (como $0,2 \%$ en peso de cemento).

Estructuras sumergidas. Cuando las estructuras de hormigón armado se sumergen en el agua, o de cualquier forma el contenido de humedad del hormigón está cerca del nivel de saturación, el transporte de oxígeno hasta el acero es bajo y las armaduras alcanzan potenciales muy negativos, por ejemplo entre -400 y $-600 \mathrm{mV}$ SCE. En este caso, el umbral de cloruros es mucho mayor, algunas veces incluso alcanzando valores un orden de magnitud mayor que el de estructuras expuestas a la atmósfera. Sin embargo, para estructuras huecas (llenas de aire) sumergidas en agua de mar (como los pilares de plataformas o túneles), las macropilas entre las armaduras externas e internas pueden causar una corrosión significativa.

\subsubsection{Penetración de cloruros}

La penetración de cloruros desde el medio produce un perfil en el hormigón caracterizado por un alto contenido de cloruros cerca de la superficie externa que disminuye hacia el interior. La experiencia tanto en estructuras marinas como en carreteras expuestas a sales de deshielo ha demostrado que, en general, estos perfiles pueden ser aproximados mediante la Ecuación 6 obtenida de la segunda ley de Fick [16]. Sólo en un hormigón completa y permanentemente saturado 
con agua pueden penetrar los cloruros por difusión pura. En la mayoría de situaciones, otros mecanismos de transporte contribuyen a la penetración de los cloruros. Por ejemplo, cuando un hormigón seco se pone en contacto con agua salina, inicialmente tiene lugar la succión capilar de la disolución de cloruros. En muchos casos tiene lugar el secado y el mojado, al menos en las zonas externas del hormigón, de forma que la evaporación del agua conduce a un enriquecimiento de iones cloruro. Por otro lado, la fijación debido a la adsorción o a la reacción química con constituyentes de la pasta de cemento altera la concentración de iones cloruro en la disolución de los poros.

No obstante, la experiencia muestra que, incluso en estos casos, los perfiles de cloruros se pueden modelar matemáticamente con una buena aproximación usando una ecuación formalmente idéntica a la Ecuación 6. En esta ecuación, se considera el contenido total de cloruros, por lo que están incluidos los cloruros fijados:

\section{Ecuación 15}

$$
C_{x}=C_{s}\left(1-\operatorname{erf} \frac{x}{2 \sqrt{D_{a p p} \cdot t}}\right)
$$

donde: $C_{x}=$ contenido total de cloruros (\% en peso de cemento u hormigón) a un tiempo $t$ (s) y una profundidad $x$ de la superficie del hormigón (m); $D_{a p p}=$ coeficiente de difusión aparente para los cloruros $\left(\mathrm{m}^{2} / \mathrm{s}\right) ; C_{s}=$ contenido de cloruros en superficie $(\%$ en peso de cemento u hormigón). El coeficiente de difusión aparente y el contenido de cloruros en la superficie se calculan ajustando los datos experimentales a la Ecuación 15 y se usan normalmente para describir el perfil de cloruros medido en estructuras reales [22,58,62 -66].

El coeficiente de difusión aparente, obtenido de estructuras reales o de ensayos de laboratorio, también se usa a menudo como el parámetro que describe la resistencia del hormigón a la penetración de cloruros, por ejemplo a la hora de comparar el rendimiento de distintos materiales. Cuanto menor es el $D_{a p p}$, mayor es la resistencia a la penetración de cloruros. Se debería, sin embargo, destacar que, mientras que el coeficiente de difusión obtenido de los ensayos de difusión pura (estado estacionario) se puede considerar una propiedad 
del hormigón, el coeficiente de difusión aparente obtenido de estructuras reales también depende de otros factores (como las condiciones de exposición o el tiempo de exposición). Por lo tanto, los resultados obtenidos bajo condiciones concretas, especialmente durante los ensayos de laboratorio a corto plazo, puede que no sean aplicables a otras condiciones de exposición.

Además, la Ecuación 15 también se usa para la predicción del rendimiento a largo plazo de estructuras expuestas a ambientes con cloruros, por ejemplo en la fase de diseño o en la evaluación de la vida útil restante de estructuras existentes. En principio, si se conoce el $D_{a p p}$ y el $C_{s}$ y se puede suponer que sean constantes en el tiempo, es posible evaluar la evolución en el tiempo del perfil de cloruros en el hormigón y entonces estimar el tiempo $t$ al cual se alcanzará un umbral de cloruros concreto y se iniciará la corrosión.

Aunque esta aproximación a la estimación del tiempo de iniciación de la corrosión es sencilla, se debería observar que su exactitud depende fuertemente de la exactitud de los parámetros utilizados, esto es no sólo $D_{a p p}$ y $C_{s}$ sino también del umbral de cloruros. En general, $D_{a p p}$ y $C_{s}$, no se pueden asumir como constantes en el caso de estructuras reales donde tiene lugar tanto la fijación como otros procesos distintos a la difusión. En particular, el coeficiente de difusión aparente cambia con el tiempo y en función de las condiciones de exposición, entre otros, debido a las lentas reacciones de hidratación de los constituyentes del cemento, en concreto la escoria de alto horno y la ceniza volante.

\subsubsection{Coeficiente de difusión aparente}

Los valores de $D_{a p p}$ normalmente varían entre $10^{-13} \mathrm{~m}^{2} / \mathrm{s}$ y $10^{-10}$ $\mathrm{m}^{2} / \mathrm{s}$ en relación con las propiedades del hormigón y las condiciones de exposición. $D_{a p p}$ depende concretamente de la estructura de poros del hormigón y de todos los factores que la determinan, tales como: la relación a/c, la compactación, el curado, y la presencia de microfisuras. El tipo de cemento también tiene un efecto considerable: al pasar de un hormigón fabricado con cemento Portland a un hormigón fabricado con cantidades crecientes de puzolana o escoria de alto horno, $D_{a p p}$ puede reducirse de forma considerable (Tabla 1). 
Resulta especialmente interesante la adición de elevados porcentajes de escoria de alto horno al cemento Portland, que como se muestra en la Figura 21, puede reducir el coeficiente de difusión en más de un orden de magnitud.

\begin{tabular}{||c|c||}
\hline \hline TIPO DE CEMENTO & $\boldsymbol{D}\left(\mathbf{1 0}^{-\mathbf{1 2}} \mathbf{~}^{\mathbf{2}} / \mathbf{s}\right)$ \\
\hline Portland & 4,47 \\
\hline Portland + 30\% PFA & 1,47 \\
\hline Portland + 65\% GGBS & 0,41 \\
\hline
\end{tabular}

Tabla 1. Ejemplos de coeficientes de difusión estacionarios, $D$, en pastas de cemento con $a / c=0,5$, curadas 60 días, fabricadas con cemento Portland y cemento con adiciones de ceniza volante (PFA) o escoria de alto horno (GGBS) [67].

De la Ecuación 15 se desprende claramente que la profundidad de penetración $x$ para un determinado contenido $C_{x}$ depende del producto $D_{a p p} \cdot t$. Consecuentemente, siendo otros factores constantes, la reducción del coeficiente de difusión aparente por un factor de 10 , aumenta el tiempo de iniciación por un factor de 10.

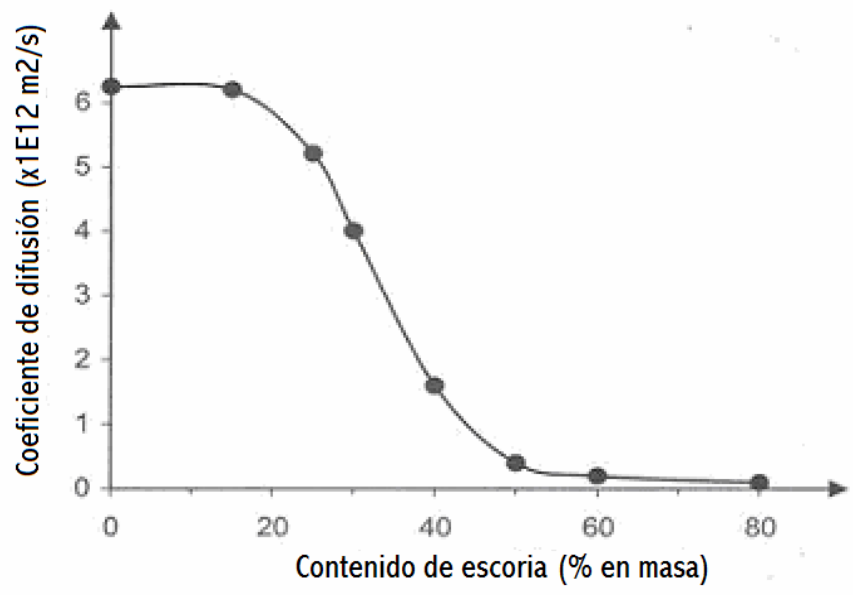

Figura 21. Influencia de la sustitución de cemento Portland por escoria de alto horno en el coeficiente de difusión de pastas de cemento con $a / c=0,6$ a $21^{\circ} \mathrm{C}$. 


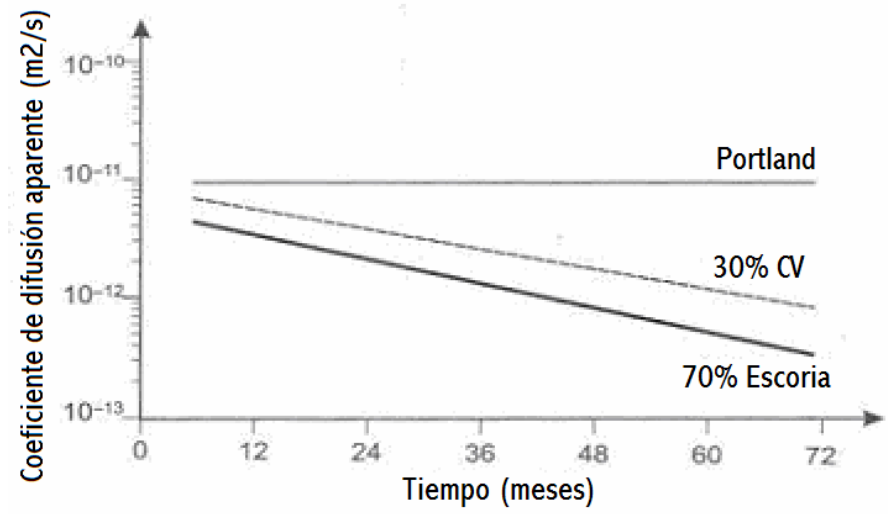

Figura 22. Esquema del coeficiente de difusión aparente para cloruros $\left(D_{a p p}\right)$ en función del tiempo y el tipo de cemento para cemento Portland, $30 \%$ de ceniza volante y $70 \%$ de escoria de alto horno durante una exposición en la zona de salpicaduras marinas, tras [58].

Cuando se usa el coeficiente de difusión aparente para fines predictivos, se debería considerar que éste tiende a reducirse con el tiempo [16,22], especialmente para cementos mixtos. Por ejemplo, la Figura 22 esquematiza la variación en el tiempo del coeficiente de difusión aparente obtenido de ensayos de campo a largo plazo en hormigones con varias composiciones expuestos a ambientes marinos [22].

\subsubsection{Velocidad de corrosión}

En estructuras expuestas a la atmósfera, la velocidad de corrosión puede variar desde varias decenas de $\mu \mathrm{m} / \mathrm{año} \mathrm{hasta} \mathrm{valores}$ localizados de $1 \mathrm{~mm} /$ año según la humedad relativa aumenta desde el 70 hasta el $95 \%$ y el contenido de cloruros aumenta desde un $1 \%$ en peso de cemento hasta valores más altos.

La influencia de la temperatura y la humedad afecta la velocidad de corrosión a través de su influencia en las reacciones electroquímicas en la interfase acero/hormigón y a través de su influencia en el transporte de iones entre los ánodos y los cátodos. Aunque los mecanismos no se conocen perfectamente, parece que la resistividad del hormigón (o conductividad) está fuertemente relacionada con la velocidad de corrosión a temperaturas bajas o 
moderadas [68-70]. La variación en la resistividad debido a la variación de la humedad relativa (a temperatura constante) provoca una variación inversamente proporcional de la velocidad de corrosión en morteros y hormigones carbonatados con pequeñas cantidades de cloruros o sin cloruros. La variación de la temperatura (a humedad constante) provoca una variación similar en la velocidad de corrosión.

Para un conjunto determinado de condiciones en términos de humedad y temperatura, y una vez que se ha iniciado la corrosión, la mayor resistividad de los cementos mixtos resulta en una menor velocidad de corrosión que la observada para el cemento Portland. Barras a $20 \mathrm{~mm}$ de profundidad en hormigones de ceniza volante y escoria de alto horno ofrecen bajas velocidades de corrosión aunque el contenido de cloruro sugiere que ha tenido lugar la iniciación de la corrosión; ambos tienen una alta resistividad (> $500 \Omega \cdot \mathrm{m})$. Las mismas barras a $20 \mathrm{~mm}$ de profundidad en bloques de cemento Portland muestran velocidades de corrosión mucho mayores, lo que se asocia con una baja resistividad $(<100 \Omega \cdot \mathrm{m})$ [72].

Excepciones. Sólo para estructuras completa y permanentemente sumergidas en agua, incluso en condiciones que satisfagan la iniciación de corrosión (aunque esto no siempre ocurre gracias al bajo potencial del acero), el muy bajo suministro de oxígeno que llega a la armadura mantiene la velocidad de corrosión tan baja que el ataque corrosivo es despreciable incluso tras largos periodos [58]. Esto implica, sin embargo, que en estructuras huecas con aire dentro, puede tener lugar la corrosión de las barras de la parte exterior debido a una macropila de corrosión. Finalmente, los defectos importantes como coqueras o las fisuras grandes en el recubrimiento de una estructura sumergida pueden permitir que una cantidad suficiente de oxígeno disuelto en el agua de mar alcance la armadura y que consecuentemente mantengan una corrosión significativa.

\subsection{El residuo de catalizador de craqueo catalítico (FCC) como puzolana}

En los últimos tiempos se han realizado numerosas investigaciones sobre cómo modifica las propiedades de los hormigones, pastas y morteros, la utilización de puzolanas cuya 
existencia se conoce desde antiguo. Para ello se han utilizado adiciones minerales naturales y artificiales como las que siguen:

- cenizas volantes

- humo de sílice

- escorias de alto horno

- cenizas volcánicas

- tierra de diatomeas

- cenizas de cáscara de arroz

- cenizas de lodos de depuradora

Algunos de estos materiales son productos minerales activos que poseen propiedades puzolánicas y/o cementantes.

La reutilización de subproductos industriales en la producción de hormigón ofrece muchas ventajas como son:

a) Beneficios medioambientales por la reducción de la extracción en canteras, ahorro de energía y reducción de las emisiones de dióxido de carbono.

b) Beneficios económicos porque los subproductos pueden ser más baratos y se pueden usar para reemplazar materiales más caros, además de evitar los costes de su eliminación.

c) Ventajas tecnológicas porque mejoran varias propiedades de los morteros y hormigones tanto frescos como endurecidos

La industria petrolífera y particularmente las refinerías de crudo obtienen fracciones de peso molecular específico usando el proceso de craqueo catalítico en lecho fluidizado (proceso FBC). Los catalizadores zeolíticos tienen un uso muy generalizado dentro de la industria en general, llegando a ocupar una quinta parte del mercado mundial de catalizadores. Frecuentemente, el catalizador usado consta de compuestos inorgánicos de base silico-aluminosa con estructuras muy abiertas (tipo zeolita). La actividad catalítica de estos productos tiene una vida útil muy corta y el catalizador "viejo" debe ser reemplazado por nuevo catalizador que sea activo. Es por esto, que grandes cantidades de residuo de catalizador de craqueo catalítico en 
lecho fluidizado (FCC) se producen al año causando problemas de desecho a las industrias que se ven en la obligación de eliminarlo de forma adecuada y dentro de las disposiciones vigentes en las normativas ambientales de los distintos países. La cantidad de este tipo de catalizador que se desecha anualmente ronda las 400.000 toneladas.

Dentro de los residuos de este tipo existen estudios en la bibliografía que se han realizado con distintas fracciones del mismo. La inmensa mayoría del residuo de catalizador de craqueo catalítico producido es retirado del fondo de los reactores en los que ejercen su función. Esta fracción presenta las partículas de mayor tamaño. Existe otra fracción que se recoge mediante precipitación electrostática en los gases que escapan de los reactores y cuyo tamaño es muy inferior al de la fracción anterior y cuyo interés relativo, en cuanto a la aplicabilidad que presenta, es inferior, dado que supone un porcentaje muy bajo del residuo total.

La composición química y la estructura atómica del FCC pueden ser apropiadas para su uso en la producción de morteros y hormigones. Otras de las aplicaciones en las que se visto implicado este subproducto son las siguientes:

- en la fabricación de materiales resistentes al fuego debido a que soporta temperaturas de hasta $1750^{\circ} \mathrm{C}$,

- en mezclas de asfalto para aumentar su dureza,

- como materiales de absorción de compuestos volátiles,

- incorporados en cerámicas y derivados del caolín.

Estudios realizados sobre materiales fabricados en parte con este subproducto han revelado que no son peligrosos, entendiendo este término como que cumplen con los requisitos medioambientales exigidos y que por lo tanto pueden ser incorporados en los materiales de construcción [73].

\subsubsection{Propiedades físicas y químicas del FCC}

La observación del residuo de catalizador con microscopía electrónica de barrido (SEM) revela que es un material de estructura 
porosa con una elevada área superficial $\left(250 \mathrm{~m}^{2} / \mathrm{g}\right.$ según $\mathrm{Su}$ y col. [74] para el residuo sin moler), compuesto principalmente por sílice $\mathrm{y}$ alúmina [75].

\begin{tabular}{|c|c|c||c|c|c||}
\hline PARÁMETRO & FCC (\%) & CP (\%) & PARÁMETRO & FCC (\%) & CP (\%) \\
\hline $\mathrm{SiO}_{2}$ & 48,2 & 20,21 & $\mathrm{~K}_{2} \mathrm{O}$ & $<0,01$ & 0,95 \\
\hline $\mathrm{CaO}$ & $<0,01$ & 62,87 & $\mathrm{SO}_{3}$ & 0,04 & 3,37 \\
\hline $\mathrm{Al}_{2} \mathrm{O}_{3}$ & 46,0 & 4,94 & $\mathrm{TiO}_{2}$ & 1,65 & 0,23 \\
\hline $\mathrm{Fe}_{2} \mathrm{O}_{3}$ & 0,95 & 2,85 & $\mathrm{Cl}^{-}$ & 0,004 & 0,018 \\
\hline $\mathrm{MgO}$ & $<0,01$ & 1,05 & P.F. & 1,50 & 2,34 \\
\hline $\mathrm{Na}_{2} \mathrm{O}$ & 0,50 & 0,10 & R.I. & 11,11 & 1,98 \\
\hline
\end{tabular}

Tabla 2. Composición química del FCC y del cemento Portland [76].

En la Tabla 2 se ofrecen los resultados de los análisis de pérdida al fuego, residuo insoluble y composición química comparativa entre el residuo de catalizador y el cemento Portland realizados por Payá y col. [76].

La Figura 23 muestra cual es la distribución de tamaños de partícula ofrecida por Su y col. [75] para las dos fracciones estudiadas de residuo de catalizador, la recogida en el reactor y la recogida mediante precipitación electrostática en los gases desprendidos. Los tamaños de la primera fracción oscilan entre 10 y $150 \mu \mathrm{m}$ mientras que la segunda fracción se ubica entre 0,1 y $80 \mu \mathrm{m}$ principalmente. 


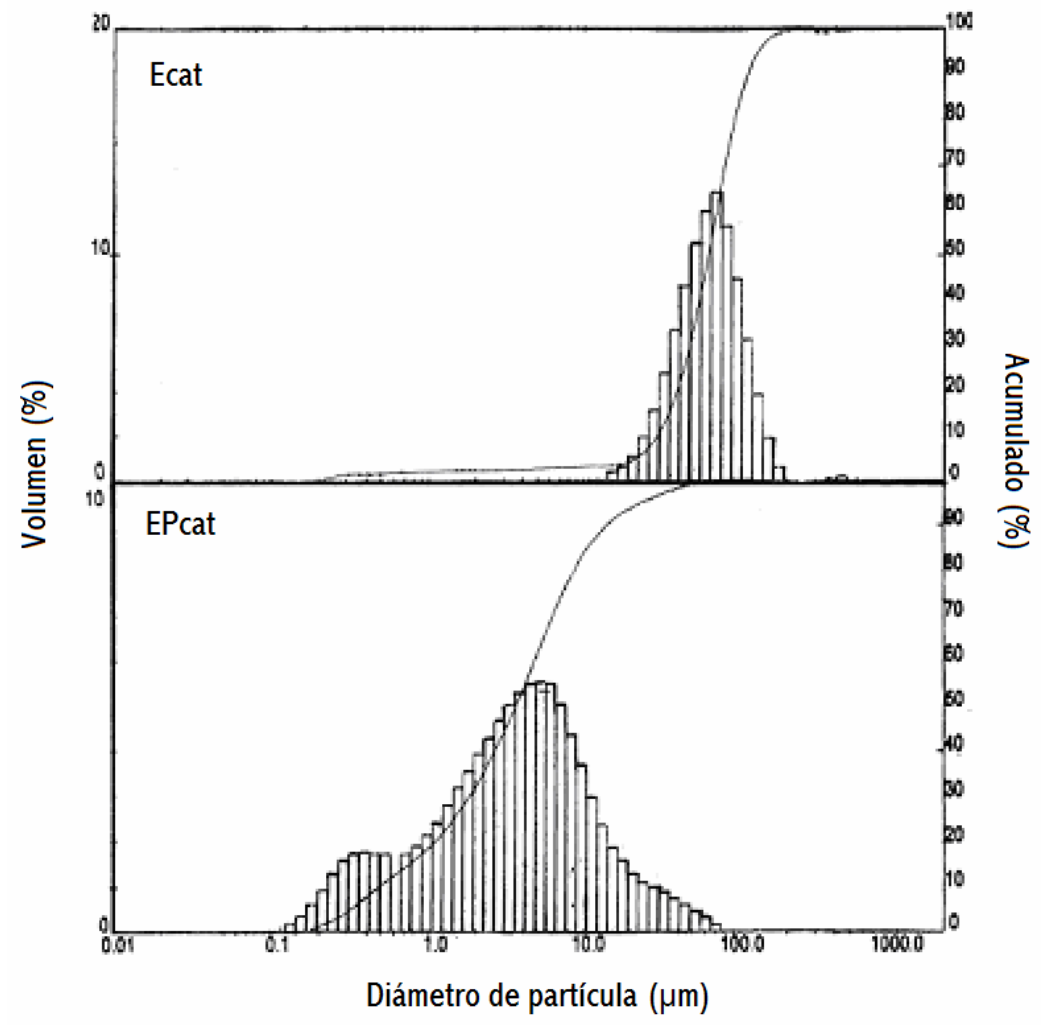

Figura 23. Distribución de tamaños de partículas del FCC [75].

\subsubsection{Propiedades de morteros $y$ hormigones frescos con FCC}

La trabajabilidad que presentan los morteros de cemento y residuo de catalizador de craqueo catalítico es menor que la mostrada por los morteros formados sólo con cemento [77] (Figura 24). La razón principal de este comportamiento es la alta superficie específica de esta adición que produce una alta absorción de agua [77,74]. 


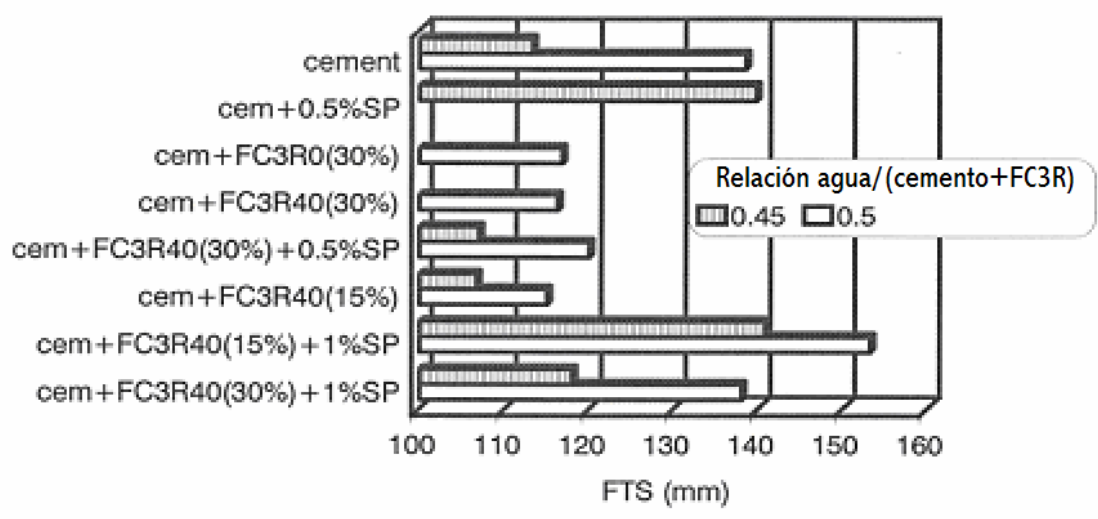

Figura 24. Valores de escurrimiento en mesa de sacudidas para diferentes morteros de cemento-FCC [77].

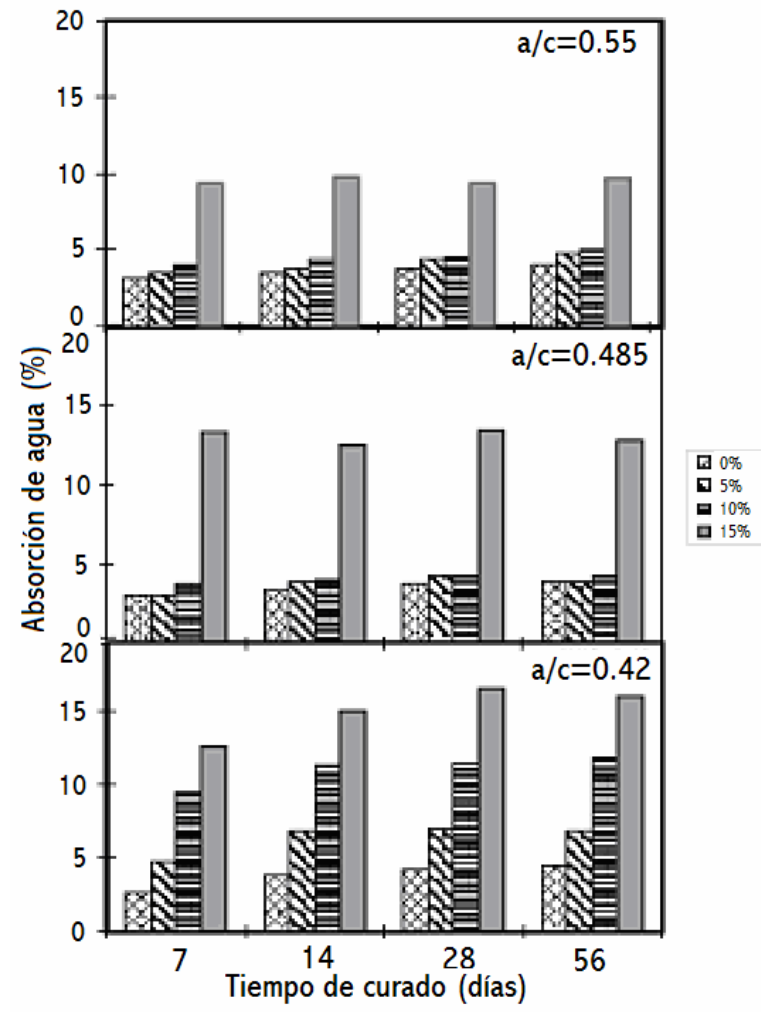

Figura 25. Cambios en la absorción de agua de morteros con adición de FCC [74]. 
Debido al descenso que se produce en la trabajabilidad de la mezcla cuando se adiciona el residuo de catalizador de craqueo catalítico se hace necesario incluir en las dosificaciones algún aditivo plastificante debido a que en caso contrario, cuando las sustituciones son altas (mayores del 10\%), se producen descensos en las resistencias mecánicas de los morteros [74] (Figura 25). No obstante, con el uso de aditivos se puede conseguir una buena compactación de la mezcla.

El valor de fluidez de los morteros sustituidos con residuo de catalizador aumenta, como se espera con la relación a/mc, pero por la razón anteriormente aludida disminuye cuando se aumenta el porcentaje de sustitución [75,74] (Tabla 3 y Figura 26).

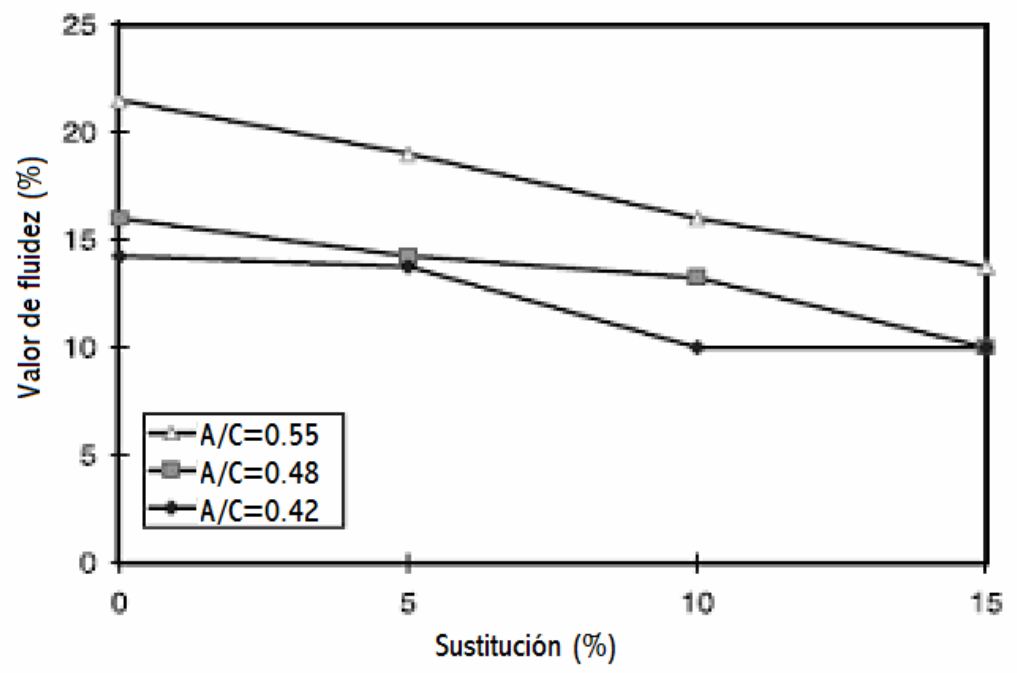

Figura 26. Cambios en la fluidez de morteros con adición de FCC [74].

Para mejorar la trabajabilidad que ofrecen los morteros con residuo de catalizador se puede recurrir al empleo de una segunda adición; se ha demostrado que la estructura esferoidal de las cenizas volantes contribuye significativamente a mejorar la trabajabilidad de los morteros de cemento debido al efecto de lubricante sólido que muestran. Payá y col. [78] han usado con éxito esta adición para mejorar la reducida trabajabilidad de los morteros con residuo de catalizador sin tener que emplear aditivos plastificantes. 


\begin{tabular}{||c|c|c|c|c||}
\hline \hline \multirow{3}{*}{ Item } & & \multicolumn{3}{|c||}{$\mathbf{a} / \mathbf{c}$} \\
\hline \multirow{4}{*}{ Ecat } & $\begin{array}{c}\text { Sustitución de } \\
\text { Cemento (\%) }\end{array}$ & $\mathbf{0 , 4 2}$ & $\mathbf{0 , 4 8 5}$ & $\mathbf{0 , 5 5}$ \\
\cline { 2 - 5 } & 0 & 42,5 & 60,0 & 115,0 \\
\cline { 2 - 5 } & 5 & 42,5 & 60,0 & 92,5 \\
\cline { 2 - 5 } & 10 & 40,0 & 57,5 & 91,0 \\
\hline \multirow{3}{*}{ EPcat } & 15 & 37,5 & 57,5 & 90,0 \\
\cline { 2 - 6 } & 0 & 42,5 & 60,0 & 115,0 \\
\cline { 2 - 6 } & 5 & 37,5 & 60,0 & 101,0 \\
\cline { 2 - 6 } & 10 & 37,5 & 55,0 & 87,5 \\
\hline \hline
\end{tabular}

Tabla 3. Valor de fluidez de morteros con sustitución de cemento por FCC [75].

Al aumentar el porcentaje de sustitución de residuo de catalizador en los morteros se puede observar que la exudación se ve reducida como se aprecia en la Tabla 4. Por otro lado, como también es previsible, se aprecia que al aumentar la relación a/mc la exudación aumenta [75,74] (Tabla 4 y Figura 27).

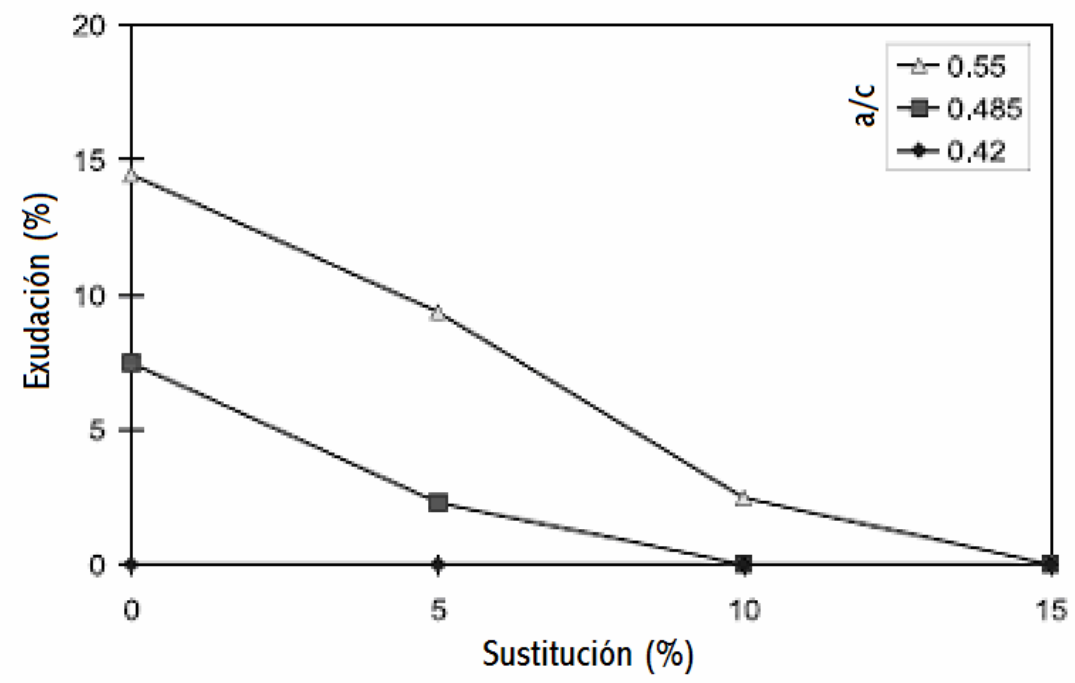

Figura 27. Capacidad de exudación de morteros con adición de FCC [74]. 


\begin{tabular}{||c|c|c|c|c|c||}
\hline & & \multicolumn{4}{|c||}{ SUSTITUCIÓN (\%) } \\
\hline $\mathbf{a} / \mathbf{c}$ & Item & $\mathbf{0}$ & $\mathbf{5}$ & $\mathbf{1 0}$ & $\mathbf{1 5}$ \\
\hline \multirow{3}{*}{0,55} & $\begin{array}{c}\text { Exudación } \\
(\%)\end{array}$ & 12,93 & 8,35 & 2,14 & 0,25 \\
\cline { 2 - 6 } & $\begin{array}{c}\text { Exudación } \\
\text { superficial } \\
\left(\mathrm{cm}^{3} / \mathrm{cm}^{2}\right)\end{array}$ & 0,349 & 0,230 & 0,055 & 0,005 \\
\hline \multirow{3}{*}{0,485} & $\begin{array}{c}\text { Exudación } \\
(\%)\end{array}$ & 7,29 & 4,65 & 0,84 & 0 \\
\cline { 2 - 6 } & $\begin{array}{c}\text { Exudación } \\
\text { superficial } \\
\left(\mathrm{cm}^{3} / \mathrm{cm}^{2}\right)\end{array}$ & 0,159 & 0,102 & 0,021 & 0 \\
\hline
\end{tabular}

Tabla 4. Exudación de morteros sustituidos con FCC [75].

En cuanto a la influencia que ejerce el FCC en los tiempos de fraguado se ha podido observar que el FCC disminuye los tiempos de fraguado. En concreto, se obtuvo una reducción del 13\% del tiempo inicial de fraguado, y un $8 \%$ para el tiempo final de fraguado para mezclas de cemento Portland con una sustitución del 15\% de FCC [76]. Estas reducciones se justificaban por la menor cantidad de sulfatos y una mayor cantidad de aluminatos de las mezclas que incorporaban FCC, y por una formación más rápida de los hidratos del cemento.

\subsubsection{Propiedades de morteros y hormigones endurecidos con FCC}

La molienda del residuo de catalizador favorece las propiedades puzolánicas del mismo [102]. En la Figura 28 se muestra la distribución de tamaños de partícula del FCC en función del tiempo de molienda del mismo. En esta figura se puede apreciar que durante los primeros 20 minutos de molienda se produce una acusada reducción de los tamaños de las partículas. Mayores tiempos de molienda no producen una reducción significativa de los tamaños de las partículas. Esto se puede apreciar claramente en la Figura 29 en la que se observa que a partir de los 20 minutos de molienda el tamaño medio de las partículas de FCC no se reduce. 


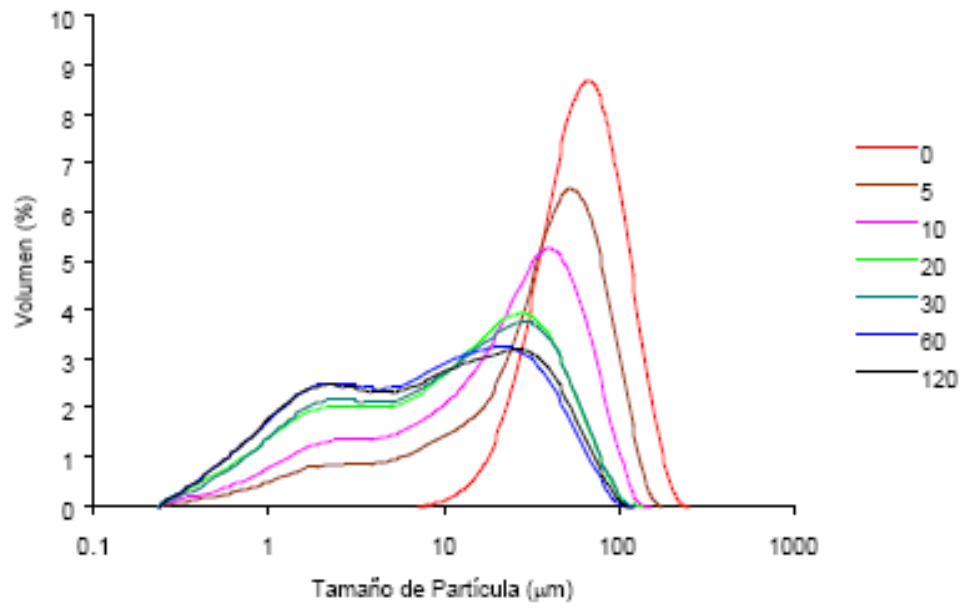

Figura 28. Distribución de tamaños de partícula del FCC para distintos tiempos de molienda. Leyenda: tiempo de molienda en minutos [102].

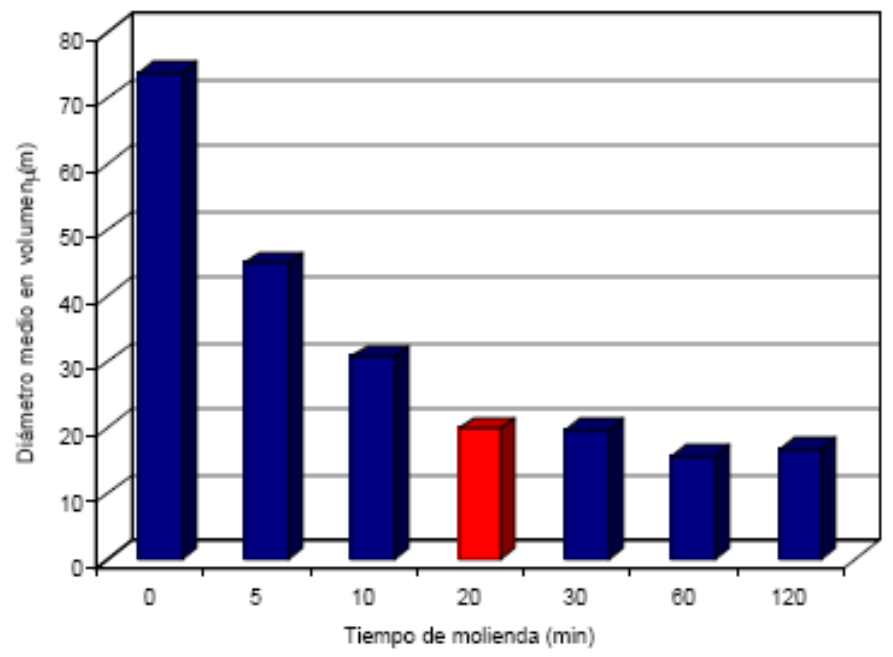

Figura 29. Evolución del diámetro medio del FCC para diferentes tiempos de molienda [102]. 
Este aumento de la actividad puzolánica del FCC producido por la molienda tiene su reflejo en las propiedades mecánicas de los productos elaborados con FCC molido.

La resistencia a compresión de los morteros fabricados con el residuo aumenta cuando aumentamos el tiempo de molienda hasta 20 min; mayores tiempos de molienda no producen aumentos significativos de esta propiedad (Figura 30). Todos los morteros con residuo dan mayores resistencias a compresión que los morteros control excepto aquéllos en los que el residuo no ha sido molido previamente [77], por ello se aconseja usar el FCC molido para su incorporación en morteros y hormigones.

El comportamiento en relación con la resistencia a flexión es mucho más errático, pero en general, los morteros con residuo de catalizador nos ofrecen valores similares o mayores que los morteros control sin residuo, excepto en aquellos casos en los que, de nuevo, no se muele la adición [77].

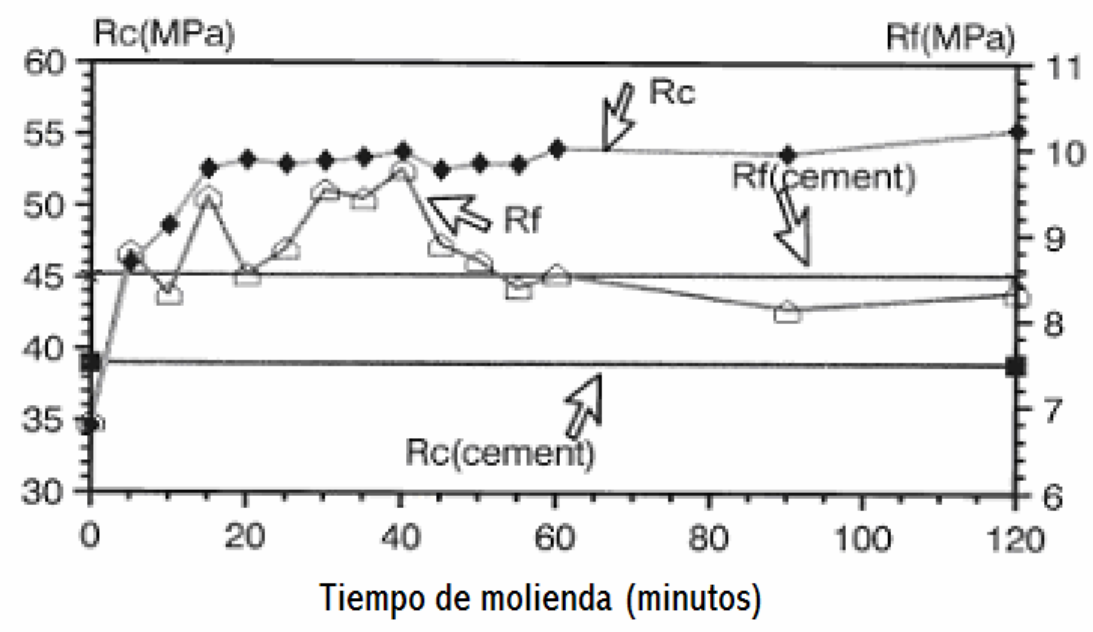

Figura 30. Valores de $R_{c} y R_{f}$ para morteros de cemento-FCC: influencia del tiempo de molido del FCC [77].

Si el residuo de catalizador no se muele, las resistencias a compresión y a flexión de los morteros son menores que las de los morteros control tanto cuando se curan a 20 como a $40^{\circ} \mathrm{C}$. El proceso 
de molienda mejora marcadamente dichas propiedades de los morteros. A los tres días de curado mejoran tanto la resistencia a flexotracción como a compresión para ambas temperaturas, lo cual es muestra de la alta reactividad del mismo [77] (Figura 31).

La actividad puzolánica del residuo de catalizador depende, pues, fuertemente de la finura que presente el mismo como demuestra Pacewska y col. [79] las fracciones de residuo de catalizador más gruesas tienen baja actividad puzolánica pero puede usarse como filler para el hormigón. Cuanto más fino es el residuo, mayor desarrollo de resistencia a edades tempranas ofrece.
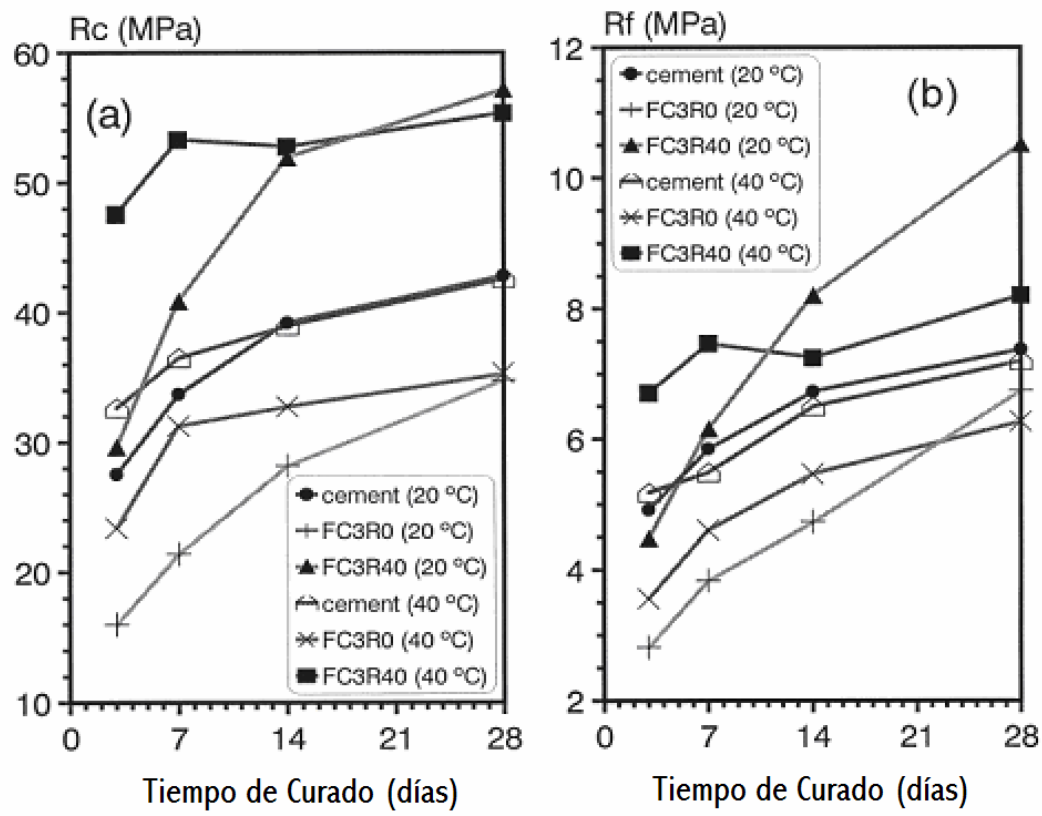

Figura 31. Valores de resistencia de morteros: influencia del tiempo de curado y la temperatura de curado en la resistencia a compresión y a flexión [77].

En otros estudios se ha puntualizado que usando porcentajes de sustitución bajos (5\%) a corto plazo sí se consigue mejorar la resistencia a compresión, sin embargo para mayores sustituciones hay que esperar a edades más avanzadas [75]. Eso sí, en estos estudios el residuo de catalizador no está molido y por lo tanto es lícito pensar 
que es necesario más tiempo para favorecer su actividad puzolánica. Si en lugar de usar este tipo de residuo se usa la fracción obtenida mediante precipitación electrostática cuyo tamaño es muy inferior, y por consiguiente su actividad debería ser superior a edades tempranas, sí que se aprecia que incluso para sustituciones del 15\%, la resistencia a compresión de los morteros con residuo es superior a los controles [75].

La influencia en las resistencias a compresión y a flexión del residuo de catalizador molido en función de las distintas proporciones de sustitución y las distintas edades del mortero muestran que a edades superiores a 7 días la presencia de esta adición incrementa de forma clara la resistencia a compresión y mantiene la resistencia a flexión de los controles [76] (Figura 32).
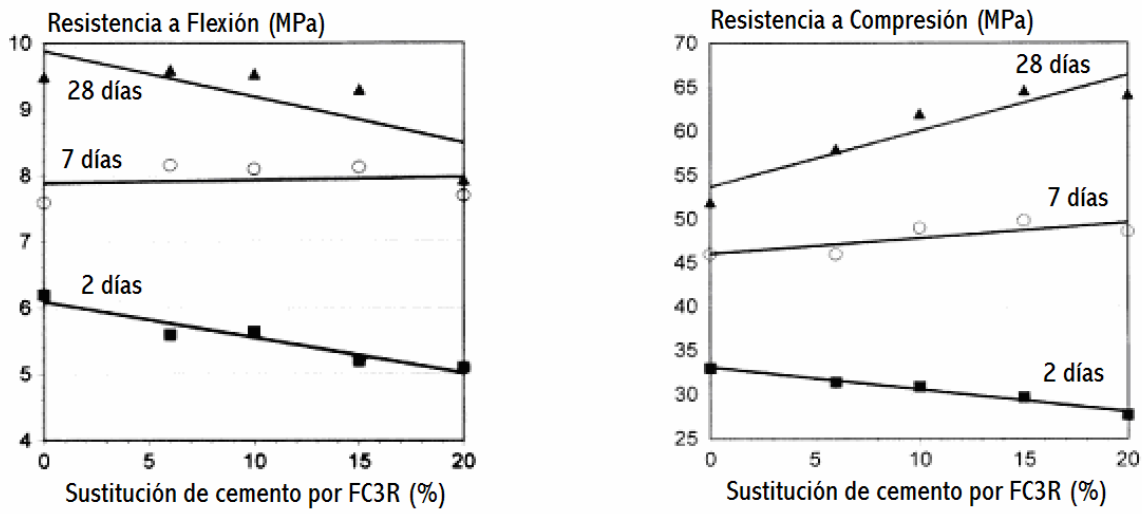

Figura 32. Influencia de la sustitución de cemento y el tiempo de curado en la resistencia a flexión y a compresión en morteros con FCC [76].

Lo mismo puede observarse en cuanto a la ganancia de resistencia. La ganancia de resistencia es un parámetro que revela la contribución de la fracción puzolánica a la resistencia [76]. La expresión matemática de este parámetro se presenta más adelante. En dicha ecuación, $\mathrm{R}_{\mathrm{i}}$ sería la resistencia del mortero sustituido; $\mathrm{R}_{0}$, la resistencia del mortero control; $\mathrm{w}_{\mathrm{c}}$, la cantidad de cemento en el mortero sustituido; $\mathrm{y} \mathrm{w}_{\mathrm{mc}}$, la suma de cemento y adición en el mortero. Una ganancia positiva indica que la adición es más activa que el 
cemento sustituido y una negativa lo contrario. En la Figura 33 se muestra este comportamiento.

Ecuación 16

$$
S G_{i}=R_{i}-\left(R_{0} \frac{w_{c}}{w_{m c}}\right)
$$

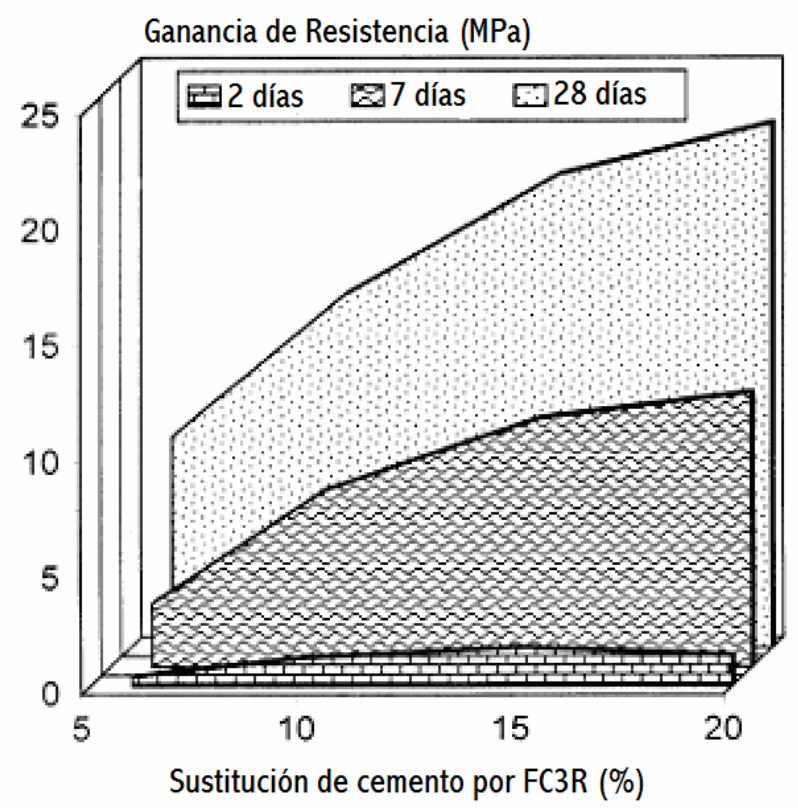

Figura 33. Ganancia de resistencia para morteros con FCC a distintas edades de curado [76].

Hsu y col. [80,81] han mostrado, coincidiendo en lo antes mencionado, que el residuo de catalizador puede ser un sustituto eficaz del cemento debido a su carácter puzolánico usando un aditivo plastificante (Figura 34). Una sustitución del 10-15\% de cemento conllevaría un aumento de la resistencia a compresión del 20-30\% a 7 y 28 días. Esto sitúa al residuo de catalizador a un nivel equivalente al de otras puzolanas más tradicionales como el metacaolín o el humo de sílice cuyo uso es reconocido a la hora de mejorar la resistencia y la durabilidad del hormigón. 


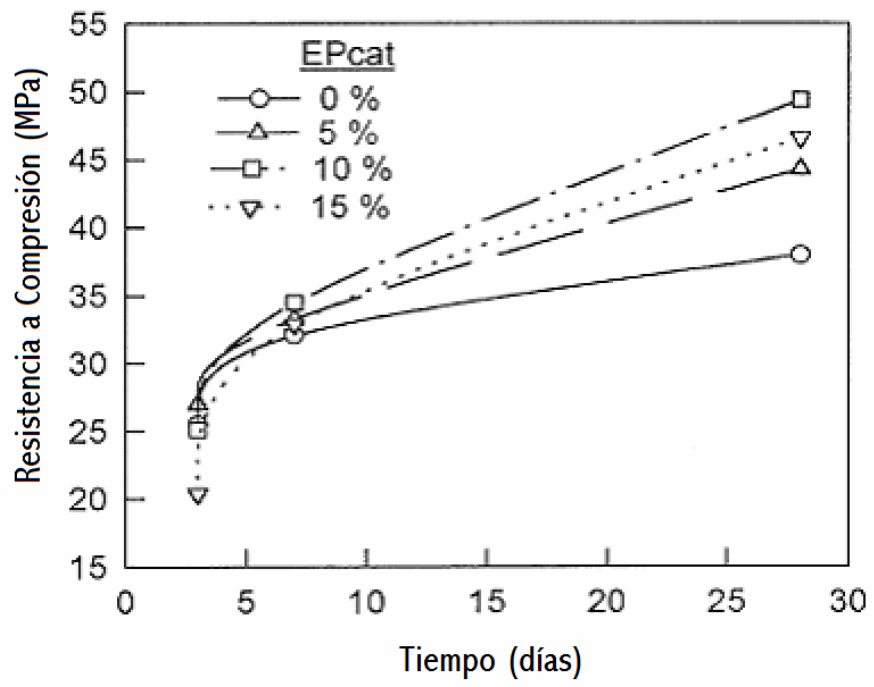

Figura 34. Efecto del FCC en la resistencia a compresión de morteros [80].

Intentando elucidar el comportamiento del residuo de catalizador en las pastas con cemento Portland y las modificaciones que introduce en las mismas, Paya y col. [82] llegaron a la conclusión de que los contenidos en $\mathrm{CSH}, \mathrm{CAH}, \mathrm{CASH}$ y $\mathrm{Af}_{\mathrm{T}}$ aumentaban según aumentaba la sustitución de cemento por residuo de catalizador, y adicionalmente el contenido de portlandita disminuía. Se observaba también que el contenido de cal fijada aumentaba según aumentaba el tiempo de curado para una sustitución determinada y una relación $\mathrm{a} / \mathrm{mc}$ determinada. Todo esto sirve para apoyar la gran reactividad del residuo de catalizador y dejar asentado su carácter puzolánico. En el mismo trabajo se decía que el comportamiento exhibido por el catalizador era muy similar al del metacaolín, excepto ligeras diferencias en cuanto al tiempo requerido por ambas adiciones para contribuir a la resistencia; el residuo de catalizador contribuía de forma más notable a edades tempranas mientras que el metacaolín requería de algo más de tiempo.

$\mathrm{Si}$ en lugar de reemplazar cemento con el residuo de catalizador se reemplaza parte de árido, se observa un aumento continuo de la resistencia a compresión como se observa en la Figura 35 . 


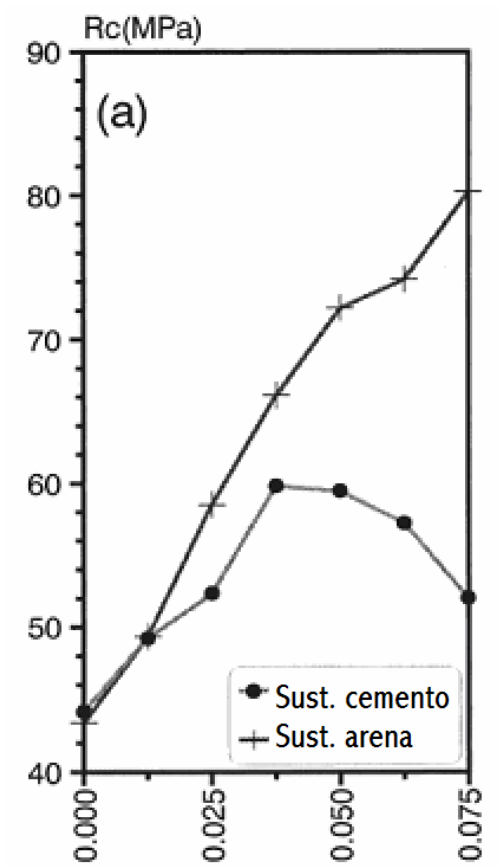

Relación FC3R40/(FC3R40+cemento+arena)

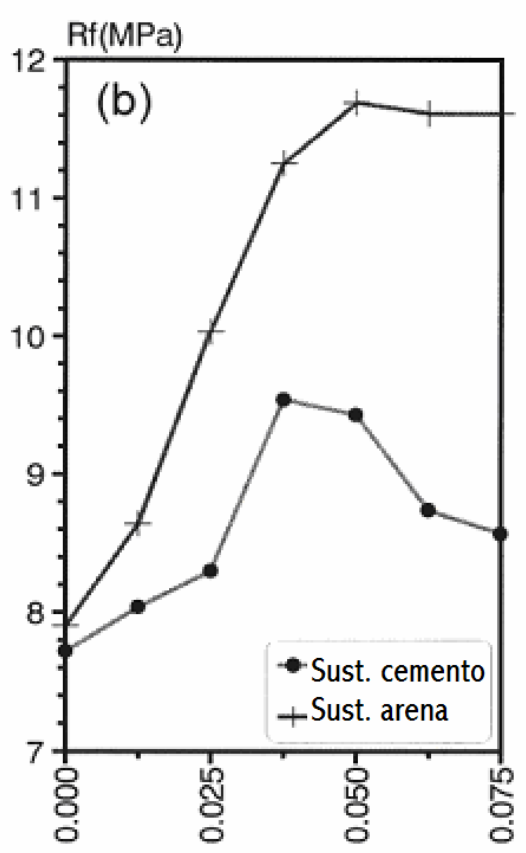

Relación FC3R40/(FC3R40+cemento+arena)

Figura 35. Resistencia de morteros con sustitución de cemento o arena por FCC [77].

Otros estudios como el realizado por Rattanasak y col. [83] concluyen que el si bien el residuo de catalizador puede ser usado como árido fino en morteros y hormigones, las altas proporciones del mismo en ausencia de aditivo plastificante conduce a descensos en la resistencia a compresión por la imposibilidad de compactar adecuadamente las mezclas (Figura 36). 


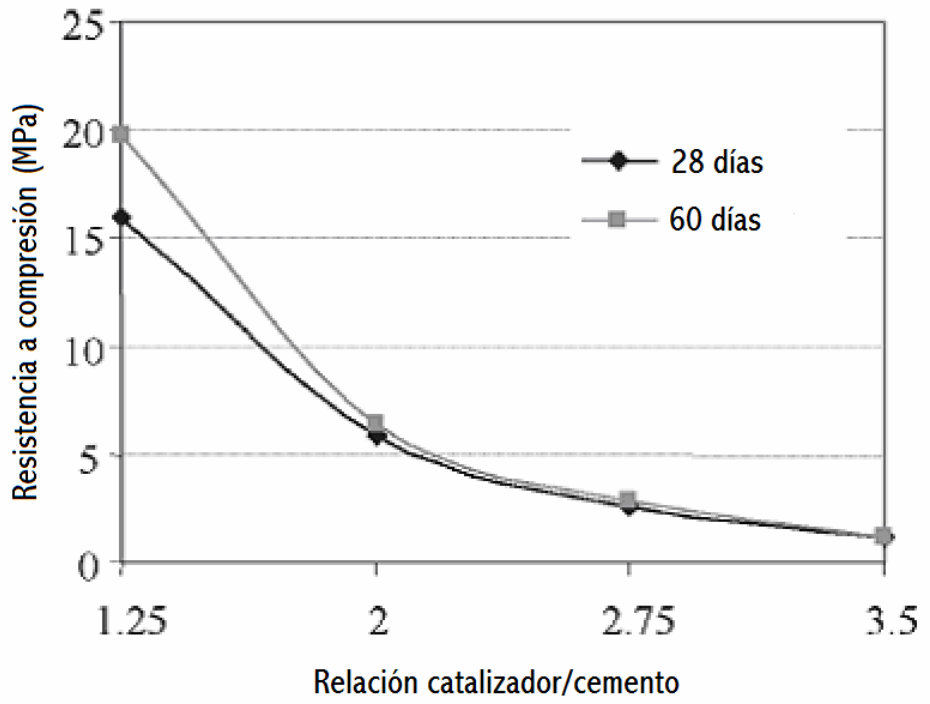

Figura 36. Relación entre la resistencia a compresión del mortero y la relación FCC/cemento [83].

\subsubsection{Durabilidad de hormigones y morteros con FCC}

En trabajos anteriores se ha estudiado el efecto que tienen varios agentes químicos agresivos sobre las matrices cementantes de cemento/FCC [84].

Frente a un ataque por ácido sulfúrico se pudo comprobar que los morteros con FCC ofrecían una mayor resistencia a la destrucción de los constituyentes cementantes de las mezclas, y la reducción de las propiedades mecánicas de los morteros con un 15\% de FCC era menor que la que presentaba los morteros sin FCC. En la Figura 37 se muestran las resistencias a flexotracción y compresión de varios morteros con una sustitución de cemento por FCC del 7,5 y del 15\% sumergidas en una disolución de $\mathrm{H}_{2} \mathrm{SO}_{4}$ 0,1 M. En el caso de la resistencia a flexotracción no parece existir una clara influencia de la sustutición de cemento por FCC, mientras que para el caso de la resistencia a compresión el comportamiento del mortero mejora al aumentar el nivel de sustitución. 

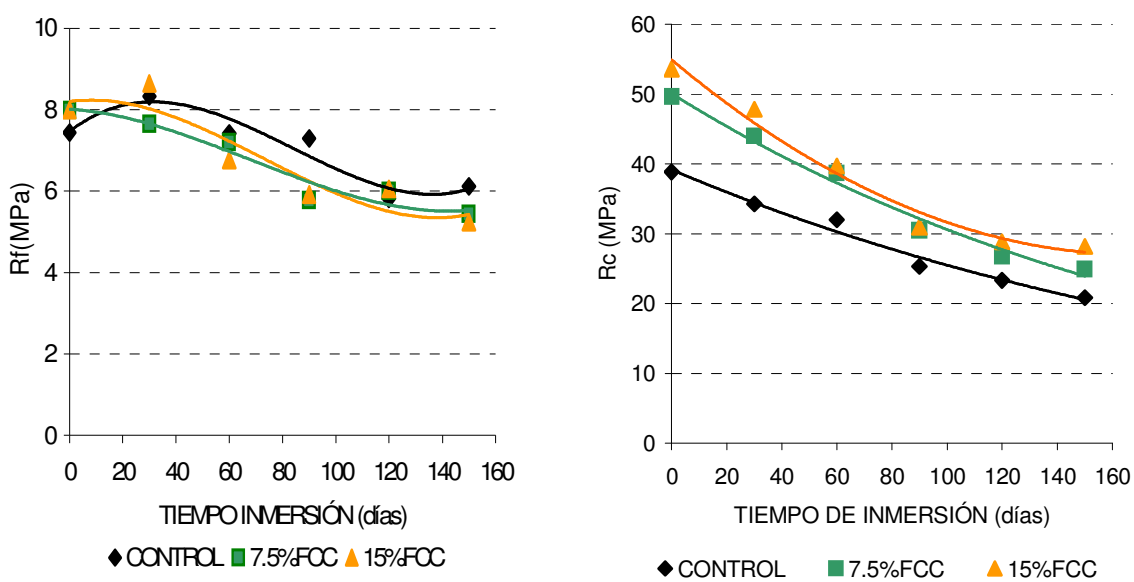

Figura 37. Variación de la resistencia a flexotracción (izda.) y resistencia a compresión (dcha.) con el tiempo de inmersión en $\mathrm{H}_{2} \mathrm{SO}_{4} \mathrm{0,1}$ M [84].

Otro de los agentes agresivos estudiados fue el sulfato amónico [84]. En este caso se observó que existía un claro empeoramiento de la resistencia a flexotracción de los morteros con FCC (Figura 38). En cuanto a la resistencia a compresión la tendencia a largo plazo mostraba que los morteros con FCC también sufrirían un mayor deterioro por la presencia de este agente agresivo, el cual producía la precipitación de cristales de yeso en los poros que deformaban las probetas debido a su crecimiento y las acababan fisurando.
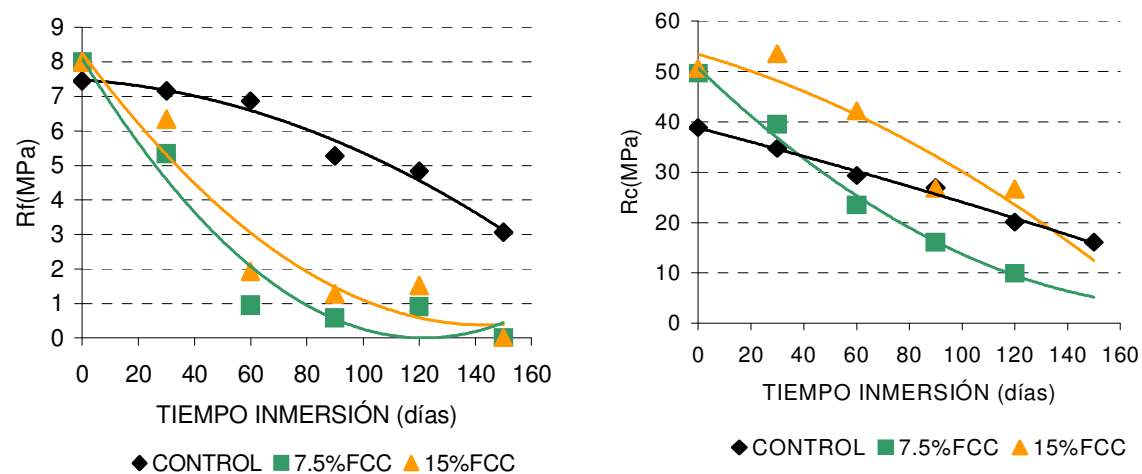

Figura 38. Variación de la resistencia a flexotracción (izda.) y resistencia a compresión (dcha.) con el tiempo de inmersión en $\left(\mathrm{NH}_{4}\right)_{2} \mathrm{SO4} 0,5 \mathrm{M}$ [84]. 
En cuanto al efecto del cloruro amónico sobre las matrices cementantes de cemento/FCC se pudo comprobar que los morteros con FCC mejoraban claramente los comportamientos ofrecidos por los morteros sin FCC, tanto en resistencia flexotracción como en resistencia a compresión [84]. En la Figura 39 se puede observar que a medida que aumenta el porcentaje de sustitución se mantiene la mejora de las propiedades mecánicas que se mostraban antes de la inmersión en la disolución de cloruro amónico $1 \mathrm{M}$.
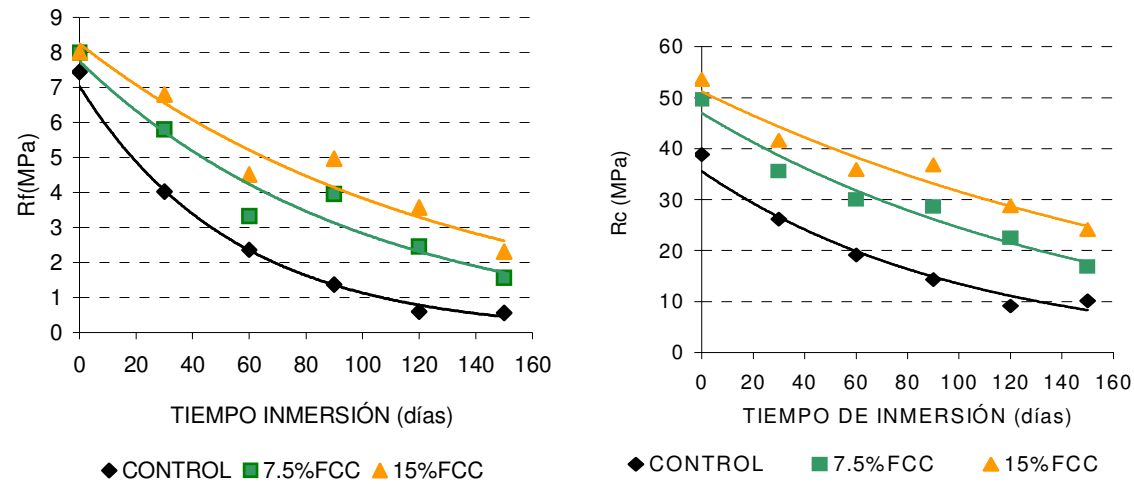

Figura 39. Variación de la resistencia a flexotracción (izda.) y resistencia a compresión (dcha.) con el tiempo de inmersión en $\mathrm{NH}_{4} \mathrm{Cl} 1 \mathrm{M}$ [84].

Relacionando el tema con la durabilidad del hormigón se ha podido observar que la microestructura del hormigón en el que se ha sustituido parte del cemento por residuo de catalizador es más compacta y tiene una menor absorción de agua. También se observó que se mejoraba la resistencia a las heladas del mismo [79]. En cuanto a la influencia sobre la pasivación de las armaduras, el uso de catalizador no empeoraba las condiciones de pasivado de las mismas [79]. 


\section{Objetivos}

El residuo de catalizador de craqueo catalítico (FCC) ha mostrado poseer aplicaciones muy interesantes como material puzolánico en morteros y hormigones. Hasta ahora se ha podido comprobar que su incorporación ofrece mejoras importantes en las propiedades mecánicas de los morteros y no ha presentado efectos adversos. En lo referente al impacto del FCC en la durabilidad de los materiales elaborados con el mismo también se ha comprobado que puede ofrecer importantes ventajas. No obstante, existe una carencia en el conocimiento sobre el efecto que este material puede producir sobre los niveles de corrosión de armaduras embebidas en morteros y/u hormigones. Esta laguna de información es la que se pretende cubrir con esta tesis doctoral.

El objetivo principal de la tesis doctoral ha sido estudiar la durabilidad de morteros de cemento parcialmente sustituido por FCC reforzados con acero, frente a los clásicos ataques que ponen en riesgo la integridad de las estructuras de hormigón armado, como son la carbonatación y el ataque por cloruros. 
Para abordar el objetivo principal se han propuesto diversos objetivos secundarios:

a) Ataque por carbonatación.

- Efecto de la carbonatación en la matriz cementante de los morteros mixtos de cemento-FCC.

- Cinéticas de carbonatación de morteros mixtos de cementoFCC.

- Estudio de la velocidad de corrosión de aceros embebidos en morteros mixtos de cemento-FCC en un ataque por carbonatación.

- Efecto de la carbonatación en morteros ternarios de cementoFCC-ceniza volante reforzados con acero.

b) Ataque por cloruros.

- Efecto del ataque por cloruros en la matriz cementante de los morteros mixtos de cemento-FCC.

- Cinéticas de ingreso de cloruros en morteros mixtos de cemento-FCC.

- Estudio de la velocidad de corrosión de aceros embebido en morteros mixtos de cemento-FCC en un ataque por cloruros.

- Efecto del ataque por cloruros en morteros ternarios de cemento-FCC-ceniza volante reforzados con acero.

Con todo esto se pretende evaluar la posibilidad de uso del FCC como material puzolánico en cementos mixtos que permita su utilización en un amplio abanico de aplicaciones en el campo de la construcción. 


\section{Efecto de la carbonatación en la matriz cementante de los morteros mixtos de cemento-FCC}

En este capítulo se analizan los resultados obtenidos mediante diversas técnicas instrumentales sobre las modificaciones en la matriz cementante producidas por la carbonatación de los morteros mixtos de cemento-FCC.

Se han realizado pruebas termogravimetricas de pastas de cal y de cemento. El objetivo que se pretende es evaluar cómo la carbonatación afecta a los productos de hidratación del cemento y a los productos resultantes de la reacción puzolánica, en la medida que se forman nuevos productos o desaparecen algunos otros.

Asimismo se abordan los análisis efectuados mediante difracción de rayos $\mathrm{X}$ de pastas de cemento y cal con sustitución parcial de residuo de FCC, con el fin de identificar los productos cristalinos presentes en dichas pastas, antes y después de la carbonatación. 
Por otro lado, se ha estudiado la morfología de la estructura porosa interna de las pastas de cemento y cal con sustitución de residuo de FCC. No sólo se pretende analizar el aspecto morfológico de dichas pastas sino además se han evaluado los constituyentes químicos que se pueden encontrar mediante el análisis de las energías de los rayos $\mathrm{X}$ dispersados por transiciones de electrones secundarios. Para ello se presentarán las fotografías realizadas y los resultados de los análisis mencionados.

Para finalizar, en este capítulo se pretende estudiar la distribución de los tamaños de poros de los morteros sustituidos con residuo de FCC. Por otro lado se intentan observar las modificaciones introducidas en estas distribuciones de tamaños de poros debidas al proceso de carbonatación al que fueron sometidos los morteros. Estos resultados vienen relacionados con las velocidades de carbonatación que se han obtenido tal y como se presenta en capítulos posteriores.

\subsection{Análisis mediante termogravimentría de pastas carbonatadas}

\subsubsection{Diseño de la experiencias}

Se han fabricado 2 pastas de cal y 4 pastas de cemento con distinta dosificación de FCC y con una relación a/mc fija de 0,8. Las sustituciones de FCC empleadas han sido del 30 y del $70 \%$ en el caso de las pastas de cal y 0, 20, 35 y 50\% de FCC en las de cemento. Para las pastas de cal se ha empleado $\mathrm{Ca}(\mathrm{OH})_{2}$ para análisis y para las pastas de cemento se ha utilizado cemento tipo CEM I 52,5 R. El residuo de FCC ha sido suministrado por BP Oil España. El FCC empleado fue molido durante 20 minutos en un molino de bolas para mejorar sus propiedades puzolánicas [102].

En la Tabla 5 y la Tabla 6 se presenta el análisis químico del FCC y el cemento utilizado en todas las experiencias de este trabajo, respectivamente. 


\begin{tabular}{||c|c|c|c||}
\hline $\mathbf{S i O}_{\mathbf{2}}$ & 46.04 & $\mathbf{P}_{\mathbf{2}} \mathbf{O}_{\mathbf{5}}$ & $\leq 0.01$ \\
\hline $\mathrm{Al}_{\mathbf{2}} \mathbf{O}_{\mathbf{3}}$ & 47.47 & $\mathbf{M n}_{\mathbf{2}} \mathbf{O}_{\mathbf{3}}$ & $\leq 0.01$ \\
\hline $\mathbf{F e}_{\mathbf{2}} \mathbf{O}_{\mathbf{3}}$ & 0.58 & $\mathbf{C l}^{-}$ & $\leq 0.01$ \\
\hline $\mathbf{C a O}$ & 0.11 & $\mathbf{V}_{\mathbf{2}} \mathbf{O}_{\mathbf{5}}$ & $\leq 0.01$ \\
\hline $\mathbf{M g O}$ & 0.17 & $\mathbf{C o}_{\mathbf{3}} \mathbf{O}_{\mathbf{4}}$ & 0.04 \\
\hline $\mathbf{S O}_{\mathbf{3}}$ & 0.02 & $\mathbf{N i O}$ & 0.16 \\
\hline $\mathrm{Na}_{\mathbf{2}} \mathbf{O}$ & 0.30 & $\mathbf{C u O}$ & $\leq 0.01$ \\
\hline $\mathbf{K}_{\mathbf{2}} \mathbf{O}$ & 0.02 & $\mathbf{Z n O}$ & $\leq 0.1$ \\
\hline $\mathbf{T i O}_{\mathbf{2}}$ & 1.18 & $\mathbf{P . F}{ }^{*}$ & 0.49 \\
\hline
\end{tabular}

Tabla 5. Composición química en porcentajes del FCC. *P.F.: pérdida al fuego, $950^{\circ} \mathrm{C}, 1 \mathrm{~h}$.

\begin{tabular}{|c|c|c|c||}
\hline $\mathbf{S i O}_{\mathbf{2}}$ & 20,21 & $\mathbf{N a}_{\mathbf{2}} \mathbf{O}$ & 0,10 \\
\hline $\mathbf{A l}_{\mathbf{2}} \mathbf{O}_{\mathbf{3}}$ & 4,94 & $\mathbf{K}_{\mathbf{2}} \mathbf{O}$ & 0,95 \\
\hline $\mathbf{F e}_{\mathbf{2}} \mathbf{O}_{\mathbf{3}}$ & 2,85 & $\mathbf{S O}_{\mathbf{3}}$ & 3,37 \\
\hline $\mathbf{C a O}$ & 62,87 & $\mathbf{P . F} *{ }^{*}$ & 2,34 \\
\hline $\mathbf{M g O}$ & 1,05 & & \\
\hline
\end{tabular}

Tabla 6. Composición química en porcentajes del cemento. *P.F.: pérdida al fuego, $950^{\circ} \mathrm{C}, 1 \mathrm{~h}$.

En la Figura 40 se presenta la granulometría del FCC antes y después de ser molido.

Las pastas se elaboraron en contenedores de plástico de $100 \mathrm{ml}$ y se amasaron manualmente mediante una varilla de vidrio. Tras su fraguado, las pastas se conservaron en ambiente de humedad relativa del $100 \%$, y se tomaron muestras de las mismas a los 9 días y a los 28 días. A continuación, se introdujeron en una cámara de carbonatación cuya atmósfera era aproximadamente del $100 \%$ de $\mathrm{CO}_{2}$ y una humedad relativa del $65 \pm 5 \%$ durante 1 mes para asegurar su completa carbonatación, y se tomó una muestra adicional de cada una de las pastas. 


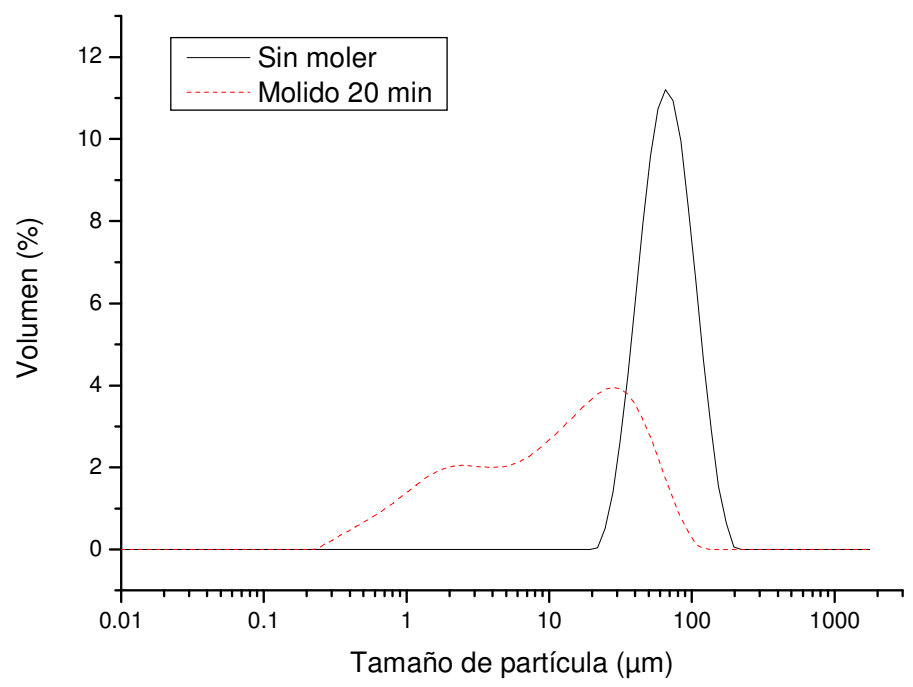

Figura 40. Distribución del tamaño de partícula del FCC sin moler y molido durante 20 minutos.

La cámara de carbonatación consiste en un recipiente hermético (un desecador) al que se había conectado una bala de $\mathrm{CO}_{2}$ (riqueza $>99.9 \%$, seco). El flujo de $\mathrm{CO}_{2}$ que se empleó fue continuo y con caudal aproximado de $10 \mathrm{ml} / \mathrm{min}$. Para simplificar, en este trabajo se hace referencia a que la atmósfera generada en la cámara es del $100 \%$ de $\mathrm{CO}_{2}$, aunque debido a la humedad de su interior, la concentración de $\mathrm{CO}_{2}$ es ligeramente inferior. La temperatura de la cámara de carbonatación se mantuvo entre $18^{\circ}$ y $20^{\circ} \mathrm{C}$ durante todo el proceso, y la humedad relativa de la misma se controló de forma que estuviera en un intervalo comprendido entre el 60 y $70 \%$. Para ello se introdujo un crisol con gel de sílice que eliminara la humedad que se producía durante el proceso de carbonatación. El gel de sílice se reponía periódicamente para asegurar que la humedad era la adecuada. La elección de la humedad relativa se hizo para acelerar al máximo la velocidad de carbonatación. Como se describió en la introducción de este trabajo, la máxima velocidad de carbonatación tiene lugar para una humedad relativa del 65\% [91,124], y precisamente en torno a ese valor se quería trabajar para acelerar al máximo los ensayos. En la 
Figura 41 se muestra una fotografía de las cámaras de carbonatación acelerada.

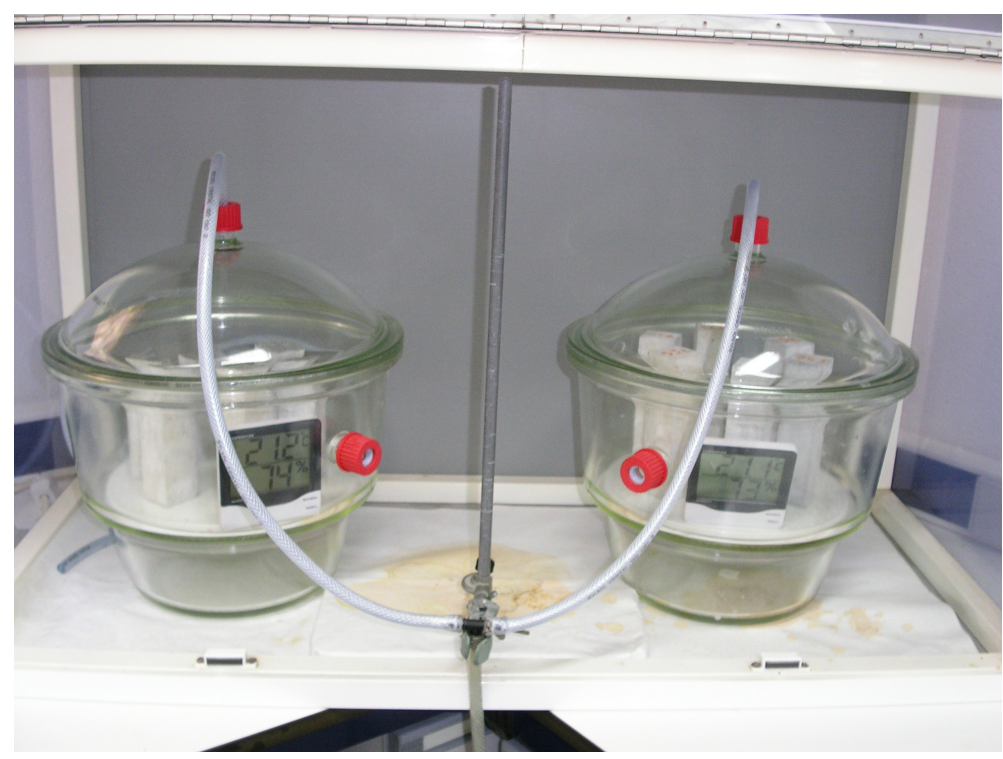

Figura 41. Cámaras de carbonatación acelerada.

La muestra para la termogravimetría se tomó de una pequeña porción de las pastas, que se pulverizó en un mortero de ágata. A la muestra pulverizada se le eliminó el agua no combinada mediante su filtrado a vacío y sucesivos lavados con acetona, tras lo cual se introdujo en una estufa a $60^{\circ} \mathrm{C}$ durante unos $15 \mathrm{~min}$. Finalmente se tamizó cada una de las muestras con un tamiz de $80 \mu \mathrm{m}$. La porción que no se retuvo en el tamiz fue la destinada a analizarse en la termobalanza (aproximadamente $30 \mathrm{mg}$ ).

La termobalanza empleada es una Mettler Toledo TGA850 (Figura 42) de brazo horizontal. De cada una de las muestras tomadas se realizaron dos ensayos termogravimétricos. El primero consistió en la aplicación de una rampa de temperatura de $20^{\circ} \mathrm{C} / \mathrm{min}$ hasta los $1000^{\circ} \mathrm{C}$ en un crisol de alúmina (Figura 43 izda.) cuya tapa poseía un orificio. La atmósfera empleada en este caso fue aire seco con un caudal de $75 \mathrm{ml} / \mathrm{min}$. El segundo consistió en la aplicación de una rampa de temperatura de $10^{\circ} \mathrm{C} / \mathrm{min}$ hasta $600^{\circ} \mathrm{C}$ que se realizó sobre la muestra en un crisol de aluminio sellado y perforado (Figura 43 
dcha.). La atmósfera de este método fue inerte, concretamente nitrógeno, con un caudal de $75 \mathrm{ml} / \mathrm{min}$. De esta forma con el primer barrido se intentaba abarcar el mayor intervalo de temperatura posible, de forma que se manifestara la máxima cantidad de procesos en la muestra, mientras que con el segundo se trataba de discriminar mejor los procesos que tienen lugar a menor temperatura. Otra diferencia que se observa entre los resultados obtenidos por ambos métodos es que los procesos aparecen a temperaturas algo inferiores cuando se usa el crisol de alúmina. Esto es debido a que la atmósfera autogenerada en el crisol de aluminio sellado retrasa los procesos de pérdida de masa (deshidrataciones y descomposiciones) y hace que aparezcan a temperaturas superiores.

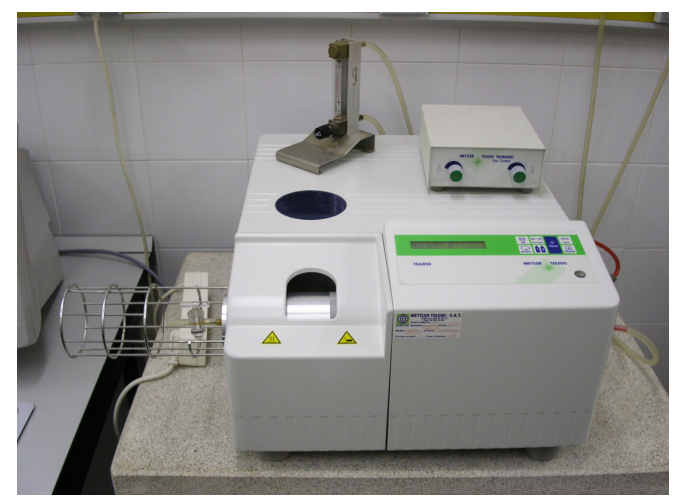

Figura 42 Termobalanza Mettler Toledo TGA850.

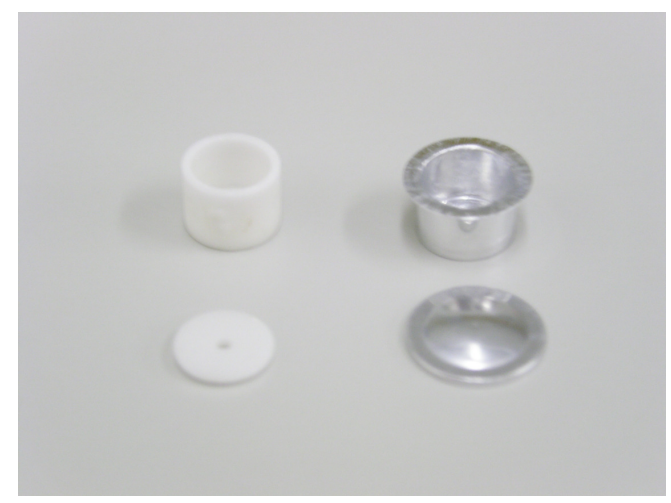

Figura 43 Crisol de alúmina con orificio (izda.) y crisol de aluminio de tapa perforada (dcha.). 


\subsubsection{Análisis de las pastas de cal}

La elaboración de las pastas de cal se realizó con el fin de identificar mejor los compuestos resultantes de la reacción puzolánica del FCC con el hidróxido cálcico. Al no haber cemento se pueden definir claramente los compuestos originados por el FCC y de esta manera se pueden evaluar más fielmente los análisis correspondientes a las pastas de cemento, que normalmente son más complejos. La representación de los gráficos que se ha empleado corresponde a las curvas derivadas de los termogramas (DTG) ya que de esta forma se aprecian mejor los procesos que tienen lugar. Antes de comentar los resultados obtenidos se muestran las curvas derivadas de los termogramas del hidróxido cálcico con agua y el FCC, por separado (Figura 44).

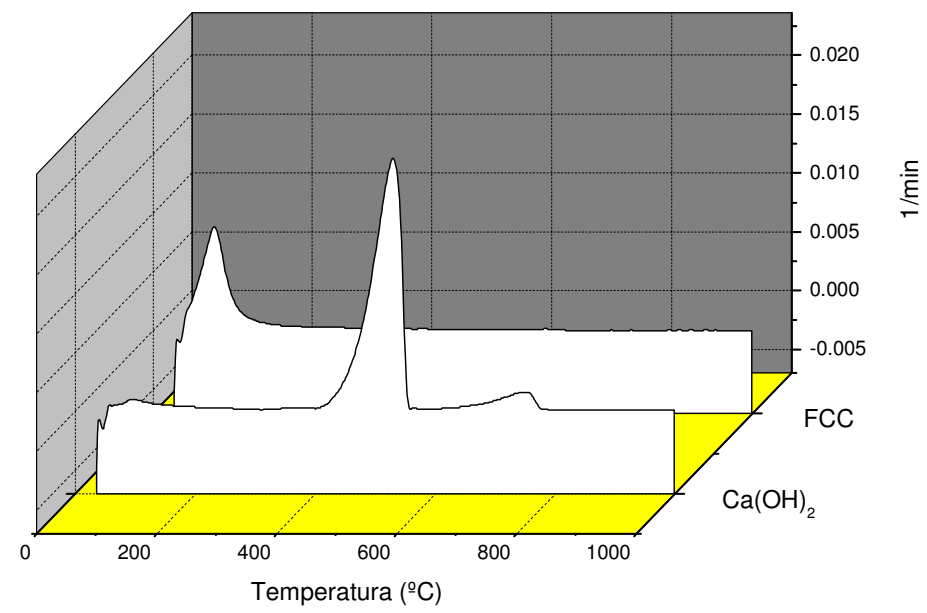

Figura 44. Curva de DTG de los productos de partida tras 9 días de curado. Velocidad de calentamiento de $20^{\circ} \mathrm{C} / \mathrm{min}$. Atmósfera de aire seco a $75 \mathrm{ml} / \mathrm{min}$. Crisol de alúmina.

En esta figura se observa, por un lado, que el FCC sin hidróxido cálcico no ofrece ningún producto cementante, ya que necesita de este para desarrollar su actividad puzolánica. La pérdida 
de masa que se aprecia a $100^{\circ} \mathrm{C}$ corresponde al agua con que se había mezclado el FCC y que no se eliminó totalmente antes de ser analizada. En cuanto al termograma del hidróxido cálcico se puede apreciar el pico a $530^{\circ} \mathrm{C}$ que es resultado de la descomposición del mismo según el proceso que se muestra más adelante (Ecuación 21). Además se aprecia que existe cierta cantidad de carbonato cálcico por el pequeño pico que se observa a $750^{\circ} \mathrm{C}$. Esto es habitual ya que la carbonatación del hidróxido cálcico durante su manipulación es sumamente fácil.

\subsubsection{Antes de la carbonatación}

En la Figura 45 y Figura 46 se muestran los termogramas obtenidos para las pastas de cal transcurridos 9 días desde su amasado. Según sabemos el FCC está formado en más de un $90 \%$ por silicatos y aluminatos [76], los cuales se encuentran aproximadamente en la misma cantidad. Por ello se espera encontrar los picos correspondientes a la deshidratación de los silicatos cálcicos y los aluminatos cálcicos hidratados. Estos son los compuestos característicos de las matrices cementantes y aparecen como pérdidas anteriores a $\operatorname{los} 300^{\circ} \mathrm{C}$ [92-96]. En este caso se observa claramente un pico a $122^{\circ} \mathrm{C}$ (Figura 46), que correspondería a la deshidratación de los silicatos cálcicos $\left(\mathrm{C}_{3} \mathrm{~S}_{2} \mathrm{H}_{3}\right.$, Ecuación 17), y otro que se sitúa en torno a los $210^{\circ} \mathrm{C}$, que se asociaría a los aluminatos cálcicos $\left(\mathrm{C}_{4} \mathrm{AH}_{13}\right.$, Ecuación 18) y silicoaluminatos cálcicos $\left(\mathrm{C}_{2} \mathrm{ASH}_{8}\right.$, Ecuación 19) del tipo de la gehlenita hidratada o estraetlingita [97]. Tanto en la pasta de cal con $30 \%$ de FCC como en la que tiene un $70 \%$ se puede observar un tercer pico de menor intensidad a unos $270^{\circ} \mathrm{C}$ que se debe probablemente a un aluminato cálcico del tipo de $\mathrm{C}_{3} \mathrm{AH}_{8}$ (Ecuación 20) [98].

Ecuación 17

$$
3 \mathrm{CaO} \cdot 2 \mathrm{SiO}_{2} \cdot 3 \mathrm{H}_{2} \mathrm{O} \rightarrow 3 \mathrm{CaO} \cdot 2 \mathrm{SiO}_{2}+3 \mathrm{H}_{2} \mathrm{O}
$$

Ecuación 18

$$
4 \mathrm{CaO} \cdot \mathrm{Al}_{2} \mathrm{O}_{3} \cdot 13 \mathrm{H}_{2} \mathrm{O} \rightarrow 4 \mathrm{CaO} \cdot \mathrm{Al}_{2} \mathrm{O}_{3}+13 \mathrm{H}_{2} \mathrm{O}
$$

Ecuación $192 \mathrm{CaO} \cdot \mathrm{Al}_{2} \mathrm{O}_{3} \cdot \mathrm{SiO}_{2} \cdot 8 \mathrm{H}_{2} \mathrm{O} \rightarrow 2 \mathrm{CaO} \cdot \mathrm{Al}_{2} \mathrm{O}_{3} \cdot \mathrm{SiO}_{2}+8 \mathrm{H}_{2} \mathrm{O}$

Ecuación 20

$$
3 \mathrm{CaO} \cdot \mathrm{Al}_{2} \mathrm{O}_{3} \cdot 8 \mathrm{H}_{2} \mathrm{O} \rightarrow 3 \mathrm{CaO} \cdot \mathrm{Al}_{2} \mathrm{O}_{3}+8 \mathrm{H}_{2} \mathrm{O}
$$




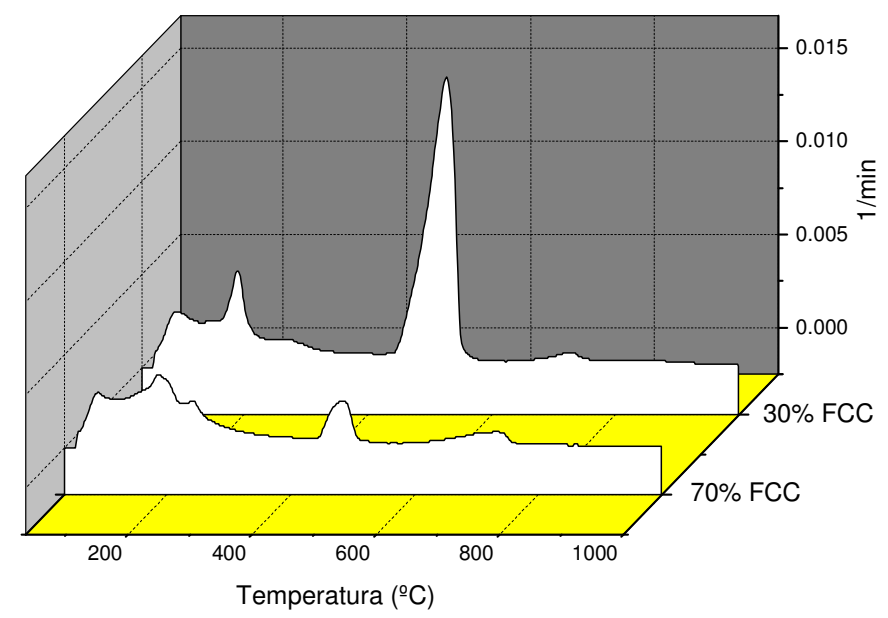

Figura 45. Curva de DTG de pastas de cal/FCC tras 9 días de curado. Velocidad de calentamiento de $20^{\circ} \mathrm{C} / \mathrm{min}$. Atmósfera de aire seco a $75 \mathrm{ml} / \mathrm{min}$. Crisol de alúmina.

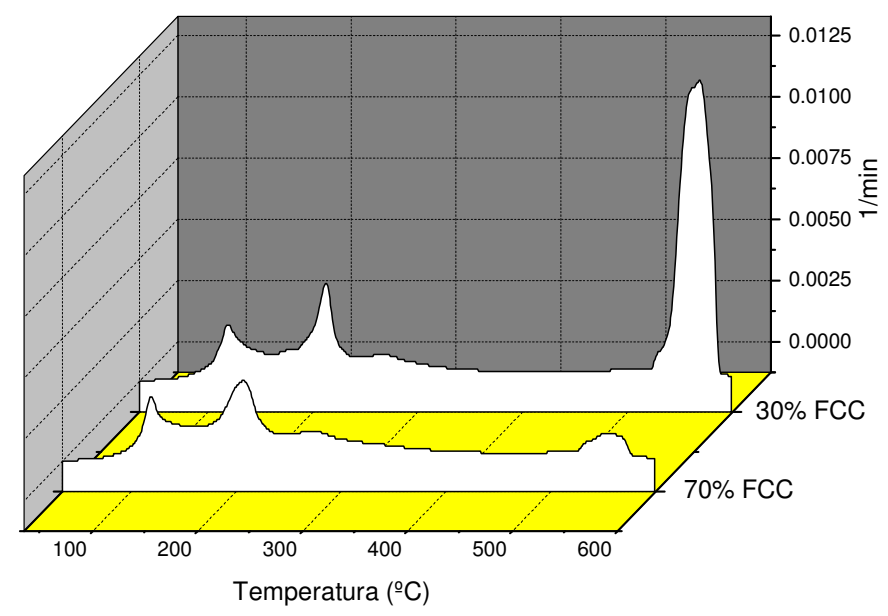

Figura 46. Curva de DTG de pastas de cal/FCC tras 9 días de curado. Velocidad de calentamiento de $10^{\circ} \mathrm{C} / \mathrm{min}$. Atmósfera de nitrógeno a $75 \mathrm{ml} / \mathrm{min}$. Crisol de aluminio sellado y perforado. 
En la zona en la que se produce la descomposición del hidróxido cálcico (Ecuación 21, aproximadamente a $500^{\circ} \mathrm{C}$ ) se observa que efectivamente éste se detecta a 9 días en ambas muestras, siendo mayor el pico con menor cantidad de FCC debido a que la reacción puzolánica no se ha desarrollado tanto como en el otro caso [97], y a que hay una mayor proporción de cal. De hecho, la pasta con $70 \%$ de FCC prácticamente ha consumido todo el hidróxido cálcico a la temprana edad de 9 días.

\section{Ecuación 21}

$$
\mathrm{Ca}(\mathrm{OH})_{2} \rightarrow \mathrm{CaO}+\mathrm{H}_{2} \mathrm{O}
$$

En la zona de altas temperaturas del termograma (Figura 45) podemos encontrar la descomposición de los carbonatos (Ecuación 22) a temperaturas comprendidas entre $\operatorname{los} 750^{\circ} \mathrm{C}$ y $\operatorname{los} 900^{\circ} \mathrm{C}$. En la bibliografía aparece descrito que las formas de carbonato cálcico de vaterita y aragonito suelen aparecer más cerca de $\operatorname{los} 750^{\circ} \mathrm{C}$, mientras que la calcita aparece a temperaturas algo superiores [39]. En las pastas de cal a 9 días vemos que la presencia de carbonatos es muy pequeña. Es habitual encontrar ciertas cantidades significativas de carbonato cálcico acompañando al $\mathrm{Ca}(\mathrm{OH})_{2}$ debido a que su carbonatación es sumamente fácil durante la manipulación, por lo que podemos intuir que viene incluida en la materia prima.

\section{Ecuación 22}

$$
\mathrm{CaCO}_{3} \rightarrow \mathrm{CaO}+\mathrm{CO}_{2}
$$

En la Tabla 7 se exponen numéricamente las pérdidas más relevantes de estas pastas. La columna "Total" representa el porcentaje de pérdida de masa registrado en todo el termograma; la columna " $\mathrm{Ca}(\mathrm{OH})_{2}$ " es el correspondiente al pico que aparece a $500^{\circ} \mathrm{C}$; la columna " $\mathrm{CaCO}_{3}$ " es la pérdida de masa observada entre 750 y $900^{\circ} \mathrm{C}$; y la columna "SCH-ACH" se obtiene por diferencia entre "Total" y la suma de " $\mathrm{Ca}(\mathrm{OH})_{2}$ " más " $\mathrm{CaCO}_{3}$ ". La columna de "Cal Fijada" se calcula mediante la Ecuación 23.

Ecuación 23

$$
\text { Cal Fijada }(\%)=\frac{\mathrm{CH}_{0}-\mathrm{CH}_{t}}{\mathrm{CH}_{0}} \times 100
$$


Donde $\mathrm{CH}_{0}$ es la cantidad de $\mathrm{Ca}(\mathrm{OH})_{2}$ inicial de la mezcla y $\mathrm{CH}_{t}$ es la cantidad de $\mathrm{Ca}(\mathrm{OH})_{2}$ de la pasta a una edad $t$, calculada a través de la relación estequiométrica de la Ecuación 21.

\begin{tabular}{||c|c|c|c|c|c||}
\hline \multicolumn{2}{|c|}{} & \multicolumn{4}{|c|}{ PÉRDIDAS (\%) } \\
\hline FCC (\%) & Cal Fijada (\%) & Total & $\mathbf{C a}(\mathbf{O H})_{\mathbf{2}}$ & $\mathbf{C a C O}_{\mathbf{3}}$ & CSH-CAH \\
\hline $\mathbf{3 0}$ & 41,74 & 22,1 & 9,92 & 0,27 & 11,91 \\
\hline $\mathbf{7 0}$ & 82,05 & 14,6 & 1,31 & 1,66 & 11,63 \\
\hline
\end{tabular}

Tabla 7. Pérdidas termogravimétricas de las pastas de cal/FCC tras 9 días de curado.

Claramente se aprecia como el consumo relativo de hidróxido cálcico es mayor en el caso de la pasta más sustituida, tal y como se apuntaba anteriormente. La cal fijada por la pasta con un $70 \%$ de sustitución es el doble de la que consigue fijar la pasta con $30 \%$ de FCC. La cantidad de silicatos y aluminatos cálcicos hidratados que se han formado son similares en ambos casos, incluso algo menor en la muestra con más FCC, lo que podría dar a entender que la poca cantidad de hidróxido cálcico de esta pasta empieza a limitar la reacción puzolánica.

Seguidamente se muestran los resultados obtenidos a 28 días para las pastas de cal. La Figura 47 y Figura 48 nos muestran los termogramas de estas pastas para una sustitución del 30 y del $70 \%$ de FCC.

En primer lugar destacamos el pico sobre $200^{\circ} \mathrm{C}$ que correspondería a la deshidratación de los aluminatos cálcicos tipo gehlenita hidratada. Además el pico que asignaba al otro tipo de aluminatos cálcicos $\left(\mathrm{C}_{3} \mathrm{AH}_{8}\right)$ [98] también se aprecia claramente con su máximo en $270^{\circ} \mathrm{C}$, sobre todo para la muestra con más cantidad de FCC lo que refuerza lo antes afirmado sobre su asignación. 


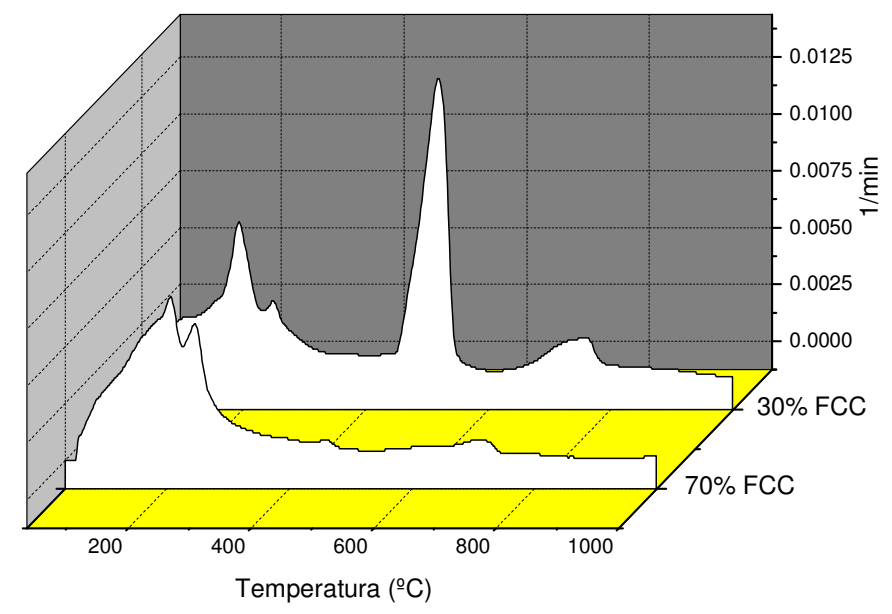

Figura 47. Curva de DTG de pastas de cal/FCC tras 28 días de curado. Velocidad de calentamiento de $20^{\circ} \mathrm{C} / \mathrm{min}$. Atmósfera de aire seco a $75 \mathrm{ml} / \mathrm{min}$. Crisol de alúmina.

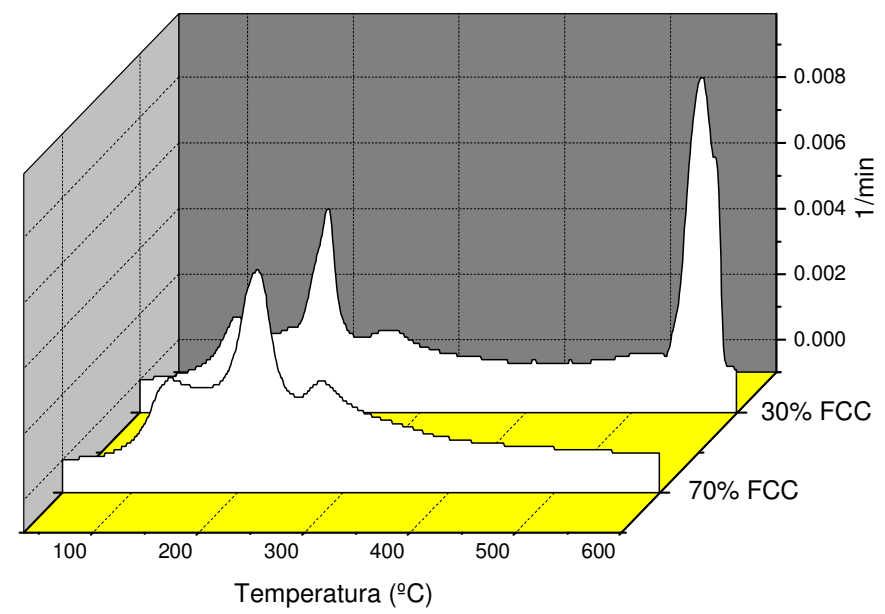

Figura 48. Curva de DTG de pastas de cal/FCC tras 28 días de curado. Velocidad de calentamiento de $1^{\circ} \mathrm{C} / \mathrm{min}$. Atmósfera de nitrógeno a $75 \mathrm{ml} / \mathrm{min}$. Crisol de aluminio sellado y perforado. 
Respecto al hidróxido cálcico vemos que, en la pasta con $30 \%$ de FCC, todavía hay parte del mismo sin reaccionar por lo que transcurrido este tiempo ya podemos afirmar que se encontraba exceso con respecto al FCC. En cambio, en la pasta con $70 \%$ de FCC ya no queda, lo cual se debe a que el FCC lo ha consumido totalmente en la reacción puzolánica.

En cuanto a los carbonatos, se observa una pequeña cantidad de los mismos en la zona en torno a $\operatorname{los} 750^{\circ} \mathrm{C}$, pudiendo coincidir con la descomposición de las estructuras polimórficas del carbonato cálcico antes comentadas.

En la Tabla 8 se muestran las pérdidas calculadas en las pastas de cal a 28 días. Se observa que en la pasta con el $70 \%$ de FCC no queda hidróxido cálcico. También se observa que el contenido de carbonatos en la pasta con 30\% de FCC, es mayor que el de la otra. Estos datos son distintos a los obtenidos para las pastas a 9 días, pero deberíamos considerar el que tras 28 días es posible que parte de la muestra en la que hay hidróxido cálcico en exceso se haya carbonatado levemente debido al $\mathrm{CO}_{2}$ atmosférico. En la muestra con $70 \%$ de FCC, este caso no se puede dar con tanta facilidad puesto que la cantidad hidróxido cálcico es menor en todo momento.

\begin{tabular}{||c|c|c|c|c|c||}
\hline \hline \multicolumn{2}{|c|}{} & \multicolumn{4}{|c|}{ PÉRDIDAS (\%) } \\
\hline FCC (\%) & Cal Fijada (\%) & Total & $\mathbf{C a}(\mathbf{O H})_{2}$ & $\mathbf{C a C O}_{3}$ & CSH-CAH \\
\hline $\mathbf{3 0}$ & 58,60 & 23,54 & 7,05 & 3,1 & 13,39 \\
\hline $\mathbf{7 0}$ & 100 & 17,28 & 0 & 1,46 & 15,82 \\
\hline
\end{tabular}

Tabla 8. Pérdidas termogravimétricas de las pastas de cal/FCC tras 28 días de curado.

En cuanto al gel de silicatos y aluminatos cálcicos, es algo mayor en la pasta con más FCC. Suponemos que una pasta con una sustitución intermedia habría obtenido valores mayores debido a que no se agotaría tan pronto el $\mathrm{FCC}$ ni el $\mathrm{Ca}(\mathrm{OH})_{2}$, ya que como se observa en los datos de cal fijada, en la primera muestra la cal está en exceso y en la segunda está por defecto. 


\subsubsection{Después de la carbonatación}

En la Figura 49 y Figura 50 podemos ver los termogramas de las pastas de cal tras el mes de carbonatación al que fueron sometidas después de los 28 días de conservación en la cámara de curado.

En la zona de la deshidratación de los silicatos y aluminatos cálcicos la pérdida de peso observada es menor en el caso de la muestra menos sustituida debido a la menor cantidad de FCC (Tabla 9).

Como se puede observar, durante el proceso de carbonatación se consume totalmente el hidróxido cálcico que no hubiera reaccionado con el FCC según:

$$
\text { Ecuación } 24 \mathrm{Ca}(\mathrm{OH})_{2}+\mathrm{CO}_{2} \rightarrow \mathrm{CaCO}_{3}+\mathrm{H}_{2} \mathrm{O}
$$

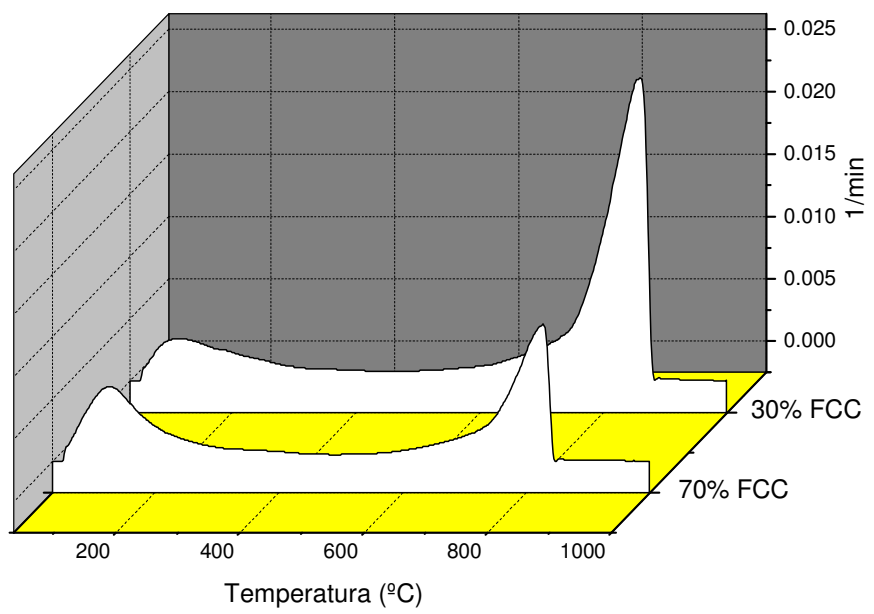

Figura 49. Curva de DTG de pastas de cal/FCC carbonatadas. Velocidad de calentamiento de $20^{\circ} \mathrm{C} / \mathrm{min}$. Atmósfera de aire seco a $75 \mathrm{ml} / \mathrm{min}$. Crisol de alúmina. 


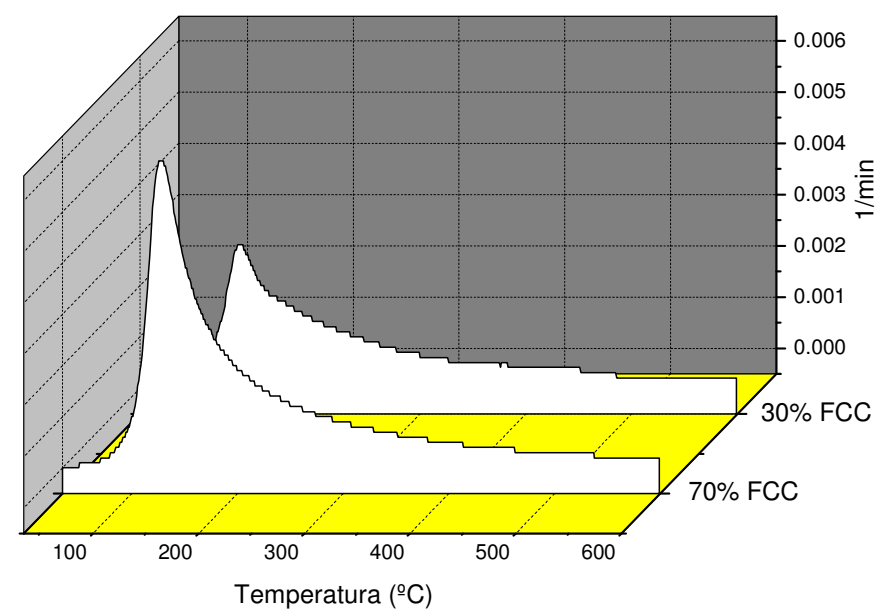

Figura 50. Curva de DTG de pastas de cal/FCC carbonatadas. Velocidad de calentamiento de $10^{\circ} \mathrm{C} / \mathrm{min}$. Atmósfera de nitrógeno a $75 \mathrm{ml} / \mathrm{min}$. Crisol de aluminio sellado y perforado.

Por otro lado existe un pico mayor en la zona de los carbonatos en la pasta con menor contenido en FCC ya que el hidróxido cálcico aquí presente, que no había reaccionado con el FCC, sí lo puede hacer con el $\mathrm{CO}_{2}$, mientras que en la muestra con $70 \%$ de $\mathrm{FCC}$ el pico de los carbonatos podría asignarse a los carbonatos producidos por el intenso ataque del $\mathrm{CO}_{2}$ sobre la matriz cementante $(\mathrm{CSH}, \mathrm{CAH}$ y $\mathrm{CASH})$.

En la Figura 51 se muestra un detalle de cómo la carbonatación ha afectado a la zona de los silicatos y aluminatos. En ella se observa la desaparición que se produce del pico de los aluminatos y aluminosilicatos cálcicos debido a que el calcio ha sido captado por el $\mathrm{CO}_{2}$ para formar carbonato cálcico [85-89]. 


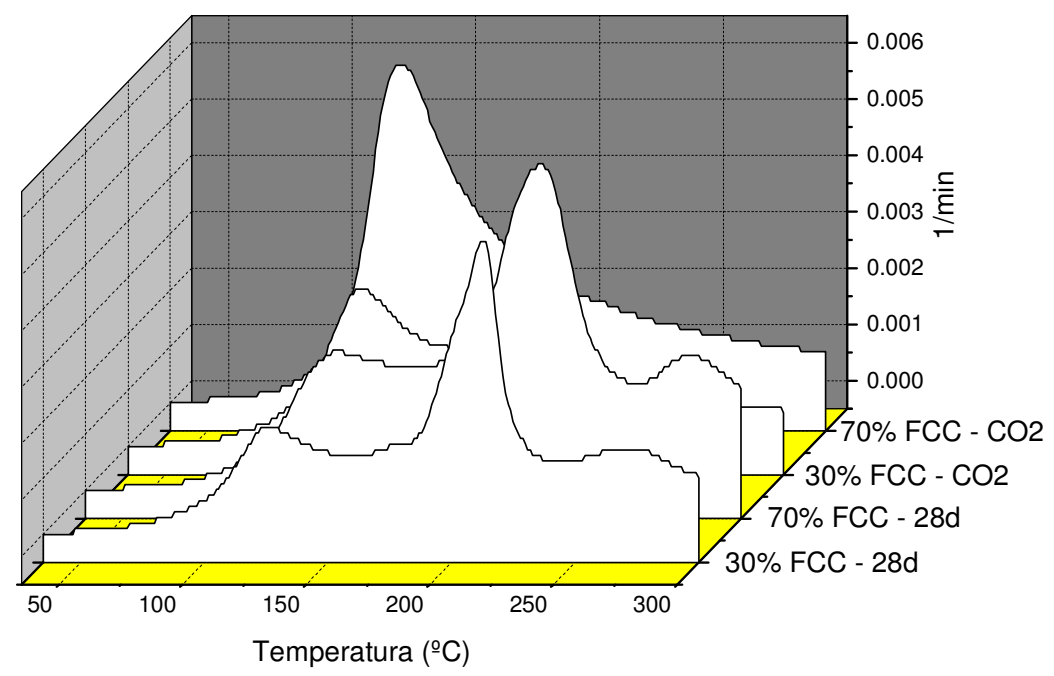

Figura 51. Detalle de las curvas DTG de las pastas de cal/FCC antes y después del proceso de carbonatación. Velocidad de calentamiento de $10^{\circ} \mathrm{C} / \mathrm{min}$. Atmósfera de nitrógeno a $75 \mathrm{ml} / \mathrm{min}$. Crisol de aluminio sellado y perforado.

Por último en la Tabla 9 se muestra numéricamente las pérdidas observadas en los termogramas para las pastas de cal carbonatadas.

Los valores que aparecen en esta tabla no hacen sino corroborar los argumentos expuestos para explicar los termogramas. Con estos valores se pone de manifiesto que se produce además la carbonatación de la matriz cementante (CSH, CAH, CASH). Los procesos que tendrían lugar debido a este ataque son los siguientes:

Ecuación 25

$$
\mathrm{CSH}+\mathrm{CO}_{2} \rightarrow \mathrm{SiO}_{2} \cdot x \mathrm{H}_{2} \mathrm{O}+\mathrm{CaCO}_{3}
$$

Ecuación 26

$$
\mathrm{CAH}+\mathrm{CO}_{2} \rightarrow \mathrm{Al}(\mathrm{OH})_{3}+\mathrm{CaCO}_{3}
$$

Ecuación 27

$$
\mathrm{CASH}+\mathrm{CO}_{2} \rightarrow \mathrm{SiO}_{2} \cdot x \mathrm{H}_{2} \mathrm{O}+\mathrm{Al}(\mathrm{OH})_{3}+\mathrm{CaCO}_{3}
$$




\begin{tabular}{||c|c|c|c|c||}
\hline & \multicolumn{4}{|c||}{ PÉRDIDAS (\%) } \\
\hline FCC $(\boldsymbol{\%})$ & Total & $\mathbf{C a}(\mathbf{O H})_{2}$ & $\mathbf{C a C O}_{3}$ & CSH-CAH \\
\hline $\mathbf{3 0}$ & 35,93 & 0 & 25,44 & 10,49 \\
\hline $\mathbf{7 0}$ & 26,03 & 0 & 12,37 & 13,66 \\
\hline
\end{tabular}

Tabla 9. Pérdidas termogravimétricas en pastas de cal/FCC carbonatadas.

Según los datos de las pérdidas termogravimétricas en la pasta de cal con un $30 \%$ de FCC, se observa que del $25,44 \%$ de pérdida debida a los carbonatos, un $3,1 \%$ ya estaba presente antes de la carbonatación y un $17,23 \%$ se ha producido a partir del $\mathrm{Ca}(\mathrm{OH})_{2}$. Así pues, el $4,81 \%$ restante proviene del ataque sobre los silicatos y aluminatos cálcicos.

En la pasta con un 70\% de FCC este fenómeno es mucho más acusado dado que no existe una "reserva alcalina" presente en la pasta antes de comenzar el proceso de carbonatación. Del 12,37\% de pérdida debida al carbonato cálcico, un 1,46\% ya estaba presente antes de comenzar la carbonatación y ninguna fracción se ha formado a partir del $\mathrm{Ca}(\mathrm{OH})_{2}$ puesto que se había agotado totalmente debido a la reacción puzolánica. Esto implica que el 10,41\% restante ha tomado el calcio de la matriz cementante. Este hecho resalta de forma contundente la importancia que tiene la reserva alcalina para preservar las propiedades cementantes de la matriz. Estos datos se presentan resumidos en la Tabla 10.

\begin{tabular}{||c|c|c|c|c||}
\hline & \multicolumn{4}{|c|}{ PÉRDIDAS DEL CARBONATO CÁLCICO ASOCIADAS A...(\%) } \\
\hline FCC $(\boldsymbol{\%})$ & Antes de $\mathbf{C O}_{\mathbf{2}}$ & $\mathbf{C a}(\mathbf{O H})_{\mathbf{2}}$ & CSH-CAH & Tras CO C $_{\mathbf{2}}$ (Total) \\
\hline 30 & 3,1 & 17,23 & 4,81 & 25,44 \\
\hline 70 & 1,46 & 0 & 10,41 & 12,37 \\
\hline
\end{tabular}

Tabla 10. Pérdidas debidas a la descomposición de los carbonatos relacionadas con su origen: previo a la carbonatación, la portlandita y el gel CSH-CAH.

La detección del gel de sílice y el hidróxido de aluminio formado durante este proceso tiene difícil identificación mediante la termogravimetría ya que ambos son eminentemente amorfos y su deshidratación tiene lugar a lo largo de un intervalo de temperatura 
muy ancho. Por otro lado la difracción de rayos $\mathrm{X}$ tampoco es eficaz en este sentido ya que al no ser cristalinos no presentan señales susceptibles de interpretación.

\subsubsection{Análisis de las pastas de cemento}

En este punto nos centramos en los termogramas obtenidos en las pastas de cemento a fin de identificar los productos formados y los procesos que tienen lugar durante la carbonatación.

\subsubsection{Antes de la carbonatación}

En primer lugar analizaremos los termogramas obtenidos a edades tempranas ( 9 días) que se muestran en la Figura 52 y Figura 53. En ellos se aprecia claramente las pérdidas debidas a las deshidrataciones de los silicatos y aluminatos cálcicos, que tienen lugar a menos de $300^{\circ} \mathrm{C}$. Dentro de esta zona se pueden observar claramente dos picos principales, uno cuyo máximo se sitúa alrededor de $\operatorname{los} 125^{\circ} \mathrm{C}$ que se relaciona con la deshidratación de los silicatos cálcicos y otro adicional sobre $190^{\circ} \mathrm{C}$ que se asocia a la deshidratación de los silicoaluminatos cálcicos tipo gehlenita hidratada [82]. Esta parte de los termogramas es prácticamente idéntica en todas las dosificaciones de FCC. No obstante, si observamos los termogramas realizados a menor velocidad de calentamiento se puede apreciar cómo el hecho de la presencia del catalizador nos ofrece nuevos picos en esta zona. Concretamente se puede ver un nuevo pico a $180^{\circ} \mathrm{C}$ que se puede asociar a una fase de silicoaluminatos cálcicos, y otro pico sobre $140^{\circ} \mathrm{C}$ que se puede relacionar con la presencia de etringita [82]. Este fenómeno se puede atribuir al hecho de que la cantidad de aluminatos aumenta considerablemente a medida que se aumenta la sustitución de FCC. 


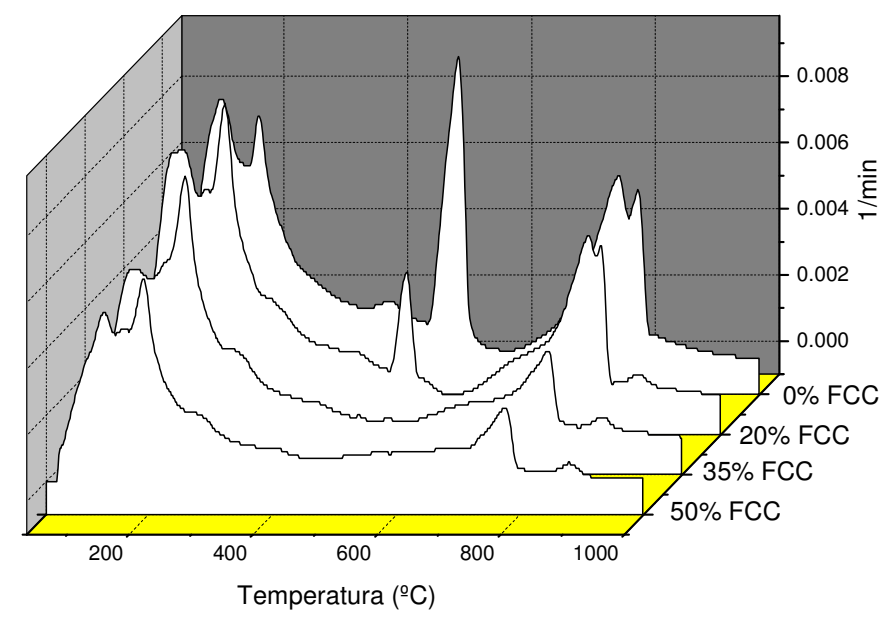

Figura 52. Curva de DTG de pastas de cemento/FCC tras 9 días de curado. Velocidad de calentamiento de $20^{\circ} \mathrm{C} / \mathrm{min}$. Atmósfera de aire seco a $75 \mathrm{ml} / \mathrm{min}$. Crisol de alúmina.

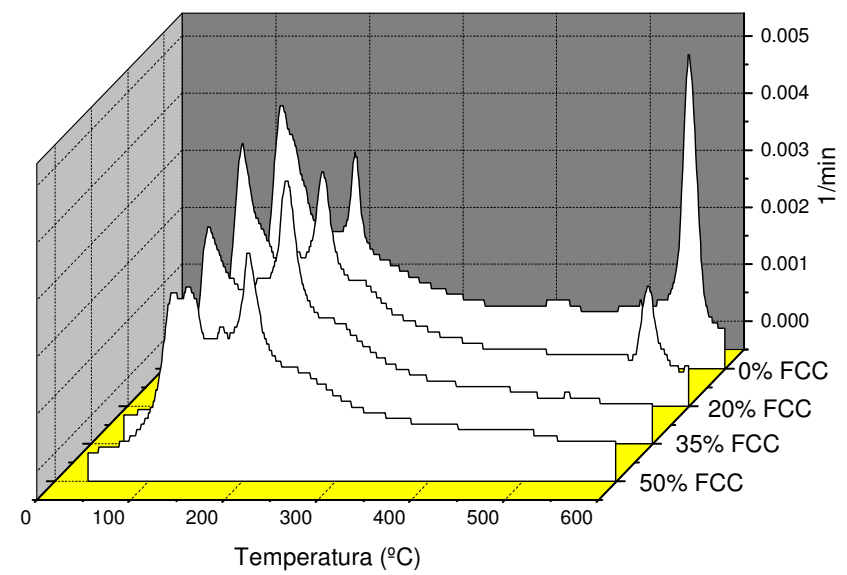

Figura 53. Curva de DTG de pastas de cemento/FCC tras 9 días de curado. Velocidad de calentamiento de $\mathbf{1 0}^{\circ} \mathrm{C} / \mathrm{min}$. Atmósfera de nitrógeno a $75 \mathrm{ml} / \mathrm{min}$. Crisol de aluminio sellado y perforado. 
A pesar de que existen pocas diferencias significativas dentro del intervalo de temperatura que llega a los $300^{\circ} \mathrm{C}$, sí que hay desviaciones más evidentes en la zona media y alta de los termogramas. En primer lugar el pico de la portlandita, que aparece en torno a $\operatorname{los} 500^{\circ} \mathrm{C}$, disminuye su intensidad cuando pasamos del 0 al $20 \%$ de sustitución de FCC y ya no aparece en las pastas más sustituidas. Esto pone de manifiesto la alta reactividad a edades tempranas que presenta el FCC. Analizando las pérdidas que sufren las muestras en este pico, se observa que para un $20 \%$ de sustitución, y a la temprana edad de 9 días, ya se ha agotado el $70 \%$ del $\mathrm{Ca}(\mathrm{OH})_{2}$ que hasta ese momento ha liberado el cemento en su hidratación.

También se han de señalar diferencias adicionales en la zona de alta temperatura de los termogramas, la zona que muestra las pérdidas debidas a la descomposición de los carbonatos. En todas las pastas de cemento que se han muestreado a una edad de 9 días se aprecia claramente el pico de $770^{\circ} \mathrm{C}$, que se puede atribuir a carbonato cálcico. La intensidad de este pico disminuye a medida que se aumenta la cantidad de FCC en la pasta. Por otro lado, en las pastas con 0 y $20 \%$ de FCC también se observa un pico a $805^{\circ} \mathrm{C}$, muy claramente, que también se debe al carbonato cálcico. Este pico desaparece en las pastas con 35 y $50 \%$ de FCC. El hecho de que aparezca un desdoblamiento del pico se puede deber a fases de carbonatos con distinto grado cristalinidad. Para finalizar se puede observar un pico incipiente sobre $\operatorname{los} 870^{\circ} \mathrm{C}$ cuya intensidad aumenta levemente al aumentar la proporción de FCC en las pastas y que se asocia a la descomposicón de algún tipo de carbonato asociado al FCC.

Las razones para explicar estas evidencias no están claras, pero puede deberse a que existen distintas fases de carbonatos. Una posible explicación sería que el origen del carbonato, o su grado de cristalinidad o el catión que acompañe al carbonato sea diferente. Esto es, la temperatura de descomposición del carbonato puede variar ligeramente dependiendo de si se ha formado a partir del $\mathrm{CO}_{2}$ atmosférico en la manipulación de las muestras, o estuviese incorporado en alguna de las materias primas, o existan ciertas fracciones de carbonato potásico, sódico o de magnesio. 
Atendiendo a las pérdidas termogravimétricas sufridas en estas pastas podemos además comentar ciertos aspectos. La Tabla 11 expresa los resultados de los termogramas obtenidos.

\begin{tabular}{||c|c|c|c|c|c||}
\hline & \multicolumn{5}{|c||}{ PÉRDIDAS (\%) } \\
\hline FCC (\%) & Cal Fijada & Total & $\mathbf{C a}(\mathbf{O H})_{\mathbf{2}}$ & $\mathbf{C a C O}_{\mathbf{3}}$ & CSH-CAH \\
\hline $\mathbf{0}$ & 0 & 21,24 & 2,51 & 5,25 & 13,48 \\
\hline $\mathbf{2 0}$ & 68,92 & 20,52 & 0,78 & 4,81 & 14,93 \\
\hline $\mathbf{3 5}$ & 100 & 18,61 & 0 & 3,56 & 15,05 \\
\hline $\mathbf{5 0}$ & 100 & 15,71 & 0 & 2,81 & 12,9 \\
\hline
\end{tabular}

Tabla 11 Pérdidas termogravimétricas de pastas de cemento/FCC tras 9 días de curado.

A tenor de estos resultados se aprecia claramente como a esta edad disminuye la cantidad de portlandita a medida que se aumenta el contenido de cemento debido a que ésta es consumida durante la reacción puzolánica. La cantidad de carbonato vemos que disminuye por lo que su pérdida se puede relacionar directamente con el contenido de cemento. Esto puede significar que, o bien acompañaban principalmente al cemento en el momento de su amasado, o bien que se ha carbonatado parte de la portlandita (que es proporcional al contenido de cemento) durante la manipulación de las muestras. Finalmente, en cuanto a las pérdidas de la zona de aluminatos y silicatos cálcicos se observa que hay un aumento significativo al añadir un $20 \%$ de FCC debido a que se forman nuevos aluminatos y silicatos cálcicos hidratados en mayor proporción de los que forma el cemento. Cuando se observa la diferencia entre el de 20 y $35 \%$ de FCC el crecimiento es pequeño porque debido a la falta de portlandita el desarrollo de la reacción puzolánica se encuentra impedido. Este hecho se manifiesta más claramente en la sustitución del $50 \%$ ya que, por un lado, la falta de cemento hace que se forme menos cantidad de aluminatos y silicatos, y que, por otra parte, la menor cantidad de portlandita liberada por el cemento, no permite la evolución puzolánica por parte del FCC.

Como ya se ha señalado anteriormente, el FCC es una puzolana de alta reactividad inicial, por lo que a 28 días ya debe haber 
reaccionado en su mayor parte. Por otro lado, el cemento también debe haber evolucionado hasta desarrollar la mayor parte de su microestructura. En la Figura 54 y Figura 55 se muestran los termogramas de las pastas transcurrido este tiempo.

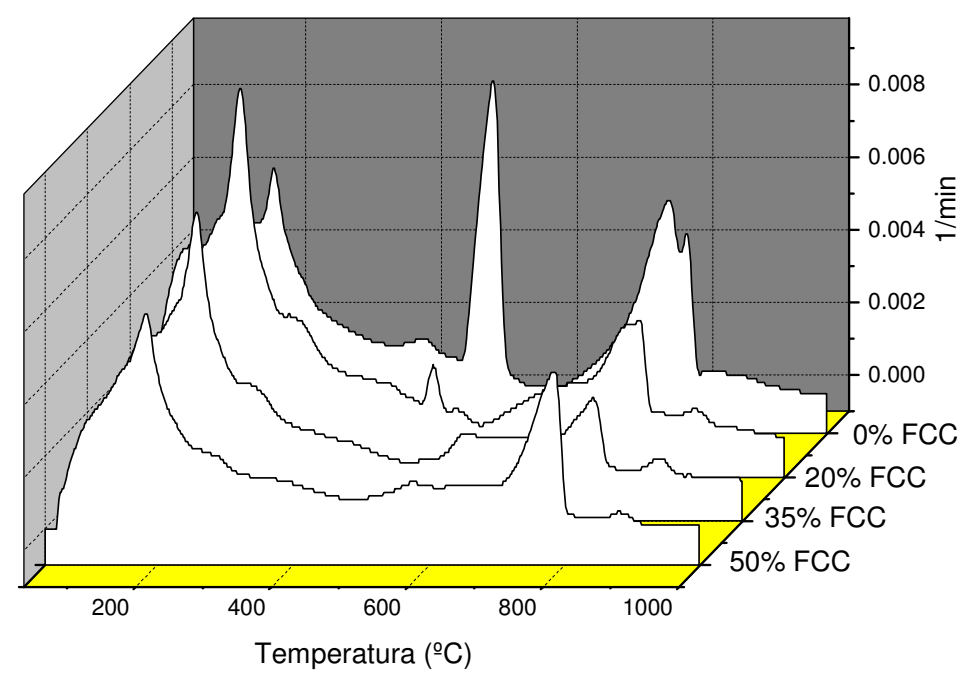

Figura 54. Curva de DTG de pastas de cemento/FCC tras 28 días de curado. Velocidad de calentamiento de $20^{\circ} \mathrm{C} / \mathrm{min}$. Atmósfera de aire seco a $75 \mathrm{ml} / \mathrm{min}$. Crisol de alúmina.

En la zona del termograma que llega hasta $\operatorname{los} 300^{\circ} \mathrm{C}$ se observan los mismos picos que se señalaban a 9 días. En primer lugar se observa el pico de la deshidratación de los silicatos cálcicos que se muestra a $125^{\circ} \mathrm{C}$ y el pico de la deshidratación de los aluminatos cálcicos que aparece a $200^{\circ} \mathrm{C}$ en todas las pastas. 


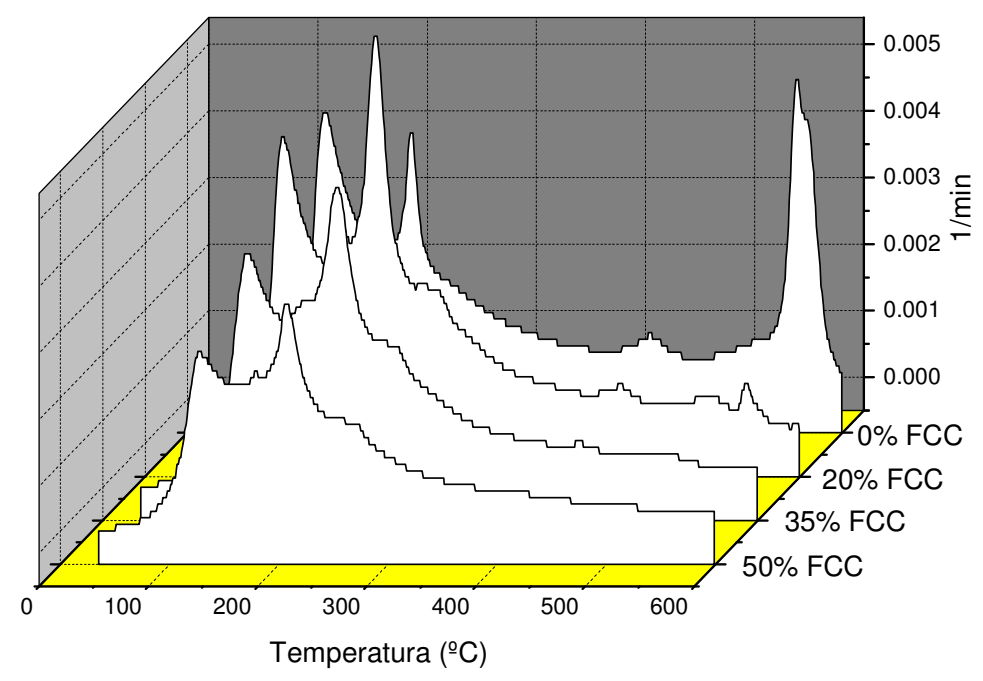

Figura 55. Curva de DTG de pastas de cemento/FCC tras 28 días de curado. Velocidad de calentamiento de $10^{\circ} \mathrm{C} / \mathrm{min}$. Atmósfera de nitrógeno a $75 \mathrm{ml} / \mathrm{min}$. Crisol de aluminio sellado y perforado.

En cuanto a la pérdida de la portlandita se observa cómo efectivamente al aumentar del 0 al $20 \%$ el contenido del FCC se disminuye de forma importante la presencia de hidróxido cálcico llegando a ser únicamente del 5\% la que se encuentra en el segundo con respecto a la que se encuentra en el primero. En las dosificaciones del 35 y del 50\% de FCC no aparecen restos de portlandita debido a que se ha consumido totalmente por el FCC, tal y como se había comprobado a 9 días. A pesar de que el cemento se ha seguido hidratando durante este intervalo, y por tanto, ha liberado más portlandita, esta ha reaccionado inmediatamente con el FCC restante en la pasta.

Si se observa la zona de alta temperatura en la que aparecen los carbonatos vemos que en la pasta de cemento sin FCC aparecen los dos picos de carbonatos a temperaturas de 765 y $790^{\circ} \mathrm{C}$. Al igual que ocurría en el caso anterior de las muestras de 9 días de curado, no se 
observa el pico de carbonato sobre $\operatorname{los} 850^{\circ} \mathrm{C}$, mientras que en las pastas que sí que contienen FCC, se aprecia levemente el mismo. Igualmente, en las muestras con FCC no se aprecian los dos picos solapados anteriores sino sólo el de $790^{\circ} \mathrm{C}$, que se va desplazando progresivamente hacia temperaturas ligeramente inferiores, y va disminuyendo en intensidad a medida que se aumenta la cantidad de FCC.

En la Tabla 12 se exponen las pérdidas de las pastas cemento a 28 días de las cuales se pueden extraer algunas observaciones interesantes.

\begin{tabular}{||c|c|c|c|c|c||}
\hline & \multicolumn{5}{|c|}{ PÉRDIDAS (\%) } \\
\hline FCC (\%) & Cal Fijada & Total & $\mathbf{C a}(\mathbf{O H})_{\mathbf{2}}$ & $\mathbf{C a C O}_{\mathbf{3}}$ & CSH-CAH \\
\hline $\mathbf{0}$ & 0 & 24,57 & 3,33 & 6,59 & 14,65 \\
\hline $\mathbf{2 0}$ & 93,39 & 23,58 & 0,22 & 4,93 & 18,43 \\
\hline $\mathbf{3 5}$ & 100 & 20,65 & 0 & 4,33 & 16,69 \\
\hline $\mathbf{5 0}$ & 100 & 17,28 & 0 & 3,96 & 12,95 \\
\hline
\end{tabular}

Tabla 12. Pérdidas termogravimétricas de pastas de cemento/FCC tras 28 días de curado.

Las pérdidas debidas a la portlandita muestran el mismo comportamiento que en el caso anterior de las muestras a 9 días. Por último, las pérdidas debido a las deshidrataciones de los silicatos y aluminatos cálcicos nos ofrecen un comportamiento relacionado con la extensión de la reacción puzolánica: cuando la cantidad de cemento es baja en la dosificación no se forman silicatos y aluminatos adicionales debido a la falta de portlandita. Este hecho se pone de relieve a partir del $20 \%$ de sustitución.

\subsubsection{Después de la carbonatación}

Finalmente se realizaron los termogramas de las muestras tras el periodo de carbonatación. Dichos termogramas se corresponden con la Figura 56 y Figura 57 que se presentan a continuación. 


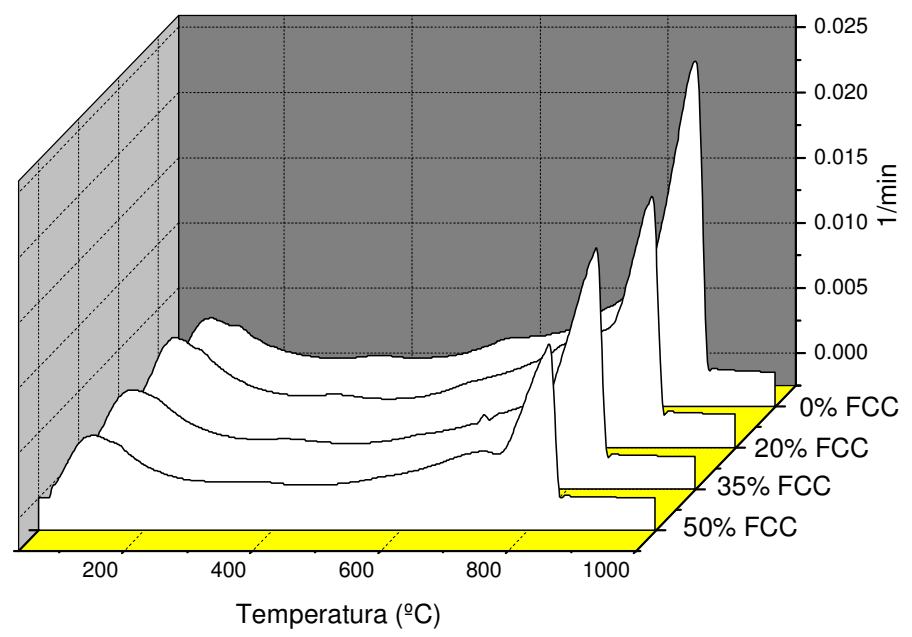

Figura 56. Curva de DTG de pastas de cemento/FCC carbonatadas. Velocidad de calentamiento de $20^{\circ} \mathrm{C} / \mathrm{min}$. Atmósfera de aire seco a $75 \mathrm{ml} / \mathrm{min}$. Crisol de alúmina.

En la zona de baja temperatura se puede apreciar un ancho pico correspondiente a la deshidratación de los silicatos cálcicos cuyo máximo se encuentra entorno a los $125^{\circ} \mathrm{C}$ en las pastas de cemento sin catalizador y que se desplaza ligeramente hacia temperaturas más altas a medida que se aumenta la cantidad de FCC llegando a situarse en $135^{\circ} \mathrm{C}$ para la pasta con $50 \%$ de FCC. Además existe un pequeño pico a $200^{\circ} \mathrm{C}$, aproximadamente, que sólo se aprecia en la Figura 57 y correspondería probablemente a la segunda deshidratación del yeso ya que aparece en las muestras de cemento tras la carbonatación y si correspondiese a aluminatos cálcicos hidratados seguramente habrían desaparecido tras la carbonatación.

En la zona intermedia ha desaparecido el pico de la portlandita como se esperaba debido a que la que no ha reaccionado con el FCC, ha sido carbonatada y se ha transformado el carbonato cálcico.

En último lugar se puede apreciar un gran pico en torno a la temperatura de $830-870^{\circ} \mathrm{C}$ que corresponde al carbonato cálcico que 
se ha formado en la carbonatación de la pasta. Este pico se desplaza desde temperaturas más altas hacia otras inferiores cuando se aumenta el contenido de FCC en las pastas. También se observa que a medida que aumenta el contenido de FCC, se produce una disminución en la intensidad del pico que cae desde el $24 \%$ de la masa de la muestra sin FCC hasta el $12 \%$ que ofrece la muestra con $50 \%$ de FCC. Se apunta como hipótesis que este carbonato se ha formado a partir del calcio de las fases hidratadas de silicatos y aluminatos, ya que su presencia es muy evidente y la ausencia de portlandita antes de la carbonatonación también lo es.

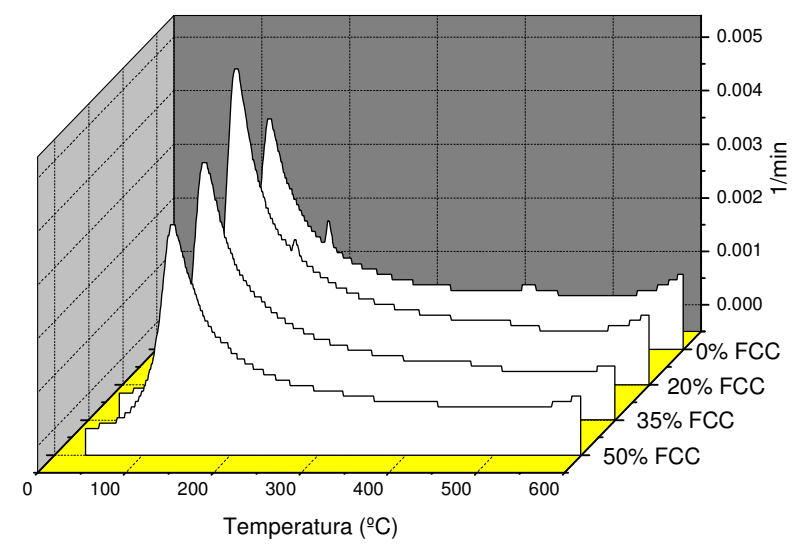

Figura 57. Curva de DTG de pastas de cemento/FCC carbonatadas. Velocidad de calentamiento de $10^{\circ} \mathrm{C} / \mathrm{min}$. Atmósfera de nitrógeno a 75 $\mathrm{ml} / \mathrm{min}$. Crisol de aluminio sellado y perforado.

Por último, en la Tabla 13 se muestran las pérdidas observadas en las pastas carbonatadas. En ella se pone de manifiesto claramente la falta de hidróxido cálcico debido a que se ha consumido por la reacción puzolánica y por la carbonatación de la muestra. Asimismo, se observa que la cantidad de carbonatos formados disminuye según se aumenta la cantidad de FCC debido a que existe menos portlandita. 


\begin{tabular}{||c|c|c|c|c||}
\hline & \multicolumn{4}{|c||}{ PÉRDIDAS (\%) } \\
\hline FCC (\%) & Total & $\mathbf{C a}(\mathbf{O H})_{\mathbf{2}}$ & $\mathbf{C a C O}_{\mathbf{3}}$ & $\mathbf{C S H}-\mathbf{C A H}$ \\
\hline $\mathbf{0}$ & 36,94 & 0 & 24,37 & 12,57 \\
\hline $\mathbf{2 0}$ & 33,82 & 0 & 19,13 & 14,69 \\
\hline $\mathbf{3 5}$ & 29,42 & 0 & 16,05 & 13,37 \\
\hline $\mathbf{5 0}$ & 23,84 & 0 & 11,92 & 11,92 \\
\hline
\end{tabular}

Tabla 13. Pérdidas termogravimétricas de pastas de cemento/FCC carbonatadas.

Análogamente a lo visto en el caso de las pastas de cal, también se observa que se producen carbonatos a partir de los silicatos y aluminatos cálcicos. En este caso los carbonatos formados a partir de los silicatos y aluminatos cálcicos se presentan la Tabla 14. La etringita que se ha formado durante las primeras fases de hidratación del cemento como consecuencia de la presencia de yeso (añadido al clínker para controlar el fraguado) y los aluminatos cálcicos también se descompone con cierta facilidad cuando se carbonata la matriz cementante produciendo yeso, carbonato de calcio y gel de alúmina [101].

\begin{tabular}{|c|c|c|c|c|}
\hline & \multicolumn{4}{|c|}{ PÉRDIDAS DEL CARBONATO CÁLCICO ASOCIADAS A...(\%) } \\
\hline FCC $(\%)$ & Antes de $\mathrm{CO}_{2}$ & $\mathrm{Ca}(\mathrm{OH})_{2}$ & CSH-CAH & Tras $\mathrm{CO}_{2}$ (Total) \\
\hline 0 & 6,59 & 8,14 & 9,64 & 24,37 \\
\hline 20 & 4,93 & 0,54 & 13,66 & 19,13 \\
\hline 35 & 3,96 & 0 & 12,09 & 16,05 \\
\hline 50 & 4,33 & 0 & 7,59 & 11,92 \\
\hline
\end{tabular}

Tabla 14. Pérdidas debidas a la descomposición de los carbonatos relacionadas con su origen: previo a la carbonatación, la portlandita y el gel CSH-CAH.

De nuevo se observa que la presencia del FCC produce una mayor producción de carbonatos cálcicos a partir del gel CSH-CAH. El dato ofrecido por la pasta con una sustitución del 50\% es muy bajo 
pero se debe tener presente que debido a la poca cantidad de cemento existente en esta pasta también limita en gran medida la cantidad de calcio disponible.

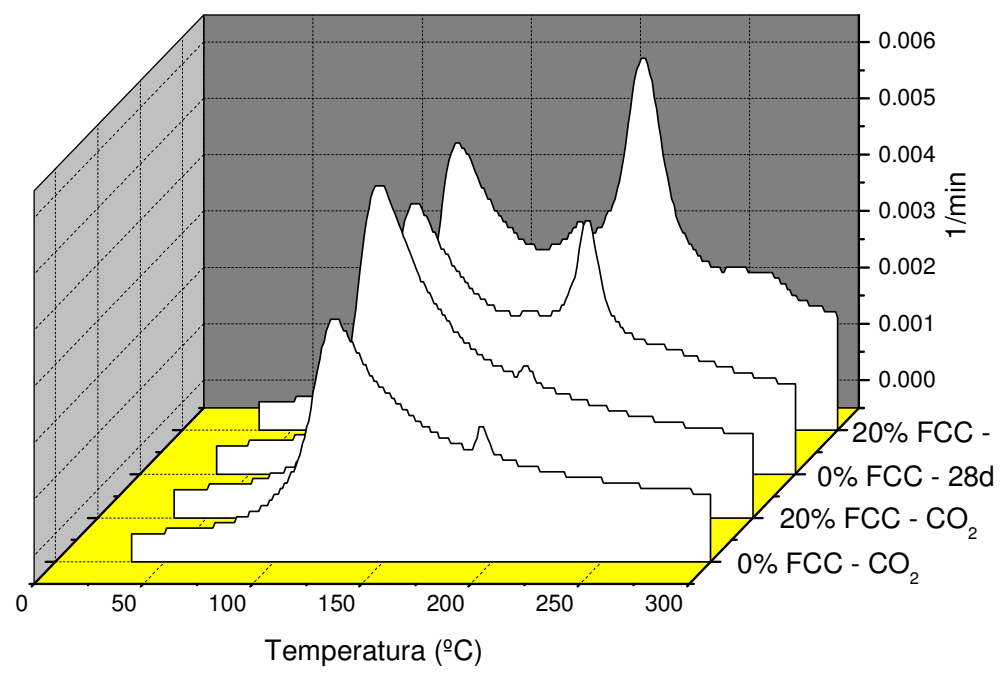

Figura 58. Detalle de las curvas DTG de las pastas de cemento/FCC antes y después del proceso de carbonatación. Velocidad de calentamiento de $10^{\circ}$ C/min. Atmósfera de nitrógeno a $75 \mathrm{ml} / \mathrm{min}$. Crisol de aluminio sellado y perforado.

En la Figura 58 se muestra un detalle de cómo la carbonatación ha afectado a la zona de los silicatos y aluminatos. En ella se observa claramente la desaparición que se produce del pico de los aluminatos y aluminosilicatos cálcicos debido a que el calcio ha sido captado por el $\mathrm{CO}_{2}$ para formar carbonato cálcico [85-89]. No es posible apreciar cómo han sido afectados los silicatos cálcicos hidratados debido a que las pérdidas de masa consecuencia de la deshidratación de los mismos se enmascaran con las que ofrecen los productos de la carbonatación de las fases cementantes (gel de sílice y gel de alúmina). 


\subsection{Análisis mediante difracción de rayos $\mathrm{X}$ de pastas carbonatadas}

\subsubsection{Diseño experimental}

Para llevar a cabo el objetivo propuesto, se han empleado las pastas preparadas para la realización de los estudios termogravimétricos que se han descrito en el capítulo anterior. Redundamos, no obstante, en los pasos seguidos para su elaboración para ahorrar tener que consultarlo en páginas anteriores y para matizar algún detalle que difiere del procedimiento anterior.

Se han fabricado 2 pastas de cal y 4 pastas de cemento con distinta dosificación de FCC y con una relación a/mc fija de 0,8. Las sustituciones de FCC empleadas han sido del 30 y del $70 \%$ en el caso de las pastas de cal y 0, 20, 35 y 50\% de FCC en las de cemento. Para las pastas de cal se ha empleado $\mathrm{Ca}(\mathrm{OH})_{2}$ para análisis y para las pastas de cemento se ha utilizado cemento tipo CEM I 52,5 R. El FCC fue molido previamente en un molino de bolas durante 20 minutos. Las pastas se elaboraron en contenedores de plástico de $100 \mathrm{ml}$ y se amasaron manualmente mediante una varilla de vidrio. Las pastas se conservaron en humedad tras su fraguado y se tomaron muestras de las mismas a los 28 días. A continuación, se introdujeron durante 1 mes en una cámara de carbonatación, cuya atmósfera era del 100\% de $\mathrm{CO}_{2}$ y una humedad relativa del $65 \pm 5 \%$, para asegurar su completa carbonatación, y se tomó una muestra adicional de cada una de las pastas.

Como muestra para la difracción de rayos $\mathrm{X}$ se tomó de una pequeña porción de las pastas que se pulverizó en un mortero de ágata. A la muestra pulverizada se le eliminó el agua no combinada mediante sucesivos lavados con acetona, tras lo cual se introdujo en una estufa a $60^{\circ} \mathrm{C}$ durante unos $15 \mathrm{~min}$. Finalmente se tamizó cada una de las muestras con un tamiz de $125 \mu \mathrm{m}$. La porción que no se retuvo en el tamiz fue la destinada para realizar los análisis de difracción. Con la muestra así pulverizada se elaboró una pastilla que se montó en las placas que se introducen en el difractómetro. 
El difractómetro empleado es un PW1710 con ánodo de cobre.

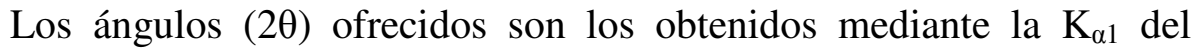
cobre $(0,154056 \mathrm{~nm})$. Los barridos se efectuaron para valores de $2 \theta$ comprendidos entre $5^{\circ}$ y $60^{\circ}$.

\subsubsection{Análisis de pastas de cal}

En primer lugar se aborda el análisis de los difractogramas de las pastas de cal, para identificar más fácilmente los productos obtenidos por la reacción puzolánica del residuo de FCC con el hidróxido cálcico y los resultantes de la carbonatación posterior.

\subsubsection{Antes de la carbonatación}

En la Figura 59 y Figura 60 se muestran los difractogramas obtenidos para las pastas de cal con un $30 \%$ y un $70 \%$ de sustitución de cal por residuo de FCC, respectivamente. El FCC es de naturaleza principalmente amorfa aunque presenta una fracción cristalina (zeolita) que se consume por la reacción puzolánica. Los productos de la reacción puzolánica del FCC son de naturaleza principalmente amorfa [102]. Como consecuencia de ello, la proporción de productos cristalinos es mucho mayor en la pasta con un 30\% de FCC. De ahí que el difractograma de la pasta más sustituida presente picos de mucha menor intensidad, consecuencia de lo cual se magnifica el ruido de la línea base. Los productos que se han identificado en la pasta con $30 \%$ de FCC son los siguientes: la portlandita $\left(\mathrm{Ca}(\mathrm{OH})_{2}\right)$ que se incluye como reactivo de amasado, la calcita y la estraetlingita. La portlandita, que presenta la máxima intensidad, es eminentemente cristalina, y su presencia delata el hecho de que no se ha consumido en su totalidad por el FCC. También se observan pequeñas señales correspondientes a calcita, que como se ha comentado anteriormente suele acompañar al hidróxido cálcico. En el difractograma de la pasta con $70 \%$ de FCC ya no se observan las señales de la portlandita; por lo que se puede deducir que el FCC está en exceso en esta pasta y la ha consumido totalmente a consecuencia de la reacción puzolánica. 


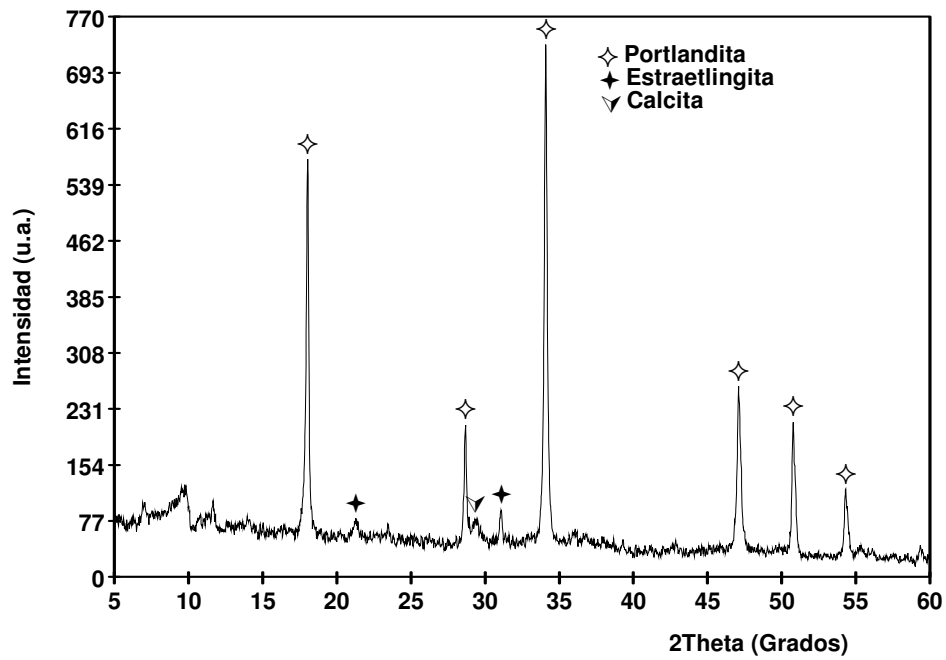

Figura 59. Difractograma de pasta de cal con $30 \%$ de FCC tras 28 días de curado.

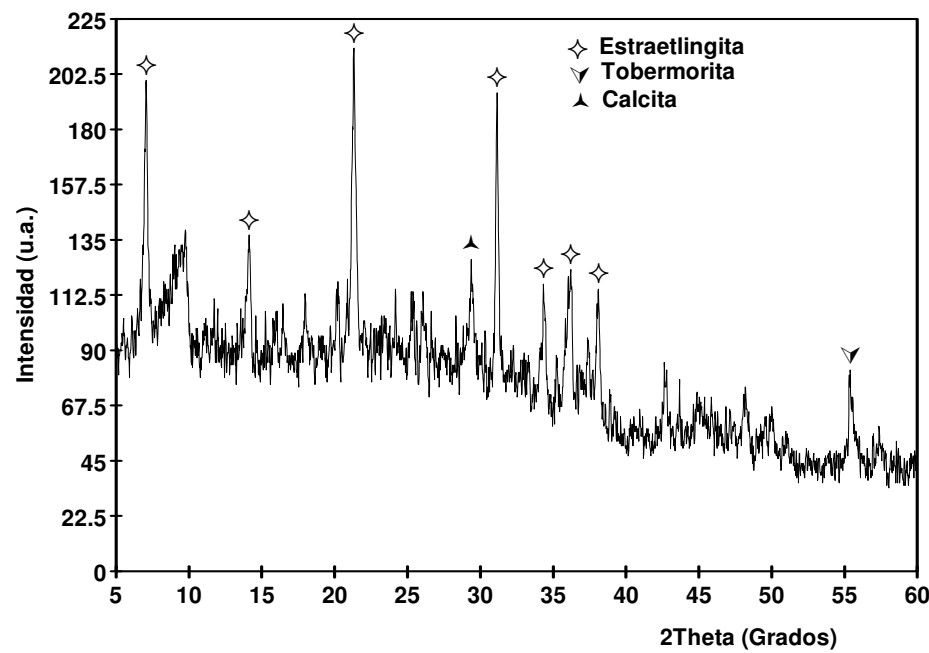

Figura 60. Difractograma de pasta de cal con $70 \%$ de FCC tras 28 días de curado.

Otras estructuras cristalinas que se aprecian aunque con una intensidad mucho más reducida que la de la portlandita son las correspondientes a la tobermorita y la estraetlingita. Estos minerales 
son de composición compleja aunque se definen genéricamente como silicatos y silicoaluminatos cálcicos hidratados, respectivamente. Debido a que su naturaleza es principalmente amorfa, su detección y asignación es compleja pero todos ellos concuerdan con los minerales que se esperan encontrar en este tipo de pastas.

\subsubsection{Después de la carbonatación}

En la Figura 61 y Figura 62 se presentan los difractogramas obtenidos tras la carbonatación para las pastas de cal con 30\% y $70 \%$ de FCC, respectivamente. Los compuestos cristalinos dominantes que se logran identificar son dos formas cristalinas distintas del carbonato cálcico, la calcita y la vaterita. De estas dos formas cristalinas la calcita es mucho más abundante [103].

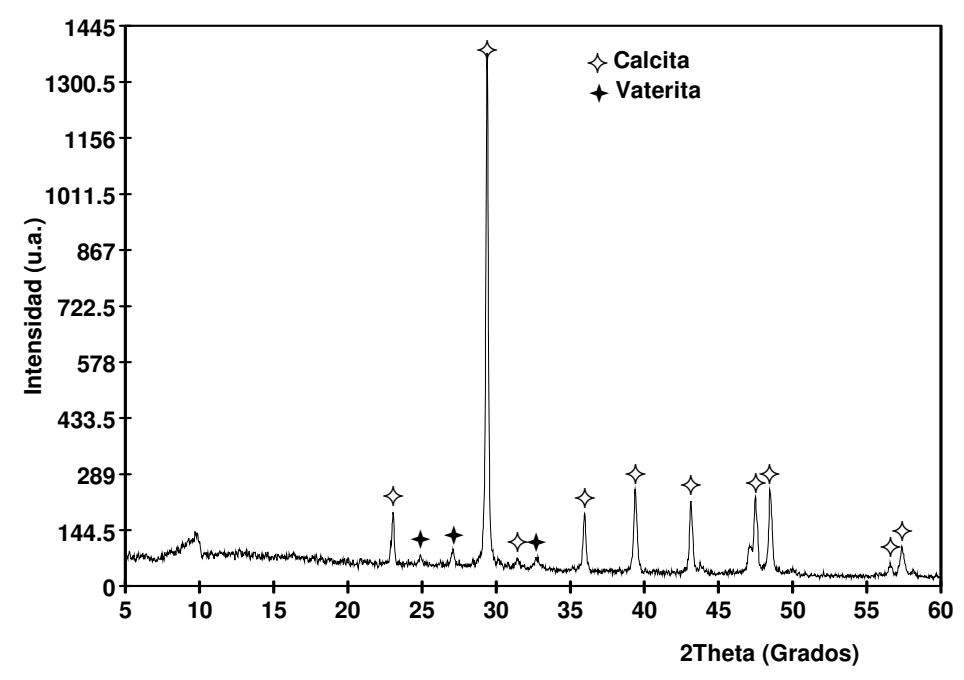

Figura 61. Difractograma de pasta de cal con 30\% de FCC tras carbonatación.

En la pasta de cal con un 30\% de FCC es fácil pensar que la portlandita presente se ha carbonatado para formar la calcita y la vaterita. No obstante, en el segundo caso se pone de relieve que la carbonatación también afecta a los silicatos y aluminatos cálcicos, ya que en la pasta con $70 \%$ de FCC no existía portlandita antes de 
carbonatar y sin embargo, la presencia de calcita y vaterita es muy evidente.

Por otro lado la presencia estos minerales impide el poder identificar otros que sean menos cristalinos como los señalados anteriormente en las pastas sin carbonatar.

La formación de carbonato cálcico suele producir que aparezca el mismo en sus tres variedades polimórficas: calcita, vaterita y aragonito [89]. No obstante la formación de calcita suele ser la más abundante, seguida de la vaterita y con muy poca presencia el aragonito [103], que en este caso no se aprecia. Posiblemente, la elevada presencia de calcita no permite distinguir si existe aragonito en este caso.

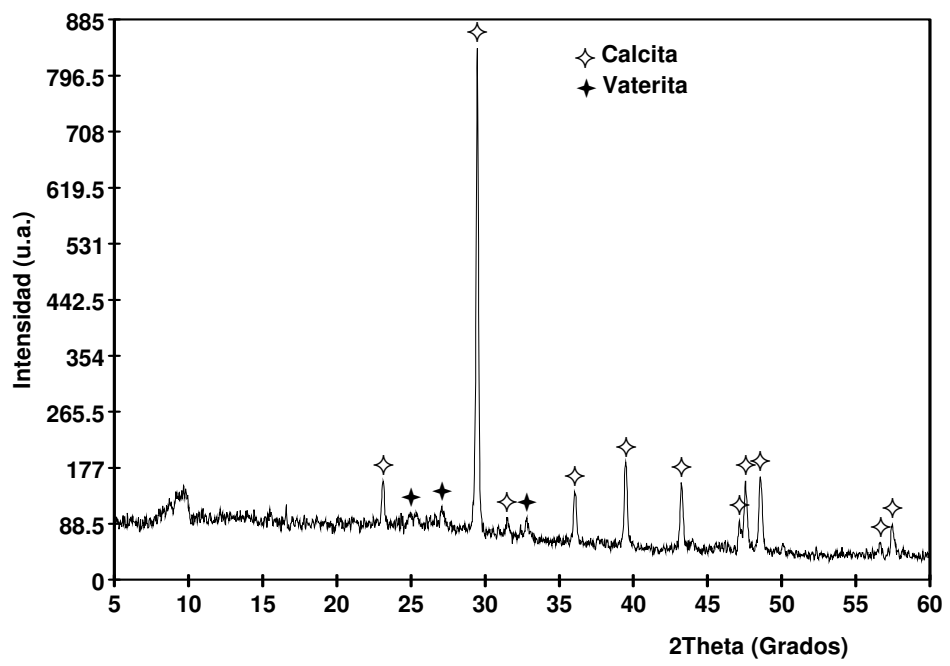

Figura 62. Difractograma de pasta de cal con $70 \%$ de FCC tras carbonatación.

\subsubsection{Análisis de las pastas de cemento}

A continuación se muestran los resultados correspondientes a las pastas elaboradas con cemento y residuo de FCC, antes de la carbonatación y tras la misma. 


\subsubsection{Antes de la carbonatación}

En la Figura 63, Figura 64 y Figura 65 se muestran los difractogramas correspondientes a pastas de cemento con $0 \%, 20 \%$ y $50 \%$ de FCC, respectivamente, antes de someterlas a carbonatación.

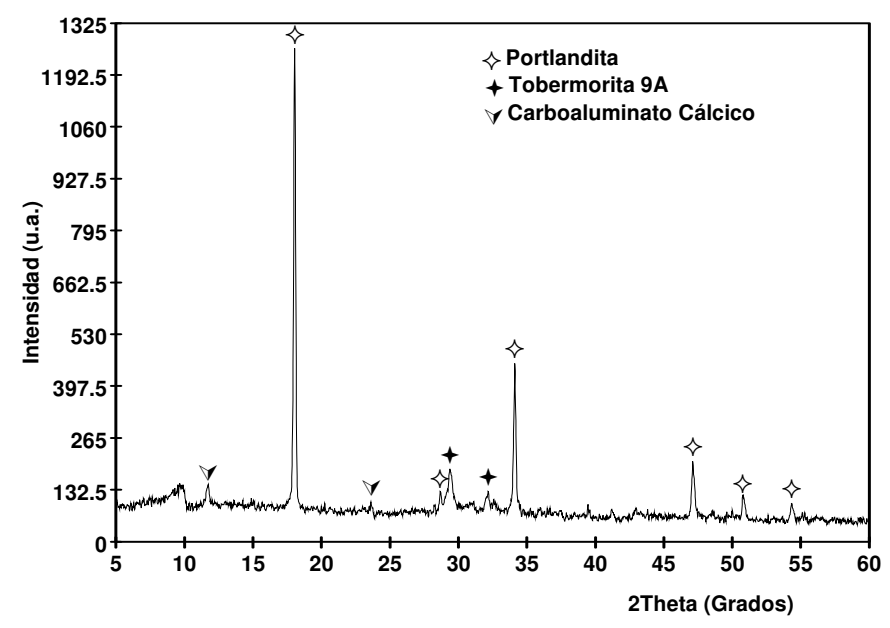

Figura 63. Difractograma de pasta de cemento sin FCC tras 28 días de curado.

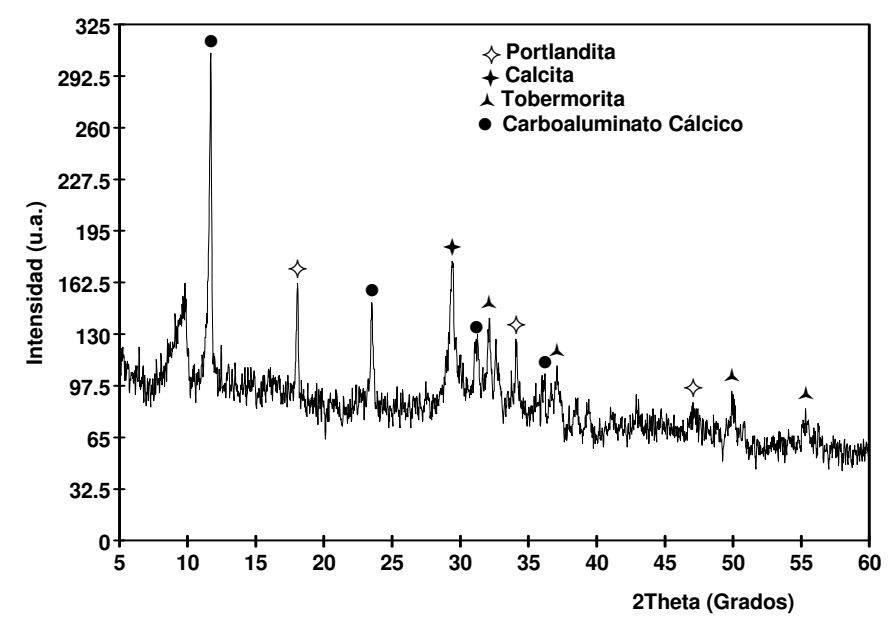

Figura 64. Difractograma de pasta de cemento con $20 \%$ de FCC tras 28 días de curado. 
En el caso de la pasta de cemento sin FCC, el compuesto cristalino más destacable es la portlandita que se genera durante la reacción de hidratación del cemento. No obstante, también se aprecian unas pequeñas señales correspondientes a la calcita y a otra estructura que podría atribuirse a una especie de carboaluminato cálcico hidratado. Este compuesto debe estar incluido en el cemento ya que se puede apreciar (aunque levemente debido a la intensidad de los picos restantes) en la pasta que no incorpora FCC (Figura 63). Además, deducimos que la cristalinidad de este compuesto debe ser bastante elevada para que se pueda apreciar su señal, a pesar de la pequeña cantidad que se estima que existe en función de los datos obtenidos en las pruebas termogravimétricas expuestas en el capítulo anterior.

En cuanto a los productos cementantes, su naturaleza eminentemente amorfa impide una clara asignación. No obstante en la pasta sin FCC se pueden encontrar señales correspondientes a la tobermorita (silicato cálcico hidratado).

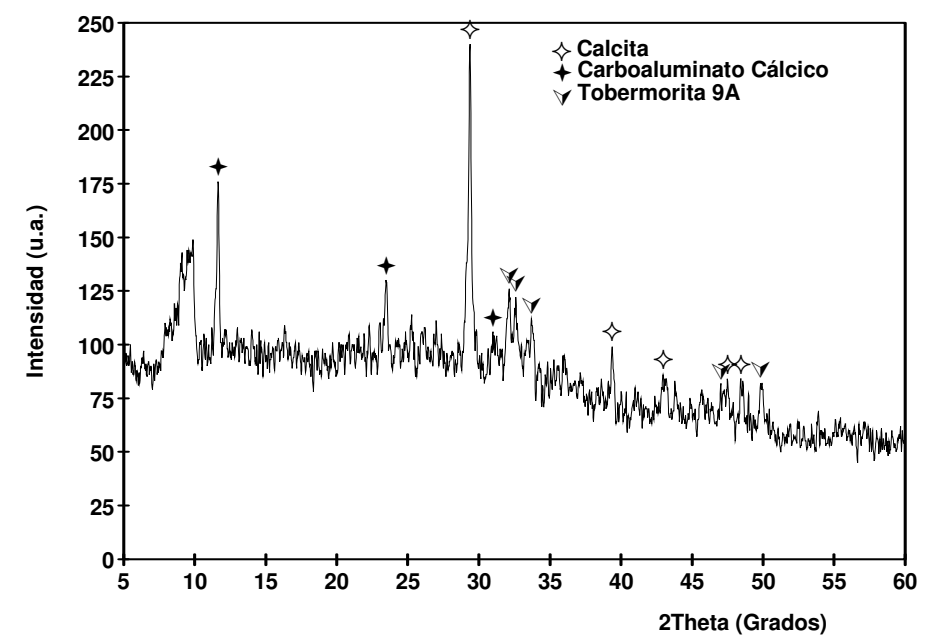

Figura 65. Difractograma de pasta de cemento con $50 \%$ de FCC tras 28 días de curado.

En el caso de las pastas con sustitución de cemento por FCC, se observa que, ante una sustitución moderada (20\%), la cantidad de portlandita suministrada por la hidratación del cemento todavía está en 
exceso, ya que se detecta presencia de la misma, aunque más reducida. Por otro lado, cuando la sustitución es muy elevada (50\%), ya no aparecen vestigios de este mineral en las muestras. En estas pastas con FCC, ante la ausencia de señales demasiado grandes, se puede identificar además algo de calcita que pudiera haber surgido de la leve carbonatación que puedan haber sufrido las pastas o por estar incluida en los productos de partida.

\subsubsection{Después de la carbonatación}

Por último se presentan los resultados de las pastas de cemento carbonatadas. Los difractogramas correspondientes a la Figura 66, Figura 67 y Figura 68 son los obtenidos por las pastas de cemento con una sustitución del 0\%, 20\% y 50\% de FCC, respectivamente.

En estos difractogramas se observan los picos correspondientes a las distintas variedades polimórficas del carbonato cálcico, especialmente la calcita, que parece ser la forma más habitual presente tras el proceso de carbonatación. Además también se pueden identificar pequeñas señales correspondientes a la vaterita [103]. Por último encontramos pequeños picos asignados al aragonito en la pasta sin FCC y en la pasta con 50\% de FCC, aunque su intensidad es muy baja por lo que deducimos que su formación es la menos favorecida de todas.

Al igual que sucediera en las pastas de cal, se observa la formación de carbonato cálcico a partir de la portlandita en la pasta de cemento sin FCC y en la que tiene un $20 \%$ de FCC, sin embargo la presencia del carbonato cálcico es patente en todas las pastas. Por ello se vuelve a constatar que la formación de carbonato cálcico también se produce a partir de los silicatos y aluminatos cálcicos hidratados. 


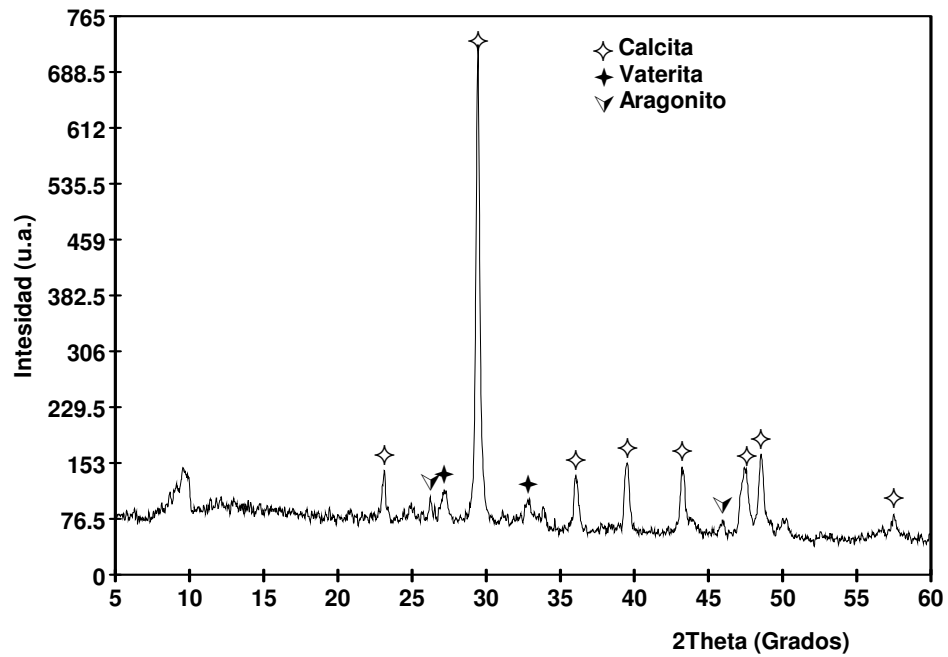

Figura 66. Difractograma de pasta de cemento sin FCC tras la carbonatación.

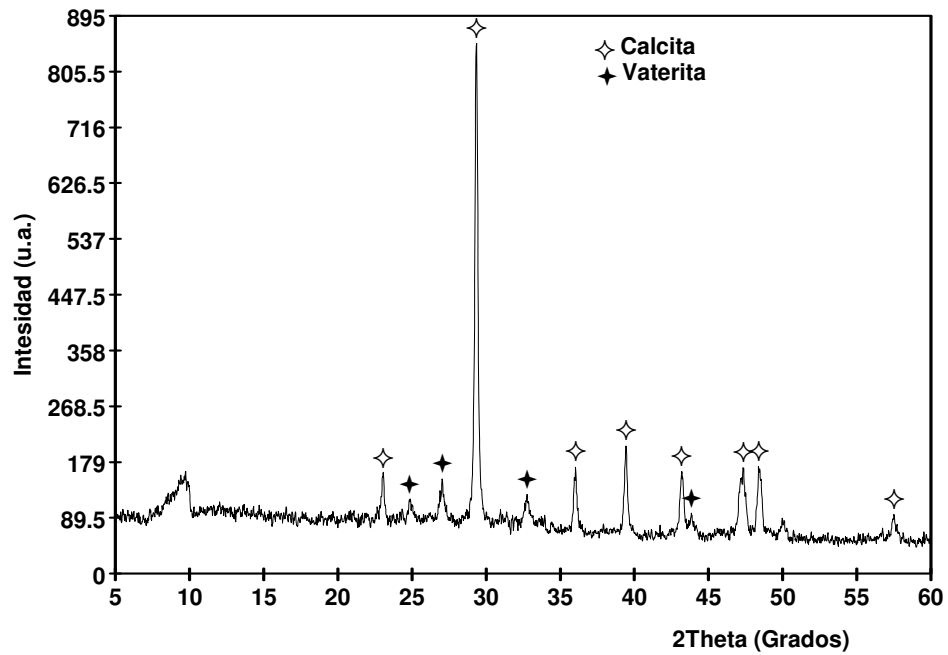

Figura 67. Difractograma de pasta de cemento con $20 \%$ de FCC tras la carbonatación. 


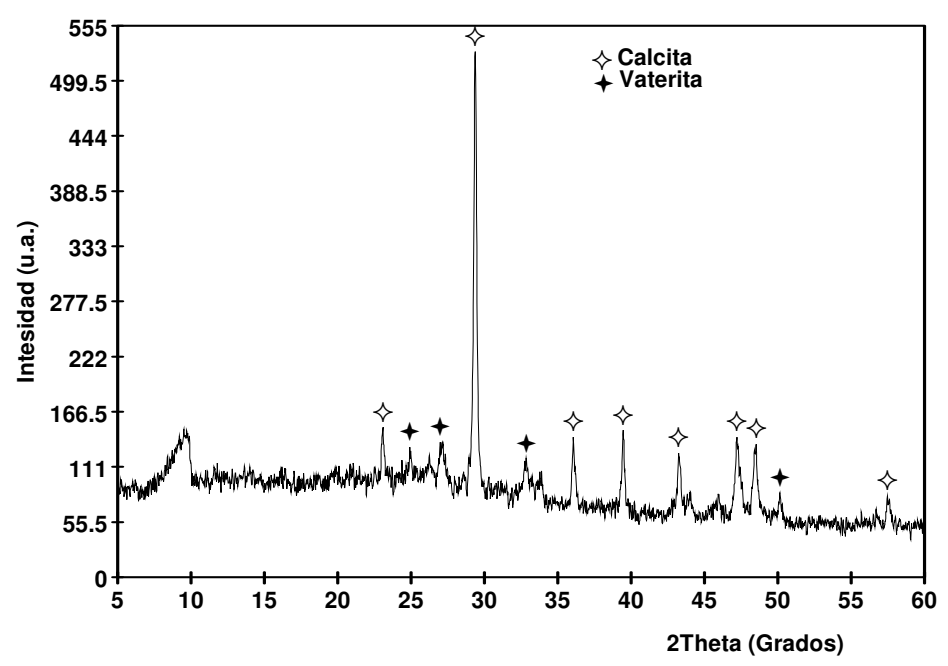

Figura 68. Difractograma de pasta de cemento con $50 \%$ de FCC tras la carbonatación.

\subsection{Análisis mediante microscopía electrónica de barrido de pastas carbonatadas}

\subsubsection{Diseño experimental}

Las muestras que se han analizado en este capítulo son pastas de cal y cemento que han sido sometidas al mismo proceso que las estudiadas en los capítulos de análisis termogravimétrico y de difracción de rayos $\mathrm{X}$.

Se han fabricado 2 pastas de cal y 4 pastas de cemento con distinta dosificación de FCC y con una relación a/mc fija de 0,8 . Las sustituciones de FCC empleadas han sido del 30 y del $70 \%$ en el caso de las pastas de cal y 0, 20, 35 y 50\% de FCC en las de cemento. Para las pastas de cal se ha empleado $\mathrm{Ca}(\mathrm{OH})_{2}$ para análisis y para las pastas de cemento se ha utilizado cemento tipo CEM I 52,5 R. Las pastas se elaboraron en contenedores de plástico de $100 \mathrm{ml}$ y se amasaron manualmente mediante una varilla de vidrio. Las pastas se conservaron en humedad tras su fraguado y se tomaron muestras de las mismas a los 28 días. A continuación, se introdujeron durante 1 mes en una cámara de carbonatación, cuya atmósfera era del 100\% de 
$\mathrm{CO}_{2}$ y el $65 \pm 5 \%$ de humedad relativa, para asegurar su completa carbonatación y se tomó una muestra adicional de cada una de las pastas.

Las muestras que se usaron en este caso fueron pequeños trozos de la pasta de aproximadamente $1 \mathrm{~cm}^{2}$ de superficie. Antes de ser introducidas en el microscopio las muestras necesitan de un recubrimiento que sea eléctricamente conductor dado que de esta forma se pueden acelerar los electrones desde el cátodo hasta la muestra donde deben impactar con la misma. Se usaron muestras recubiertas con carbono para efectuar microanálisis elemental de las muestras y otras recubiertas de oro para obtener una mayor resolución en las fotografías.

El microscopio empleado en los análisis es de la marca JEOL y el modelo es un JSM-6300. El microscopio está dotado con un analizador de rayos $\mathrm{X}$ que recoge las señales emitidas por las transiciones de electrones secundarios en la muestra (EDX).

\subsubsection{Análisis de pastas de cal}

En el caso de las pastas de cal sólo fueron recubiertas de carbono para llevar a cabo los microanálisis correspondientes y tomar algunas fotografías. Se han analizado mediante SEM las pastas de cal con sustitución de FCC del 30\% y el $70 \%$ para poder observar tanto el reactivo original (hidróxido cálcico) como los productos de la reacción puzolánica del mismo con el residuo de FCC.

\subsubsection{Antes de la carbonatación}

Como se puede observar en las siguientes figuras, la morfología de las pastas de cal es eminentemente amorfa y no se aprecian cristales de gran tamaño. En la Figura 69 se muestra una panorámica general efectuada a 5000 aumentos del aspecto que ofrece la pasta de cal con un 30\% de FCC antes de la carbonatación. 


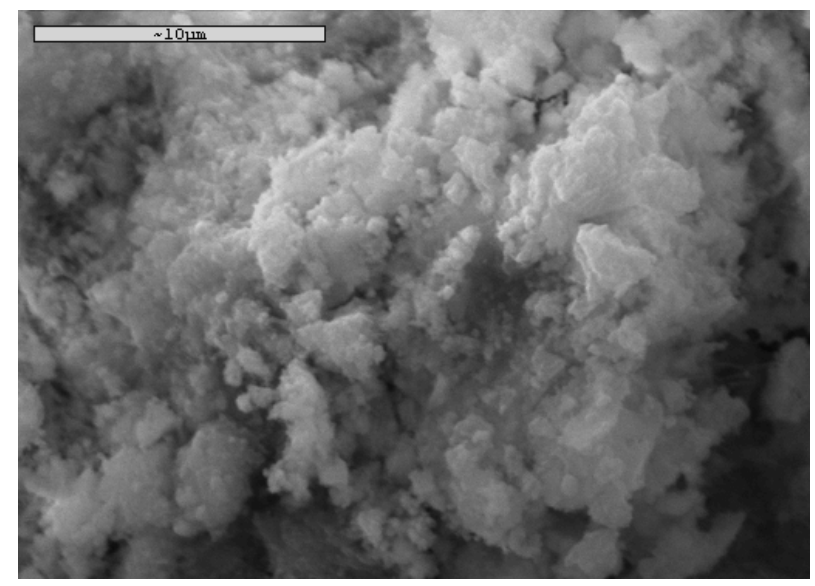

Figura 69. Fotografía de la superficie de una pasta de cal con $30 \%$ de FCC antes de la carbonatación a 5000 aumentos.

En esta fotografía se puede apreciar que el aspecto de los productos de hidratación es eminentemente amorfo y su composición (obtenida cualitativamente por SEM/EDX) es básicamente a base de silicio, aluminio y calcio delatando la formación de silicoaluminatos cálcicos.

En la siguiente imagen (Figura 70) se muestra un detalle de los pequeños cristales de silicatos cálcicos hidratados fibrosos.

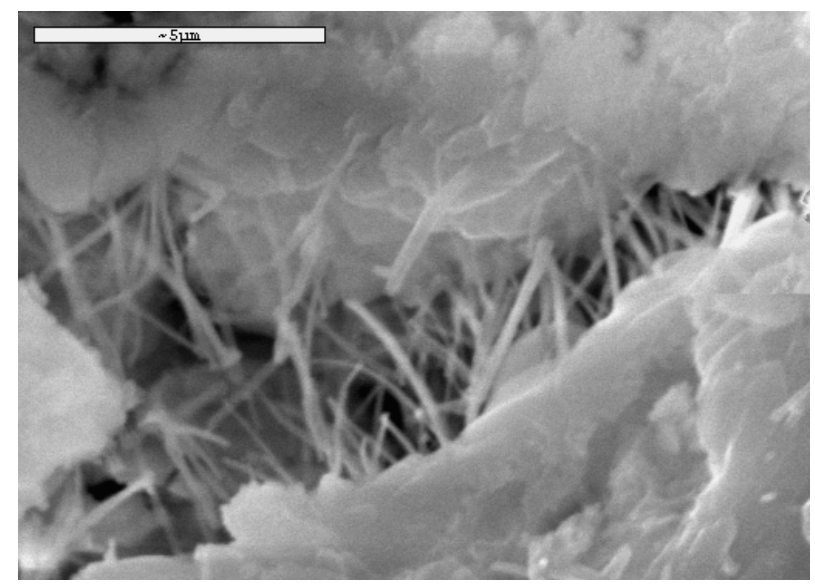

Figura 70. Fotografía de cristales de CSH fibrosos en la pasta de cal con $30 \%$ de FCC antes de la carbonatación a 10000 aumentos. 
La Figura 71 muestra una fotografía realizada a 7500 aumentos de una zona en la que se aprecian cristales de gehlenita hidratada típicos en los productos de la reacción puzolánica del FCC con el $\mathrm{Ca}(\mathrm{OH})_{2}$ [97]. Se ha podido comprobar a través del microanálisis realizado por SEM/EDX que los productos de la reacción puzolánica son similares a los producidos por el metacaolín en pastas de cal $[104,105]$. Estos productos de la reacción puzolánica que hemos llamado genéricamente aluminosilicatos cálcicos hidratados se corresponderían con la siguiente fórmula, similar a los de la gehlenita hidratada que han incorporado silicio en su estructura [97]:

$$
C_{2} A_{(0,40-0,96)} S_{(0,29-1,32)} H_{(3,12-10,21)}
$$

En la Figura 72 se observa una zona que presenta las mismas formaciones de gehlenita hidratada obtenida en la pasta con un $70 \%$ de FCC.

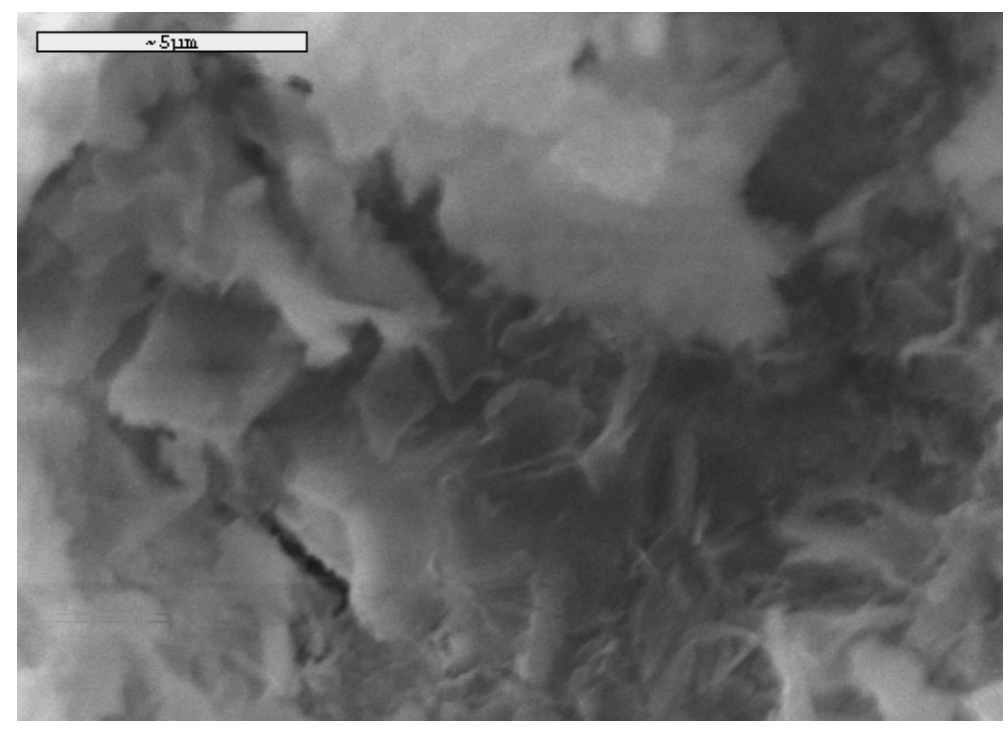

Figura 71. Fotografía de gehlenita hidratada en la pasta de cal con $30 \%$ de FCC realizada a 7500 aumentos. 


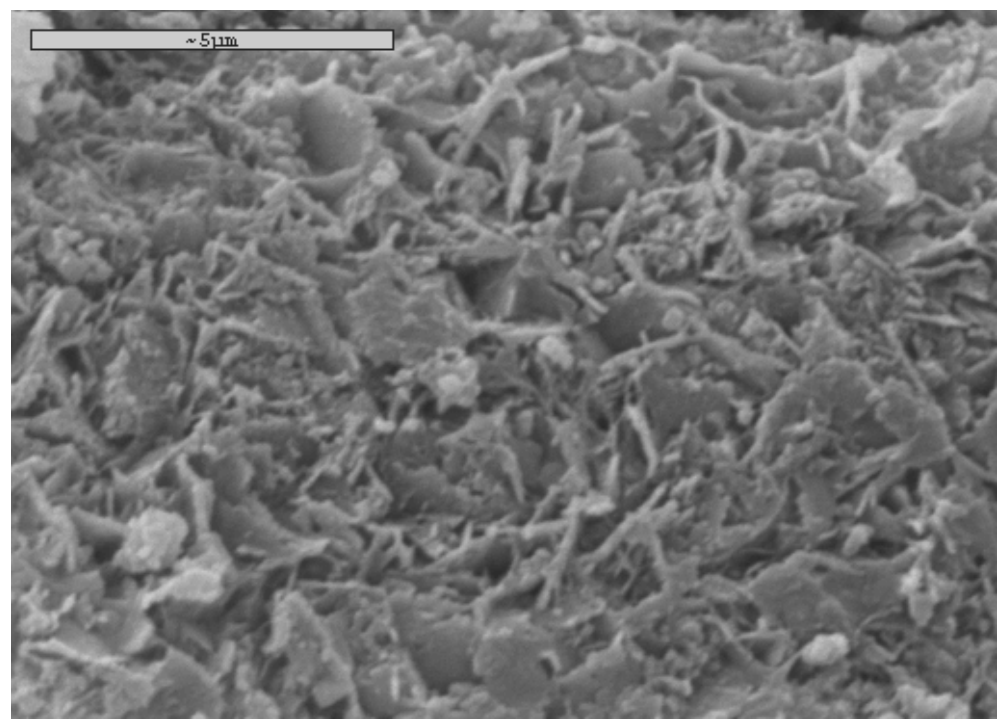

Figura 72. Fotografía de gehlenita hidratada en la pasta de cal con $70 \%$ de FCC realizada a 10000 aumentos.

\subsubsection{Después de la carbonatación}

Las fotografías que se muestran a continuación se han realizado sobre la pasta de cal con un $30 \%$ de residuo de FCC tras someterlas al proceso de carbonatación.

En este caso la presencia de la portlandita debe ser muy reducida ya que la carbonatación a la que se ha sometido la pasta ha sido muy exhaustiva. Esto produce que el hidróxido cálcico se transforme en carbonato cálcico. La siguiente fotografía (Figura 73) pone de manifiesto esto. En ella se pueden observar los cristales de carbonato cálcico de forma prismática [106]. 


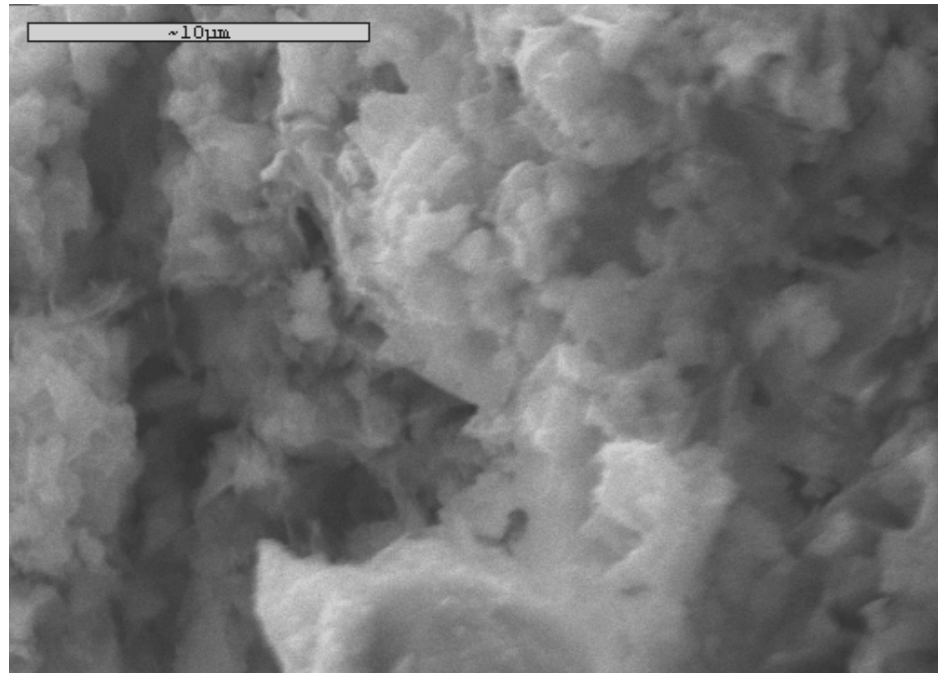

Figura 73. Fotografía de la pasta de cal con $30 \%$ de FCC tras la carbonatación realizada a 5000 aumentos.

A continuación se muestra una imagen (Figura 74) en la que se distingue claramente una esfera de residuo de FCC que permaneció intacta tras el proceso de molienda previo [97] y sobre la que se encuentran depositados productos de reacción.

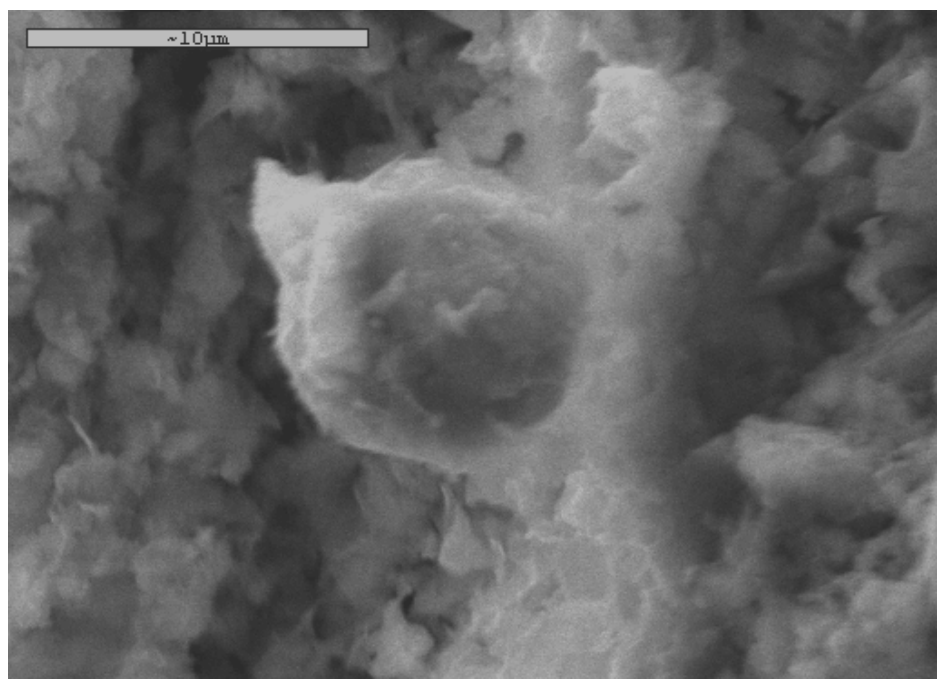

Figura 74. Fotografía de una esfera de catalizador en la pasta de cal con $30 \%$ de FCC realizada a 5000 aumentos. 
Algo parecido muestra la siguiente fotografía (Figura 75) en la que aparece una esfera de catalizador rodeada de productos de la reacción puzolánica y carbonato cálcico (cristales más claros).

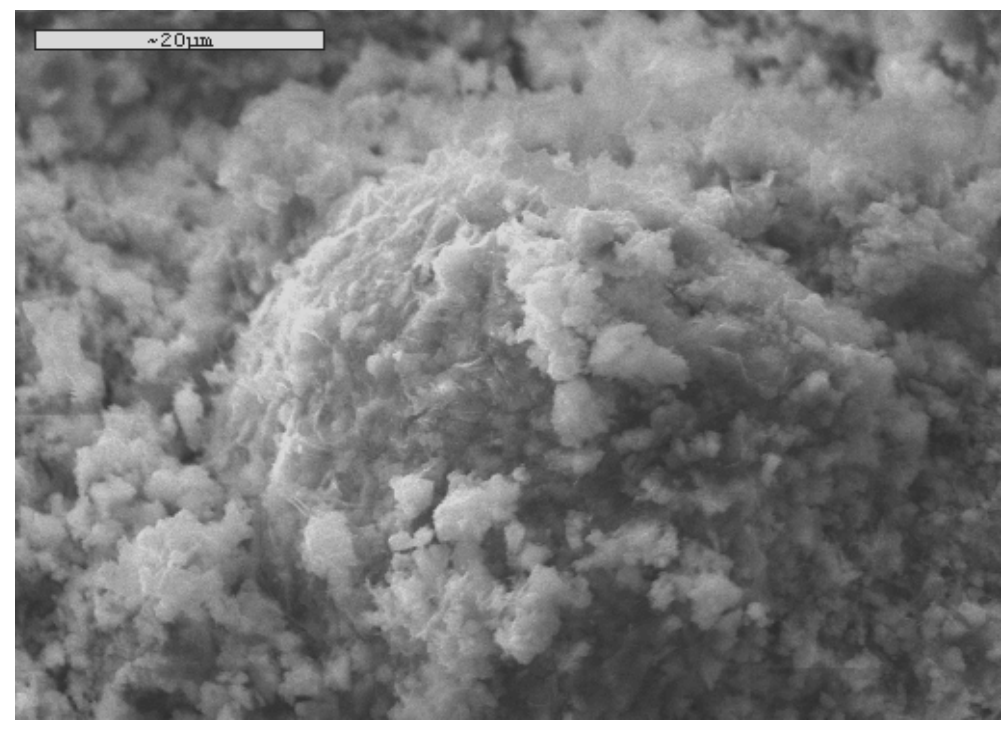

Figura 75. Fotografía de una esfera de catalizador rodeada de productos de reacción en la pasta de cal/FCC realizada a 2000 aumentos.

\subsubsection{Análisis de pastas de cemento}

A continuación, se muestran las fotografías realizadas en pastas de cemento con y sin residuo de FCC. El recubrimiento empleado en estas muestras es oro por lo que su resolución se podrá apreciar que es algo mayor que en el caso anterior.

\subsubsection{Antes de la carbonatación}

En este apartado tenemos las fotografías de las pastas que se realizaron antes de someterlas a carbonatación. Primeramente mostramos las realizadas sobre la pasta de cemento sin residuo de FCC. En las dos siguientes imágenes (Figura 76 y Figura 77) se aprecian los productos típicos de la hidratación del cemento.

En la Figura 76 se aprecian los cristales aciculares típicos de la etringita [107] y al fondo se pueden observar las superficies amorfas 
que forman los silicatos cálcicos hidratados del cemento una vez que se han hidratado.

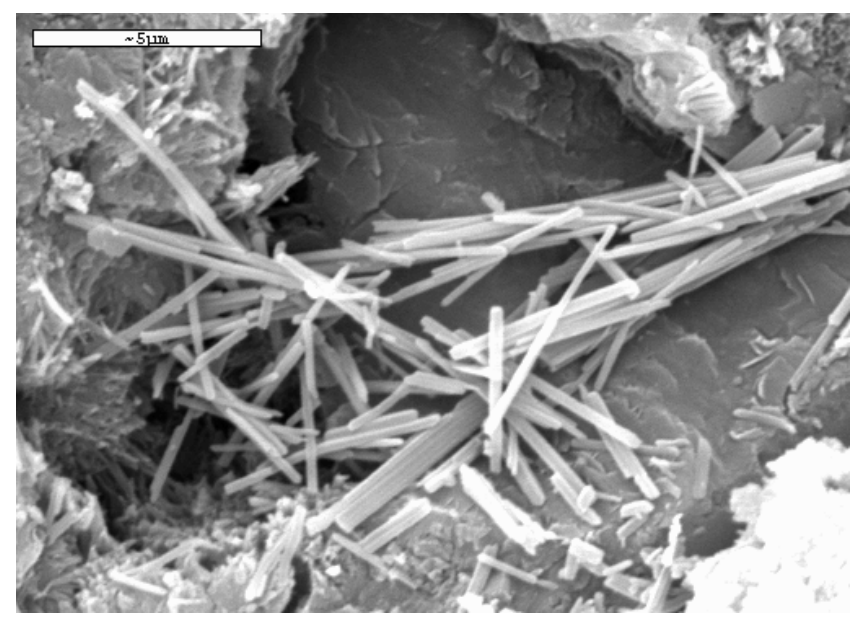

Figura 76. Fotografía de la pasta de cemento sin FCC antes de la carbonatación tomada a 7500 aumentos.

En la Figura 77 se muestra las placas formadas por la portlandita que se produce como consecuencia de la hidratación de los constituyentes del cemento. La portlandita suele aparecer en las pastas de cemento formando cristales planos cuya extensión puede llegar a ser bastante grande [108].

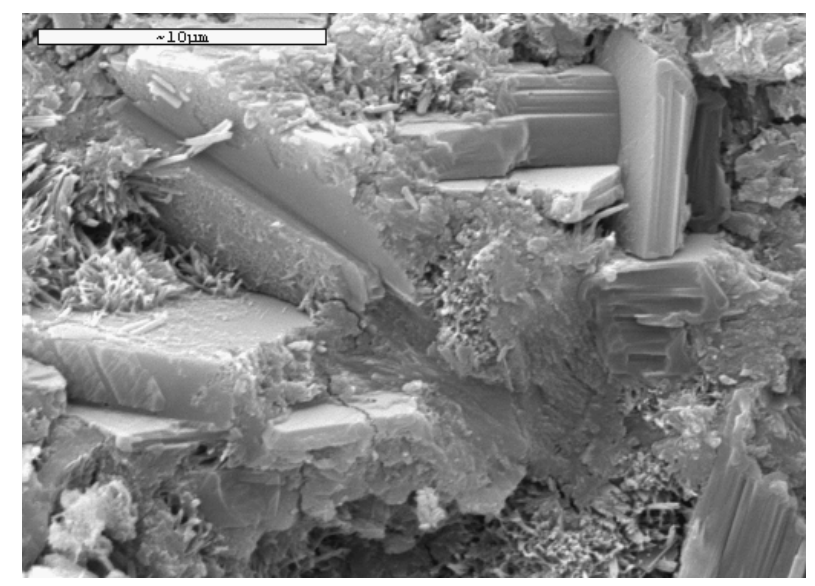

Figura 77. Fotografía de la pasta de cemento sin FCC antes de la carbonatación tomada a 5000 aumentos. 
El análisis efectuado de estas pastas de cemento sin FCC muestra como elementos principales al calcio y al silicio lo que indica una composición mayoritaria de silicatos cálcicos hidratados.

En cuanto a las pastas de cemento con FCC (35\%) se ofrecen las siguientes imágenes. En la primera (Figura 78), se aprecia una panorámica bastante general de la superficie de la pasta en la que se pueden apreciar láminas de los productos de la reacción puzolánica, que destacan sobre un resto bastante amorfo constituido principalmente por silicatos cálcicos.

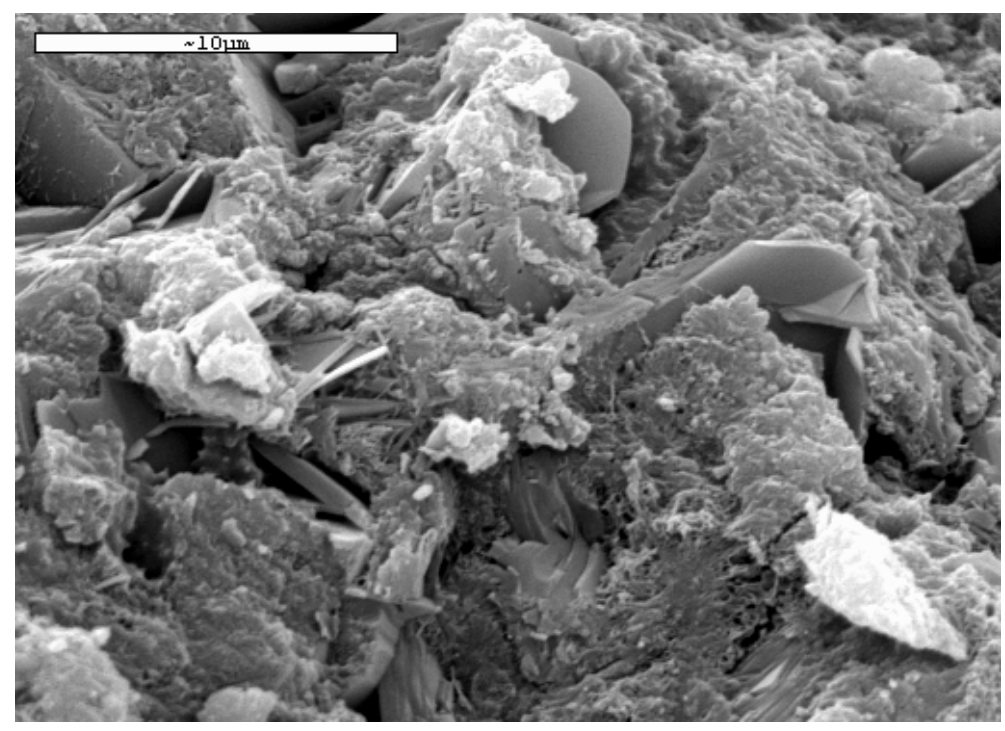

Figura 78. Fotografía de la pasta de cemento con $35 \%$ de FCC antes de la carbonatación realizada a 5000 aumentos.

En la siguiente imagen (Figura 79) se aprecia un gran cristal cuya composición revela su naturaleza de silicoaluminato cálcico hidratado. Además, debido a la morfología que presenta se puede decir que es gehlenita hidratada ya que este mineral crece formando láminas. 


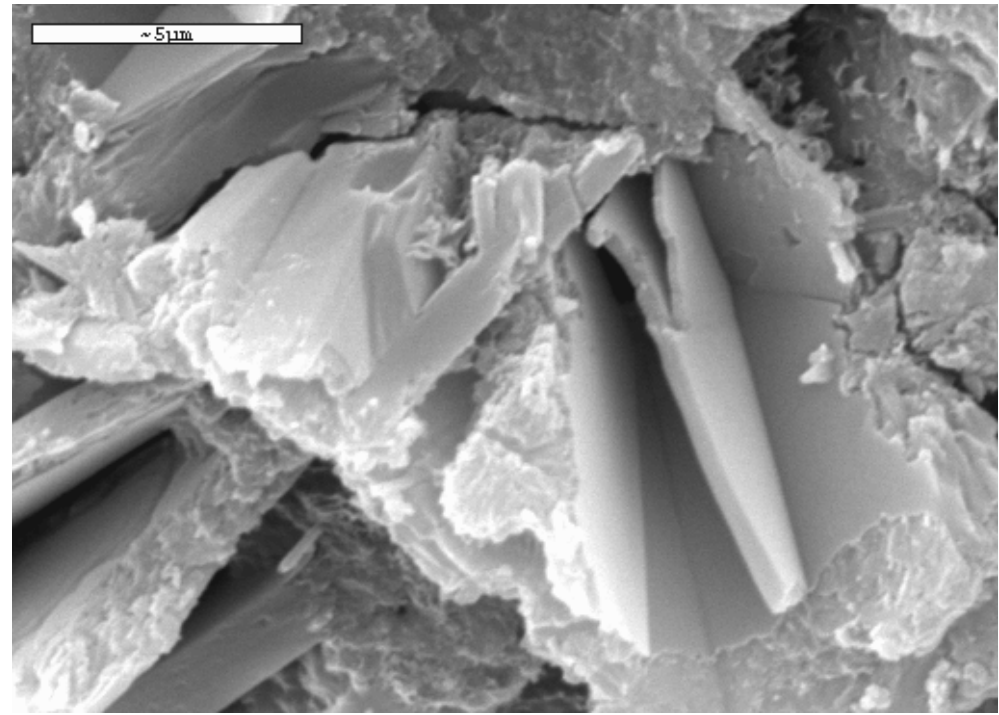

Figura 79. Fotografía de la pasta de cemento con $35 \%$ de FCC antes de la carbonatación tomada a 7500 aumentos.

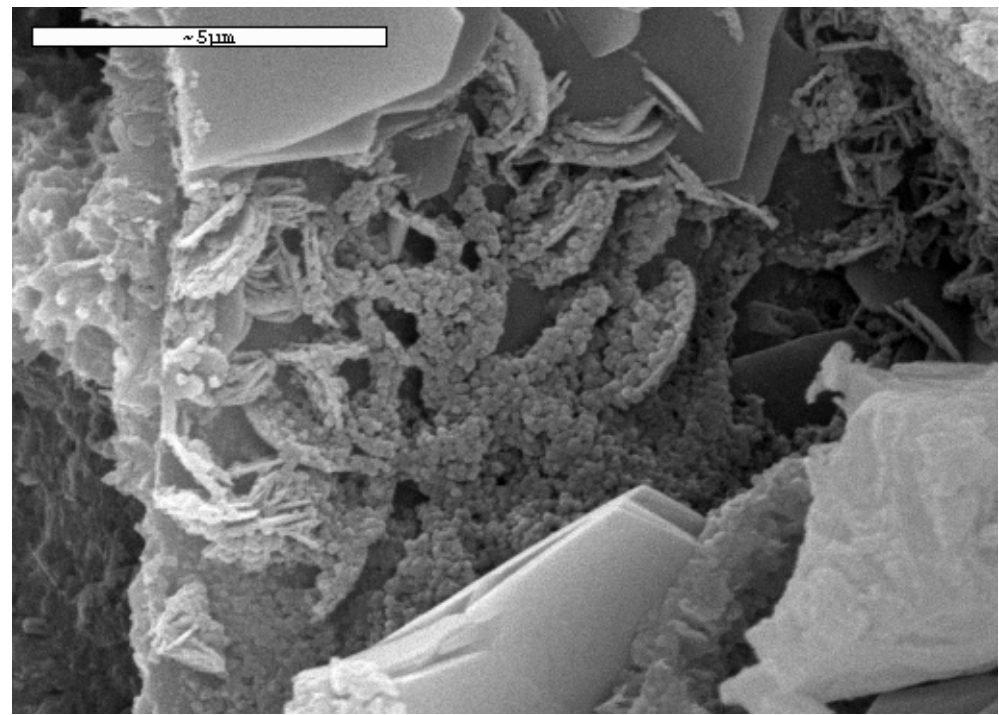

Figura 80. Micrografía de la pasta de cemento con $35 \%$ de FCC antes de la carbonatación tomada a 9000 aumentos.

En la Figura 80 se observan láminas de gehlenita hidratada producidas en la reacción puzolánica del FCC así como zonas de 
silicatos cálcicos hidratados de aspecto muy amorfo. Los análisis de estas pastas ofrecen mayoritariamente calcio, silicio y aluminio. En este caso la cantidad de aluminatos y silicoaluminatos es muy superior a la encontrada en las pastas de cemento sin FCC debido a que, precisamente, el FCC aporta gran cantidad de éstos.

\subsubsection{Después de la carbonatación}

En las siguientes figuras se muestran las fotografías tomadas sobre las pastas de cemento una vez que se han carbonatado. En primer lugar (Figura 81), se ofrece la correspondiente a la pasta de cemento sin FCC. Consiste en una panorámica general en la que el análisis revela grandes cantidades de carbonato cálcico.

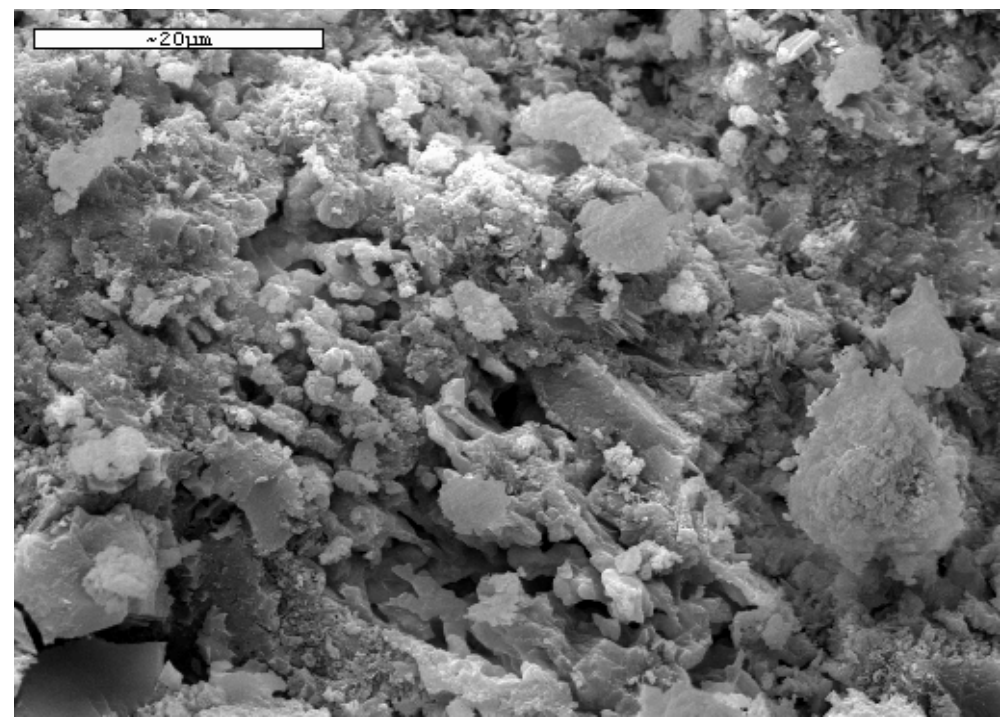

Figura 81. Fotografía de la pasta de cemento sin FCC tras la carbonatación tomada a 2000 aumentos.

En la Figura 82 se ofrece una imagen con más detalle de los cristales de carbonato cálcico que se han formado en esta pasta. Dado que su composición no presenta ni aluminio ni azufre no pueden confundirse con etringita. 


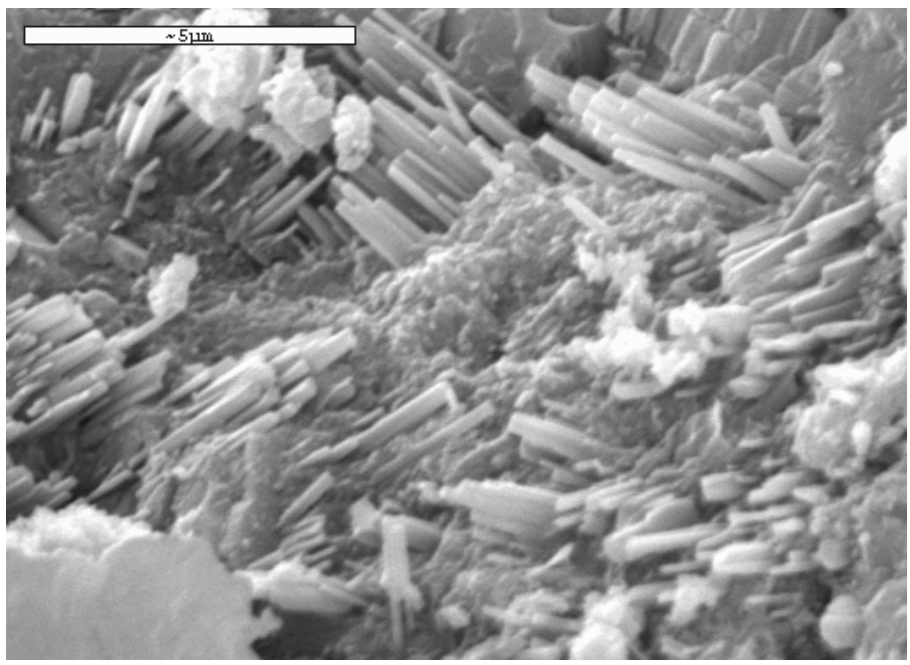

Figura 82. Fotografía de la pasta de cemento sin FCC tras la carbonatación tomada a 10000 aumentos.

A continuación se muestran varias imágenes que se han tomado sobre las pastas de cemento con un 35\% de FCC tras el proceso de carbonatación. En las dos primeras (Figura 83 y Figura 84), se vuelve a apreciar los cristales de carbonato cálcico con idéntica morfología a los identificados en las pastas de cemento sin FCC.

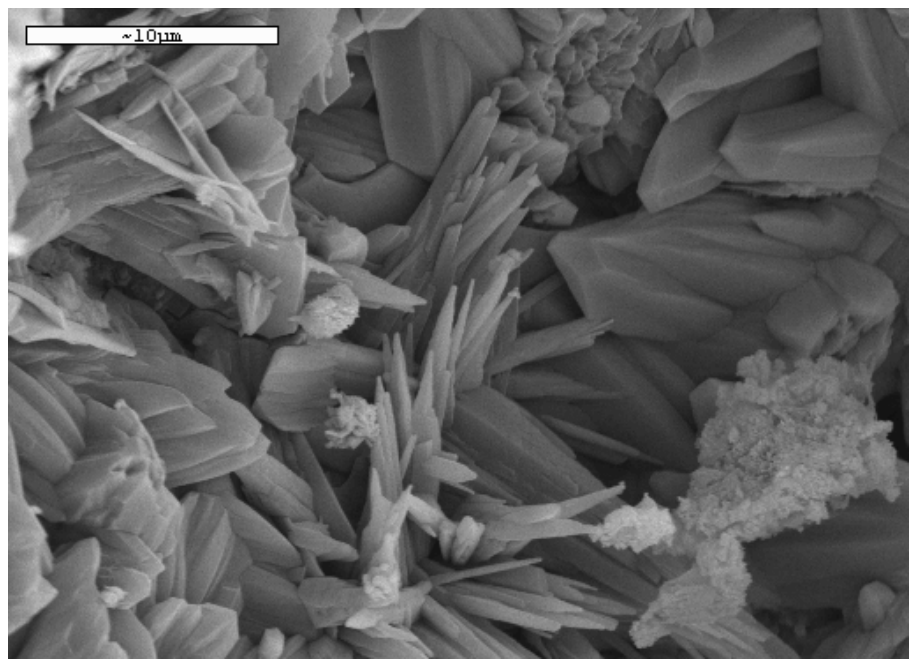

Figura 83. Fotografía de la pasta de cemento con $35 \%$ de FCC tras la carbonatación tomada a 7500 aumentos. 
Efecto de la carbonatación en la matriz cementante de los morteros mixtos de cemento-FCC

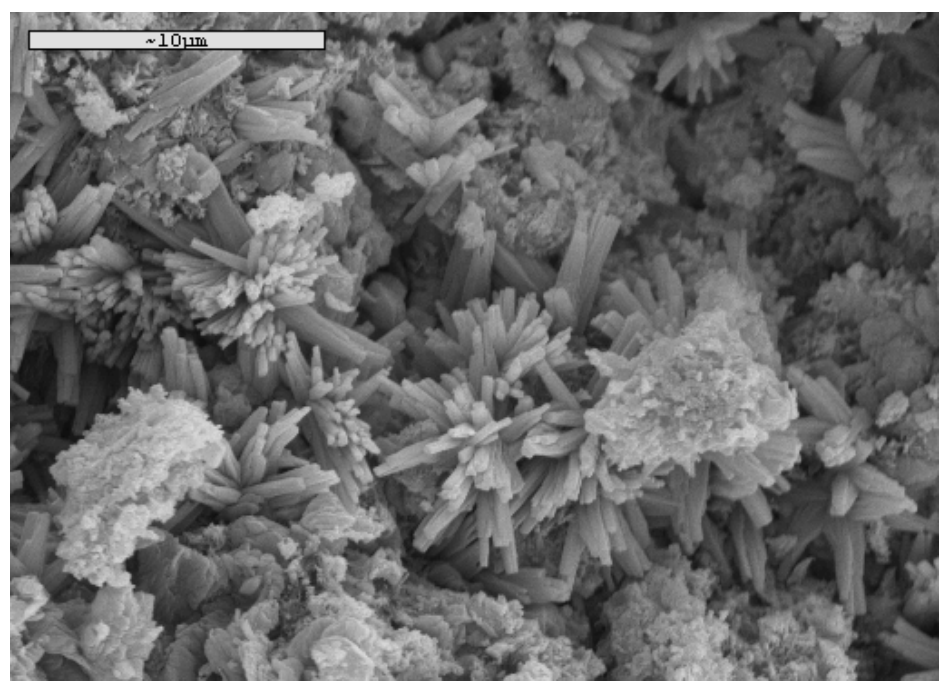

Figura 84. Fotografía de la pasta de cemento con $35 \%$ de FCC tras la carbonatación tomada a 4000 aumentos.

En la siguiente (Figura 85) se aprecia un gran cristal de carbonato cálcico rodeado de carbonato cálcico cuya morfología es bastante más amorfa.

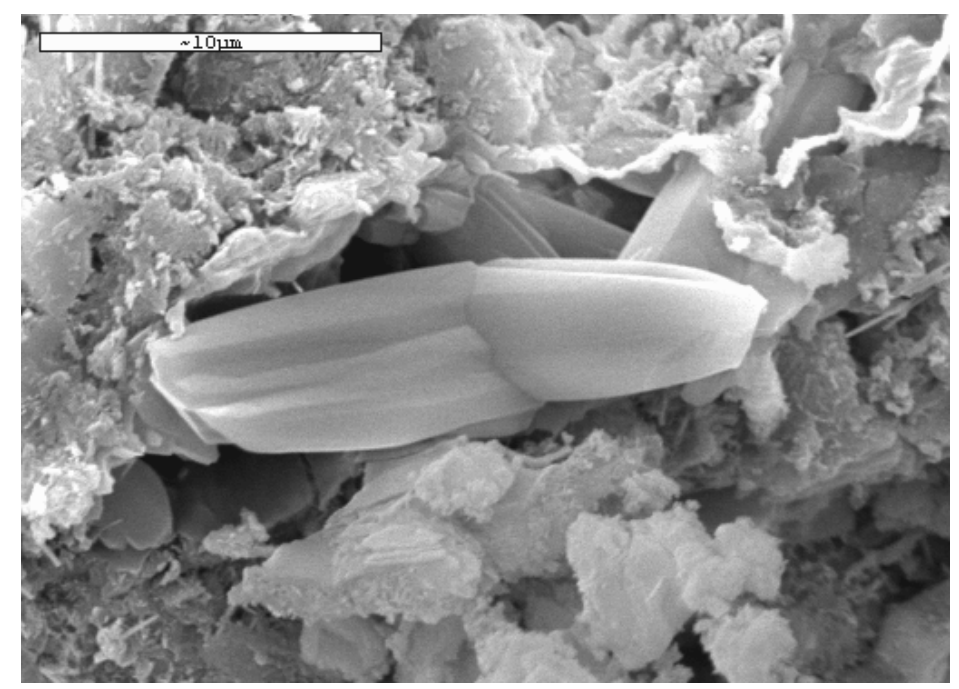

Figura 85. Fotografía de un cristal de carbonato cálcico en la pasta de cemento con $35 \%$ de FCC tomada a 5000 aumentos. 
Los elementos encontrados en estas pastas de cemento con FCC tras la carbonatación son calcio, silicio, aluminio y carbono de forma mayoritaria. Aunque en las fotografías anteriores se ha mostrado la evidente presencia de carbonato cálcico, lo que predomina en las muestras es la confluencia de silicatos cálcicos hidratados, aluminosilicatos cálcicos hidratados y carbonato cálcico como se muestra en la Figura 86.

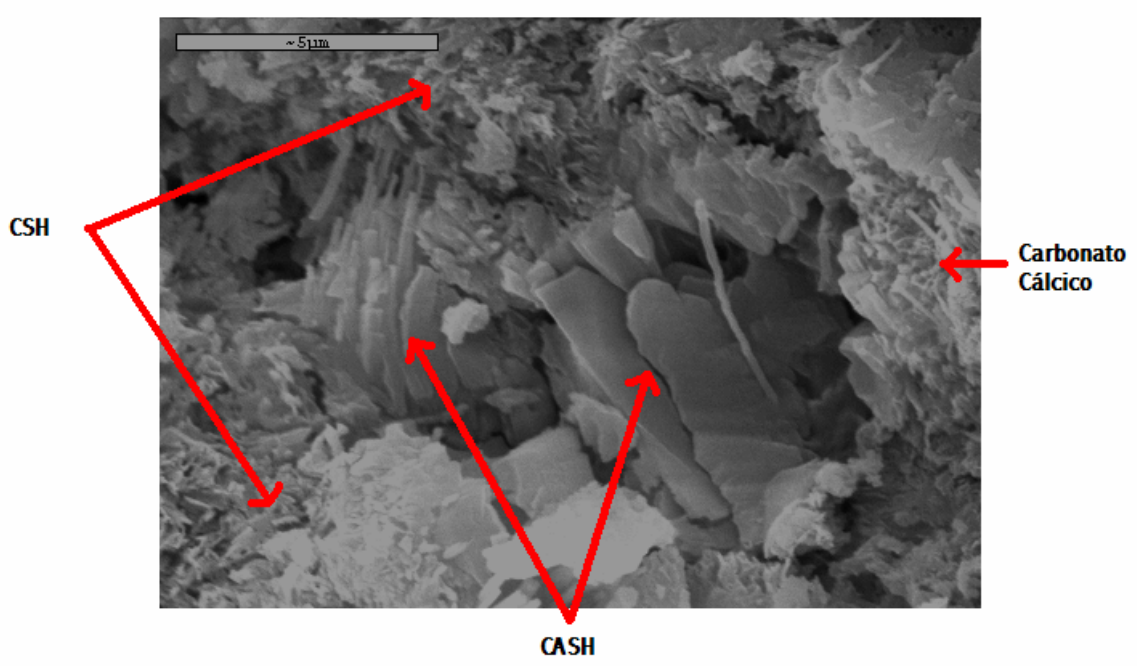

Figura 86. Fotografía de la pasta de cemento con $35 \%$ de FCC tras la carbonatación tomada a 8000 aumentos.

\subsection{Caracterización de la estructura porosa de morteros carbonatados}

\subsubsection{Diseño experimental}

Las muestras que se analizan en este caso han sido tomadas de los morteros fabricados en la segunda y tercera serie de las amasadas que se describen en el apartado 4.1. En la Tabla 15, se recogen las variables manejadas en este estudio de porosimetría. 


\begin{tabular}{|c|c|}
\hline RELACIÓN a/mc & SUSTITUCIÓN FCC (\%) \\
\hline \multirow{2}{*}{0,5} & 0 \\
\hline & 15 \\
\hline \multirow{2}{*}{0,7} & 0 \\
\hline & 15 \\
\hline \multirow{2}{*}{0,3 (con plast.) } & 0 \\
\hline & 15 \\
\hline \multirow{2}{*}{0,4 (con plast.) } & 0 \\
\hline & 15 \\
\hline
\end{tabular}

Tabla 15. Variables que se han manejado en el estudio de porosimetría.

Se han analizado 16 muestras: 8 de referencia (sin carbonatar) y otras 8 idénticas a las primeras pero sometidas al proceso de carbonatación acelerada. Dicho proceso de carbonatación acelerada consistió en someter las probetas a una atmósfera del $100 \%$ de $\mathrm{CO}_{2}$ y un $65 \pm 5 \%$ de humedad relativa. Para mantener la humedad relativa de las probetas en la cámara de carbonatación se colocó gel de sílice en la misma, el cual se renovaba periódicamente. Las muestras corresponden a trozos de probeta de mortero que fueron extraídos tras los ensayos mecánicos de las probetas que se estudiaron en el capítulo 4. Las dimensiones de los trozos son aproximadamente de $1 \mathrm{~cm}^{3}$. Las muestras fueron tomadas de la parte más externa del mortero, es decir, aquellas que habían sufrido una carbonatación más acusada.

El porosímetro empleado es el modelo Autopore IV 9500 V1.05 de la marca Micromeritics Instrument Corporation.

\subsubsection{Resultados de las porosimetrías de los morteros}

Los resultados de porosimetría ofrecidos en este apartado se han realizado con un único replicado de cada muestra. Según datos bibliográficos de Laskar y col. [109], para que los resultados sean totalmente representativos es necesario efectuar porosimetrías en un número más elevado de replicados. No obstante, dado que las condiciones de trabajo de laboratorio están más controladas que las 
que se pueden encontrar en trabajos de campo, el número aquí empleado es suficiente para mostrar las diferencias entre los distintos morteros.

En la Figura 87 se observan los valores de las intrusiones acumuladas de los morteros, en función de su relación a/mc y de la presencia de FCC. En ella se aprecia cómo la intrusión acumulada final (el valor obtenido para el diámetro más pequeño) sigue un orden creciente según aumenta la relación a/mc. Esto es lógico, ya que la porosidad de los morteros aumenta según aumenta la relación a/mc.

También se observa en dicha gráfica que la sustitución de cemento por FCC produce una reducción de la porosidad total (ver nuevamente el valor de la intrusión acumulada final). Esto es debido a la densificación que se produce en la probeta por la formación de productos cementantes, a consecuencia de la reacción puzolánica entre el FCC y la portlandita liberada por la hidratación del cemento.

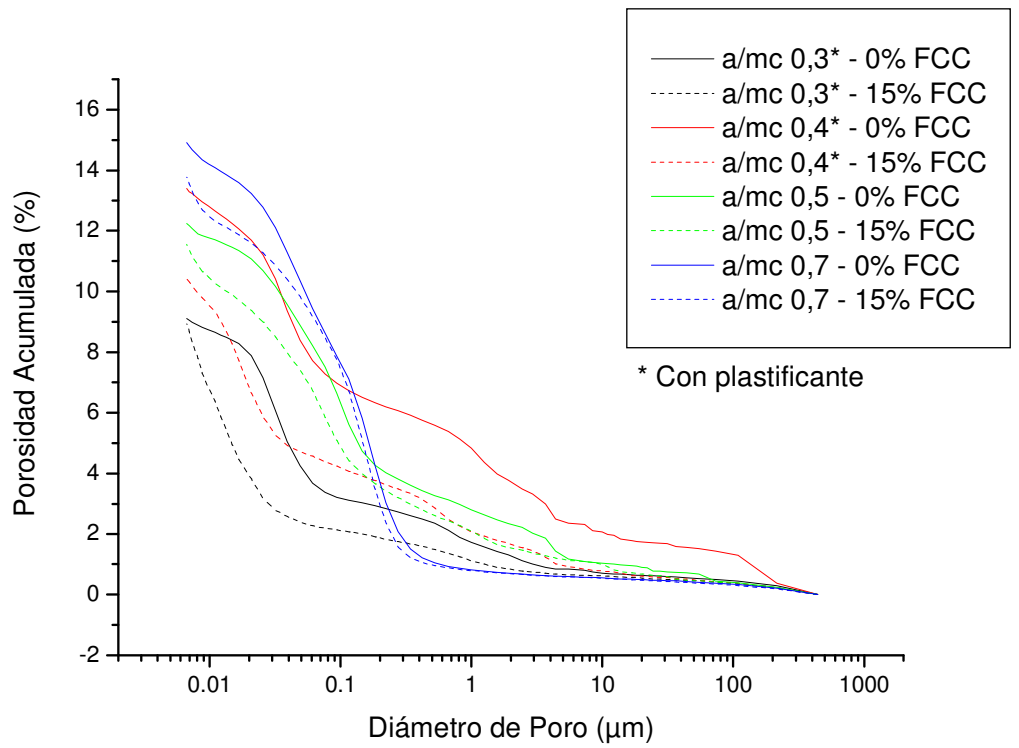

Figura 87. Distribución de tamaños de poros en los morteros de cemento/FCC en función de la relación a/mc. 
En la introducción del presente trabajo, se avanzaba que aquella porosidad cuyo tamaño está comprendido entre 0,05 y $3 \mu \mathrm{m}$ (porosidad capilar) es la que mayores cambios experimenta al variar la relación a/mc. Además, se afirma que la porosidad de este intervalo de tamaños es la que más influencia tiene en la permeabilidad de hormigones y morteros, y por lo tanto en la facilidad con la que pueden introducirse agentes agresivos, como el $\mathrm{CO}_{2}$, en el mismo.

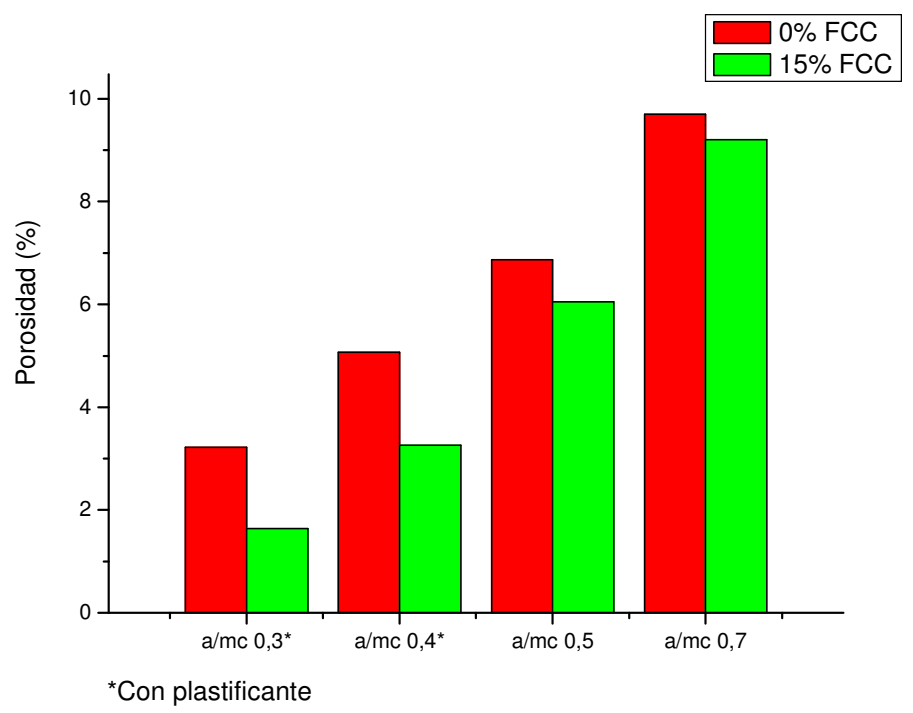

Figura 88. Volumen de poros acumulado en los poros cuyo tamaños está comprendido entre 0,05 y $3 \mu \mathrm{m}$.

En la Figura 88 se muestra el volumen de poros acumulado en este intervalo de porosidad para las distintas relaciones a/mc. Se observa que a medida que se aumenta la relación a/mc se produce un incremento de la porosidad cuyo tamaño está comprendido entre 0,05 y $3 \mu \mathrm{m}$ [110]. Ello implicaría que la velocidad de carbonatación aumentase al aumentar la relación a/mc. También se aprecia que la presencia de residuo de FCC en los morteros reduce, precisamente, la porosidad en este intervalo crítico. Esto puede llevar a pensar que la velocidad de carbonatación de estos morteros con FCC será menor pero no se debe olvidar que la reserva alcalina es el otro factor de peso en el fenómeno de la carbonatación. En el siguiente capítulo, se pone 
de manifiesto cual de estos dos factores tiene más peso a la hora de producir la carbonatación del mortero. El refinamiento que se produce por las adiciones puzolánicas en morteros u hormigones es un hecho ampliamente contrastado en la bibliografía [111-113], el cual se basa en la formación de productos cementantes (silicatos, aluminatos y silicoaluminatos cálcicos hidratados) adicionales debido a la reacción puzolánica.

En las gráficas que se muestran a continuación (Figura 89, Figura 90, Figura 91 y Figura 92) se ha representado la distribución de tamaños de poros de los morteros antes y después de la carbonatación, para cada una de la relaciones a/mc estudiadas $(0,3$ con plastificante, 0,4 con plastificante, 0,5 y 0,7 , respectivamente). Este tipo de figuras relaciona el volumen de poros atribuibles a los distintos diámetros, dentro del intervalo de tamaños de poro estudiado.

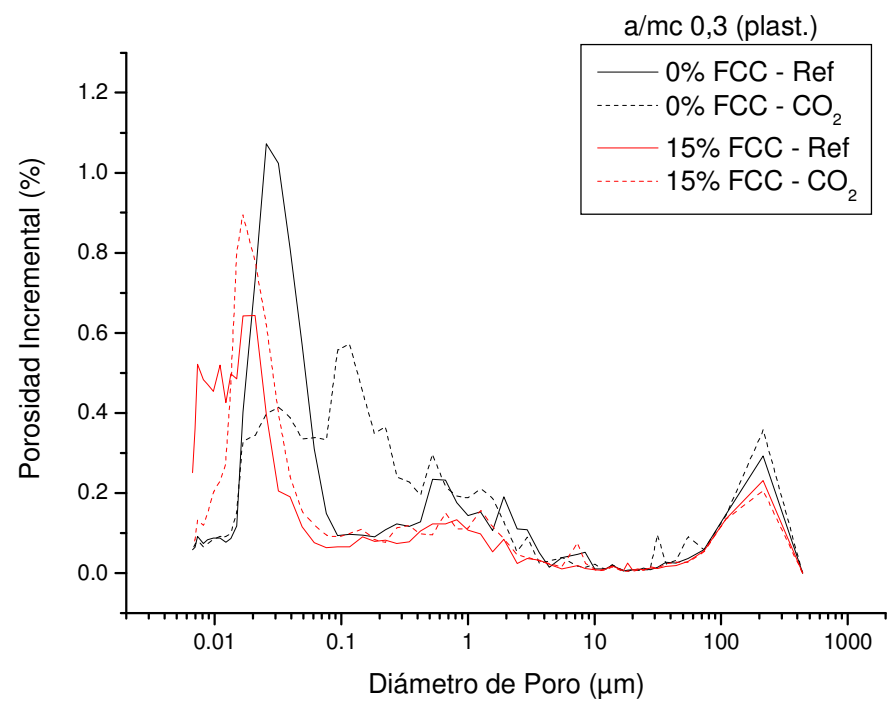

Figura 89. Distribución de tamaños de poro para el mortero de cemento/FCC antes y después de la carbonatación. Relación a/me de 0,3 con plastificante. 


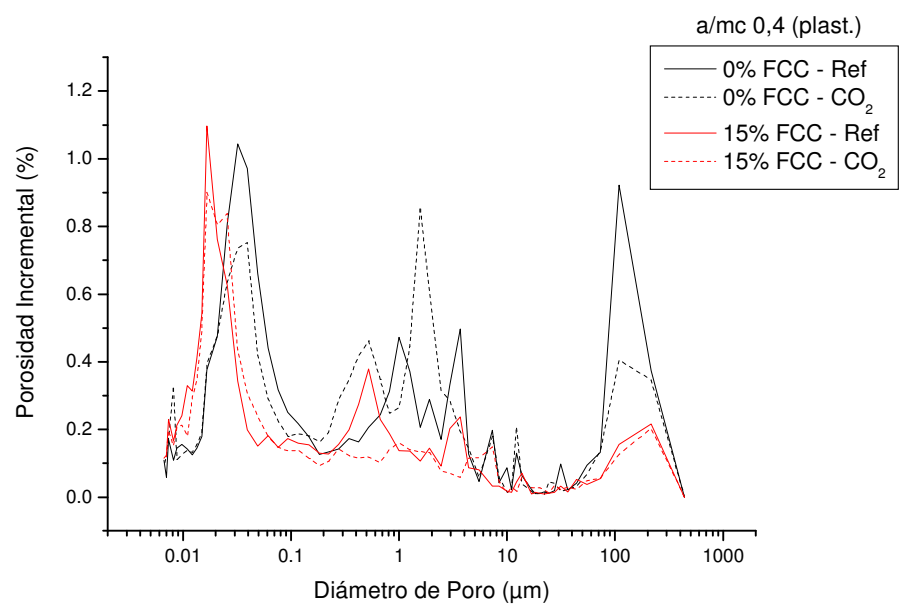

Figura 90. Distribución de tamaños de poro para el mortero de cemento/FCC antes y después de la carbonatación. Relación a/me de 0,4 con plastificante.

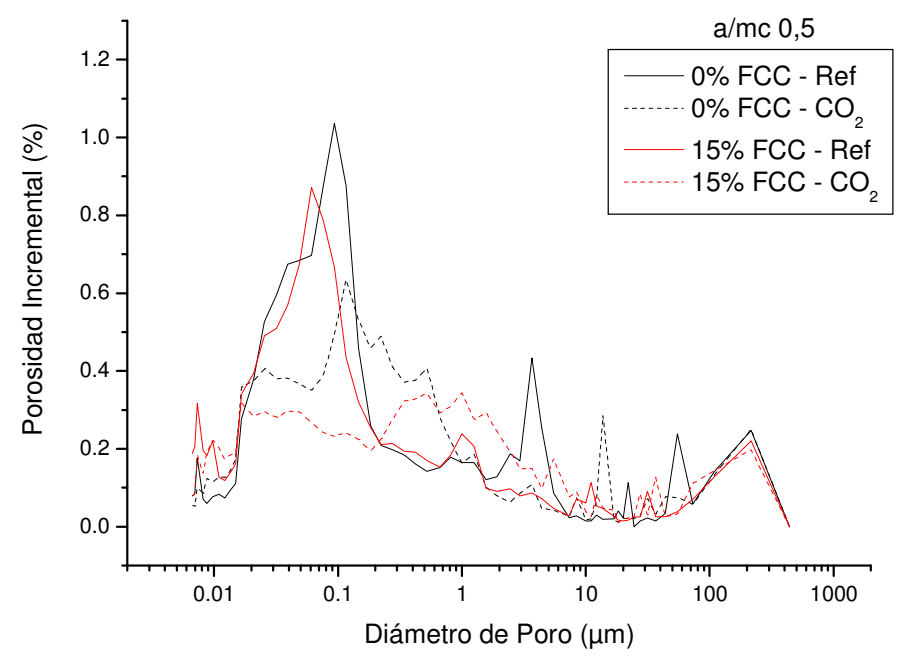

Figura 91. Distribución de tamaños de poro para el mortero de cemento/FCC antes y después de la carbonatación. Relación a/me de 0,5 . 


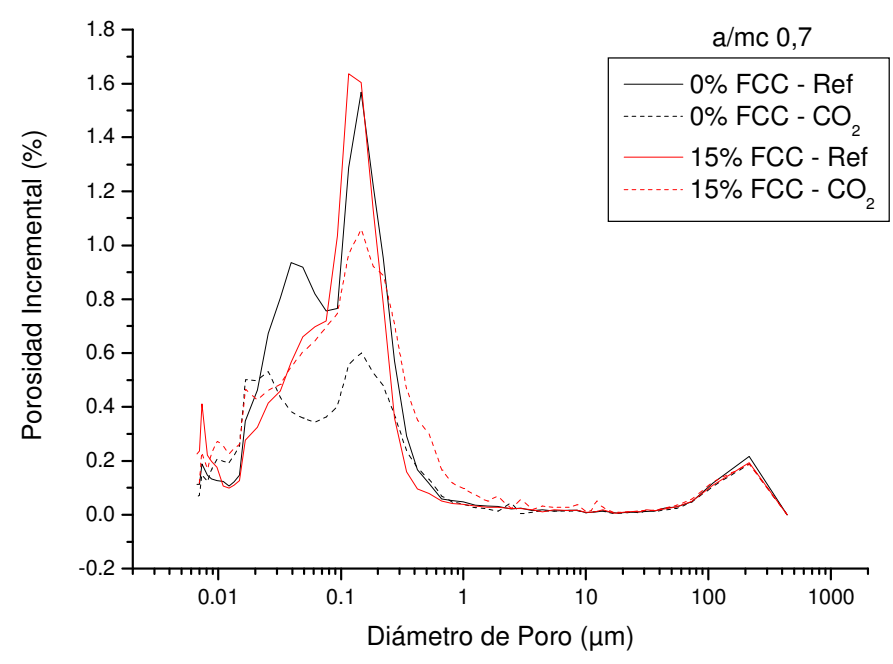

Figura 92. Distribución de tamaños de poro para el mortero de cemento/FCC antes y después de la carbonatación. Relación a/mc de 0,7 .

En estas figuras se aprecia cómo la carbonatación produce una reducción en la porosidad de las muestras como consecuencia de la formación de carbonato cálcico que precipita en los poros accesibles para el $\mathrm{CO}_{2}$. El rellenado de los poros por la precipitación del carbonato cálcico no se produce por igual en todos los poros, ya que depende de la presión parcial de $\mathrm{CO}_{2}$ [116]. Esto hace pensar que en condiciones de carbonatación naturales este refinamiento de la porosidad producido por la carbonatación tiene lugar en los poros de mayor diámetro, mientras que en el ensayo acelerado se pueden refinar poros de menor diámetro. El efecto de refinado es, por tanto, más acusado cuanto mayor ha sido la carbonatación de la muestra [114,115]. Por otro lado, la carbonatación debe aumentar cuanto mayor sea la porosidad, lo que es esperable que ocurra cuando se aumenta la relación a/mc. Conforme la porosidad de los morteros antes de la carbonatación sea mayor (mayor relación a/mc), el frente de carbonatación debe penetrar más, lo que debe originar una mayor reducción de la porosidad. En estudios realizados por otros autores $[116,117]$ se ha mostrado como se produce este fenómeno para una gran variedad de adiciones puzolánicas y, para todas ellas, se produce 
esta reducción de la porosidad cuando se carbonatan las matrices cementantes.

En la Figura 93 se representa la porosidad total del mortero calculada a través de la técnica de porosimetría de intrusión de mercurio. Se puede observar que la sustitución de cemento por FCC produce una reducción en la porosidad de dichos morteros. También se aprecia que la carbonatación tiene el mismo efecto, es decir, reduce la porosidad de los morteros. En las relaciones a/mc bajas $(0,3$ y 0,4 , ambos con plastificante), debido a que la carbonatación debe ser menor, apenas varía este parámetro. Por otro lado, los morteros con relación a/mc 0,5 y 0,7 , que habrán experimentado una carbonatación mucho mayor, reflejan una mayor reducción de la porosidad.

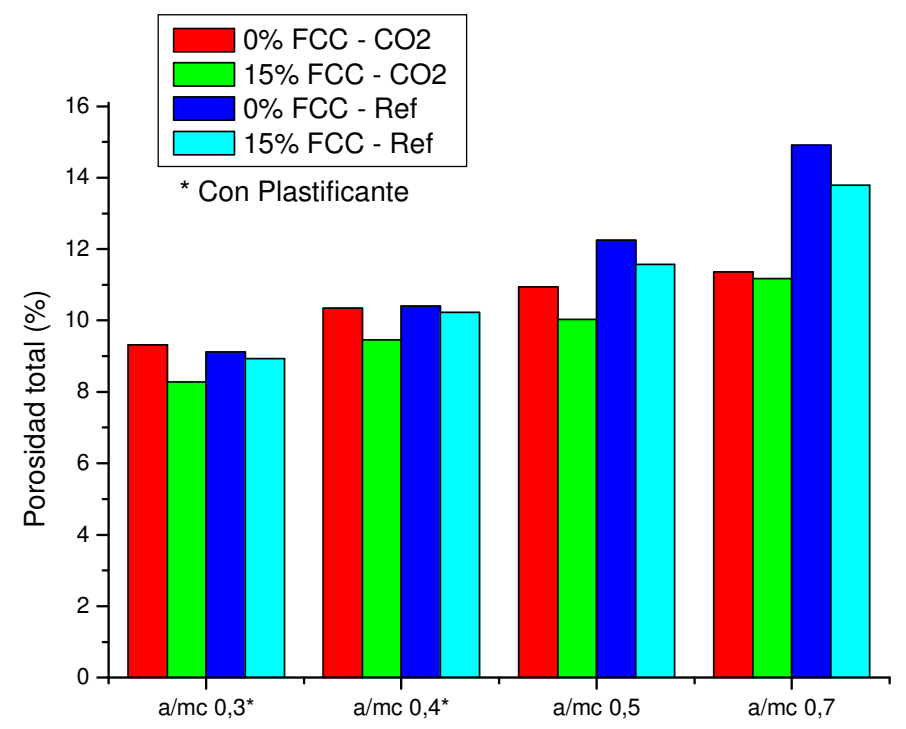

Figura 93. Porosidad total obtenida mediante MIP para los morteros de cemento/FCC.

Cabe destacar también, el que la reducción de la porosidad en el mortero con relación a/mc 0,7 sin FCC, es mucho mayor que la ofrecida por el mismo mortero con FCC. Recordemos que en este mortero la carbonatación del mismo será mucho mayor debido a la 
relación a/mc alta. Por esta razón, el mortero sin $\mathrm{FCC}$, que tiene una gran cantidad de portlandita, sufre una gran reducción de su porosidad ya que en la carbonatación se forma una importante cantidad de carbonato cálcico. En cambio, el mortero con FCC tiene una menor cantidad de portlandita debido a la reacción puzolánica, y por ello al carbonatar totalmente, la cantidad de carbonato cálcico formada debe ser menor.

\subsection{Conclusiones}

Tras el análisis de los datos ofrecidos por las termogravimetrías practicadas en las pastas de cemento, podemos obtener las siguientes conclusiones:

- La sustitución de hasta un $20 \%$ de cemento por FCC en las pastas conduce a un mayor nivel de silicatos y aluminatos cálcicos hidratados (especialmente de estos últimos). A partir de ese umbral de concentración de FCC, el cemento no es capaz de producir suficiente hidróxido cálcico para que se desarrolle más allá la reacción puzolánica.

- La aplicación de un proceso de carbonatación acelerada a las pastas estudiadas conlleva la formación de carbonatos a partir del hidróxido cálcico generado durante el proceso de hidratación de la pasta. Sin embargo, una vez agotado el hidróxido cálcico la generación de carbonatos continúa a partir de los silicatos y aluminatos.

- No se detecta la presencia de ningún pico nuevo que pueda sugerir la formación de carboaluminatos, aunque es posible que se haya formado una pequeña cantidad del mismo y su presencia esté enmascarada por la calcita. Debido a la alta agresividad del proceso de carbonatación se piensa que la gran banda de carbonatos se debe a la captura del calcio de las fases de silicatos y aluminatos.

Del estudio realizado mediante difracción de rayos $\mathrm{X}$ en pastas de cal y cemento carbonatadas se han podido extraer las siguientes conclusiones: 
- En los difractogramas de pastas de cal sin carbonatar se puede observar la naturaleza de los compuestos formados por la reacción puzolánica del FCC con hidróxido cálcico. Estos se corresponderían con silicatos y silicoaluminatos cálcicos hidratados.

- El proceso de carbonatación acelerada al que se han sometido las pastas produce la formación de carbonato cálcico, eminentemente como calcita y en menor medida como vaterita.

- La carbonatación agresiva produce la formación de carbonato cálcico no sólo a partir de portlandita, sino también a partir de los silicatos y aluminatos cálcicos hidratados.

Mediante el estudio por microscopía electrónica de barrido se han puesto de manifiesto los siguientes aspectos:

- En la pasta de cal se observa que el FCC ofrece productos de reacción del tipo de la gehlenita hidratada. Estos productos no se aprecian tras la carbonatación debido a que, tal y como se observó en los estudios termogravimétricos, se destruyen durante la carbonatación.

- Tras la carbonatación, se observan grandes formaciones de carbonato cálcico con una cristalinidad muy baja en las pastas de cal con FCC.

- En la pasta de cemento se aprecian los productos cristalinos típicos del cemento: portlandita, etringita y gel de silicatos. En la pasta de cemento con FCC se aprecia además la gehlenita hidratada, producto de la reacción puzolánica.

- La carbonatación produce efectos similares en las pastas de cemento con y sin FCC: la desaparición del hidróxido cálcico y la aparición de carbonato cálcico.

Las conclusiones que se pueden extraer de los estudios de porosimetría de intrusión de mercurio son los siguientes: 
- Se ha observado una relación directa entre la relación a/mc y la porosidad ofrecida por los morteros. Cuanto mayor es la relación a/mc mayor es la porosidad del mortero.

- La sustitución de hasta un $15 \%$ de cemento por residuo de FCC produce una reducción de la porosidad de los morteros y una densificación de los mismos. Esto es consecuencia de los productos cementantes formados en la reacción puzolánica del FCC con el $\mathrm{Ca}(\mathrm{OH})_{2}$. Este fenómeno se aprecia en todas las relaciones a/mc estudiadas.

- La carbonatación produce una densificación del mortero y una reducción de la porosidad como consecuencia de la formación de carbonato cálcico en el interior de los poros.

- En aquellos morteros donde la carbonatación ha sido mayor, la reducción de la porosidad también lo ha sido. Estos morteros son los de relación a/mc más altas $(0,5$ y 0,7$)$.

- En aquellos morteros en los que la carbonatación ha sido exhaustiva, la mayor reducción de la porosidad se obtiene cuando la reserva alcalina del mortero es mayor (morteros sin FCC), ya que se forma mayor cantidad de carbonato cálcico. 
Efecto de la carbonatación en la matriz cementante de los morteros mixtos de cemento-FCC 


\section{Cinética de carbonatación de morteros mixtos de cemento-FCC}

En este capítulo se ha realizado un estudio de la velocidad de avance del frente de carbonatación a través de morteros de cemento sustituidos con residuo de FCC. Dentro del mismo, se ha evaluado la influencia de la presencia de FCC en el mortero y la influencia de la relación a/mc. Se trata de dilucidar si la reducción de reserva alcalina que produce el residuo de FCC, puede ser compensada por la densificación del mortero que produce la reacción puzolánica del mismo.

\subsection{Diseño experimental}

Para abordar el objetivo propuesto se plantearon una serie de amasadas de morteros con residuo de FCC y con distintas relaciones a/mc. En la Tabla 16 se especifican las distintas amasadas que se realizaron: 


\begin{tabular}{||c|c||}
\hline \hline \multirow{2}{*}{0,3 (con plast.) } & 0 \\
\cline { 2 - 2 } & $\mathbf{S U S T I T U C I O ́ N ~ F C C ~} \mathbf{( \% )}$ \\
\hline \multirow{2}{*}{0,4 (con plast.) } & 0 \\
\cline { 2 - 2 } & 15 \\
\hline \multirow{2}{*}{0,5} & 0 \\
\cline { 2 - 2 } & 15 \\
\hline \multirow{2}{*}{0,7} & 0 \\
\cline { 2 - 2 } & 15 \\
\hline
\end{tabular}

Tabla 16. Variables manejadas en las amasadas para el estudio de la velocidad de carbonatación.

Las variables que se manejan en este caso fueron limitadas, debido a que el desarrollo de las experiencias puede alargarse demasiado en el tiempo si se plantea el estudio con demasiados parámetros.

Las amasadas se realizaron con cemento Portland tipo CEM I 52,5 $\mathrm{R}$, arena normalizada [138], agua corriente y residuo de catalizador suministrado por BP España, el cual había sido previamente molido durante 20 minutos en un molino de bolas. De cada amasada se obtuvieron tres probetas normalizadas de 40x40x160 $\mathrm{mm}$ que fueron las empleadas para la realización de los posteriores ensayos. Los resultados que se ofrecen más adelante hacen referencia a la media de las tres probetas fabricadas de cada amasada.

Se efectuaron tres series de amasadas con las mismas variables implicadas para realizar distintas pruebas sobre los morteros. Una de las series se utilizó para medir el avance del frente de carbonatación a lo largo del proceso. Para ello se realizó el siguiente procedimiento. En primer lugar, se curaron las probetas en agua durante 28 días tras su amasado. Posteriormente, se acondicionaron las probetas durante 21 días, proceso que consistió en dejarlas expuestas en ambiente de laboratorio para que perdieran la humedad, y de esta forma evaporar el agua de los poros que impediría una velocidad de carbonatación apreciable. A continuación, se colocaron las probetas en la cámara de 
carbonatación. Las probetas se mantuvieron en la cámara durante 21 días.

Durante su estancia en la cámara de carbonatación se monitorizó la evolución de la masa de las probetas y el avance del frente de carbonatación. Para esto último se fracturaba la probeta, y se revelaba la superficie de la fractura mediante una disolución de fenolftaleína al 1\% en agua/etanol 1:1 [90,91]. Los valores de profundidad de carbonatación se obtuvieron mediante la media de los cuatros valores medidos en cada una de las caras de cada probeta. La media de las tres probetas de cada amasada se tomó como el valor de profundidad de carbonatación para cada una de las condiciones empleadas. Durante los últimos años se han desarrollado otras metodologías a la hora de determinar el avance del frente de carbonatación ya que el uso de fenolftaleína adolece de cierto error por defecto en la detección del frente de carbonatación y una precisión por encima de 0,5 mm [91]. Estas metodologías se sirven de XPS [118], espectroscopia infrarroja [91,119], el uso de termogravimetría [120], o densimetría por rayos gamma [92,121]. No obstante, el método de la fenolftaleína sigue siendo hoy en día el más usado por sencillez, rapidez y economía.

La segunda serie de amasadas se empleó para estudiar la influencia de la carbonatación en las propiedades mecánicas de los morteros. El proceso al que fueron sometidas las probetas de esta segunda serie fue idéntico al de la primera serie, pero en ellas no se monitorizó el avance del frente de carbonatación. Se curaron durante 28 días en agua, se acondicionaron durante 21 días en ambiente de laboratorio, y se carbonataron en la cámara durante 21 días más. Durante los 21 días que duró su carbonatación se siguió la evolución de las masas de las probetas para comprobar que su tendencia era similar a las probetas de la primera serie. Una vez cumplidos los 21 días de carbonatación en la cámara, se efectuaron ensayos de resistencia a compresión y resistencia a flexotracción, y se midieron las densidades y porosidades de los morteros carbonatados.

En la tercera y última serie, las probetas no se sometieron a un proceso de carbonatación y se utilizaron como referencia para comparar el efecto de la carbonatación en las propiedades mecánicas 
que se habían medido en la segunda serie. Para ello se curaron las probetas resultantes de las amasadas durante 28 días en agua, se acondicionaron durante 21 días en ambiente de laboratorio y se conservaron dentro de bolsas (para evitar que se carbonataran) durante 21 días más. Este último periodo equivaldría al tiempo que las probetas de la segunda serie estuvieron en la cámara de carbonatación. Al finalizar el proceso se efectuaron los mismos ensayos que los descritos para la segunda serie.

Los ensayos de resistencia a flexotracción y resistencia a compresión en los morteros se realizaron según la norma [122] UNEEN 196-1:1996. En la Figura 94 y Figura 95 se muestran unas fotografías de las máquinas empleadas en los ensayos de resistencia a flexotracción y a compresión, respectivamente.

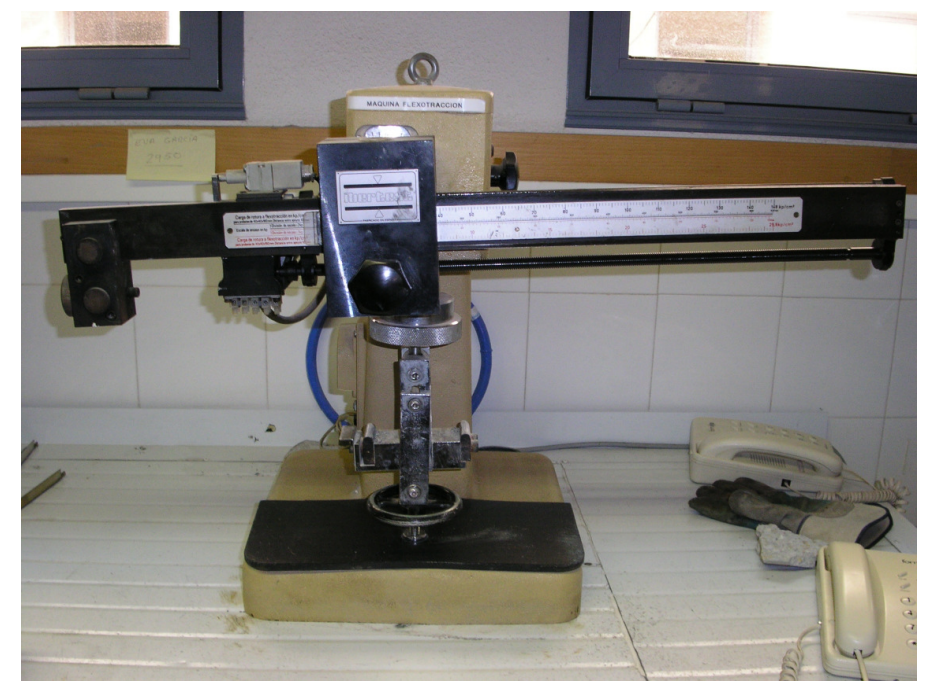

Figura 94. Máquina de ensayos de resistencia a flexotracción para morteros. 


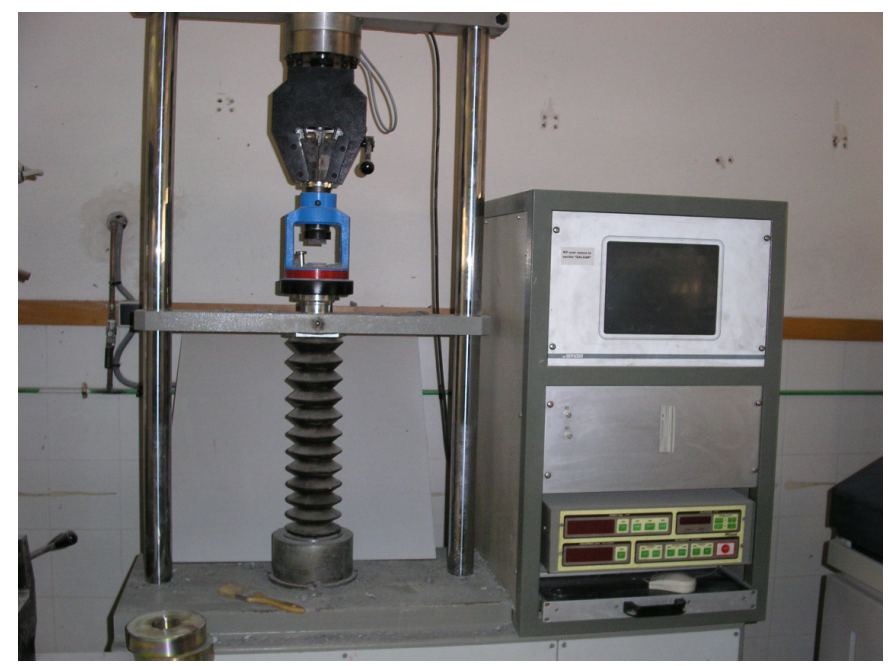

Figura 95. Máquina multiensayos para realización de ensayos de resistencia a compresión en morteros.

La determinación de densidades y porosidades de los morteros se efectuó sobre trozos de los extremos de las probetas que, tras el ensayo de resistencia a compresión no habían sufrido carga. El cálculo de estos parámetros se efectuó mediante las siguentes ecuaciones:

$$
\text { Ecuación } 28 \quad \operatorname{Densidad}\left(\mathrm{g} / \mathrm{cm}^{3}\right)=\frac{M_{s}}{M_{a}-M_{a}^{\prime}}
$$

Donde $M_{s}$ es la masa del mortero tras secarlo en estufa a $105^{\circ} \mathrm{C}$ hasta pesada constante, $M_{a}$ es la masa del mortero sumergido en agua durante 1 día, y $M^{\prime}{ }_{a}$ es la masa del mortero sumergido en agua durante 1 día pesado en balanza hidrostática.

\section{Ecuación 29}

$$
\operatorname{Porosidad}(\%)=\frac{M_{w}-M_{s}}{M_{w}-M_{w}^{\prime}}
$$

Donde $M_{w}$ es la masa del mortero tras sumergirlo en agua a vacío durante $2 \mathrm{~h}$ y mantenerlo sumergido durante 7 días, $M_{s}$ es la masa del mortero tras secarlo en estufa a $105^{\circ} \mathrm{C}$ hasta pesada constante, y $M^{\prime}{ }_{w}$ es la masa del mortero tras sumergirlo en agua a vacío durante $2 \mathrm{~h}$ y mantenerlo sumergido durante 7 días pesado en balanza hidrostática. 


\subsection{Cinética de carbonatación de morteros}

A la hora de evaluar la velocidad de carbonatación de los morteros, se procedió al seguimiento de la masa y del frente de carbonatación, tal y como se ha descrito anteriormente. Debido a que los resultados que aquí se presentan se han obtenido mediante la carbonatación acelerada, su extrapolación a condiciones de carbonatación natural es complicada, aunque algunos autores han trasladado sus resultados de carbonatación acelerada mediante el uso de un factor que depende de las condiciones ambientales naturales de exposición a las que se quiera trasladar el resultado [125]. Son muchos los modelos de predicción de vida de servicio de estructuras en función de la velocidad de avance de la carbonatación en elementos en servicio. Estos modelos pueden ser más o menos completos e intentan abarcar todos los factores que influyen en la velocidad de carbonatación, como pueden ser: la humedad ambiental, el contenido de portlandita de los hormigones, el grado de hidratación del cemento, etc. En un trabajo de M. A. Sanjuán [126] se describen cuatro modelos teóricos que pueden servir como ejemplo de lo expuesto.

El propósito que pretendemos en nuestro caso es comparar cómo influyen la sustitución de cemento por residuo de FCC y la relación a/mc en la velocidad de carbonatación de los morteros. Para ello seguimos el modelo clásico [125,127-129] que relaciona la profundidad de carbonatación con la raíz cuadrada del tiempo mediante una constante, que denominamos velocidad de carbonatación, y cuya ecuación responde a la siguiente expresión:

$$
x=V_{\mathrm{CO} 2} \sqrt{t}
$$

Con los resultados experimentales se ha podido calcular el coeficiente $V_{\mathrm{CO} 2}$ que nos sirve para comparar la resistencia que ofrecen los distintos morteros ante el avance del frente de carbonatación.

En la Figura 96 se puede observar que a medida que se aumenta la relación a/mc, la velocidad de carbonatación crece considerablemente. Este fenómeno era esperable debido a que la porosidad de los morteros aumenta al aumentar la relación a/mc, y por 
lo tanto el $\mathrm{CO}_{2}$ encuentra el camino mucho más despejado para penetrar hacia el interior del mortero.

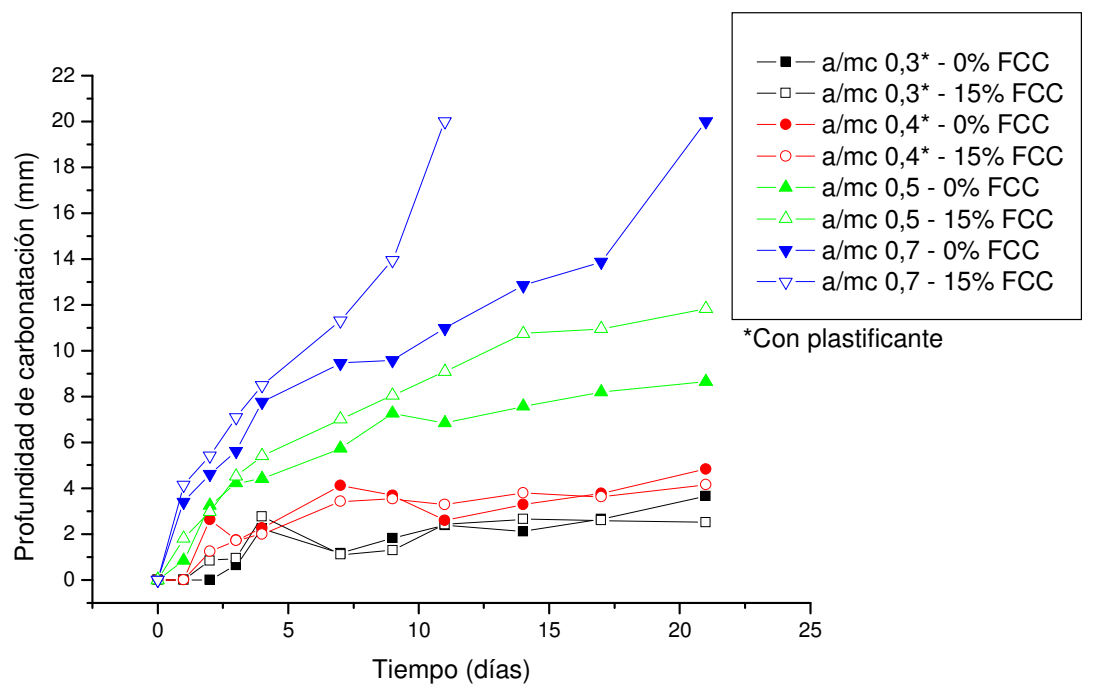

Figura 96. Evolución del perfil de carbonatación de morteros durante el ensayo de carbonatación acelerada.

En las relaciones a/mc bajas $(0,3$ y 0,4 con plastificante) la presencia del catalizador no ofrece diferencias apreciables con respecto a los morteros sin residuo de FCC. En cambio, para las relaciones a/mc 0,5 y 0,7, el residuo de FCC empeora la resistencia del mortero frente a la carbonatación. Parece ser que la reducción de la reserva alcalina debido al consumo de la misma por el FCC es bastante importante, y ello conlleva una menor cantidad de sustancias carbonatables que frenen el avance de la carbonatación.

En la Figura 97 se muestra la dependencia lineal que ofrece la profundidad de carbonatación con la raíz cuadrada del tiempo. 


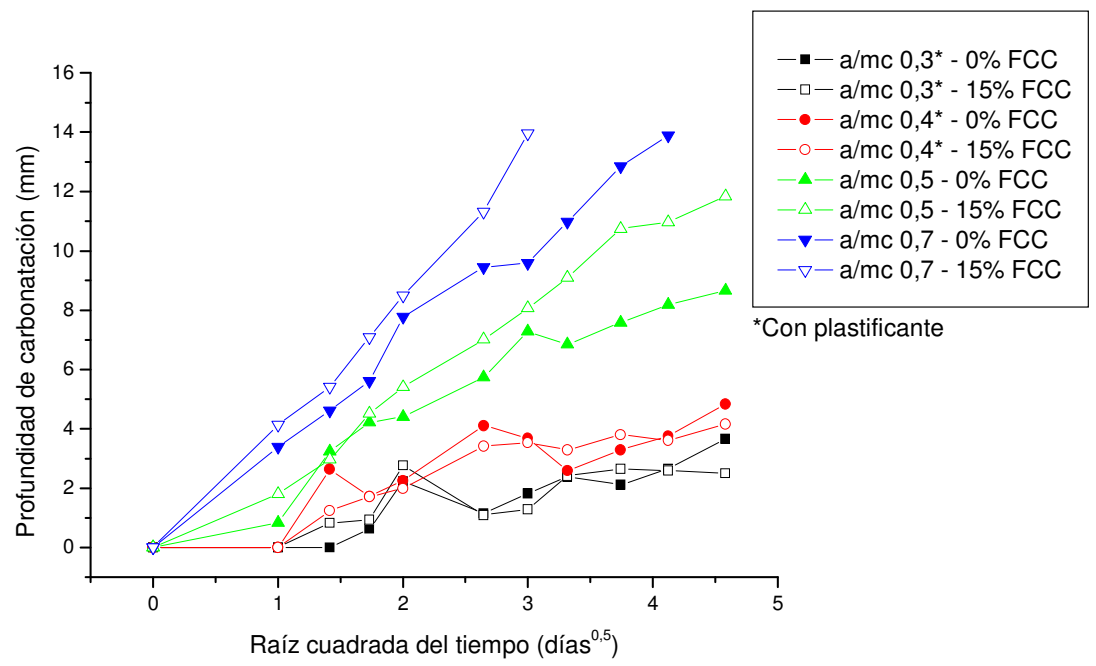

Figura 97. Dependencia lineal entre la profundidad de carbonatación y la raíz cuadrada del tiempo para mortero de cemento/FCC.

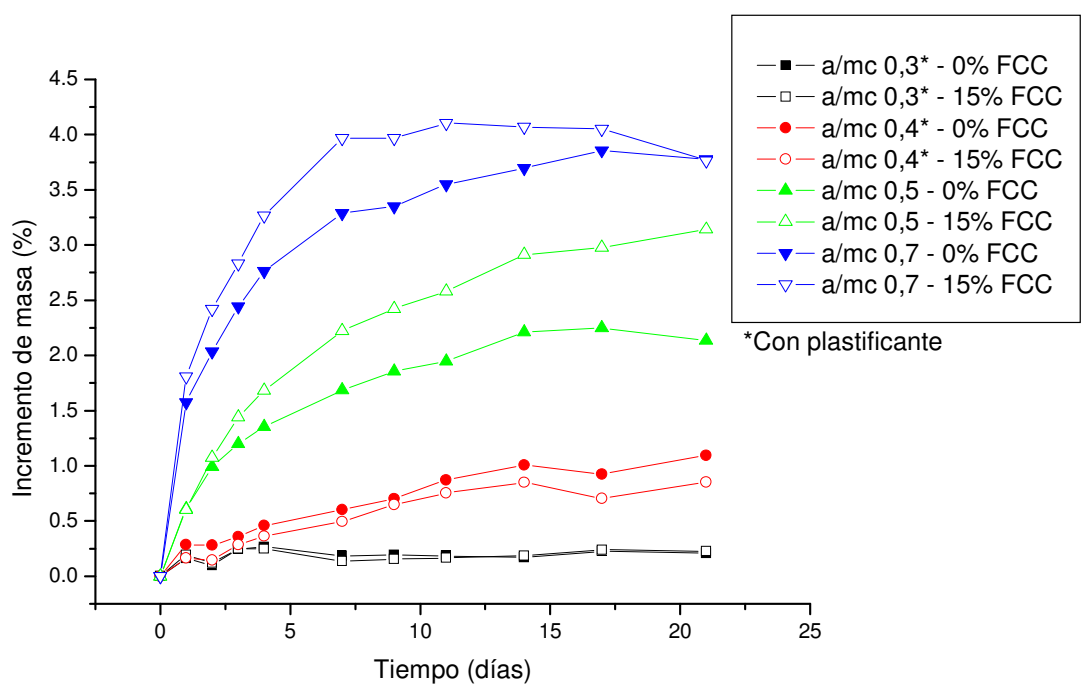

Figura 98. Evolución de la masa de los morteros durante el ensayo de carbonatación acelerada. 
Si se observa (Figura 98) cómo ha evolucionado la masa de los morteros durante el proceso, se aprecia una correlación muy fiel con los datos anteriores. En el caso del mortero con relación a/mc de 0,7 y $15 \%$ de FCC, el incremento de masa se ve detenido tras los 14 primeros días debido a que la carbonatación del mismo ha sido total.

Para los datos de incremento de masa también se ha podido establecer una relación lineal entre este incremento de la masa durante el proceso de carbonatación y la raíz cuadrada del tiempo (Figura 99).

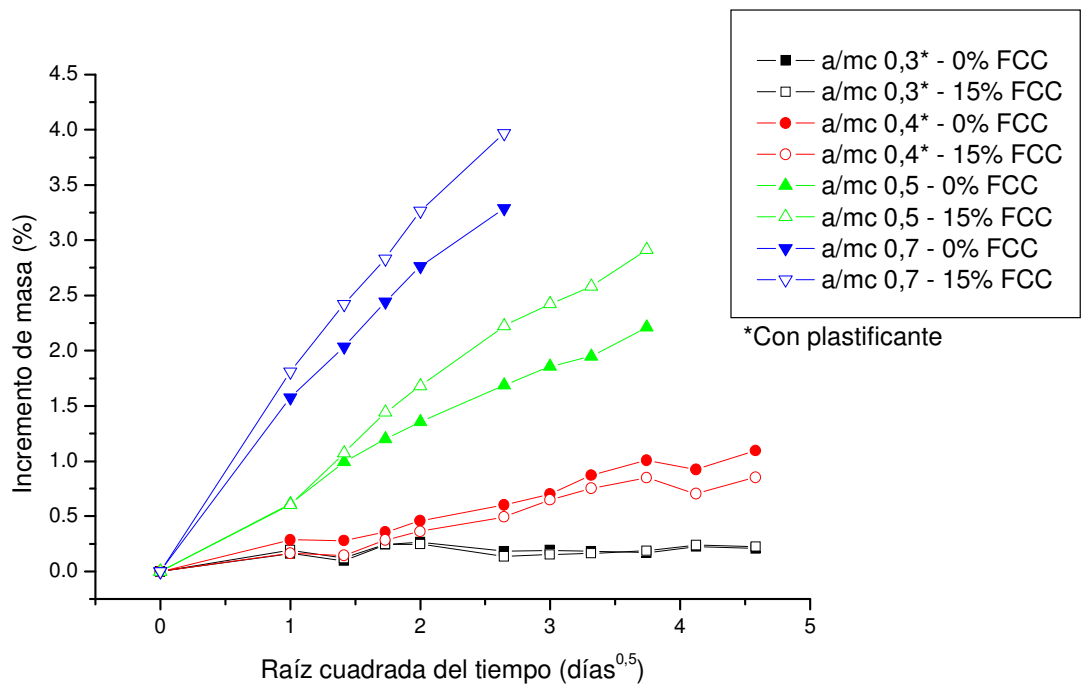

Figura 99. Dependencia lineal entre el incremento de masa y la raíz cuadrada del tiempo para morteros de cemento/FCC a lo largo del proceso de carbonatación.

Con los resultados obtenidos en los ensayos de profundidad de carbonatación se calcularon las velocidades de carbonatación de los morteros $\left(V_{\mathrm{CO} 2}\right)$ cuyos valores se muestran en la Tabla 17 y la Figura 100. Los intervalos presentados para cada valor se corresponden con el error típico de cada serie. En la Tabla 17 se puede apreciar claramente que cuanto mayor es la relación a/mc mayor es la velocidad de carbonatación de los morteros. Este hecho ha sido ampliamente descrito en la bibliografía $[91,125,127,130,131]$. 


\begin{tabular}{||c|c|c|c|c||}
\hline \hline \multirow{2}{*}{$\begin{array}{c}\text { SUSTITUCIÓN } \\
\text { FCC }\end{array}$} & \multicolumn{4}{|c|}{ RELACIÓN a/mc } \\
\cline { 2 - 5 } & $\mathbf{0 , 3}$ (plast.) & $\mathbf{0 , 4}$ (plast.) & $\mathbf{0 , 5}$ & $\mathbf{0 , 7}$ \\
\hline $0 \%$ & $12,4 \pm 1,2$ & $19,7 \pm 1,7$ & $39,3 \pm 1,4$ & $69,2 \pm 2,8$ \\
\hline $15 \%$ & $11,9 \pm 1,3$ & $18,8 \pm 1,0$ & $50,9 \pm 1,0$ & $92,5 \pm 6,2$ \\
\hline
\end{tabular}

Tabla 17. Velocidad de carbonatación en mm/año, ${ }^{0,5}$ de los morteros en el ensayo de carbonatación acelerada, calculada a partir de los datos de profundidad de carbonatación.

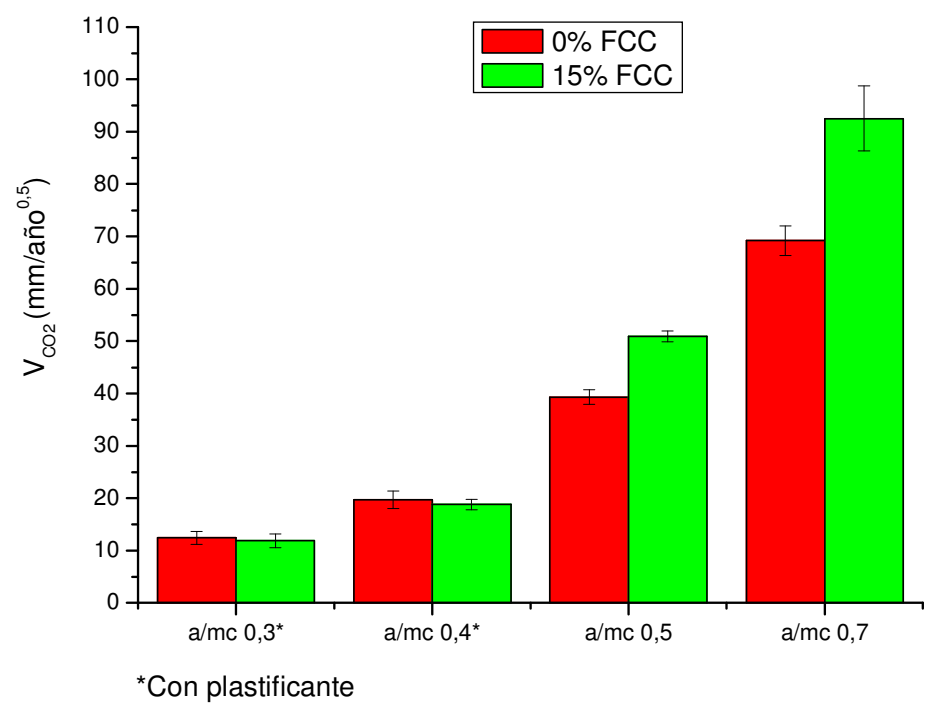

Figura 100. Velocidad de carbonatación de los morteros en el ensayo de carbonatación acelerada.

Análogamente se obtuvieron valores de velocidad de carbonatación, pero expresados esta vez en función del incremento de masa. Aunque el valor informativo de estos datos es limitado, sí que sirven para confirmar que el seguimiento de la masa del mortero también es representativo del avance del frente de carbonatación ya que sus tendencias son similares. Además, la obtención de estos datos es mucho más sencilla que la de la medición de la profundidad de carbonatación (Tabla 18). 


\begin{tabular}{||c|c|c|c|c||}
\hline \multirow{2}{*}{$\begin{array}{c}\text { SUSTITUCIÓN } \\
\text { FCC }\end{array}$} & \multicolumn{4}{|c||}{ RELACIÓN a/mc } \\
\cline { 2 - 5 } & $\mathbf{0 , 3}$ (plast.) & $\mathbf{0 , 4}$ (plast.) & $\mathbf{0 , 5}$ & $\mathbf{0 , 7}$ \\
\hline $0 \%$ & $1,17 \pm 0,16$ & $4,60 \pm 0,12$ & $11,82 \pm 0,26$ & $25,75 \pm 0,94$ \\
\hline $15 \%$ & $1,15 \pm 0,16$ & $3,74 \pm 0,17$ & $15,20 \pm 0,28$ & $30,53 \pm 0,89$ \\
\hline
\end{tabular}

Tabla 18. Velocidad de carbonatación en (incremento de masa porcentual)/año ${ }^{0,5}$ de los morteros en el ensayo de carbonatación acelerada, calculada a partir de los datos de incremento de masa.

En estos resultados se confirma que, para relaciones $\mathrm{a} / \mathrm{mc}$ bajas, el uso del residuo de FCC como sustitutivo de cemento en las dosificaciones empleadas no presenta problemas aparentes frente a un posible ataque por carbonatación. Sin embargo, en las relaciones a/mc medias y altas, el residuo de FCC puede aumentar la velocidad de carbonatación hasta en un $40 \%$.

Parece ser, por lo tanto, que la reducción en la portlandita de los poros del mortero es considerable cuando se sustituye parte del cemento por residuo de FCC y que la densificación que pueda producirse debido a la reacción puzolánica no compensa este fenómeno. En el caso de morteros con baja relación a/mc no se pone de manifiesto este fenómeno debido a que la conectividad de los poros es muy reducida y el $\mathrm{CO}_{2}$ tiene muy difícil su acceso al interior del mortero (ver más adelante la Figura 112 y Figura 113). Este comportamiento se ha puesto de manifiesto en otros estudios efectuados con otras puzolanas como las cenizas volantes y el metacaolín de forma sistemática [132-134].

En la Figura 101 se ha representado la velocidad de carbonatación de los morteros estudiados en función de la resistencia a compresión a 28 días de curado de los mismos. En ella se puede apreciar que existe una clara relación entre ambos parámetros debido a que ambos se encuentran fuertemente afectados por la porosidad de la matriz cementante $[125,129,127,133,135,136]$. Cuanto menor es la porosidad del mortero, mayor suele ser su resistencia a compresión ya que el material es más denso. Asimismo, cuanto menor es la porosidad del mortero, más impedida se encuentra la difusión del $\mathrm{CO}_{2}$ a través de la red de poros de la pasta. 


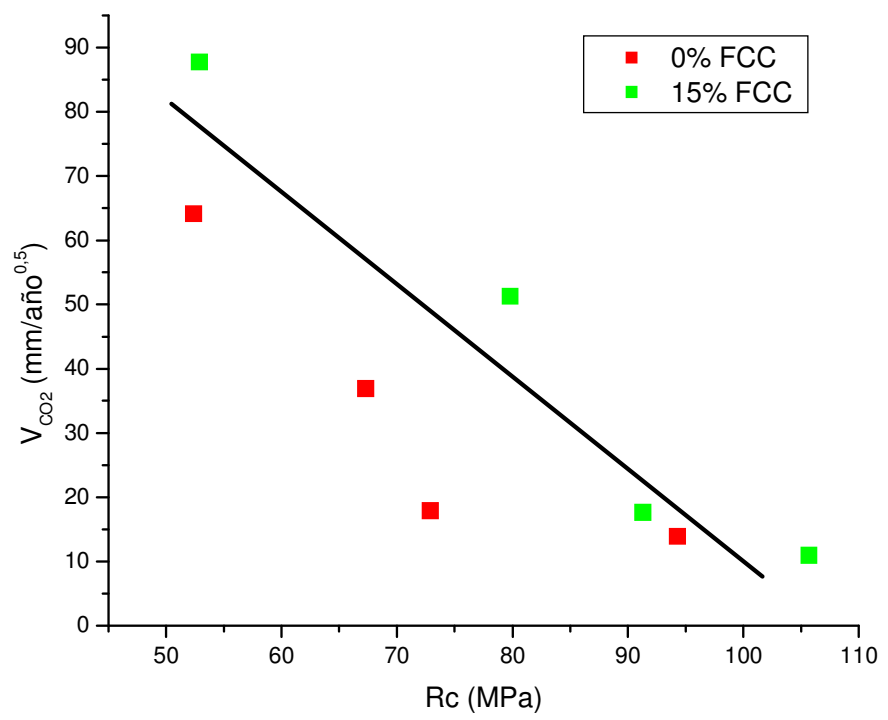

Figura 101. Relación entre la resistencia a compresión a 70 días de los morteros (Rc) y la velocidad de carbonatación en el ensayo de carbonatación acelerada $\left(\mathrm{V}_{\mathrm{CO} 2}\right)$.

A continuación se presentan las fotografías tomadas al final del proceso de carbonatación de los morteros (Figura 102, Figura 103, Figura 104 y Figura 105).
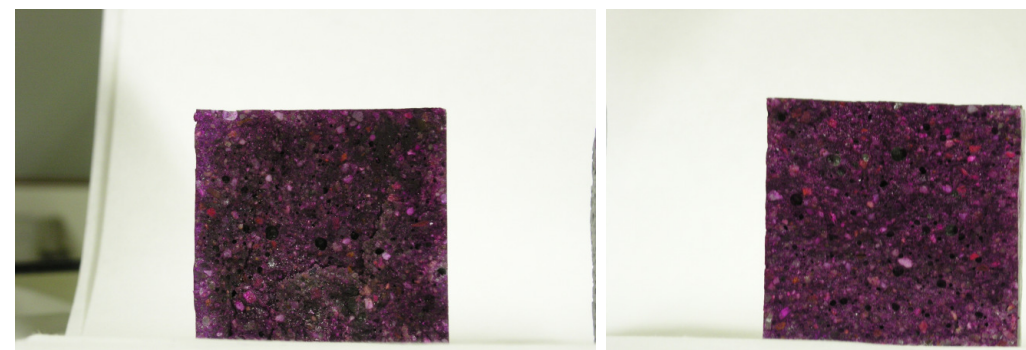

Figura 102. Fotografías de morteros tras la el proceso de carbonatación. Relación a/mc de 0,3 con plastificante. Izquierda: 0\% FCC; derecha: $15 \%$ FCC. 


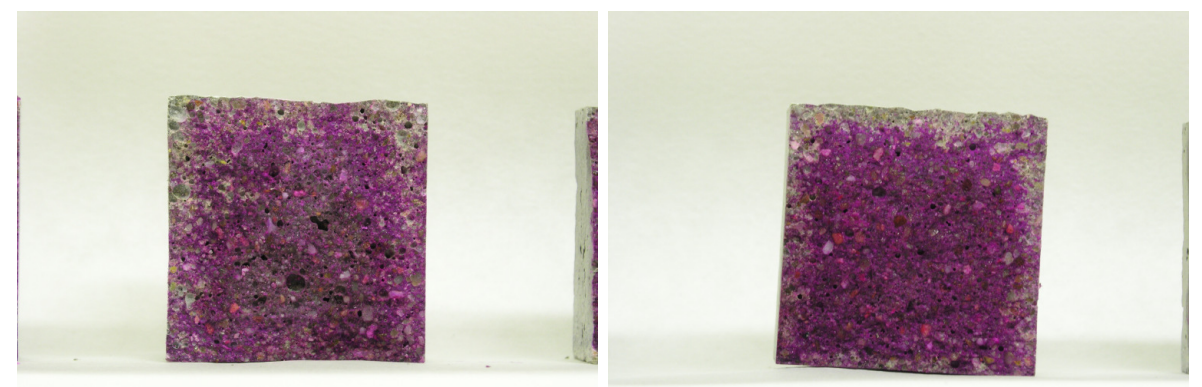

Figura 103. Fotografías de morteros tras la el proceso de carbonatación. Relación a/mc de 0,4 con plastificante. Izquierda: $0 \%$ FCC; derecha: $15 \%$ FCC.
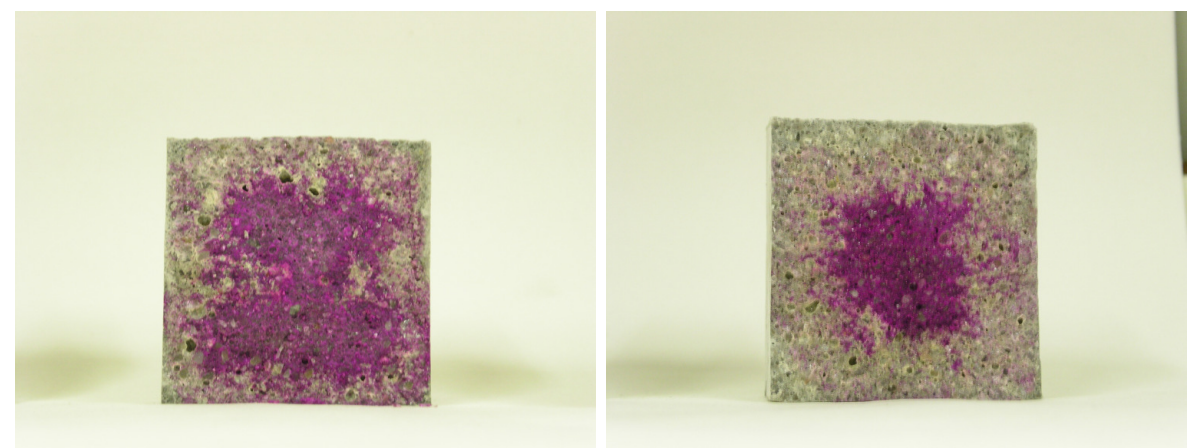

Figura 104. Fotografías de morteros tras la el proceso de carbonatación. Relación a/mc de 0,5. Izquierda: 0\% FCC; derecha: $15 \%$ FCC.
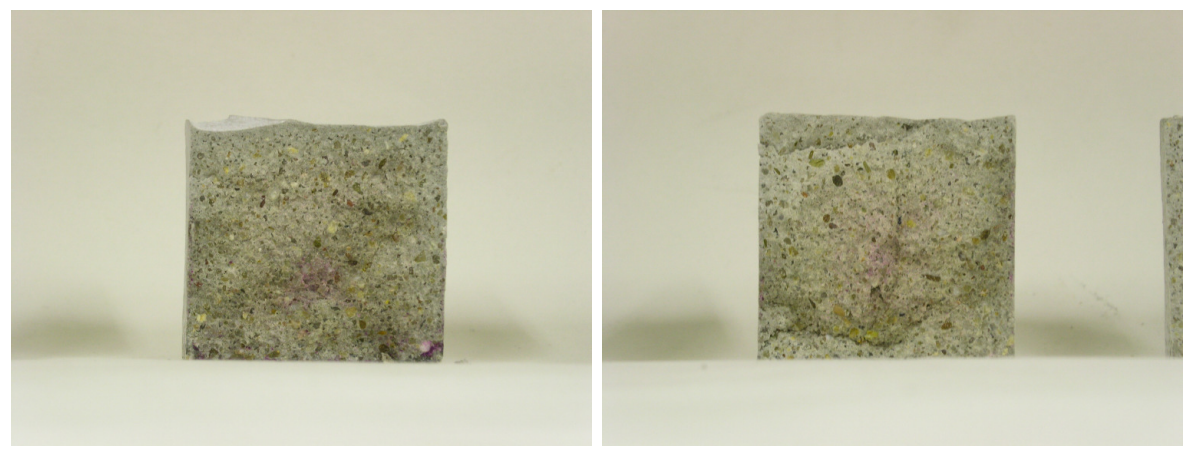

Figura 105. Fotografías de morteros tras la el proceso de carbonatación. Relación a/mc de 0,7. Izquierda: 0\% FCC; derecha: 15\% FCC. 
Puede apreciarse en estas fotografías que mientras que con una relación a/mc muy baja, la carbonatación apenas ha conseguido penetrar, en el caso de una relación muy alta la carbonatación ha sido completa.

Por último, en la siguiente secuencia de fotografías (Figura 106) se muestra cómo ha ido avanzando el frente de carbonatación en el mortero con una relación a/mc de 0,7 y $0 \%$ de residuo de FCC. Se ha elegido este mortero porque se evidencia más fácilmente cómo se produce este fenómeno.

Día 1
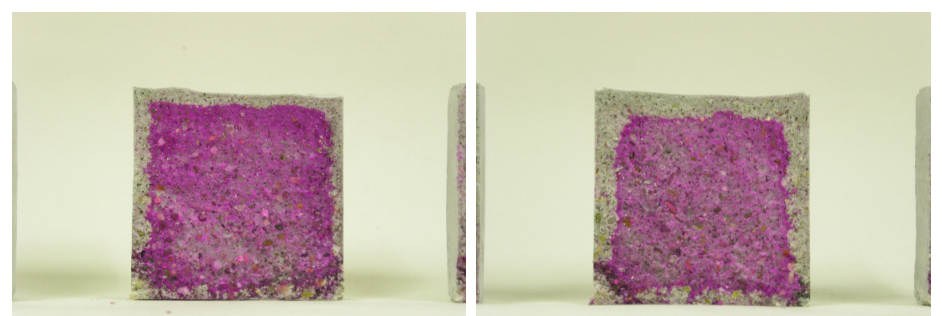

Día 2

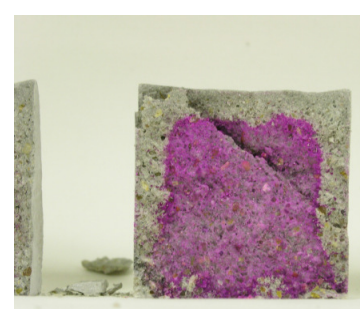

Día 3
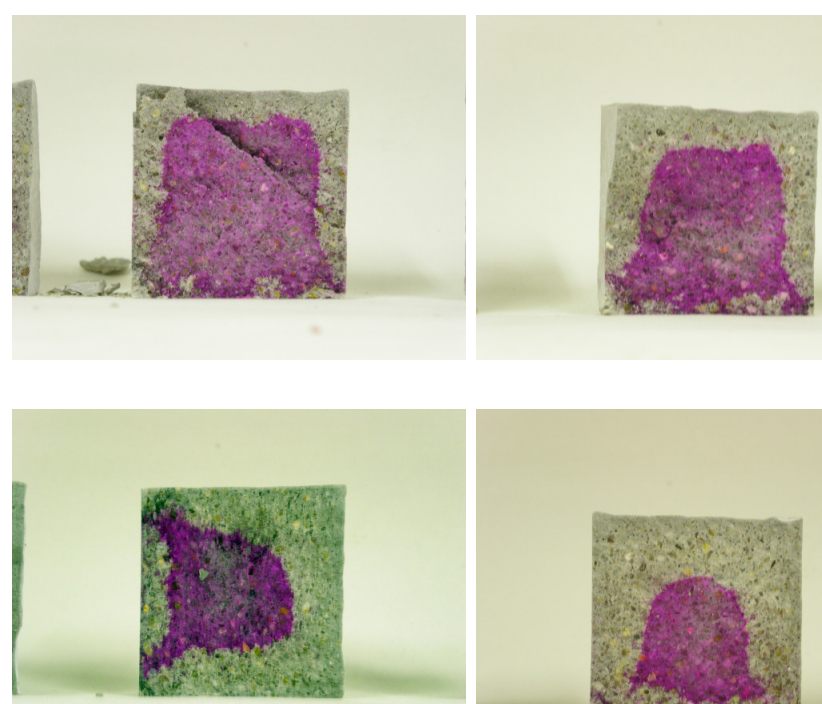

Día 7

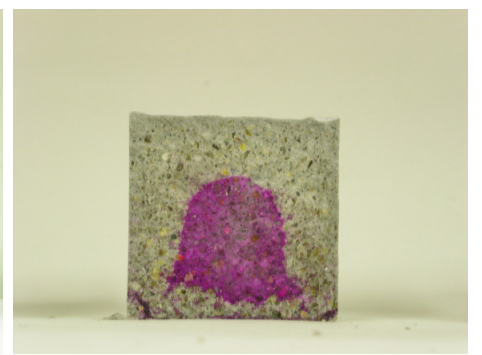

Día 4

Día 9 


\section{Día 11}

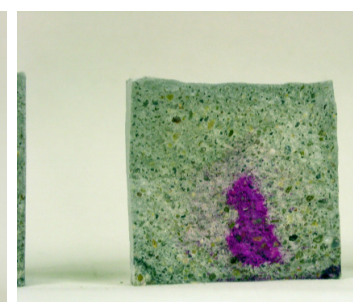

Día 14

Día 16
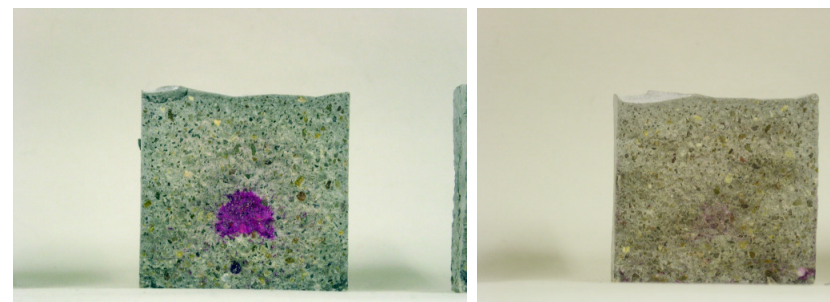

Figura 106. Fotografías de la evolución del frente de carbonatación a lo largo del ensayo de carbonatación acelerada. Mortero con relación a/me de 0,7 y 0\% de FCC.

En estas fotografías se aprecia que existe una cara en la que el frente de carbonatación es siempre inferior. Esta cara se corresponde con la opuesta a la cara de enrase y se debe a que la compactación que en ella se produce es mayor. Debido a la alta relación a/mc puede encontrarse algo de segregación y por ello la uniformidad del material no es constante.

\subsection{Efecto de la carbonatación en las propiedades mecánicas de los morteros}

En este apartado se expone cómo han variado las propiedades mecánicas de los morteros estudiados debido al proceso de carbonatación.

En las siguientes tablas se muestran los datos obtenidos para las resistencias a compresión de los morteros de referencia (sin carbonatar) y los morteros carbonatados a la edad de 70 días, de los cuales, 28 días fueron de curado en bajo agua, 21 días estuvieron en atmósfera del laboratorio a un 50\% de humedad relativa, y los 21 días 
restantes, o bien estuvieron embolsados (referencia), o bien en la cámara de carbonatación (carbonatados). El intervalo presentado en las tablas se corresponde con la desviación estándar de las 6 medidas tomadas para cada caso.

\begin{tabular}{||c|c|c|c|c||}
\hline \hline Rc (MPa) REFERENCIA & \multicolumn{4}{|c|}{ RELACIÓN a/mc } \\
\hline Sustitución FCC & $\mathbf{0 , 3}$ (plast.) & $\mathbf{0 , 4}$ (plast.) & $\mathbf{0 , 5}$ & $\mathbf{0 , 7}$ \\
\hline $0 \%$ & $94,3 \pm 3,8$ & $72,9 \pm 4,2$ & $67,3 \pm 3,2$ & $52,4 \pm 2,4$ \\
\hline $15 \%$ & $105,7 \pm 1,2$ & $91,3 \pm 3,1$ & $79,8 \pm 2,6$ & $52,9 \pm 1,0$ \\
\hline
\end{tabular}

Tabla 19. Resistencias a compresión en MPa de morteros de cemento/FCC sin carbonatar.

\begin{tabular}{|c|c|c|c|c||}
\hline \hline Rc (MPa) CARBONATADOS & \multicolumn{4}{|c|}{ RELACIÓN a/mc } \\
\hline Sustitución FCC & $\mathbf{0 , 3}$ (plast.) & $\mathbf{0 , 4}$ (plast.) & $\mathbf{0 , 5}$ & $\mathbf{0 , 7}$ \\
\hline $0 \%$ & $94,2 \pm 2,3$ & $77,9 \pm 3,8$ & $81,2 \pm 2,9$ & $74,5 \pm 2,4$ \\
\hline $15 \%$ & $103,8 \pm 3,8$ & $94,3 \pm 3,8$ & $93,3 \pm 4,5$ & $69,6 \pm 2,9$ \\
\hline
\end{tabular}

Tabla 20. Resistencias a compresión en MPa de morteros de cemento/FCC tras el proceso de carbonatación.

A continuación, se presenta una gráfica con las resistencias a compresión de los morteros carbonatados, otra con las de los morteros de referencia, y otra en la que se muestra la relación entre la resistencia a compresión de los morteros carbonatados y los morteros de referencia (Figura 107, Figura 108 y Figura 109, respectivamente). El intervalo de error se corresponde con la desviación estándar de las 6 medidas tomadas en cada caso.

En esta primera gráfica (Figura 107) se puede observar cómo en los morteros que han sufrido una carbonatación leve o moderada (aquellos con relación a/mc igual o inferior a 0,5), la contribución del residuo de FCC sigue siendo muy alta. En estos morteros el residuo de FCC sigue proporcionando resistencias a compresión superiores a los morteros sin sustitución por lo que la carbonatación no ha mermado selectivamente a los productos cementantes producidos por la reacción puzolánica del FCC. 


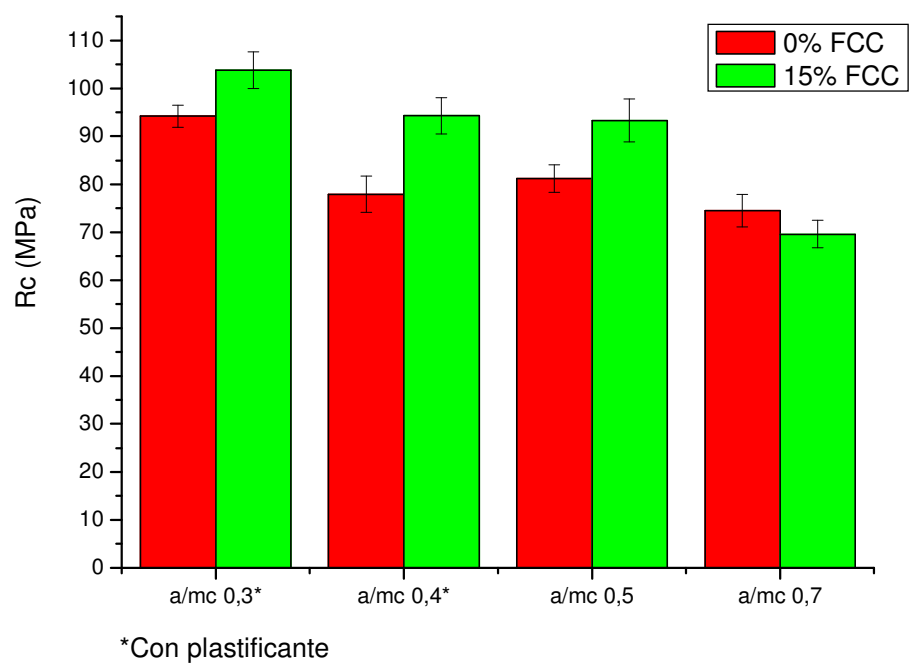

Figura 107. Resistencia a compresión de morteros tras el proceso de carbonatación acelerada.

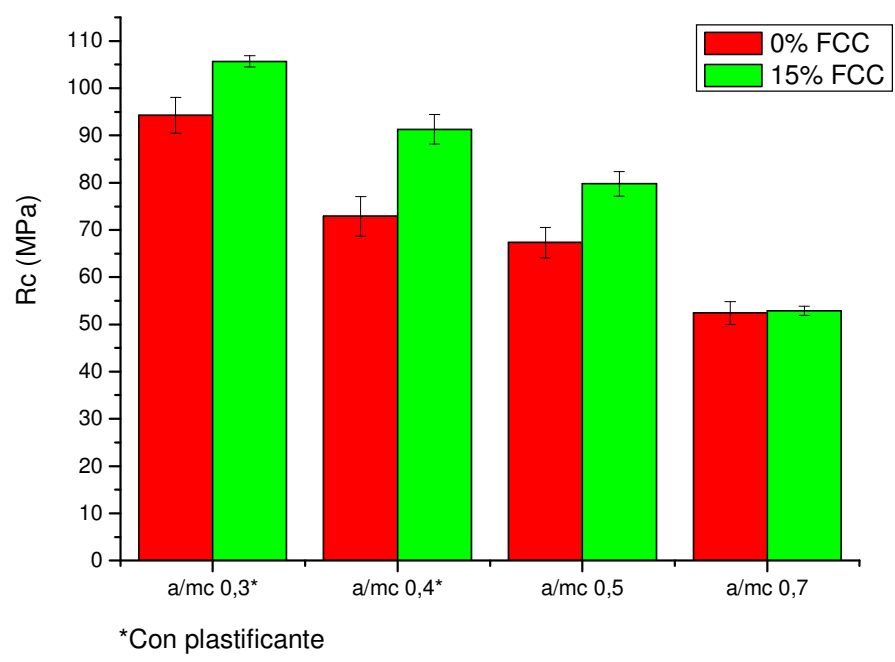

Figura 108. Resistencia a compresión de morteros antes del proceso de carbonatación acelerada. 
En el caso de la relación a/mc de 0,7 , la resistencia a compresión del mortero sustituido es inferior a la del mortero sin sustituir. En este caso particular la carbonatación ha sido mucho más agresiva (como se vio en el apartado anterior) con el mortero sustituido, pero la estructura del mortero sin FCC se ha densificado más, ya que la mayor cantidad de portlandita que contiene hace que se forme más carbonato cálcico. Por eso se puede observar que la carbonatación produce un mayor incremento de la resistencia a compresión del mortero que no incorpora FCC.

En la Figura 109 puede observarse cómo influye la carbonatación en las propiedades mecánicas. Cuando la carbonatación ha sido muy leve (relación a/mc 0,3) apenas se modifica el valor de resistencia a compresión. En cambio, a medida que el mortero se ha carbonatado más (relaciones a/mc crecientes), se produce un aumento significativo en la resistencia a compresión de los morteros. Por ello los aumentos son superiores en los morteros con relación a/mc mayor. Este fenómeno ha sido evidenciado en estudios realizados previamente por otros autores [39,100,114,137], aludiendo a la densificación que se produce en el material como consecuencia de la formación del carbonato cálcico en los poros del mortero.

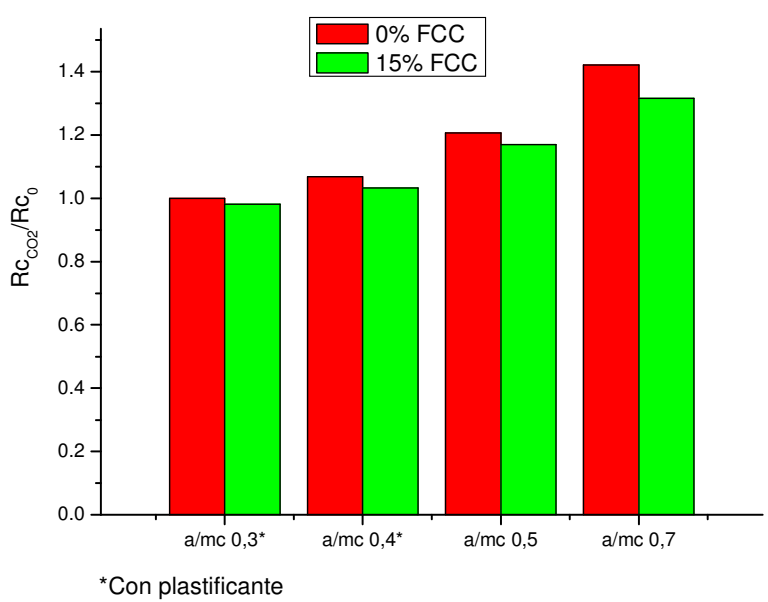

Figura 109. Relación de resistencias a compresión entre los morteros tras el proceso de carbonatación acelerada $\left(\operatorname{Rc}_{\mathrm{CO} 2}\right)$ y los morteros de referencia $\left(\mathbf{R c}_{0}\right)$. 
Destaca, sin embargo, que en todos los casos los incrementos son mayores en los morteros sin sustitución, a pesar de que su carbonatación es igual o inferior a la de los morteros con residuo de FCC. Este hecho puede estar relacionado con la menor cantidad de portlandita existente en los poros del mortero con residuo de FCC [124]. El que la penetración del frente de carbonatación sea más rápida no implica que se formen más productos de carbonatación $\left(\mathrm{CaCO}_{3}\right)$, sino todo lo contrario. Al existir menos cantidad de portlandita, el avance del frente de carbonatación es más rápido y la cantidad de carbonato cálcico que deja a su paso es inferior, por lo que la densificación del material como consecuencia de la carbonatación es menor en el caso de los morteros con residuo de FCC, y por ello el aumento de resistencia a compresión por este fenómeno también.

En las siguientes tablas se muestran los datos obtenidos para las resistencias a flexotracción de los morteros de referencia (sin carbonatar) y los morteros carbonatados a la edad de 70 días, de los cuales, 28 días fueron de curado en bajo agua, 21 días estuvieron en atmósfera del laboratorio a un 50\% de humedad relativa, y los 21 días restantes, o bien estuvieron embolsados (referencia), o bien en la cámara de carbonatación (carbonatados). El intervalo presentado en las tablas se corresponde con la desviación estándar de las 3 medidas tomadas para cada caso.

\begin{tabular}{||c|c|c|c|c||}
\hline \hline Rf (MPa) REFERENCIA & \multicolumn{4}{|c|}{ RELACIÓN a/mc } \\
\hline Sustitución FCC & $\mathbf{0 , 3}$ (plast.) & $\mathbf{0 , 4}$ (plast.) & $\mathbf{0 , 5}$ & $\mathbf{0 , 7}$ \\
\hline $0 \%$ & $12,5 \pm 0,7$ & $10,7 \pm 0,7$ & $10,9 \pm 1,3$ & $10,1 \pm 0,3$ \\
\hline $15 \%$ & $11,1 \pm 0,4$ & $11,0 \pm 0,4$ & $11,1 \pm 0,6$ & $8 \pm 0,7$ \\
\hline
\end{tabular}

Tabla 21. Resistencias a flexotracción en MPa de los morteros de cemento/FCC de referencia sin carbonatar. 


\begin{tabular}{||c|c|c|c|c||}
\hline Rf (MPa) CARBONATADOS & \multicolumn{4}{|c||}{ RELACIÓN a/mc } \\
\hline Sustitución FCC & $\mathbf{0 , 3}$ (plast.) & $\mathbf{0 , 4}$ (plast.) & $\mathbf{0 , 5}$ & $\mathbf{0 , 7}$ \\
\hline $0 \%$ & $8,9 \pm 0,5$ & $9,3 \pm 0,1$ & $6,0 \pm 0,7$ & $10,3 \pm 1,0$ \\
\hline $15 \%$ & $9,7 \pm 0,3$ & $10,9 \pm 0,4$ & $7,2 \pm 0,6$ & $8,7 \pm 1,0$ \\
\hline
\end{tabular}

Tabla 22. Resistencias a flexotracción en MPa de los morteros de cemento/FCC tras el proceso de carbonatación.

A continuación, se presenta una gráfica con las resistencias a flexotracción de los morteros carbonatados y otra en la que se muestra la relación entre la resistencia a flexotracción de los morteros carbonatados y los morteros de referencia (Figura 110 y Figura 111, respectivamente). El intervalo de error se corresponde con la desviación estándar de las 3 medidas tomadas en cada caso.

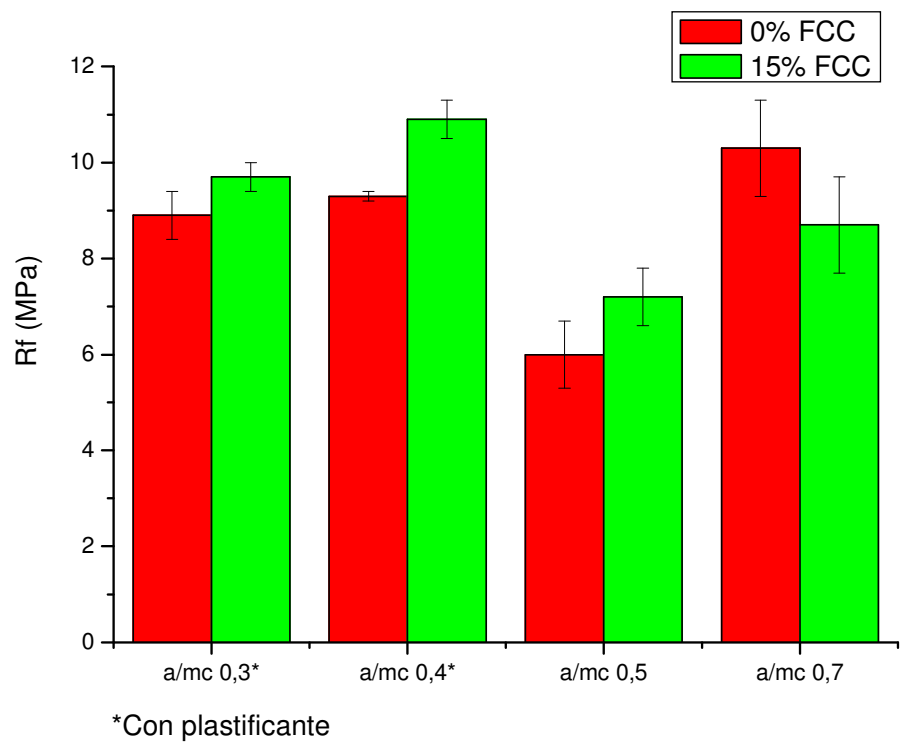

Figura 110. Resistencia a flexotracción de los morteros tras el proceso de carbonatación acelerada.

En la Figura 110 se aprecia el mismo comportamiento que el exhibido en la de resistencia a compresión. En la relación a/mc de 
0,7, el mortero sin sustituir ofrece un valor de resistencia a flexotracción superior al mortero con residuo de FCC. En las restantes ocurre lo contrario. Destaca, además el valor anormalmente alto ofrecido por el mortero con relación a/mc de 0,7 . El porqué de este resultado podrá entenderse observando la Figura 111, en la que se muestran las relaciones entre las resistencias a flexotracción de los morteros tras el proceso de carbonatación con las de los morteros de referencia.

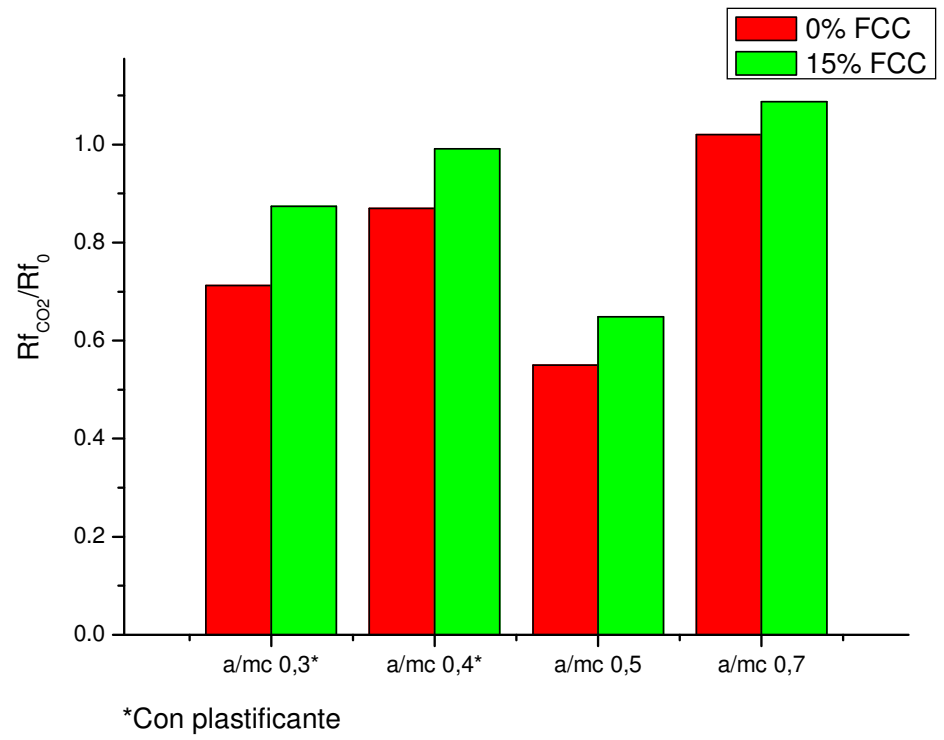

Figura 111. Relación de resistencias a flexotracción entre los morteros tras el proceso de carbonatación acelerada $\left(\mathbf{R f}_{\mathrm{CO}_{2}}\right)$ y los morteros de referencia $\left(\mathbf{R f}_{\mathbf{0}}\right)$.

En esta gráfica (Figura 111) la tendencia es opuesta la observada en la análoga correspondiente a la resistencia a compresión (Figura 109), es decir, los morteros sustituidos con FCC ofrecen relaciones superiores. Además, en todos los casos excepto para la relación a/mc de 0,7 , sus valores son inferiores a 1 lo que implica que la carbonatación ha perjudicado esta propiedad mecánica. Como hemos comentado anteriormente, cuando un mortero se carbonata se produce una densificación de su microestructura que proporciona mayores resistencias a compresión. Sin embargo, esta densificación 
originada por el crecimiento de cristales de carbonato cálcico en el material, acarrea también esfuerzos a tracción por el impedimento que representan las paredes de los poros al crecimiento de estos cristales. Estos esfuerzos residuales producen que la resistencia a flexotracción que pueda soportar el material sea inferior, puesto que ya está sometido a tensión antes de comenzar a cargar la probeta. Por ello cuanto más compacto es el mortero y cuanto mayor es la cantidad de carbonato cálcico por unidad de volumen que se genera en el mismo, mayores son los esfuerzos que se producen y más acusada es la caída de resistencia a flexotracción.

Por esta razón, el mortero con relación a/mc 0,7 es el que menos caída experimenta por causa de la carbonatación, ya que es el más poroso. Esto también explica que los morteros sustituidos tengan menores caídas, ya que al tener menos portlandita por unidad de volumen, también generan menos cantidad de carbonato cálcico por unidad de volumen, y por ello las tensiones que han de soportar como consecuencia de la carbonatación son inferiores. El hecho de que el mortero con relación a/mc de 0,5 sufra la caída más fuerte se explica por la convergencia de dos factores: primero, la carbonatación penetra más en él que en los morteros con menor relación a/mc; y segundo, no es tan poroso como el de relación a/mc de 0,7 como para que los cristales de carbonato cálcico puedan crecer sin tensionar el material.

Estos datos referentes a las propiedades mecánicas de los morteros carbonatados y sin carbonatar se pueden relacionar con los datos obtenidos mediante termogravimetría que se han presentado en la sección 3.1. En estos últimos se observaba que la carbonatación producía modificaciones en la composición de la matriz cementante. En concreto, el carbonato cálcico podía formarse a través de la captura del calcio de las fases de CSH, CAH y CASH, una vez que se había consumido la portlandita. Se puede comprobar ahora que estos cambios observados no producen merma de las propiedades mecánicas, especialmente en lo que a resistencia a compresión se refiere.

También se ha podido analizar cómo varían otras propiedades como la densidad del mortero y la porosidad total debido al proceso de carbonatación efectuado sobre las muestras. 
En la Figura 112 se muestran las densidades de los morteros carbonatados y los morteros de referencia. Como se esperaba, las mayores variaciones ocurren en aquellos morteros que han sufrido una mayor carbonatación, es decir, los de relaciones a/mc de 0,5 y 0,7 . En cambio, los morteros con las otras relaciones a/mc apenas sufren variaciones puesto que las transformaciones debidas a la carbonatación son muy pequeñas en ellos. Las densidades son superiores cuanto menor es la relación $\mathrm{a} / \mathrm{mc}$ en los morteros sin carbonatar.

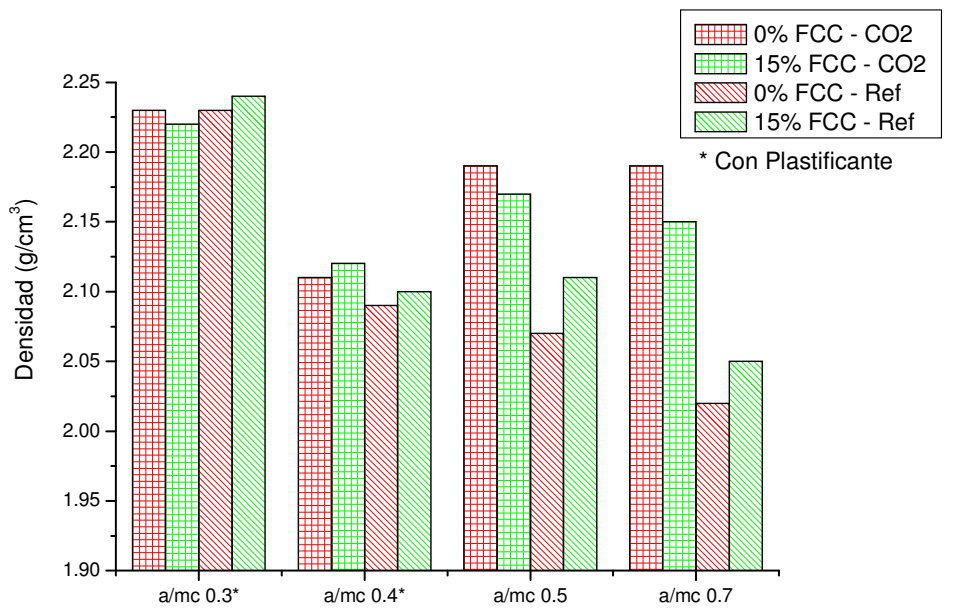

Figura 112. Densidades de los morteros tras el proceso de carbonatación y los morteros de referencia.

Por otro lado, también se aprecia que la carbonatación de los morteros produce una densificación del material como consecuencia de la precipitación del carbonato cálcico en los poros del mortero $[114,115]$. Esto puede relacionarse directamente con los cambios en resistencia a compresión que han tenido lugar en los morteros. Allí donde se ha producido un mayor aumento en la densidad del mortero también se ha producido un mayor aumento en la resistencia a compresión. Por ello se pueden relacionar directamente ambos resultados y concluir que este último es consecuencia de aquél. Otro fenómeno destacable es que la densidad de los morteros con sustitución de cemento por residuo de FCC es mayor que la de los 
morteros sin FCC, por lo que podemos achacar sus mayores valores de resistencia a la formación de una matriz cementante más resistente (disminución de la porosidad del CSH) debido a una densificación global producida por la reacción puzolánica.

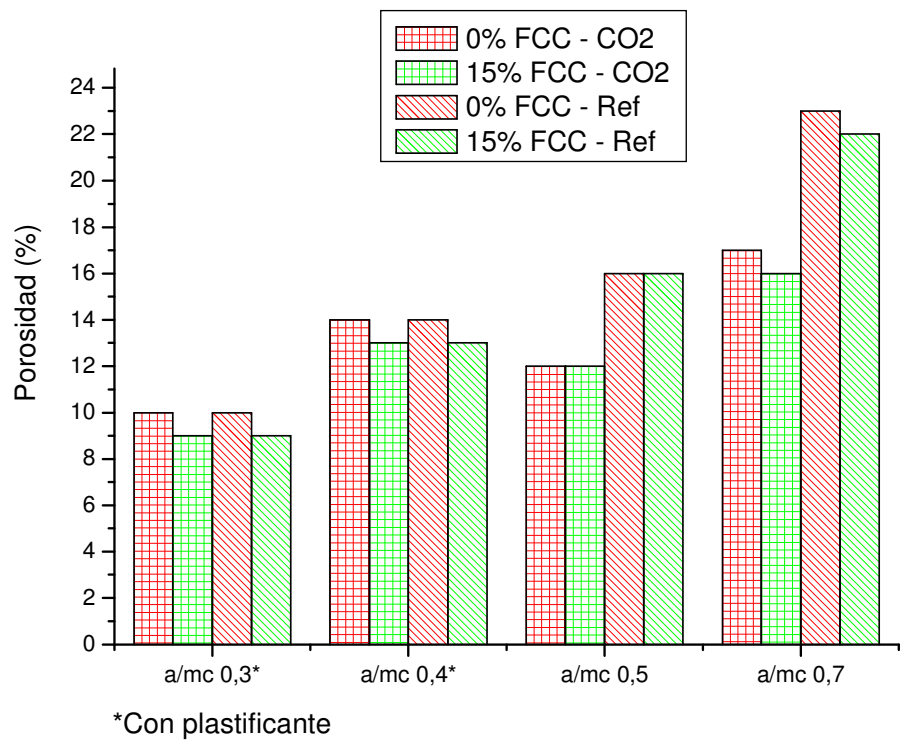

Figura 113. Porosidades de los morteros tras el proceso de carbonatación y los morteros de referencia.

Para finalizar, se muestra la Figura 113 que corresponde la porosidad total de los mismos morteros que han sido estudiados mediante pesada en balanza hidrostática. Los datos ofrecidos son análogos a los anteriores correspondientes a las densidades. Donde más ha progresado la carbonatación, mayor ha sido la reducción de la porosidad, es decir, en los morteros con relación a/mc de 0,5 y 0,7 . Los morteros que apenas se han carbonatado no muestran cambios evidentes en la porosidad (relación a/mc 0,3 y 0,4 con plastificante). Los cambios debidos a la sustitución de cemento por FCC también son similares a los que se pueden observar en los resultados de densidad: los morteros con FCC muestran una porosidad inferior a los morteros sin FCC. Este hecho concuerda con los resultados obtenidos mediante porosimetría por intrusión de mercurio. La evolución de la 
porosidad con la relación a/mc en los morteros de referencia (sin carbonatar), muestra que aquélla aumenta al aumentar ésta, tal y como se esperaba $[114,115]$.

\subsection{Conclusiones}

Las conclusiones que se pueden extraer de este estudio se han enumerado en los siguientes puntos:

- A medida que aumenta la relación a/mc se produce un aumento de la velocidad de carbonatación de los morteros como consecuencia de la mayor porosidad de los mismos.

- La sustitución de cemento por residuo de FCC produce un aumento de la velocidad de carbonatación para relaciones a/mc altas (0,5 o mayor) debido a una disminución de la reserva alcalina como consecuencia de la reacción puzolánica, que no es compensada por la densificación que pudiera originarse de la misma.

- No obstante, para relaciones a/mc de 0,3 ó 0,4 no se observan diferencias entre las velocidades de carbonatación de los morteros con un $15 \%$ de FCC y los que no lo incorporan.

- La carbonatación de los morteros produce un aumento de la resistencia a compresión de los mismos. Cuanto mayor es la cantidad de carbonato cálcico que se produce y la penetración del frente de carbonatación, mayor es este incremento.

- Los morteros con una sustitución del $15 \%$ de cemento por FCC siguen siendo más resistentes que los morteros control para relaciones a/mc iguales o inferiores a 0,5 .

- La carbonatación de los morteros produce una disminución de la resistencia a flexotracción de los mismos. Cuanto mayor es la porosidad y menor es la cantidad de carbonato cálcico generado por unidad de volumen, menor es esta caída como consecuencia de una estructura porosa más abierta que ofrece 
espacio al carbonato cálcico para depositarse sin tensionar el material.

- La carbonatación de los morteros produce un aumento de la densidad de los mismos. Cuanto mayor es la carbonatación sufrida por el mortero, mayor es el aumento de la densidad. Los morteros carbonatados con FCC muestran densidades ligeramente inferiores a los morteros sin sustitución.

- La carbonatación de los morteros produce una reducción de la porosidad. La mayor carbonatación se ve reflejada en una mayor reducción de la porosidad.

- En relaciones a/mc bajas, el FCC no afecta a las velocidades de carbonatación de los morteros mientras que sigue aportando un aumento importante de las propiedades mecánicas. 


\section{Estudio de la velocidad de corrosión de aceros embebidos en morteros mixtos de cemento-FCC sometidos a un ataque por carbonatación}

Una vez que se han estudiado las modificaciones que produce el FCC en las matrices cementantes de los morteros y el comportamiento de estas matrices frente a un ataque por carbonatación, se analiza ahora velocidad de corrosión de aceros embebidos en estas matrices sometidas a un ataque por carbonatación. En primer lugar se presentan los resultados obtenidos en distintas humedades relativas para, a continuación, someter las probetas a un ataque por carbonatación. 


\subsection{Diseño experimental}

\subsubsection{Materiales usados y elaboración de probetas}

Para el estudio realizado se han fabricado distintas probetas de mortero de dimensiones $2 \times 6 \times 8 \mathrm{~cm}$ con barras de acero liso de $8 \mathrm{~mm}$ de diámetro embebidas en su interior (Figura 114), cuyo diseño ha sido empleado anteriormente [140]. El cemento empleado en la fabricación es tipo CEM I 52,5 R. La arena empleada es arena normalizada [138] y el agua de amasado es agua corriente. Se han aplicado las siguientes relaciones a/mc: $0,4,0,5,0,6$ y $0,7 \mathrm{sin}$ plastificante, y 0,3 y 0,4 con plastificante. La relación arena/mc ha sido 3/1. Las dosificaciones de FCC como sustitución de cemento han sido $0 \%, 5 \%, 10 \%, 15 \%$ y $20 \%$ con respecto al peso de cemento. Los morteros se han amasado siguiendo la norma EN 1015-2 [139]. En los morteros se han embebido tres electrodos: dos de acero para monitorizar su corrosión y un tercero de grafito como contralelectrodo para poder realizar las medidas de velocidad de corrosión.

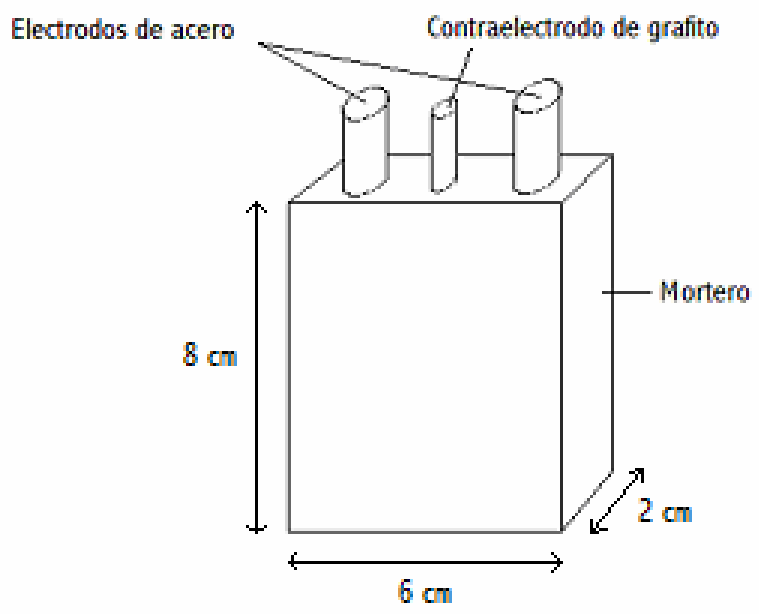

Figura 114. Probeta empleada en las medidas de corrosión. 


\subsubsection{Conservación de las probetas}

Las probetas se han mantenido en los siguientes ambientes tras su amasado. En primer lugar se almacenaron en cámara húmeda (100\% HR) para asegurar un correcto curado y se monitorizó su corrosión durante 190 días. Seguidamente fueron sometidas a distintas humedades relativas para estudiar cómo afectaba este parámetro a la velocidad de corrosión de los aceros. Para ello fueron almacenadas en los siguientes ambientes: $40 \%$ y $80 \%$ de HR durante 100 días y 85 días, respectivamente. El tiempo de permanencia en cada condición ambiental se estableció de forma que se alcanzara un nivel de corrosión estable en cada tipo de ambiente. Tras ello, se conservaron en un ambiente de $5 \%$ de $\mathrm{CO}_{2}$ a una humedad relativa del $65 \pm 5 \%$ durante 71 días. Posteriormente se sometieron a una carbonatación más agresiva en un ambiente del $100 \%$ de $\mathrm{CO}_{2}$ a una humedad relativa del $65 \pm 5 \%$ durante 40 días. La elección de la humedad relativa en el proceso de carbonatación se fijó de forma que la carbonatación fuera lo más rápida posible $[91,124]$. Tras todo ello se volvieron a introducir las probetas en un ambiente del $100 \%$ de HR para dejar que evolucionara la velocidad de corrosión en un ambiente con una concentración de oxígeno superior a la que existía en la cámara de carbonatación.

\subsubsection{Medida de la velocidad de corrosión}

Los parámetros elegidos para evaluar la corrosión de los aceros embebidos han sido el potencial de corrosión (Ecorr) y la velocidad de corrosión (Icorr). Los potenciales de corrosión han sido medidos frente a un electrodo de calomelanos saturado (SCE). La medida de Icorr se ha efectuado mediante la técnica de resistencia a la polarización [141] mediante un potenciostato EG\&G modelo 362 de Princetone Applied Research. Los barridos se potencial se han realizado desde $-10 \mathrm{mV}$ hasta $+10 \mathrm{mV}$ respecto del potencial de corrosión (Ecorr) a una velocidad de $0,5 \mathrm{mV} / \mathrm{s}$. El valor de $B$ de la ecuación de Stern-Geary que se utiliza para calcular la Icorr oscila entre 13 y $52 \mathrm{mV}$ para el acero en el hormigón [141]. Normalmente se opta por tomar este valor como $26 \mathrm{mV}$ y aceptar que existe un error de factor 2 en las medidas realizadas [142]. 
Una vez finalizadas todas las etapas del estudio se extrajeron los electrodos de las probetas y se limpiaron mediante una disolución de hexametiltetramina en $\mathrm{HCl} 1 \mathrm{M}$ para eliminar todos los óxidos de hierro adheridos a la superficie de los electrodos y mediante acetona, para eliminar los restos de pegamento de la cinta adhesiva utilizada para limitar el área de electrodo expuesta. Se pesaron los electrodos y se contrastó la pérdida de masa gravimétrica con la pérdida de masa electroquímica. La pérdida de masa gravimétrica se obtiene mediante la diferencia de masa de los electrodos entre el inicio y el final de estudio. La pérdida de masa electroquímica se obtiene a través de la integral de la intensidad de corrosión en función del tiempo, y aplicando la ley de Faraday.

\subsection{Influencia de la relación a/mc}

En la Figura 115 y Figura 116 se presenta la evolución de los potenciales y la velocidad de corrosión de los aceros embebidos en morteros con distintas relaciones a/mc para una sustitución de FCC del $0 \%$ y del $15 \%$, respectivamente, y conservadas en una humedad relativa del $100 \%$. En estas figuras y en las siguientes se observa una banda que comprende el intervalo de velocidad de corrosión entre 0,1 y $0,2 \mu \mathrm{A} / \mathrm{cm}^{2}$. Esta banda se corresponde con el umbral que separa lo que sería una corrosión activa (por encima de $0,2 \mu \mathrm{A} / \mathrm{cm}^{2}$ ) de una corrosión despreciable (por debajo de $0,1 \mu \mathrm{A} / \mathrm{cm}^{2}$ ) [143], aunque en la bibliografía también se han adoptado otros criterios [144]. No obstante todos coindicen en señalar como umbral de inactividad el valor de 0,1 $\mu \mathrm{A} / \mathrm{cm}^{2}$.

Tanto en el caso de morteros con FCC como en el de morteros sin FCC se aprecia que los valores de corrosión se han mantenido durante esta etapa del proceso en la zona de corrosión inactiva. Es decir, para estas condiciones no se aprecia que la relación a/mc influya en el nivel de corrosión de las armaduras. En cuanto a los potenciales de corrosión, se pueden observar diferencias entre las distintas relaciones $\mathrm{a} / \mathrm{mc}$. No obstante, el potencial de corrosión es un parámetro termodinámico, no cinético, que indica la posibilidad de que se produzca un proceso, pero no informa de su velocidad [145]. Por ello, aunque existan diferencias, tanto en los morteros con FCC como los que no lo incorporan, ésto no ha afectado a las velocidades 
de corrosión. Por lo tanto, se puede afirmar que la incorporación de FCC en estas relaciones a/mc y a una humedad relativa del $100 \%$, no afecta significativamente a la velocidad de corrosión. Además, el hecho de que las probetas se mantuvieran a una humedad relativa del $100 \%$ puede producir que la oxidación de los aceros esté controlada catódicamente por la difusión de oxígeno hacia su interior [146,147], aunque sería prematuro en este caso atribuirlo a este fenómeno, dado que todavía no se ha producido la despasivación de las armaduras.

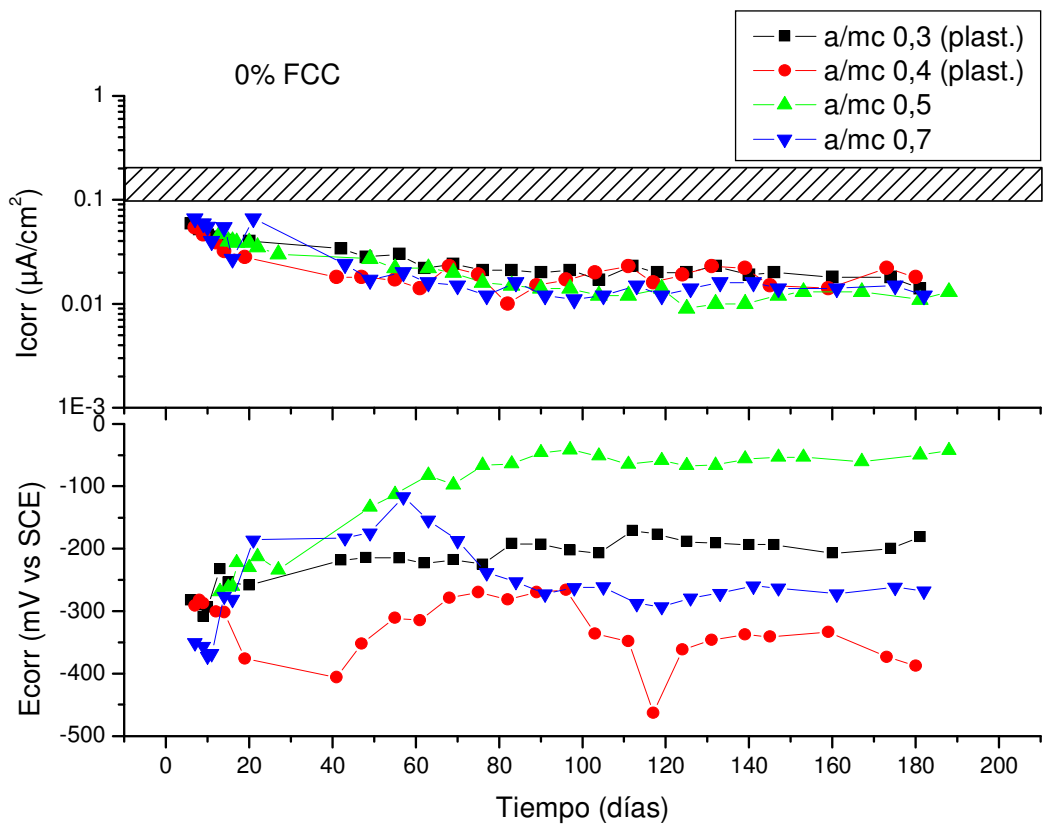

Figura 115. Velocidad de corrosión y potencial de corrosión de acero para distintas relaciones a/me en morteros con 0\% de FCC. Conservación en 100\% de HR.

Cabe destacar que, aunque no se ha representado en estas gráficas, en la relación a/mc de 0,4 sin plastificante sí que se observa un mayor nivel de corrosión. Esto se debe a que la porosidad del mortero con relación a/mc 0,4 es muy superior a la del resto de morteros. Esta mayor porosidad está originada por la falta de 
trabajabilidad de estos morteros que no permite una compactación adecuada con los medios mecánicos utilizados.

En la bibliografía [148] se encuentra descrito que el aumento de la relación a/mc produce un aumento de la difusión de oxígeno lo cual puede provocar un aumento de la velocidad de corrosión. En este caso no se aprecian diferencias entre las distintas relaciones a/mc debido probablemente, a que la elevada humedad relativa no deja traslucir diferencias en la difusión de oxígeno.

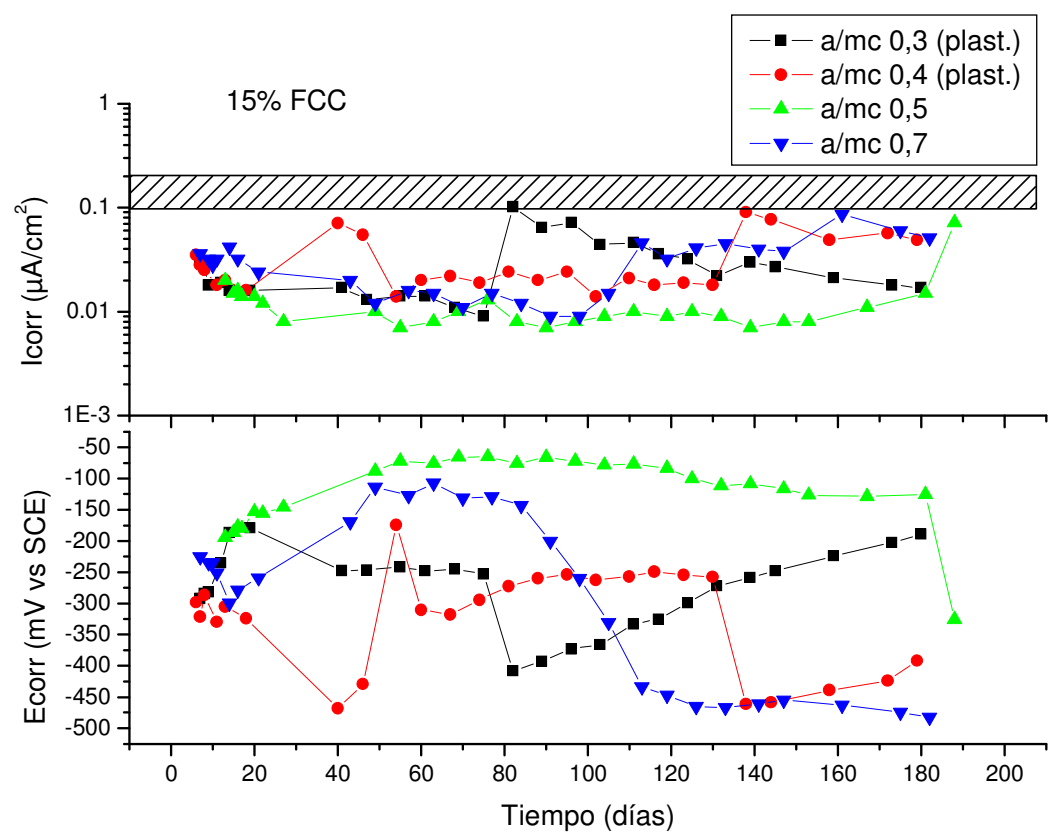

Figura 116. Velocidad de corrosión y potencial de corrosión de aceros para distintas relaciones a/mc en morteros con $15 \%$ de FCC. Conservación en $100 \%$ de HR.

\subsection{Influencia del porcentaje de sustitución de FCC}

En la Figura 117 se representan los valores de velocidad de corrosión y de potencial de corrosión para los morteros con distintas sustituciones de FCC con una relación a/mc de 0,5 y usando como 
medio una humedad relativa del $100 \%$. En este caso se observa que para todos los niveles de sustitución estudiados (5-20\%), la velocidad de corrosión se mantiene dentro de la zona inactiva, excepto para la sustitución superior del 20\%. Para este mortero en particular el nivel de corrosión se sitúa en la zona de transición de corrosión. Este fenómeno se produce debido a la elevada demanda de agua del FCC $[77,80]$. Esto provoca que cuando se usa una sustitución tal alta, la porosidad del mortero aumente debido a la falta de trabajabilidad del mismo, lo cual conduce a una pobre compactación. Observando la parte correspondiente al potencial de corrosión se aprecia que existe una analogía clara entre ambas figuras, siendo el potencial del acero embebido en el mortero con un $20 \%$ de FCC el que registra potenciales más negativos. Según la norma americana ASTM C876 [149], los aceros con potenciales de corrosión por debajo de $-426 \mathrm{mV}$ vs SCE tienen un elevado riesgo de corrosión severa. En este caso, los aceros correspondientes al mortero con $20 \%$ de FCC cumplirían con dicha estadística.

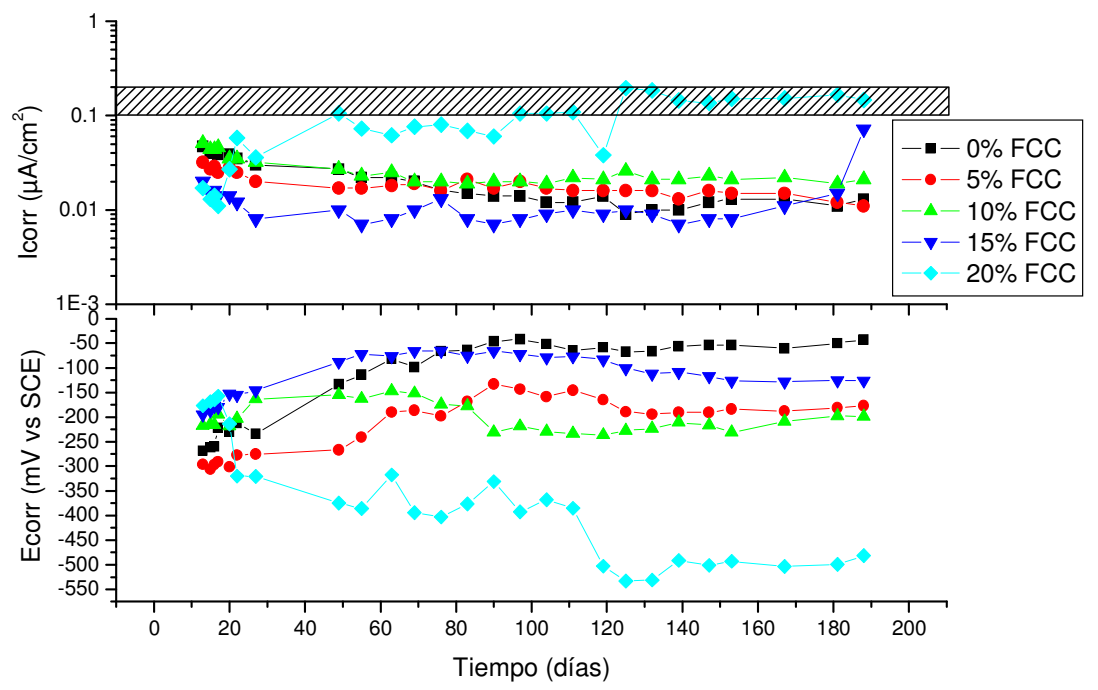

Figura 117. Velocidad de corrosión y potencial de corrosión de aceros para distintas sustituciones de FCC en morteros. Conservación en $100 \%$ de HR y relación a/me de 0,5 . 
En la Figura 118 y Figura 119 se representan los valores de velocidad de corrosión y de potencial de corrosión para los morteros con distintas sustituciones de FCC con una relación a/mc de 0,3 con plastificante y 0,7 , respectivamente, usando como medio una humedad relativa del 100\%. En ambos casos los valores de velocidad de corrosión permanecen en la zona de inactividad de forma sostenida. Se observa que existen ciertos aceros que presentan leves incrementos de su velocidad de corrosión que van acompañados de descensos en los potenciales de corrosión que pueden deberse a algún defecto en el mortero de recubrimiento.

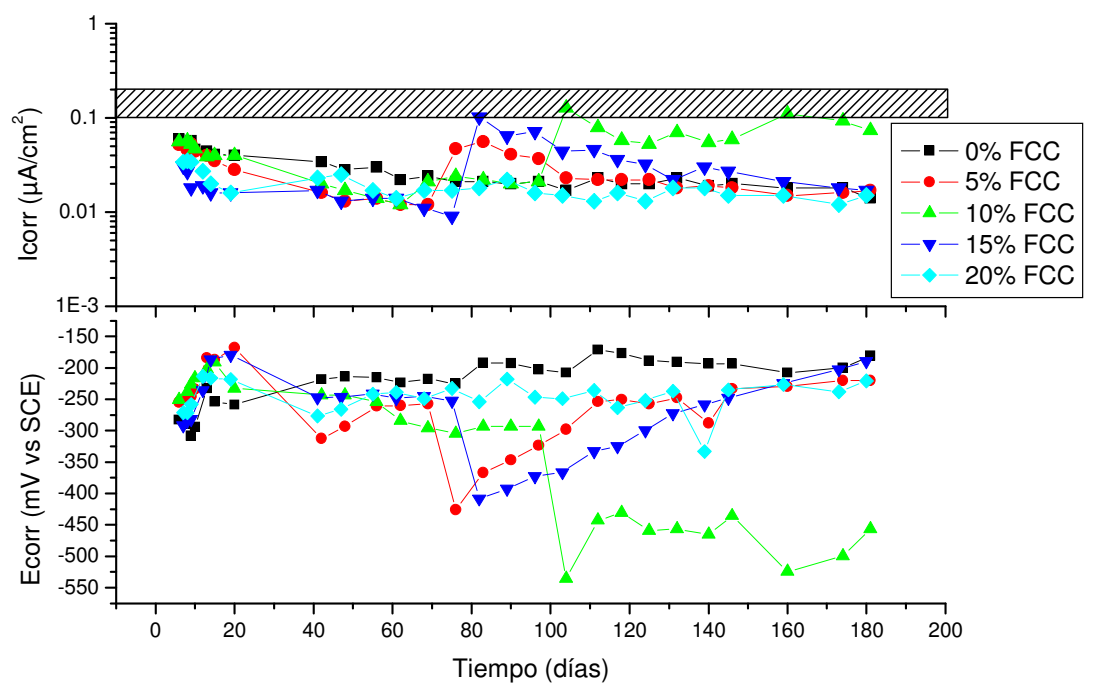

Figura 118. Velocidad de corrosión y potencial de corrosión de aceros para distintas sustituciones de FCC en morteros. Conservación en 100\% de HR y relación a/mc de 0,3 con plastificante. 


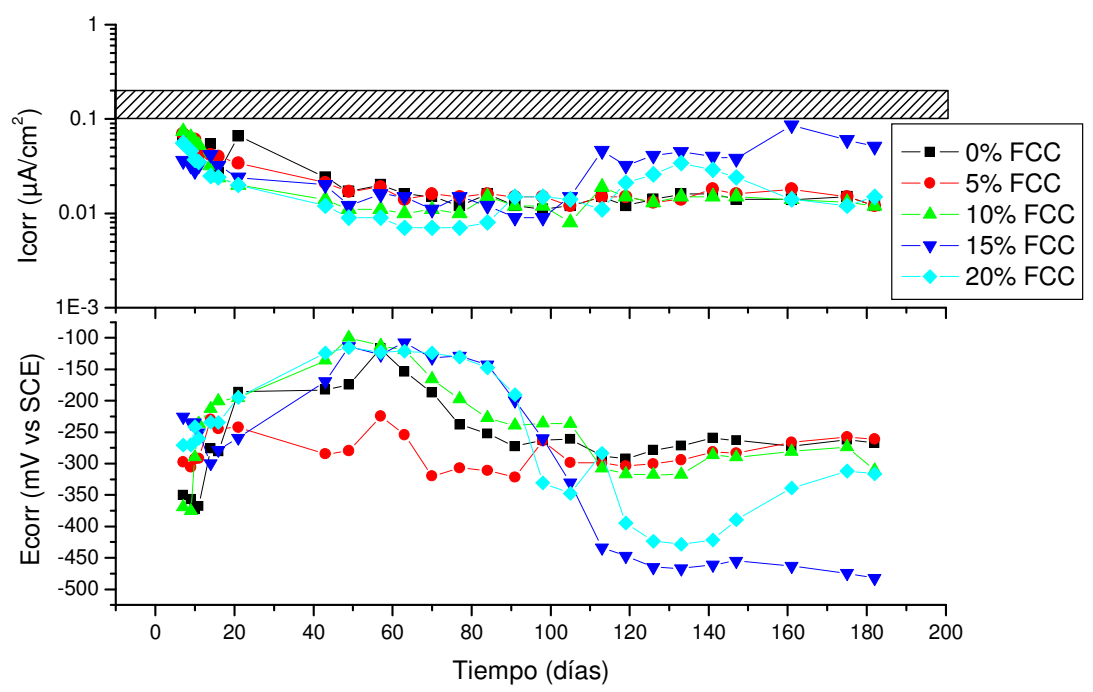

Figura 119. Velocidad de corrosión y potencial de corrosión de aceros para distintas sustituciones de FCC en morteros. Conservación en 100\% de HR y relación a/me de 0,7 con plastificante.

\subsection{Influencia de la humedad relativa del medio de conservación}

En la Figura 120 se presenta la velocidad de corrosión y el potencial de corrosión para los aceros embebidos en morteros con un $0 \%$ y un $15 \%$ de sustitución, y una relación a/mc de 0,5 sometidos a distintos niveles de humedad relativa. En ella se puede apreciar que en las tres humedades relativas $(100 \%, 80 \%$ y $40 \%)$ las velocidades de corrosión se mantienen dentro de la zona de corrosión inactiva. Esto se observa tanto para el mortero control como para el mortero con un $15 \%$ ó $20 \%$ de sustitución. Además no se aprecian diferencias significativas entre ellos.

En cuanto a la parte correspondiente a los potenciales de corrosión se puede observar una influencia de la humedad relativa en este parámetro. Cuanto mayor es la humedad relativa del medio, menor es el potencial del acero. Estos cambios afectan por igual a morteros con y sin FCC, no apreciándose diferencias importantes 
entre el potencial de los electrodos en cada mortero. Al variar la humedad relativa, varía el coeficiente de difusión del $\mathrm{O}_{2}$ a través de la pasta cementicia, y en consecuencia su presión parcial en la interfase. Este hecho condiciona las características de la capa pasivante, y por ende, del campo eléctrico de la interfase. Todo ello se refleja en el desplazamiento del potencial hacia valores positivos cuando la humedad relativa disminuye (aumento de la $\left[\mathrm{O}_{2}\right]$ ) [145]. En cualquier caso estos cambios de potencial no afectan de forma significativa a la velocidad de corrosión de los electrodos.

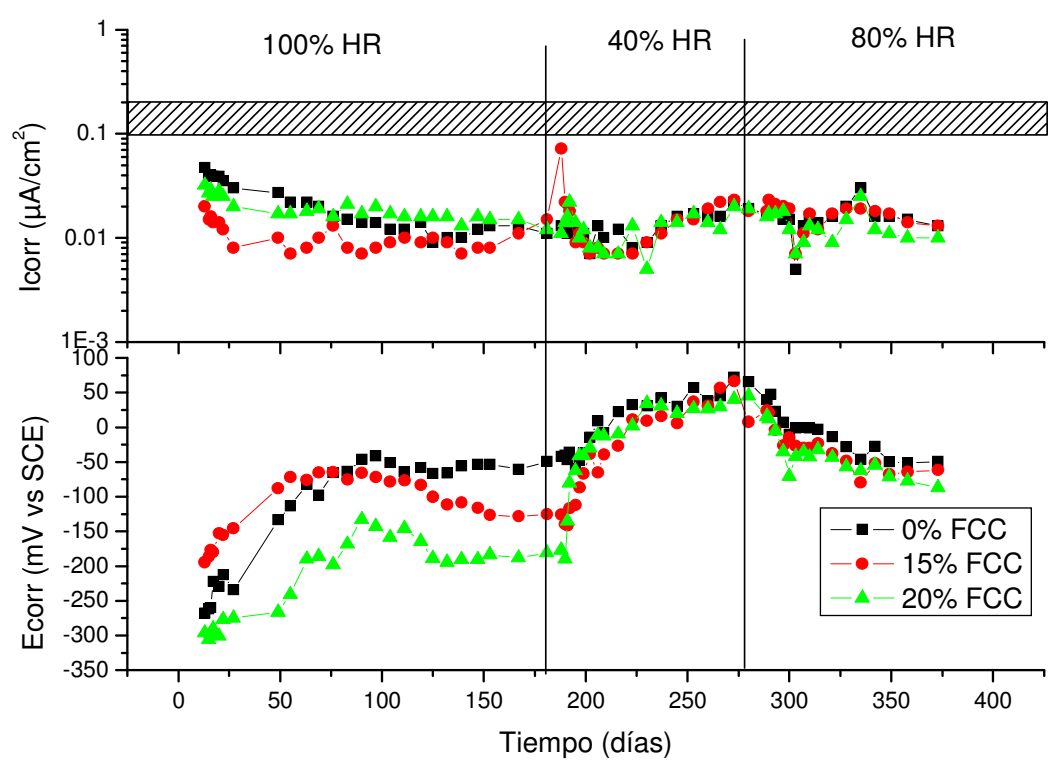

Figura 120. Velocidad de corrosión y potencial de corrosión de aceros en morteros con $0 \%, 15 \%$ y $20 \%$ de FCC en distintos ambientes de HR. Relación a/mc de 0,5 .

\subsection{Efecto de la carbonatación de los morteros}

En la Figura 121 se presentan los valores de velocidad de corrosión y potencial de corrosión en los aceros de los morteros con $0 \%$ y $15 \%$ de FCC y distintas relaciones a/mc sometidos a carbonatación. La carbonatación del mortero se dividió en dos etapas, 
una primera con una atmósfera menos agresiva del $5 \%$ de $\mathrm{CO}_{2} \mathrm{y}$ posteriormente una fase de ataque más agresivo con un $100 \% \mathrm{CO}_{2}$. Observando los niveles de velocidad de corrosión de los morteros se aprecia que en la primera etapa la carbonatación no llegó a consumir totalmente la reserva alcalina durante el periodo de tiempo que se mantuvo en esa atmósfera salvo en el mortero con relación a/mc de 0,7 y un $15 \%$ de FCC. En este mortero, la porosidad es bastante elevada debido a la alta relación a/mc, y además la reserva alcalina se ha reducido considerablemente debido a la reacción puzolánica del FCC. Se observa que el aumento de la velocidad de corrosión va acompañado de una disminución importante del potencial de corrosión.

En la segunda fase de carbonatación en atmósfera de 100\% de $\mathrm{CO}_{2}$, se ha podido observar que para las relaciones a/mc de 0,5 y 0,7 se produce un aumento en la velocidad de corrosión como consecuencia de la penetración del frente de carbonatación hasta los aceros y la consecuente despasivación de los mismos. Esto se observa tanto para los morteros con FCC como para los morteros control. No obstante, los valores de velocidad de corrosión son algo superiores en los morteros con un $15 \%$ de FCC, pero la diferencia no es importante. En cambio, el mortero con una relación a/mc de 0,3 con plastificante no es afectado durante el proceso de carbonatación debido a que su porosidad es muy reducida, consecuencia de la baja relación a/mc. Por ello, tras la etapa de carbonatación, ni la velocidad de corrosión, ni el potencial de corrosión se ven afectados, dado que el frente de carbonatación no consigue penetrar en el mortero, o al menos de forma significativa. 


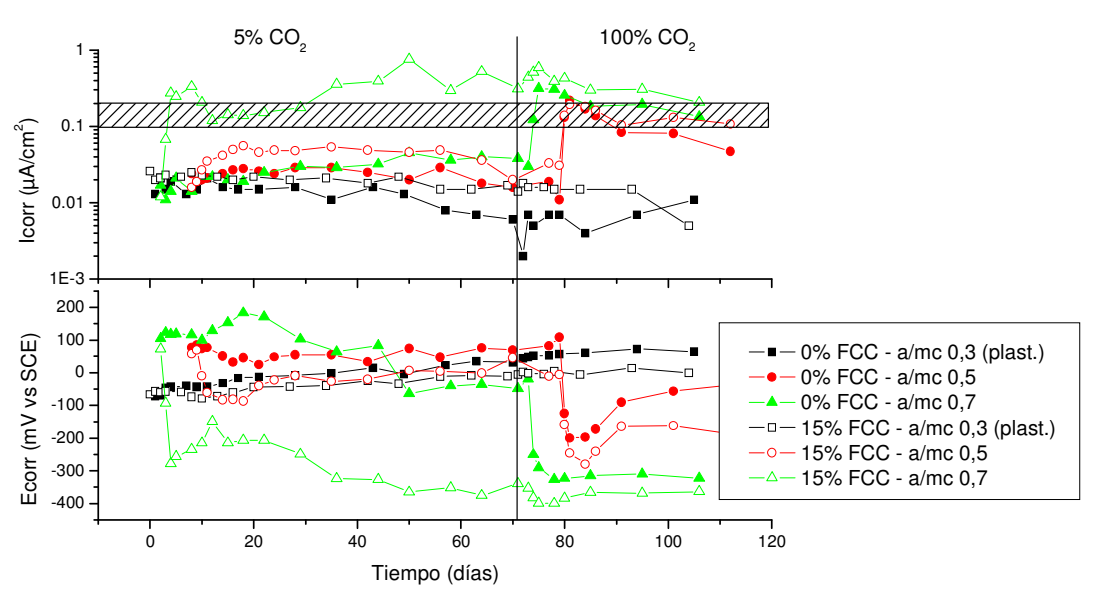

Figura 121. Velocidad de corrosión y potencial de corrosión de aceros en morteros con $0 \%$ y $15 \%$ de FCC para distintas relaciones a/mc, durante la carbonatación acelerada.

El comportamiento, pues, del FCC ante los procesos de corrosión producidos por un ataque por carbonatación es bueno cuando la relación a/mc es baja y empeora cuando la relación a/mc es elevada con respecto al ofrecido por los morteros de cemento Portland. Esto hace que sus características sean similares a las que presenta el humo de sílice según se ha descrito por otros autores [150,151], y mejora el comportamiento ofrecido por las cenizas volantes, que normalmente hace que aumente el riesgo de corrosión de las armaduras frente a un ataque por carbonatación [152]. Estos resultados se deben a que la mejora que produce en la microestructura de la pasta cementante por parte del FCC y el humo de sílice es más importante que la ofrecida por la ceniza volante para una relación a/mc determinada. No obstante, la mejora en la trabajabilidad que produce la ceniza volante [153] puede ofrecer la posibilidad de reducir la relación a/mc lo que provoca a su vez una mejora de la resistencia al ingreso de agentes externos de los morteros que la incorporan. Por otro lado, el FCC y el humo de sílice tienen la ventaja de ofrecer una mayor reactividad a edades tempranas lo que favorece un mejor desarrollo prematuro del gel cementante. 
Transcurrido el tiempo de permanencia en la cámara de carbonatación, se sacaron las probetas y se mantuvieron en una atmósfera del $100 \%$ de humedad relativa para observar la evolución de las velocidades de corrosión en un ambiente con una mayor concentración de oxígeno. En la Figura 122 se presentan los datos de Icorr y Ecorr para distintas relaciones a/mc con y sin FCC. En este medio se realizó el seguimiento de la corrosión de los aceros durante 2 meses. Como se aprecia en la Figura 122, los aceros que se encontraban embebidos en el mortero con relación a/mc de 0,3 con plastificante siguen inmunes frente a los cambios producidos en el ambiente, lo cual demuestra, una vez más, su baja permeabilidad, independientemente de que incorporen FCC. En cambio, los aceros embebidos en los morteros de relación a/mc de 0,5 y 0,7 , lejos de acercarse a un estado de menor corrosión, lo que se observa es que sus parámetros de Icorr y Ecorr, aumentan y disminuyen, respectivamente.

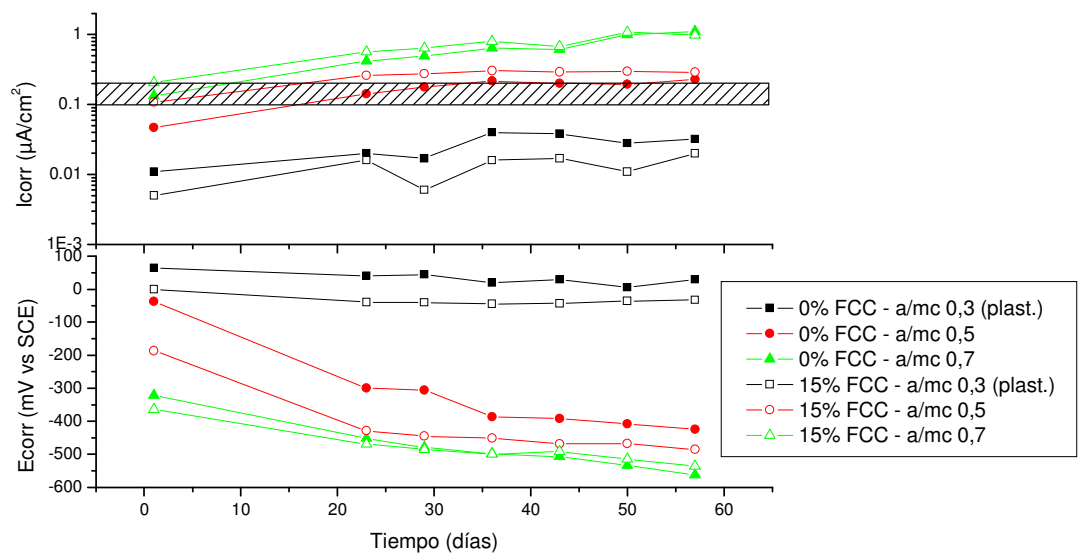

Figura 122. Velocidad de corrosión y potencial de corrosión de aceros en morteros con $0 \%$ y $15 \%$ de FCC para distintas relaciones a/mc, en humedad relativa del $100 \%$, tras el proceso de carbonatación acelerada.

Este fenómeno se debe a que cuando se encontraban dentro de la cámara de carbonatación, la presencia de oxígeno en la misma era residual, mientras que fuera de la cámara es mucho mayor, lo cual hace que los potenciales de corrosión se desplacen a valores más 
activos y que la intensidad de corrosión de los aceros aumente todavía más. Esto además confirma que, independientemente de la presencia de FCC en el mortero, para la relación a/mc de 0,5 y 0,7 la carbonatación del mismo había sido total, por lo que la reserva alcalina se había consumido en el ataque. Como cabría esperar, se comprueba además, que el mortero con relación a/mc de 0,7 , con y sin FCC, es el que menos protege a los aceros embebidos, y por lo tanto el que los expone a una corrosión más elevada.

Una vez finalizadas las medidas de corrosión de los aceros se procedió a la comprobación de las medidas electroquímicas mediante su comparación con las pérdidas de masa gravimétricas de los electrodos, observándose una buena concordancia entre ambos parámetros. En la Figura 123 se aprecia que todos los valores se agrupan dentro de las bandas error aceptadas en la técnica de resistencia a la polarización. Se calcularon dichos valores y se obtuvo que la media de las pérdidas de masa electroquímica era un $97 \pm 24 \%$ con respecto al valor de pérdida de masa gravimétrica, siendo el margen de error permitido en la técnica el intervalo [50\%,200\%] [154].

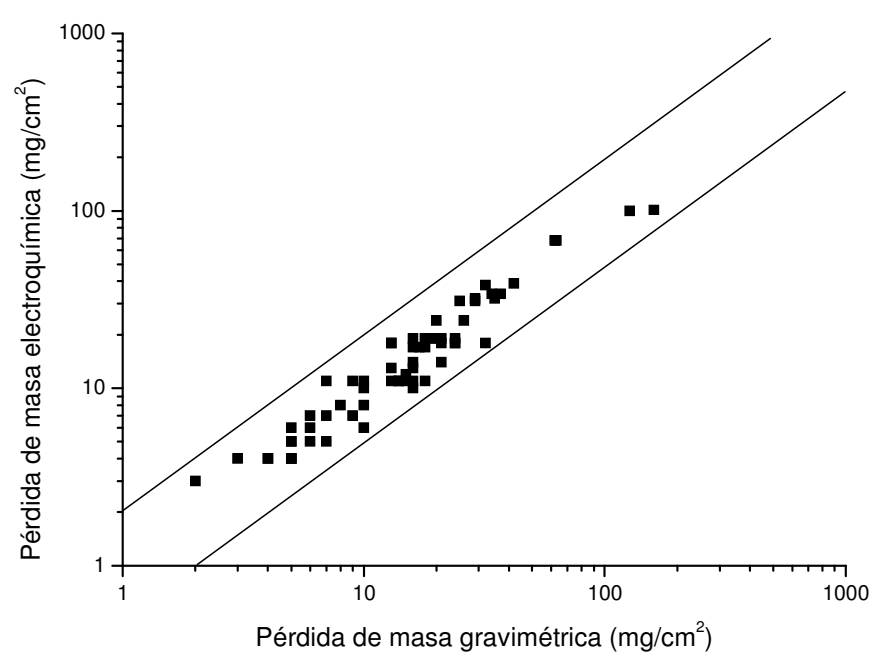

Figura 123. Comparación de las medidas electroquímicas mediante la pérdida de masa gravimétrica. 


\subsection{Conclusiones}

En este capítulo se han podido establecer las siguientes conclusiones:

- El parámetro de la relación a/mc influye de forma más importante en el acceso de $\mathrm{CO}_{2}$, que el parámetro de sustitución de cemento por FCC. Por ello se puede afirmar que el FCC no representa ningún riesgo adicional frente a un ataque de carbonatación para relaciones a/mc bajas, y por otro lado ofrece importantes ventajas tecnológicas (mejora de las propiedades mecánicas de morteros y hormigones de forma significativa) y medioambientales (reutilización de un residuo industrial) que no conviene despreciar.

- Para las relaciones a/mc elevadas el mortero control de cemento Portland también sufre un acusado aumento en la velocidad de corrosión de sus aceros cuando el mortero se ha carbonatado por lo que es evidente que lo que es realmente arriesgado para la vida útil de una estructura de hormigón armado sería el empleo de elevadas relaciones a/mc, no la presencia del FCC. Es por ello que lo que se aconseja es utilizar relaciones $\mathrm{a} / \mathrm{mc}$ bajas con plastificante para asegurar una correcta protección de las armaduras para prevenir la corrosión de las armaduras frente a una posible carbonatación del mortero u hormigón de recubrimiento.

- Sólo en el caso de usar sustituciones de cemento por FCC superiores al $15 \%$ se pone en riesgo la reserva alcalina de los morteros por lo que también conviene ser cuidadoso en no sobrepasar este límite en la dosificación si el elemento de destino está armado y se prevé un ataque por carbonatación. 
Estudio de la velocidad de corrosión de aceros embebidos en morteros mixtos de cemento-FCC en un ataque por carbonatación 


\section{Efecto de la carbonatación en morteros ternarios de cemento- FCC-ceniza volante reforzados con acero}

Durante los últimos años muchos investigadores han realizado esfuerzos en producir combinaciones de cementos que cada ofrezcan mejores prestaciones tanto mecánicas como de durabilidad. Por otro lado, existe una tendencia desde las diferentes administraciones para fomentar una reducción en las emisiones de $\mathrm{CO}_{2}$ a la atmósfera y evitar así parcialmente la emisión de gases de efecto invernadero. Por ello se ha puesto gran atención en incorporar subproductos industriales a los cementos con la finalidad de unir estos dos criterios consiguiendo, por un lado, mejorar los productos cementicios, y por otro reducir las emisiones de $\mathrm{CO}_{2}$ y los desechos en vertederos.

El FCC ha demostrado en otros estudios [76,77,79-81] una elevada actividad puzolánica a edades tempranas. No obstante, 
también se ha observado que produce cierta demanda de agua que origina pérdidas apreciables en la trabajabilidad [74,75,77].

Por otro lado, la ceniza volante (CV) se viene utilizando desde hace tiempo, sabiendo que posee actividad puzolánica a edades medias y que mejora la trabajabilidad de los morteros debido a la forma esférica de las partículas que lo componen [78,155,156].

Una combinación de ambas puzolanas puede, por lo tanto, aportar grandes sustituciones de cemento en los morteros, sin que la trabajabilidad quede mermada por ello. No obstante, el empleo de sustituciones tan elevadas conlleva una reducción muy importante de la reserva alcalina que puede ocasionar una disminución en la resistencia a la carbonatación de los morteros y hormigones.

En este estudio se pretende evaluar la cinética de carbonatación de morteros que combinan FCC con CV y el impacto del mismo en los niveles de corrosión de armaduras ante un ataque de carbonatación.

\subsection{Diseño experimental}

\subsubsection{Materiales y elaboración de las probetas}

Se han elaborado probetas de mortero con cemento Portland tipo CEM I 52,5 R, parcialmente sustituido con ceniza volante (CV) y residuo de catalizador de craqueo catalítico (FCC) suministrado por BP España. Las composiciones características de la CV y el FCC se presentan en la Tabla 23. La CV se utilizó según se recibió, mientras que el FCC fue molido en un molino de bolas durante 20 minutos para activar sus propiedades puzolánicas. El plastificante usado ha sido Sika Viscocrete suministrado por SIKA, S.A. Para la fabricación de los morteros se ha empleado arena silícea normalizada [138]. La relación arena/material cementante ha sido 3/1 en todos los casos. La relación agua/material cementante ha sido 0,4 en todos los casos. Para el estudio de velocidad de carbonatación de morteros se han elaborado probetas prismáticas de dimensiones 40x40x160 mm. Para el estudio de velocidad de corrosión se ha elaborado probetas de dimensiones 20x60x80 mm en las que se han embebido dos electrodos de acero de 
$8 \mathrm{~mm}$ de diámetro y un electrodo adicional de grafito como contraelectrodo (Figura 114).

\begin{tabular}{||c|c|c||}
\hline PARÁMETRO & CV (\%) & FCC (\%) \\
\hline P.F. & 2,44 & 1,50 \\
\hline $\mathrm{SiO}_{2}$ & 40,94 & 48,2 \\
\hline $\mathrm{Al}_{2} \mathrm{O}_{3}$ & 24,65 & 46 \\
\hline $\mathrm{Fe}_{2} \mathrm{O}_{3}$ & 13,59 & 0,95 \\
\hline $\mathrm{CaO}$ & 9,83 & - \\
\hline $\mathrm{MgO}$ & 1,59 & - \\
\hline $\mathrm{Na}_{2} \mathrm{O}$ & 0,34 & 0,50 \\
\hline $\mathrm{K}_{2} \mathrm{O}$ & 1,40 & - \\
\hline $\mathrm{SO}_{3}$ & 1,60 & 0,04 \\
\hline
\end{tabular}

Tabla 23. Composición química de las puzolanas empleadas expresadas en \%.

\begin{tabular}{||c|c|c|c||}
\hline \hline MORTERO & SUST. FCC (\%) & SUST. CV (\%) & PLASTIFICANTE (\%) \\
\hline Control & 0 & 0 & 0 \\
\hline Plast & 0 & 0 & 0,5 \\
\hline FCC Plast & 15 & 0 & 0,5 \\
\hline CV & 0 & 30 & 0 \\
\hline FCC-CV & 15 & 30 & 0 \\
\hline FCC-CV-Plast & 15 & 30 & 0,5 \\
\hline
\end{tabular}

Tabla 24. Dosificaciones empleadas en la fabricación de morteros de cementoFCC-CV. Valores referidos como porcentajes respecto del peso de cemento.

Se han elaborado los distintos morteros según las dosificaciones que se muestran en la Tabla 24. Se emplearon estas dosificaciones ya que según estudios previos [102] con esta combinación del $15 \%$ de FCC y $30 \%$ de $\mathrm{CV}$ se consigue ajustar al máximo la cantidad de cal fijada por los morteros (alrededor del 70\%) sin comprometer la reserva alcalina de los morteros. Además se conseguía una velocidad de reacción lineal a lo largo del tiempo, ya 
que el FCC reacciona a tiempos más cortos, mientras que la $\mathrm{CV}$ lo hace a más largo plazo.

\subsubsection{Ensayos de velocidad de carbonatación de morteros}

Se efectuaron tres series de amasadas con las mismas variables implicadas para realizar distintas pruebas sobre los morteros. Una de las series se utilizó para medir el avance del frente de carbonatación a lo largo del proceso. La metodología seguida en los ensayos de velocidad de carbonatación de morteros consistió en lo siguiente: tras el amasado de las probetas se sometieron a un curado bajo agua durante 28 días. Tras este periodo se mantuvieron durante 21 días a una humedad relativa del $40 \%$ para evaporar parte del agua de los poros y de esta manera acelerar el proceso de carbonatación. A continuación se inició la carbonatación de morteros en una cámara de carbonatación acelerada con una atmósfera del $100 \%$ de $\mathrm{CO}_{2}$ y una humedad relativa del $65 \pm 5 \%$ que asegura que el proceso de carbonatación se realice más rápidamente [91,124]. El proceso de carbonatación acelerada duró 21 días en los cuales se tomaban lecturas del avance del frente de carbonatación mediante el revelado con fenolftaleína de una sección de las probetas [90,91].

La segunda serie de amasadas se empleó para estudiar la influencia de la carbonatación en las propiedades mecánicas de los morteros. El proceso al que fueron sometidas las probetas de esta segunda serie fue idéntico al de la primera serie, pero en ellas no se monitorizó el avance del frente de carbonatación. Se curaron durante 28 días en agua, se acondicionaron durante 21 días en ambiente de laboratorio, y se carbonataron en la cámara durante 21 días más. Durante los 21 días que duró su carbonatación se siguió la evolución de las masas de las probetas para comprobar que su tendencia era similar a las probetas de la primera serie. Una vez cumplidos los 21 días de carbonatación en la cámara, se efectuaron ensayos de resistencia a compresión y resistencia a flexotracción, y se midieron las densidades y porosidades de los morteros carbonatados.

La tercera y última serie, sirvió como referencia para comparar el efecto de la carbonatación en las propiedades mecánicas que se 
habían medido en la segunda serie. Para ello se curaron las probetas resultantes de las amasadas durante 28 días en agua, se acondicionaron durante 21 días en ambiente de laboratorio y se conservaron dentro de bolsas durante 21 días más. Este último periodo equivaldría al tiempo que las probetas de la segunda serie estuvieron en la cámara de carbonatación. Al finalizar el proceso de efectuaron los mismos ensayos que los descritos para la segunda serie.

Los ensayos de resistencia a flexotracción y resistencia a compresión en los morteros se realizaron según la norma [122] UNEEN 196-1:1996. La determinación de densidades y porosidades de los morteros se efectuaron siguiendo las indicaciones presentadas en la sección 4.1.

\subsubsection{Ensayos de velocidad de corrosión de aceros}

Una vez amasadas las probetas se mantuvieron en cámara de humedad (100\% HR). Desde el día siguiente al amasado se monitorizó la velocidad de corrosión (Icorr) y el potencial de corrosión (Ecorr) durante un periodo de 80 días hasta que se alcanzaron valores estables de los mismos. Finalizada esta etapa se introdujeron las probetas en una cámara de carbonatación acelerada en la que la atmósfera era del $100 \%$ de $\mathrm{CO}_{2}$ y la humedad relativa del $65 \pm 5 \%$ para acelerar el proceso de carbonatación [91,124]. Análogamente se registraron los valores de Icorr y Ecorr hasta que se alcanzaron valores estables de los mismos. Tras ello se volvieron a introducir las probetas en la cámara húmeda para dejar que evolucionara la corrosión de los electrodos en un ambiente con una concentración de oxígeno superior. Los potenciales de corrosión han sido medidos frente a un electrodo de calomelanos saturado (SCE). La medida de Icorr se ha efectuado mediante la técnica de resistencia a la polarización (Rp) [141] mediante un potenciostato EG\&G modelo 362 de Princetone Applied Research. Los barridos se potencial se han realizado desde $-10 \mathrm{mV}$ hasta $+10 \mathrm{mV}$ respecto del potencial de corrosión (Ecorr) a una velocidad de $0,5 \mathrm{mV} / \mathrm{s}$. El valor de $B$ de la ecuación de Stern-Geary que se utiliza para calcular la Icorr oscila entre 13 y $52 \mathrm{mV}$ para el acero en el hormigón [141]. Normalmente se opta por tomar como 26 $\mathrm{mV}$ este valor y aceptar que existe un error de factor 2 en las medidas realizadas [142]. Al finalizar todo el proceso de medida se extrajeron 
los electrodos de las probetas para su inspección visual y para comparar la pérdida de masa electroquímica calculada con la técnica de resistencia a la polarización con la pérdida de masa gravimétrica calculada mediante la diferencia de masa del electrodo antes y después del ataque.

\subsection{Velocidad de carbonatación de morteros de cemento-FCC-CV}

En la Figura 124 se presenta la evolución de la profundidad de carbonatación en los morteros estudiados durante el proceso de carbonatación acelerada. Se observa que la menor velocidad de carbonatación se obtiene para el mortero Plast y FCC Plast, seguidos del mortero Control y el mortero FCC-CV-Plast. A continuación se sitúa el mortero $\mathrm{CV}$ y la mayor velocidad de carbonatación se obtiene para el mortero FCC-CV. Los datos obtenidos en esta curva se han ajustado según la ecuación [125,127-129]:

$$
x=V_{\mathrm{CO} 2} \sqrt{t}
$$

donde $x$ es la profundidad de carbonatación en mm y $t$ es el tiempo en años y $V_{C O 2}$ es la velocidad de carbonatación en mm·año ${ }^{-0,5}$.

La constante de velocidad que se obtiene, $V_{\mathrm{CO} 2}$, para los distintos morteros son las que se muestran en la Tabla 25 y Figura 125.

\begin{tabular}{||c|c||}
\hline Mortero & $\mathbf{V}_{\mathbf{C O} 2}\left(\mathbf{m m} / \mathbf{a n n o} \mathbf{0}^{\mathbf{0 . 5}}\right)$ \\
\hline Control & $37,0 \pm 3,7$ \\
\hline Plast & $17,8 \pm 1,7$ \\
\hline FCC-Plast & $17,7 \pm 1,0$ \\
\hline $\mathbf{C V}$ & $55,0 \pm 3,1$ \\
\hline FCC-CV & $118,0 \pm 2,3$ \\
\hline FCC-CV-Plast & $46,2 \pm 0,6$ \\
\hline
\end{tabular}

Tabla 25. Velocidad de carbonatación de morteros de cemento-FCC-CV. 


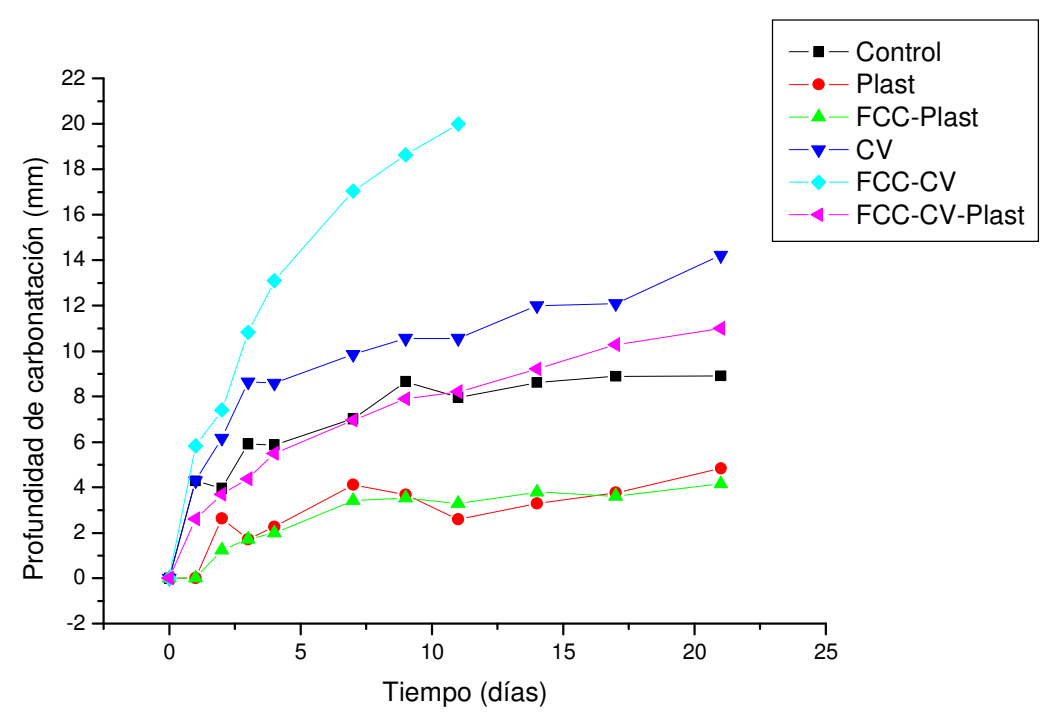

Figura 124. Evolución de la profundidad de carbonatación de morteros durante el ensayo de carbonatación acelerada. Relación a/mc de 0,4.

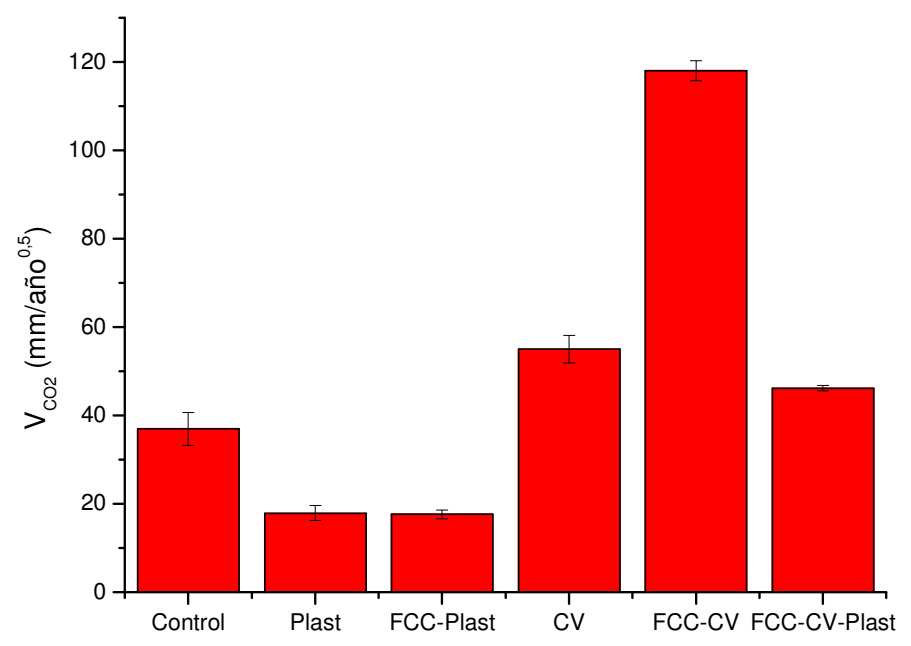

Figura 125. Velocidad de carbonatación de los distintos morteros en el ensayo de carbonatación acelerada. Relación a/mc de 0,4 . 
Para justificar los valores obtenidos es importante tener en cuenta los dos parámetros principales que influyen en la velocidad de carbonatación: la porosidad y la reserva alcalina $[125,127,129,133,135,136]$.

En la Figura 126 se presentan las porosidades de los morteros antes y después del proceso de carbonatación acelerada. Como se observa en esta figura, la menor porosidad se obtiene para el mortero Plast y FCC Plast, seguido de la del mortero Control y el mortero FCC-CV Plast. En otros estudios se ha podido comprobar que el parámetro más influyente en la velocidad de carbonatación es la porosidad, y que sólo cuando ésta es elevada, entra en juego la reserva alcalina. Por esta razón, los morteros menos porosos (Plast y FCC Plast) ofrecen una velocidad de carbonatación muy baja, a pesar de que existen diferencias en la reserva alcalina entre ambos. Seguidamente el mortero Control y FCC-CV Plast, de porosidad baja pero con diferencias muy importantes de reserva alcalina debido a la elevada sustitución en FCC-CV Plast (sustitución total de cemento del $45 \%$ ), presentan velocidades de carbonatación similares. En el caso de los otros dos morteros, FCC-CV y CV, se observa que poseen porosidades mayores a las anteriores y similares entre ellas. En este caso, la reserva alcalina afecta de forma significativa a la velocidad de carbonatación, ya que la elevada porosidad que presentan no supone un obstáculo importante a la penetración del $\mathrm{CO}_{2}$ y el papel de la portlandita es más importante a la hora de frenar el avance del frente de carbonatación. Esto explica que a pesar de que sus porosidades sean similares la velocidad de carbonatación sea superior en el caso del mortero FCC-CV, ya que la reserva alcalina de este mortero es muy pequeña. Además se comprueba lo expuesto por otros autores acerca del empeoramiento que suele producir en la resistencia a la carbonatación la incorporación CV como sustitución de cemento [132134]. 


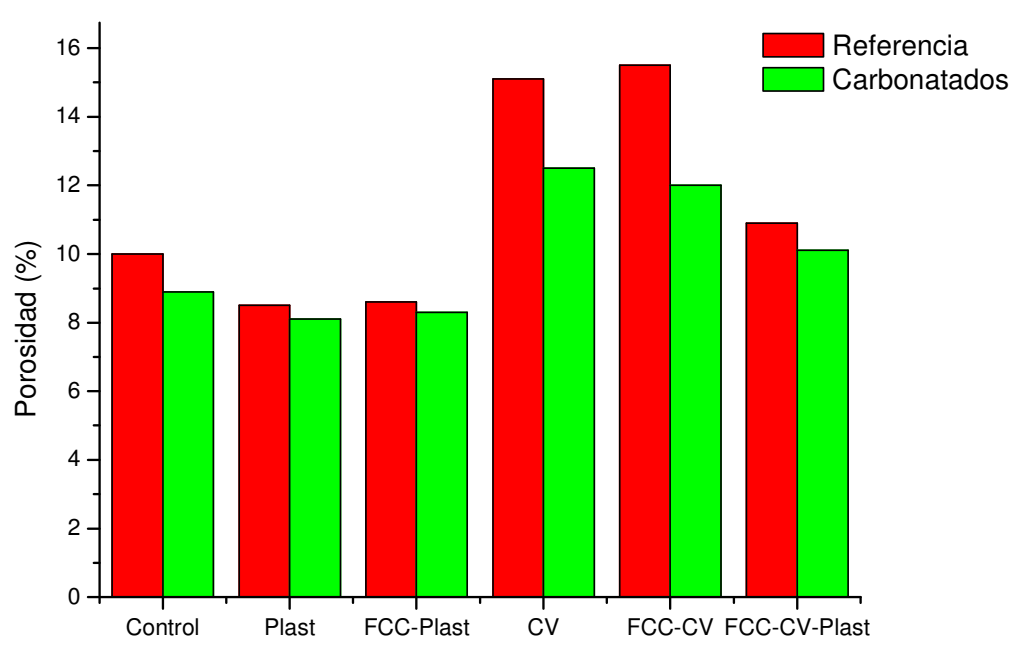

Figura 126. Porosidad de los morteros carbonatados ( 21 días de carbonatación acelerada) y sin carbonatar. Relación a/mc de 0,4 .

Adicionalmente, en la Figura 126 se observa que la carbonatación produce una reducción de la porosidad del mortero como consecuencia de la precipitación de $\mathrm{CaCO}_{3}$ en los poros, aumentando la densidad de los mismos [39,100,114,137].

En la Figura 127 se presenta la resistencia a flexotracción de los morteros antes y después del proceso de carbonatación. Se puede observar que la resistencia a flexotracción de los morteros antes de la carbonatación es muy similar en todos ellos, excepto en el caso del mortero FCC-CV, ya que, debido a la elevada sustitución de cemento la disponibilidad de portlandita es limitada y el desarrollo de la reacción puzolánica puede verse afectado. En el caso del mortero FCC-CV-Plast, la mayor compacidad del mortero por la incorporación de plastificante consigue compensar este efecto. Por otro lado, se puede apreciar que el proceso de carbonatación afecta de forma negativa a la resistencia a flexotracción, como ya se ha apuntado en el apartado 4.3. Esto se debe a que la precipitación de $\mathrm{CaCO}_{3}$ se encuentra confinada en los poros del mortero, generando esfuerzos de tracción sobre las paredes los poros que reducen la Rf. 


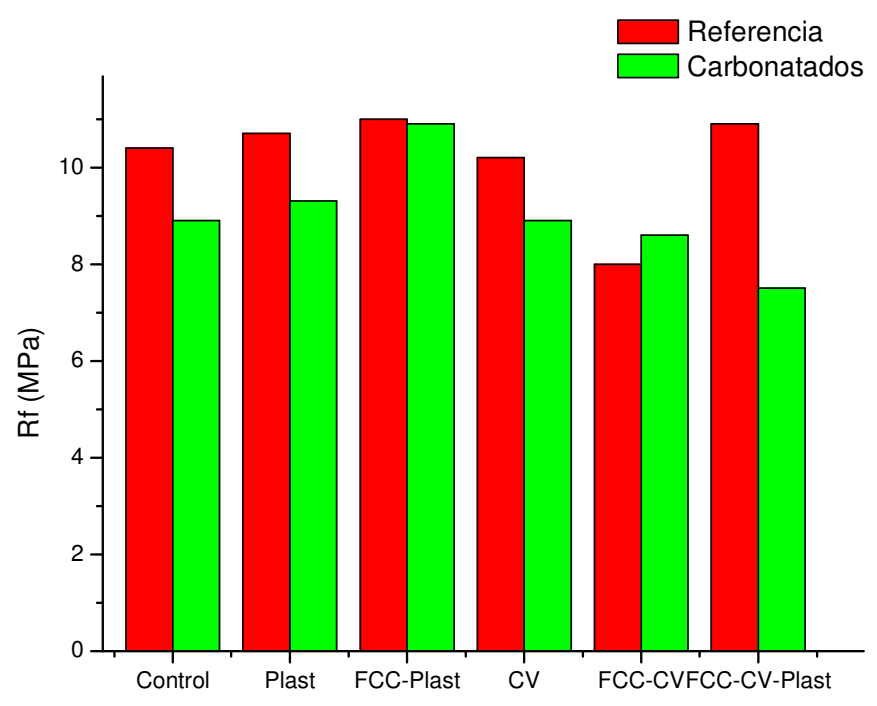

Figura 127. Resistencias a flexotracción de los morteros carbonatados (21 días en la cámara de carbonatación) y sin carbonatar. Relación a/mc de 0,4 .

En la Figura 128 se presentan los resultados de resistencia a compresión (Rc) de los morteros antes y después del proceso de carbonatación. En este caso únicamente los morteros que consiguen superar al mortero control son el FCC Plast y el FCC-CV Plast ya que el efecto del plastificante se hace notar a la hora de mejorar esta propiedad mecánica. Además en el caso del mortero FCC Plast existe una contribución muy importante por la reacción puzolánica del FCC. El mortero CV presenta una disminución de la Rc respecto al mortero control ya que el desarrollo de la reacción puzolánica de la CV no es tan rápido como el del FCC. Debido a esto, posiblemente a edades más tardías se obtendría una mejoría del valor de Rc en el mortero CV. 


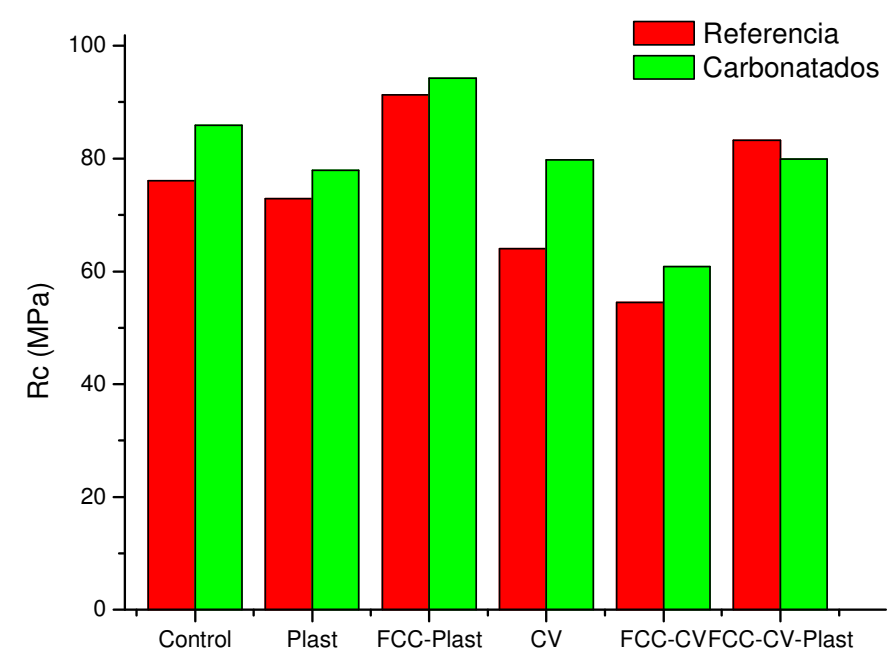

Figura 128. Resistencias a compresión de los morteros carbonatados (21 días de carbonatación acelerada) y sin carbonatar. Relación a/mc de 0,4.

Adicionalmente, en la Figura 128 se puede observar que el proceso de carbonatación produce un aumento generalizado de la resistencia a compresión debido a que se aumenta la densidad y se disminuye la porosidad de los mismos por la formación de $\mathrm{CaCO}_{3}$ en los poros $[39,100,114,137]$.

\subsection{Velocidad de corrosión de aceros embebidos en morteros de cemento-FCC-CV carbonatados}

Tras el estudio de la cinética de carbonatación de los morteros se evaluó la capacidad de algunos de ellos a la hora de proteger armaduras de acero embebidas frente a un ataque por carbonatación. En este caso se analizó la respuesta de los aceros embebidos en los morteros Control, CV, FCC-CV y FCC-CV Plast. En la parte superior de las gráficas de corrosión se aprecia una banda que abarca desde 0,1 a $0,2 \mu \mathrm{A} / \mathrm{cm}^{2}$ que delimita la zona de corrosión activa de la zona de corrosión despreciable [143]. 
En la Figura 129 se presentan los resultados de Icorr y Ecorr obtenidos para estos morteros durante una primera fase en la que se mantuvieron en un ambiente de $100 \%$ de humedad relativa. Se puede observar que durante los primeros días tras la preparación de las probetas, se produce una corrosión acusada debido a que se está formando la capa de pasivación de las armaduras de las probetas [157]. Tras este periodo inicial, los valores se estabilizaron en la zona de frontera del gráfico de corrosión, excepto en el caso del mortero control que ofreció valores de Icorr claramente inferiores. Por lo tanto, en esta primera fase, se observó que las sustituciones estudiadas afectaban negativamente a la protección de las armaduras. Los valores de Ecorr obtenidos no presentan una ordenación clara, aunque sí parece que el mortero FCC-CV Plast se desplaza hacia valores más negativos debido, posiblemente a que su baja porosidad produce una deficiencia de oxígeno en la superficie de la armadura que según la ecuación de Nernst produce un desplazamiento del potencial hacia valores más negativos [145]. Esto además explicaría, por qué el mortero $\mathrm{CV}$, que más poroso y permite un acceso superior del oxígeno hacia el interior, presenta los valores menos negativos de Ecorr.

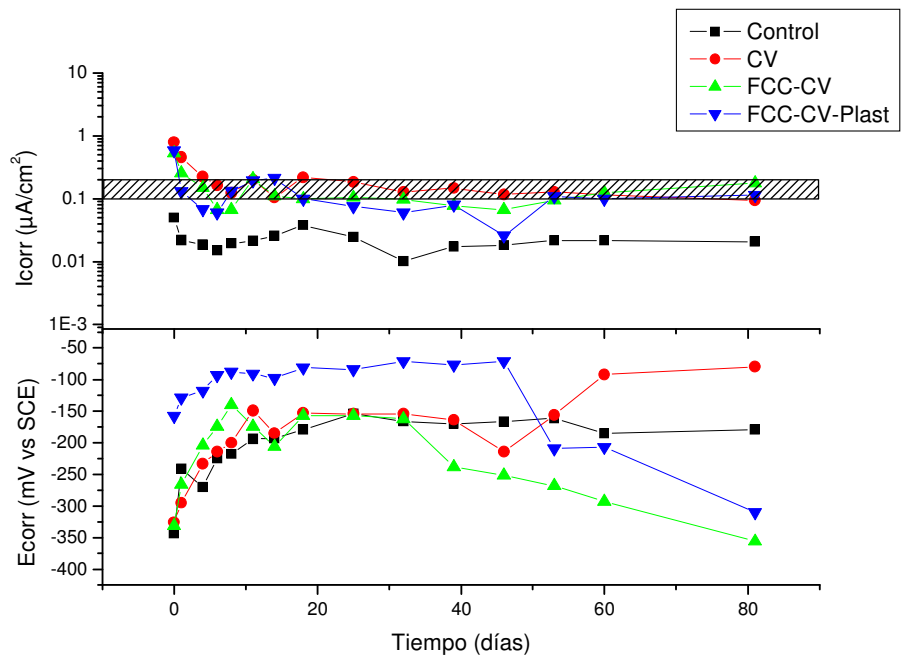

Figura 129. Velocidad y potencial de corrosión de aceros en morteros a una humedad relativa del $100 \%$. 
Tras esta fase, se ubicaron las probetas en la cámara de carbonatación acelerada con una atmósfera del $100 \%$ de $\mathrm{CO}_{2}$ y la humedad relativa del $65 \pm 5 \%$. Los resultados de Icorr y Ecorr en los aceros durante esta fase se presentan en la Figura 130. Durante los primeros días en la cámara de carbonatación se aprecia claramente el efecto de la atmósfera agresiva en los valores de Icorr. Se observa un aumento brusco del valor de Icorr en todos los casos excepto en el mortero FCC-CV-Plast que lo hace a tiempos mayores y de forma más progresiva. Esta subida de Icorr es coherente con la disminución del valor de Ecorr observado en los aceros durante esta fase. Tras este incremento en la Icorr observado los valores tienden a estabilizarse en valores menos activos quedando los aceros del mortero Control con una Icorr inferior al resto de morteros.

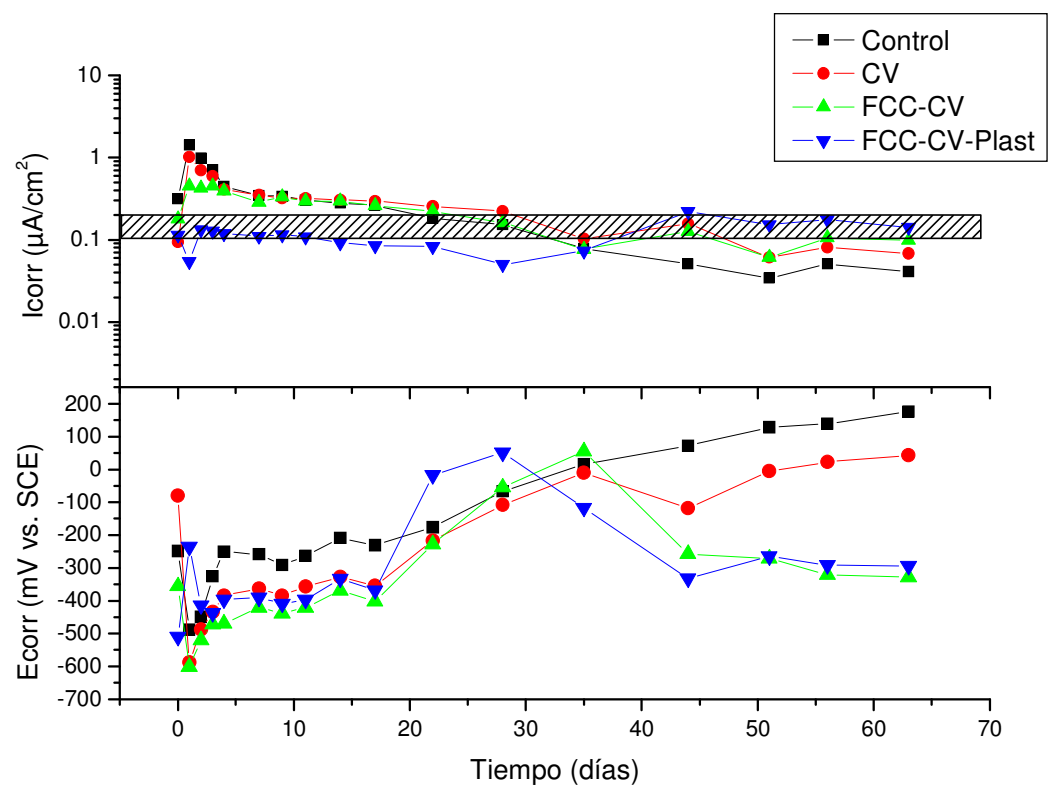

Figura 130. Velocidad y potencial de corrosión de aceros en morteros sometidos a una atmósfera del $100 \%$ de $\mathrm{CO}_{2}$ y una humedad relativa del $65 \%$.

El progresivo descenso que tiene lugar en la Icorr estaría justificado por el hecho de que la precipitación de $\mathrm{CaCO}_{3}$ puede llegar a producir una red porosa más cerrada. Esto puede originar que el 
proceso global de oxidación de las barras de acero pase a estar controlado catódicamente por la difusión de oxígeno hasta la superficie de las armaduras, lo que estaría apoyado por el aumento progresivo de los potenciales de corrosión.

El aumento de Ecorr que se produce con el tiempo durante el proceso de carbonatación viene apoyado en dos fenómenos contrapuestos, ambos de tipo termodinámico. En primero lugar la escasez de $\mathrm{O}_{2}$, que ya se ha apuntado anteriormente, tiende a desplazar el Ecorr hacia valores más negativos. Por otro lado, la disminución del $\mathrm{pH}$ que tiene lugar como consecuencia de la neutralización de la alcalinidad del mortero por el ataque del $\mathrm{CO}_{2}$ produce el efecto contrario. Según [145] la fuerza electromotriz del proceso de oxidación del $\mathrm{Fe}$ en $\mathrm{Fe}^{2+}$ y la reducción del $\mathrm{O}_{2}$ a $\mathrm{OH}^{-}$vendría dada por la siguiente expresión (en voltios):

$$
e=1,669+0,0148 \log \left[O_{2}\right]-0,0591 p H-0,0296 \log \left[\mathrm{Fe}^{2+}\right]
$$

Donde se puede comprobar que de todas las especies implicadas en el proceso, la que más peso tiene en el Ecorr es el $\mathrm{pH}$, o lo que es lo mismo, la concentración de $\mathrm{OH}^{-}$.

Para concluir, en la Figura 131 se presentan los valores de velocidad de corrosión y potencial de corrosión de los aceros en un ambiente del $100 \%$ de humedad relativa tras el proceso de carbonatación acelerada. Tras la etapa de carbonatación en la que la presión parcial de oxígeno en el interior de la cámara estaba limitada por la alta concentración de $\mathrm{CO}_{2}$ se colocaron las probetas en una cámara con el $100 \%$ de humedad relativa. Se puede observar que los aceros experimentan una subida de la velocidad de corrosión. Los aceros más afectados, que se sitúan claramente en la zona de corrosión activa son los correspondientes a los morteros FCC-CV y FCC-CVPlast. Estos morteros son lo que menos reserva alcalina poseen debido al consumo de portlandita por parte de ambas puzolanas (FCC y CV) por lo que la despasivación de los aceros es mucho más acusada y su corrosión más elevada. A continuación, el mortero con un $30 \%$ de CV se sitúa en la zona frontera y, por último, el mortero Control queda en la zona de corrosión inactiva. 
Por su parte, los potenciales de corrosión se ordenan claramente de forma inversa a las velocidades de corrosión, lo cual da muestra del estado termodinámico de las interfases acero-mortero: cuanto mayor es la velocidad de corrosión, menor es el potencial de corrosión de los aceros.

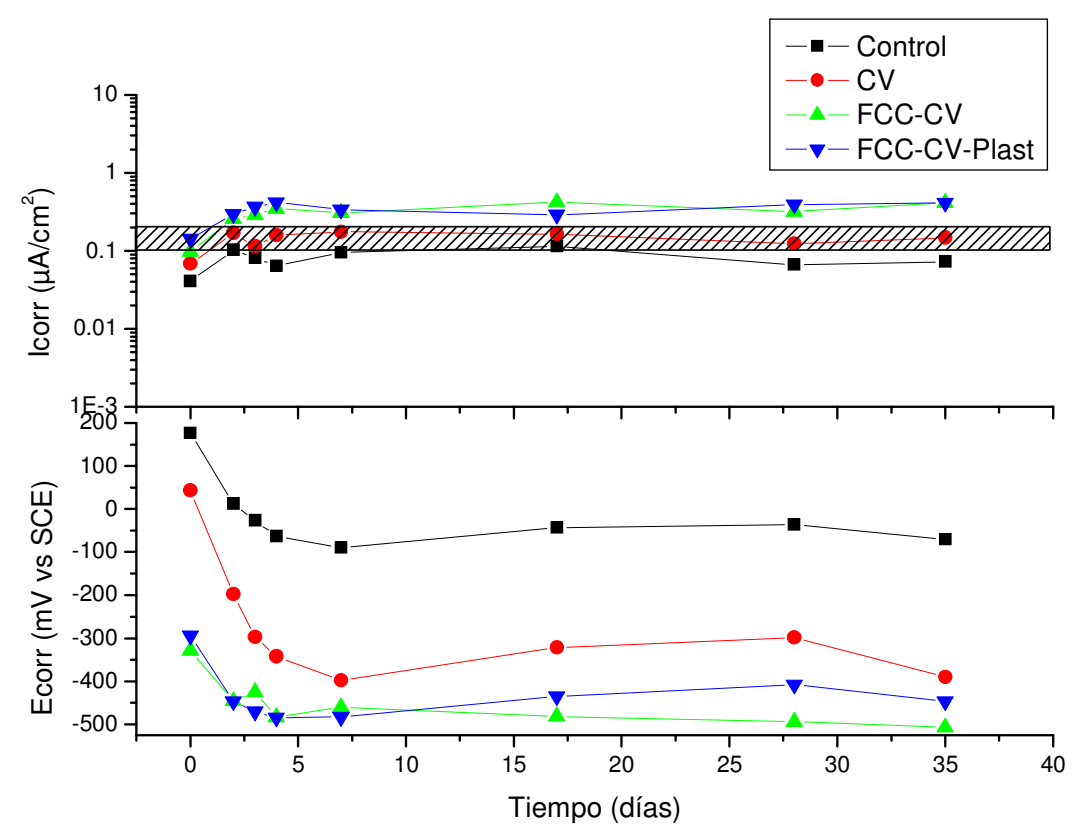

Figura 131. Velocidad y potencial de corrosión de aceros en morteros a una humedad relativa del $100 \%$ tras la etapa de carbonatación acelerada.

\subsection{Conclusiones}

Una vez concluido el estudio se han podido establecer las siguientes conclusiones:

- El uso de mezclas ternarias de cemento/FCC/CV como conglomerantes en morteros en las dosificaciones empleadas en este estudio (55/15/30), produce una importante disminución de la resistencia a la carbonatación con respecto al mortero control. 
- Este empeoramiento de propiedades se puede paliar mediante la incorporación de un plastificante, en cuyo caso la velocidad de carbonatación del mortero es similar a la del que incorpora únicamente cemento Portland.

- El uso de mezclas ternarias de cemento/FCC/CV como conglomerantes en morteros en las dosificaciones empleadas en este estudio (55/15/30), produce una disminución de las propiedades mecánicas de los morteros (Rc y Rf).

- Si a la mezcla anterior se le incorpora plastificante se consigue una mejora de las propiedades mecánicas respecto al mortero control que sólo contiene cemento Portland.

- Se ha observado que la menor resistencia a la carbonatación de los morteros de cemento-FCC-CV afecta de forma negativa a la corrosión de las armaduras embebidas en los morteros.

- La ceniza volante no compensa el efecto de la demanda de agua del FCC en cuanto al proceso de carbonatación y corrosión de los aceros para la relación a/mc usada. 


\section{Efecto del ataque por cloruros en la matriz cementante de los morteros mixtos de cemento-FCC}

Análogamente a lo hecho en el ataque del $\mathrm{CO}_{2}$ a las matrices cementantes de cemento con FCC, en este capítulo se presentan y discuten los resultados obtenidos mediante la aplicación de la termogravimetría en pastas de cemento con FCC sometidas a la acción del ion cloruro. De este modo se pretende evaluar las modificaciones y los procesos químicos que tienen lugar en los productos de hidratación del cemento y de la reacción puzolánica en presencia del ion cloruro. Adicionalmente se estudió el efecto de la carbonatación sobre las matrices cementantes tras ser expuestas a la acción de los cloruros. Por último, en este capítulo se ha incluido un pequeño apartado con los datos referentes al impacto que puede ocasionar la incorporación de distintas cantidades de cloruros sobre las propiedades mecánicas de los morteros. 


\subsection{Diseño de las experiencias}

Se han elaborado 5 tipos distintos de pastas de cemento en función de la sustitución de cemento por FCC. El cemento utilizado en todas ellas ha sido CEM I 52,5 R. Las sustituciones de cemento por FCC empleadas en cada una de las pastas ha sido del 0, 5, 10, 15 y 20\%. El FCC se incorporó tras ser molido durante 20 min en un molino de bolas. Para la elaboración de las pastas se empleó agua destilada manteniendo una relación agua/material cementante $(\mathrm{a} / \mathrm{mc})$ de 0,5 .

Las pastas se amasaron en contenedores de plástico y se curaron en cámara húmeda ( $100 \%$ de humedad relativa) durante 28 días. Posteriormente se sumergieron en una disolución de $\mathrm{NaCl}$ de concentración $1 \mathrm{M}$ y se mantuvieron sumergidas durante 6 meses. Tras este periodo, las muestras se almacenaron en una cámara de carbonatación acelerada cuya atmósfera tenía una proporción de $\mathrm{CO}_{2}$ del $100 \%$ y una humedad relativa del $65 \pm 5 \%$ [91,124].

Se tomaron muestras de las pastas a distintos tiempos para seguir la evolución de las mismas. En total se efectuaron 5 análisis de cada pasta según la siguiente relación:

- Tras 28 días de curado.

- $\quad$ Tras 28 días de curado y un mes sumergidas en $\mathrm{NaCl} 1 \mathrm{M}$.

- Tras 28 días de curado y 2 meses sumergidas en $\mathrm{NaCl} 1 \mathrm{M}$.

- $\quad$ Tras 28 dias de curado y 6 meses sumergidas en $\mathrm{NaCl} 1 \mathrm{M}$.

- Tras 28 días de curado, 6 meses sumergidas en $\mathrm{NaCl} 1 \mathrm{M}$, y un mes en la cámara de carbonatación.

Como muestra para la termogravimetría, se tomó una pequeña porción de las pastas que se pulverizó en un mortero de ágata. La muestra analizada siempre se tomó de la superificie original de cada pasta de modo que hubiera sufrido la exposición a los cloruros desde el momento de la inmersión en la disolución de cloruro sódico. A la 
muestra pulverizada se le eliminó el agua no combinada mediante su filtrado y sucesivos lavados con acetona, tras lo cual se introdujo en una estufa a $60^{\circ} \mathrm{C}$ durante unos $15 \mathrm{~min}$. Finalmente se tamizó cada una de las muestras con un tamiz de $80 \mu \mathrm{m}$. La porción que no se retuvo en el tamiz fue la destinada a introducir en la termobalanza para su ensayo (aproximadamente $30 \mathrm{mg}$ ).

La termobalanza empleada es una Mettler Toledo TGA850 (Figura 42) de brazo horizontal. El ensayo consistió en la aplicación de una rampa de temperatura de $10^{\circ} \mathrm{C} / \mathrm{min}$ hasta $600^{\circ} \mathrm{C}$ que se realizó sobre la muestra en un crisol de aluminio sellado y perforado (Figura 43 dcha.). La atmósfera de este método fue inerte, concretamente nitrógeno, a un caudal de $75 \mathrm{ml} / \mathrm{min}$.

Adicionalmente se realizó una serie de amasadas de morteros de cemento sin FCC y con un $15 \%$ de FCC, a las que se les incorporó diferentes cantidades de cloruros en el agua de amasado $(0,0,5,1,2$ y $5 \%)$. Las probetas que se fabricaron fueron probetas prismáticas

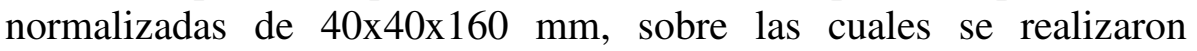
ensayos de resistencia a flexotracción y resistencia a compresión. En dichas probetas la relación $\mathrm{a} / \mathrm{mc}$ fue constante de 0,5 y la relación árido/material cementante de 3.

\subsection{Análisis termogravimétrico de las pastas de cemento-FCC}

En la Figura 132 se muestran los termogramas obtenidos de las pastas de cemento para varias sustituciones de cemento por FCC tras los 28 días de curado. En todos ellos se aprecian tres picos diferenciados. La banda situada entre 100 y $180{ }^{\circ} \mathrm{C}$ corresponde a la deshidratación de los silicatos cálcicos hidratados y la etringita formados durante la hidratación del cemento. Sobre $200{ }^{\circ} \mathrm{C}$ aparece un pico correspondiente a la deshidratación de aluminatos y aluminosilicatos cálcicos hidratados de la matriz cementante. Finalmente, a unos $550^{\circ} \mathrm{C}$, se puede observar un pico correspondiente a la descomposición del hidróxido cálcico liberado durante la hidratación del cemento [82,92-98]. 


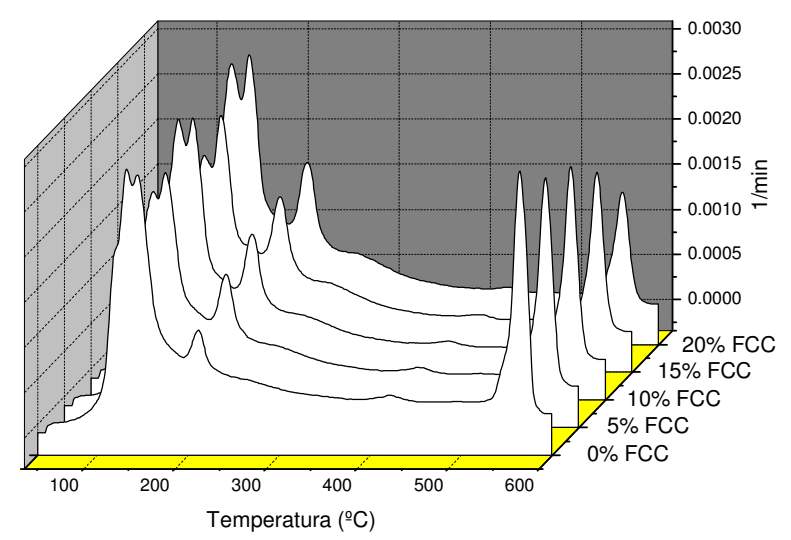

Figura 132. Curva derivada (DTG) de los termogramas para las pastas de cemento y $\mathrm{FCC}(\mathbf{a} / \mathrm{mc} 0,5)$ tras 28 días de curado en cámara húmeda.

Existen pocas diferencias cualitativas en los termogramas a medida que se aumenta la proporción de FCC en las pastas, aunque sí que las hay cuantitativas. Más adelante se detalla este aspecto, aunque lo que se observa más claramente en los termogramas es que hay una disminución del contenido de portlandita, que como ya se ha visto anteriormente se debe precisamente a dos factores: el primero es que hay una menor proporción de cemento en la pasta debido a que una parte se ha sustituido por FCC; el segundo, viene dado porque parte del hidróxido cálcico es consumido por la reacción puzolánica del FCC, que tiene como productos de reacción silicatos, aluminatos y silicoaluminatos cálcicos hidratados [97,98].

En la Tabla 26 se presentan las pérdidas termogravimétricas de las pastas de cemento para varias sustituciones de cemento por FCC tras los 28 días de curado. Se puede observar que, tal y como se esperaba, la cantidad de cal fijada aumenta al aumentar la sustitución de cemento por FCC debido a la reacción puzolánica. Consecuentemente, la pérdida de masa asociada a la descomposición de la portlandita disminuye al aumentar la sustitución. Además, el contenido de aluminatos y silicoaluminatos cálcicos hidratados sigue 
una tendencia análoga a la de la cal fijada: aumenta al aumentar el contenido de FCC en la pasta.

\begin{tabular}{||c|c|c|c|c|c||}
\hline \multicolumn{2}{|c|}{} & \multicolumn{4}{|c|}{ PÉRDIDAS (\%) } \\
\hline FCC (\%) & Cal Fijada (\%) & Total & Ca(OH) & CSH & CAH-CASH \\
\hline $\mathbf{0}$ & 0 & 20,59 & 3,11 & 17,12 & 0,36 \\
\hline $\mathbf{5}$ & 12,68 & 20,17 & 2,58 & 16,99 & 0,61 \\
\hline $\mathbf{1 0}$ & 19,19 & 21,22 & 2,26 & 18,21 & 0,75 \\
\hline $\mathbf{1 5}$ & 27,79 & 19,9 & 1,91 & 17,17 & 0,82 \\
\hline $\mathbf{2 0}$ & 43,45 & 21,28 & 1,41 & 18,95 & 0,92 \\
\hline
\end{tabular}

Tabla 26. Pérdidas termogravimétricas de pastas de cemento/FCC tras 28 días de curado.

En la Figura 133 se presentan los termogramas para las pastas con distintas sustituciones de cemento por FCC tras los 6 meses de inmersión en la disolución de $\mathrm{NaCl} 1 \mathrm{M}$. Además de los picos comentados anteriormente, se observa la aparición de uno nuevo a unos $350{ }^{\circ} \mathrm{C}$. Este pico es debido a la descomposición del cloroaluminato cálcico hidratado (sal de Friedel, $\mathrm{Ca}_{2} \mathrm{Al}(\mathrm{OH})_{6} \mathrm{Cl} \cdot 2 \mathrm{H}_{2} \mathrm{O}$ ) [158]. Es decir, el ataque de los cloruros sobre las pastas ha producido la formación de este nuevo compuesto, el cual se forma en dos etapas a partir de los aluminatos cálcicos hidratados $\left(\mathrm{C}_{3} \mathrm{AH}_{8}\right)$ y la portlandita (CH) según la Ecuación 30 y la Ecuación 31. Inicialmente la formación de este compuesto no es perjudicial ya que no produce ningún efecto adverso en las propiedades mecánicas de la matriz cementante, más bien su formación es positiva ya que consigue retrasar el avance de los cloruros hacia el interior del hormigón, lo cual retrasa la llegada de los mismos a las armaduras en el hormigón armado [158-161].

Ecuación 30

$$
\mathrm{Ca}(\mathrm{OH})_{2}+2 \mathrm{NaCl} \rightarrow 2 \mathrm{NaOH}+\mathrm{CaCl}_{2}
$$

Ecuación 31

$$
\begin{aligned}
\mathrm{CaCl}_{2}+\mathrm{Ca}_{3} \mathrm{Al}_{2} \mathrm{O}_{6} & \cdot 8 \mathrm{H}_{2} \mathrm{O}+2 \mathrm{H}_{2} \mathrm{O} \rightarrow \\
& \rightarrow \mathrm{Ca}_{4} \mathrm{Al}_{2} \mathrm{O}_{6} \mathrm{Cl}_{2} \cdot 10 \mathrm{H}_{2} \mathrm{O}
\end{aligned}
$$


Adicionalmente, se ha descrito que la formación de la sal de Friedel también puede llevarse a cabo a partir del monosulfoaluminato de calcio hidratado y la etringita de una forma similar sugiriendo que la presencia del ion sulfato no impide la fijación de los cloruros. Esto hace que la correlación directa de la cantidad de aluminatos cálcicos hidratados y la formación de la sal de Friedel no sea posible [160].

No obstante, como se verá más adelante, la presencia de dióxido de carbono en el medio, en un momento dado, conlleva la reversión de esta formación, por lo que libera los cloruros que se encuentran combinados formando la sal de Friedel [162,163]. El mecanismo por el cual tiene lugar este proceso es debido a que la sal de Friedel precipitada se encuentra en equilibrio según la Ecuación 32. Por ello, cuando la matriz cementante se carbonata se produce un descenso del $\mathrm{pH}$ que conlleva que el equilibrio se desplace hacia la derecha. Esto produce un aumento en la concentración de cloruros en el medio intersticial del hormigón lo cual supone un riesgo para la corrosión de las armaduras.

$$
\begin{aligned}
& \text { Ecuación } 32 \quad \mathrm{Ca}_{4} \mathrm{Al}_{2} \mathrm{O}_{6} \mathrm{Cl}_{2} \cdot 10 \mathrm{H}_{2} \mathrm{O} \leftrightarrow \\
& \leftrightarrow 4 \mathrm{Ca}^{+2}+2 \mathrm{Cl}^{-}+6 \mathrm{OH}^{-}+2 \mathrm{Al}(\mathrm{OH})_{3}+4 \mathrm{H}_{2} \mathrm{O}
\end{aligned}
$$

Otra diferencia que se puede apreciar en la Figura 133 es que las pérdidas de masa asociadas a la descomposición de la portlandita son menores que las observadas tras los primeros 28 días de curado (Figura 132). Esta disminución se atribuye fundamentalmente a la presencia de cloruros en el medio, ya que según la Ecuación 30 el paso previo a la formación de la sal de Friedel es la formación del cloruro cálcico a partir del cloruro sódico y la portlandita. Otra posible causa sería la evolución de la reacción puzolánica del FCC, aunque tras 28 días de curado inicial, ésta ya se debería haber completado. 


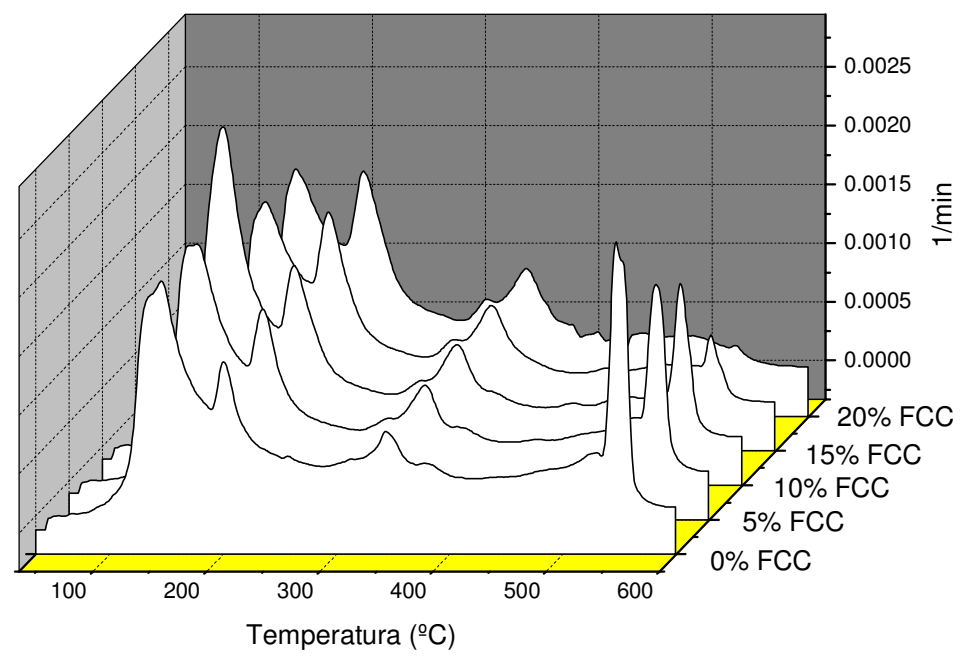

Figura 133. Curva derivada (DTG) de los termogramas para las pastas de cemento y FCC $(\mathrm{a} / \mathrm{mc} 0,5)$ tras 28 días de curado en cámara húmeda y 6 meses de inmersión en NaCl $1 \mathrm{M}$.

En la Tabla 27 se presentan las pérdidas termogravimétricas para las pastas con distintas sustituciones de cemento por FCC tras los 6 meses de inmersión en la disolución de $\mathrm{NaCl} 1 \mathrm{M}$. En ella se puede observar que la pérdida correspondiente a la portlandita disminuye al aumentar el contenido de FCC. Además también aumentan las pérdidas asociadas a los aluminatos y silicoaluminatos cálcicos hidratados cuando se aumenta la sustitución de cemento por FCC. Análogamente, las pérdidas termogravimétricas de la sal de Friedel también aumentan con la sustitución de FCC ya que, al ser superior la cantidad de aluminatos, se produce una mayor formación de sal de Friedel. 


\begin{tabular}{||c|c|c|c||}
\hline & \multicolumn{3}{|c||}{ PÉRDIDAS (\%) } \\
\hline FCC $(\boldsymbol{\%})$ & $\mathbf{C a}(\mathbf{O H})_{\mathbf{2}}$ & Sal de Friedel & CAH-CASH \\
\hline $\mathbf{0}$ & 2,13 & 0,31 & 0,44 \\
\hline $\mathbf{5}$ & 1,37 & 0,42 & 0,64 \\
\hline $\mathbf{1 0}$ & 1,09 & 0,50 & 0,81 \\
\hline $\mathbf{1 5}$ & 0,35 & 0,54 & 0,93 \\
\hline $\mathbf{2 0}$ & 0 & 0,55 & 1,10 \\
\hline
\end{tabular}

Tabla 27. Pérdidas termogravimétricas de pastas de cemento/FCC tras 28 días de curado y 6 meses de inmersión en una disolución de $\mathrm{NaCl} 1 \mathrm{M}$.

La Figura 134 muestra la cuantificación de los picos de los termogramas asociados a la descomposición del hidróxido cálcico de las pastas de cemento con distintas sustituciones de FCC. Como se ha comentado, existe una clara relación entre la cantidad de portlandita y la proporción de FCC en las pastas, a medida que aumenta el contenido en FCC más portlandita se consume. Se puede apreciar que la relación entre ambos parámetros es lineal. También se observa un descenso entre la cantidad de portlandita registrada tras los 28 días de curado y las obtenidas en los posteriores análisis tras la inmersión durante 1, 2 y 6 meses. La razón se debe al consumo de portlandita para la formación de sal de Friedel, aunque este descenso tras el curado también se podría deber a la disolución de parte de la portlandita en la disolución de $\mathrm{NaCl} 1 \mathrm{M}$ en que fueron sumergidas las pastas. Tras cada toma de muestra para su análisis, se cambiaba la disolución de $\mathrm{NaCl}$ por una nueva, por lo que se habrían esperado descensos similares tras tomar cada una de las muestras en los intervalos de tiempo estipulados. En la Figura 134 vemos que esto no sucede. Además la solubilidad del hidróxido cálcico en agua es muy baja $\left(0,127 \mathrm{~g}\right.$ en $100 \mathrm{ml}$ de agua a $\left.25^{\circ} \mathrm{C}\right)$, por lo que la cantidad que se puede disolver es muy pequeña en comparación con la que se produce durante la hidratación del cemento. La causa de este descenso tampoco parece ser la evolución de la reacción puzolánica porque incluso la pasta sin FCC presenta una disminución de hidróxido cálcico similar a las que sí lo incorporan. Por último se puede observar que tras la carbonatación la cantidad de portlandita es nula dentro de 
las pastas debido a la reacción del $\mathrm{CO}_{2}$ con el $\mathrm{Ca}(\mathrm{OH})_{2}$ para formar $\mathrm{CaCO}_{3}$.

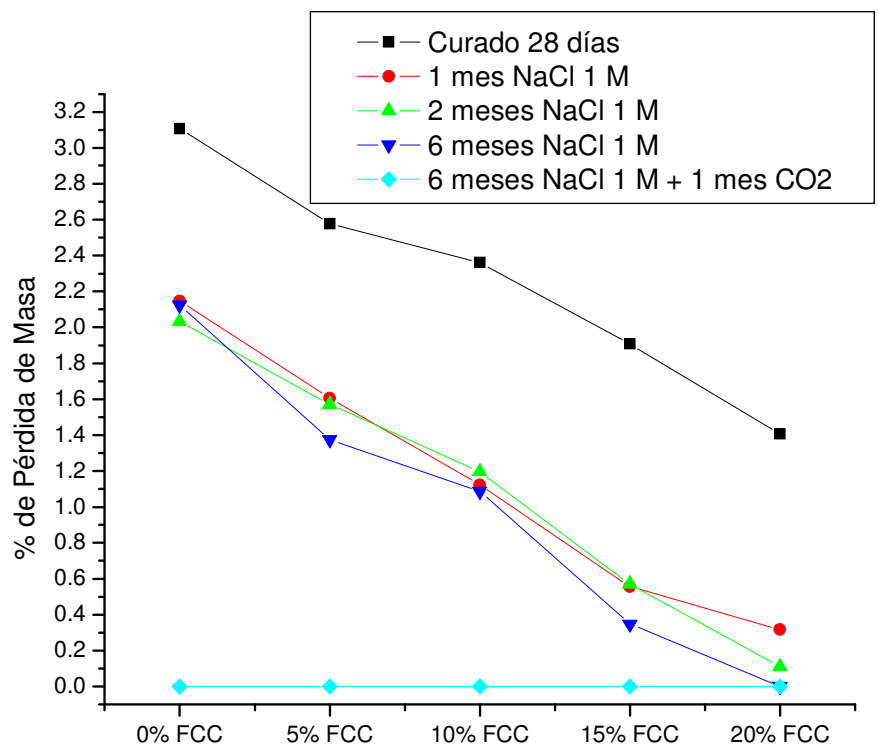

Figura 134. Cuantificación de la pérdida de masa registrada en los termogramas asociada a la portlandita en las pastas de cemento con FCC (a/mc $0,5)$ durante el proceso de ataque por cloruros.

La Figura 135 presenta la curva derivada de los termogramas obtenidos para las distintas pastas de cemento sin FCC y una relación a/mc de 0,5 durante el curado y la inmersión en la disolución de $\mathrm{NaCl}$ $1 \mathrm{M}$. Se puede observar que tras el curado, aparecen las pérdidas de masa asociadas a los productos típicos de la reacción de hidratación del cemento que ya han sido comentados. 


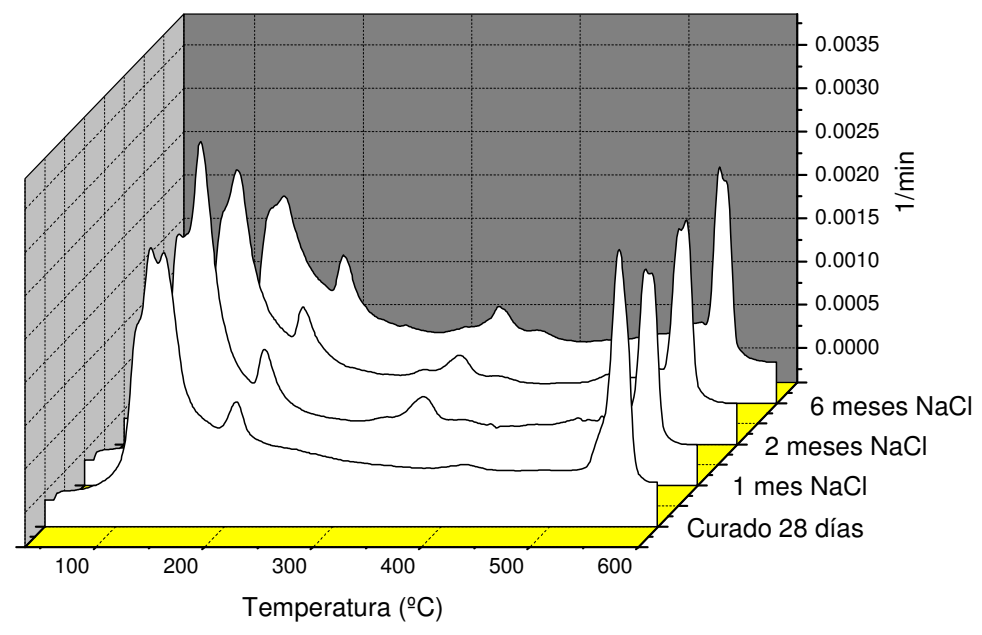

Figura 135. Curva derivada (DTG) los termogramas para una pasta de cemento $(0 \% \mathrm{FCC}, \mathrm{a} / \mathrm{mc} \mathbf{0 , 5})$ atacadas por una disolución de $\mathrm{NaCl} 1 \mathrm{M}$.

Los termogramas correspondientes a las muestras tomadas tras 1 mes, 2 meses y 6 meses de ser sumergidas en la disolución de $\mathrm{NaCl}$ $1 \mathrm{M}$ presentan pocas variaciones cualitativas con respecto al inicial, excepto por la aparición del pico debido a la descomposición de la sal de Friedel que aparece a unos $350{ }^{\circ} \mathrm{C}$. En la Tabla 28 se muestran las pérdidas termogravimétricas calculadas a partir de los termogramas para las pastas de cemento sin FCC durante el curado y la inmersión en la disolución de $\mathrm{NaCl} 1 \mathrm{M}$. De los resultados presentados en esta tabla se destaca que la sal de Friedel se forma a una elevada velocidad y agota en poco tiempo la capacidad de fijación de cloruros de la matriz cementante ya que apenas hay diferencias en la cantidad de sal de Friedel existente tras 1 mes de inmersión y tras 6 meses de inmersión. Análogamente, se produce un descenso de la cantidad de portlandita tras 1 mes de inmersión en la disolución de $\mathrm{NaCl} 1 \mathrm{M}$ que permanece aproximadamente constante hasta los 6 meses. Este descenso se debe al consumo de portlandita que se produce por la formación de sal de Friedel. 


\begin{tabular}{||c|c|c|c|c|c||}
\hline & \multicolumn{5}{|c||}{ PÉRDIDAS (\%) } \\
\hline Muestra & Total & Sal de Friedel & $\mathbf{C a}(\mathbf{O H})_{\mathbf{2}}$ & CSH & CAH-CASH \\
\hline Curado 28d & 20,59 & 0,00 & 3,11 & 17,13 & 0,36 \\
\hline $\mathbf{1}$ mes NaCl & 21,60 & 0,33 & 2,15 & 18,69 & 0,43 \\
\hline 2 meses NaCl & 20,60 & 0,25 & 2,03 & 17,93 & 0,39 \\
\hline 6 meses NaCl & 19,53 & 0,31 & 2,13 & 16,65 & 0,44 \\
\hline
\end{tabular}

Tabla 28. Pérdidas termogravimétricas de las pastas de cemento $(0 \%$ FCC, a/mc 0,5) atacadas por una disolución de $\mathrm{NaCl} 1 \mathrm{M}$.

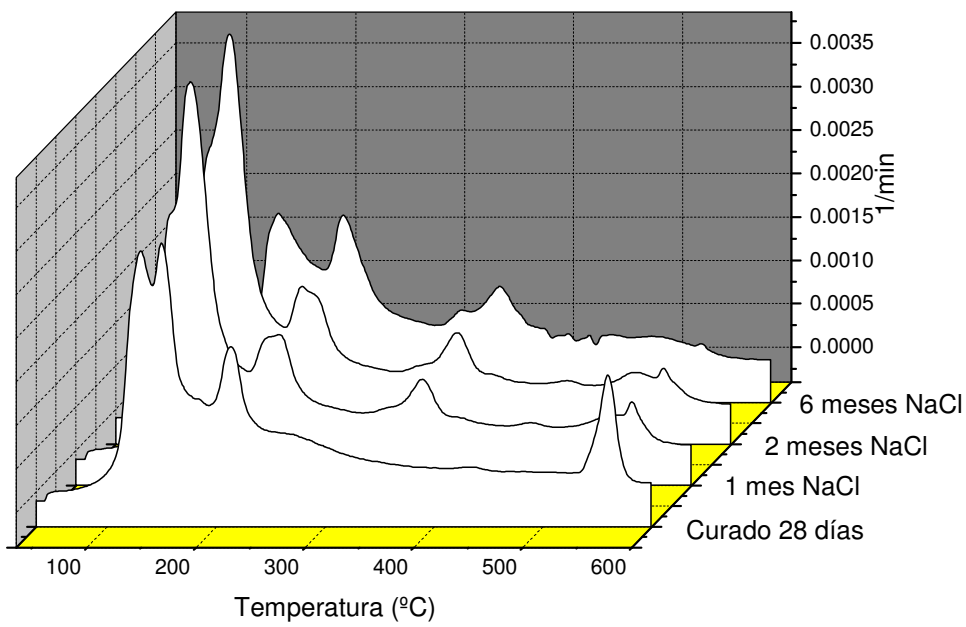

Figura 136. Curva derivada (DTG) de los termogramas para una pasta de cemento y FCC (20\% FCC, a/mc 0,5) atacadas por una disolución de $\mathrm{NaCl} 1 \mathrm{M}$.

En la Figura 136 se presenta la curva derivada de los termogramas obtenidos para las distintas pastas de cemento con un $20 \%$ de FCC y una relación a/mc de 0,5 durante el curado y la inmersión en la disolución de $\mathrm{NaCl} 1 \mathrm{M}$. En la Tabla 29 se muestran las pérdidas termogravimétricas de estas pastas. Durante el primer mes de inmersión en la disolución de $\mathrm{NaCl}$ se produce la formación de casi toda la sal de Friedel que viene acompañada por el descenso de 
portlandita paralelo a este proceso. A partir del primer mes las variaciones en la pérdida de masa asociada a la sal de Friedel son muy pequeñas por lo que se puede confirmar que la formación de la misma ocurre rápidamente y que tras el primer mes no existen variaciones importantes.

\begin{tabular}{||c|c|c|c|c|c||}
\hline \hline & \multicolumn{5}{|c||}{ PÉRDIDAS (\%) } \\
\hline Muestra & Total & Sal de Friedel & $\mathbf{C a}(\mathbf{O H})_{\mathbf{2}}$ & CSH & CAH-CASH \\
\hline Curado 28d & 21,28 & 0,00 & 1,41 & 18,95 & 0,92 \\
\hline $\mathbf{1}$ mes NaCl & 23,74 & 0,51 & 0,32 & 21,88 & 1,03 \\
\hline $\mathbf{2}$ meses NaCl & 24,20 & 0,61 & 0,11 & 22,72 & 1,08 \\
\hline $\mathbf{6}$ meses NaCl & 18,56 & 0,55 & 0,00 & 16,92 & 1,10 \\
\hline
\end{tabular}

Tabla 29. Pérdidas termogravimétricas de las pastas de cemento y $20 \%$ FCC $(\mathrm{a} / \mathrm{mc} 0,5)$ atacadas por una disolución de $\mathrm{NaCl} 1 \mathrm{M}$.

En la Figura 137, donde se cuantifican las pérdidas de masa debidas a la descomposición de la sal Friedel, se observa que para todas las pastas, existe muy poca variación en la pérdida de masa asociada al pico de la sal de Friedel tras el primer mes de inmersión en la disolución. Además, en la Figura 137 se pone de manifiesto que a medida que se aumenta el porcentaje de sustitución de cemento por FCC se produce una mayor cantidad de sal de Friedel en la pasta, aunque esto no se aprecia a simple vista en los termogramas presentados en la Figura 133. Esta diferencia en la cantidad de sal de Friedel formada, se atribuye a la mayor cantidad de aluminatos en la matriz cementante de las pastas con FCC, ya que los productos de la reacción puzolánica son aluminatos y silicoaluminatos cálcicos hidratados. 


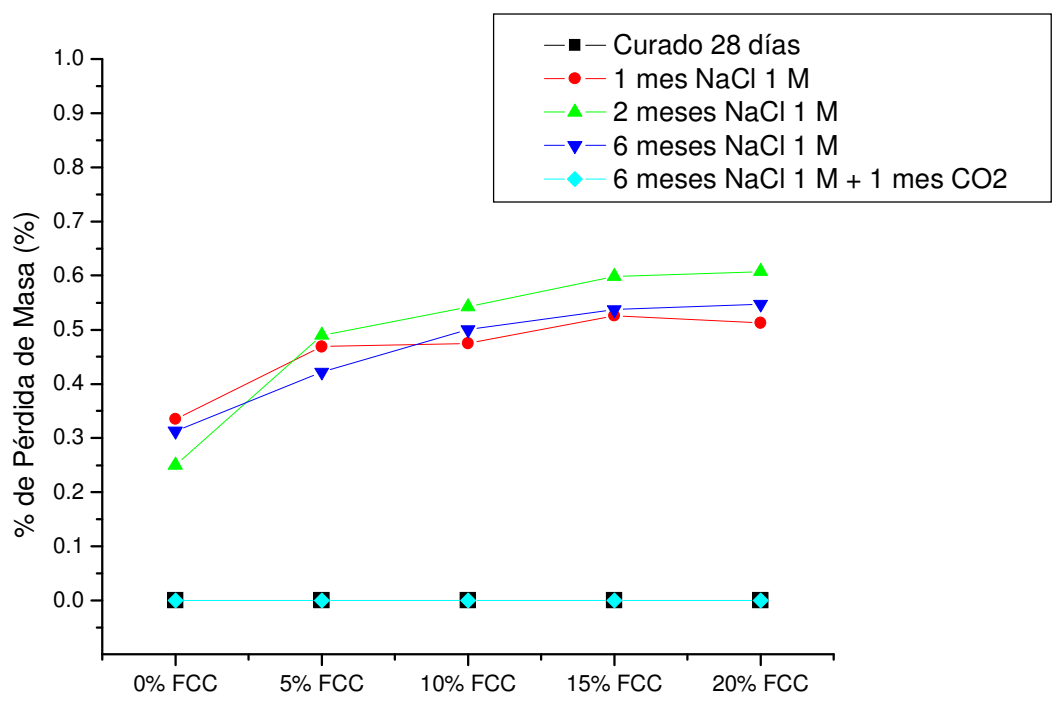

Figura 137. Cuantificación de la pérdida de masa registrada en los termogramas asociada al cloroaluminato cálcico hidratado (sal de Friedel) en las pastas de cemento con $\mathrm{FCC}(\mathrm{a} / \mathrm{mc} \mathbf{0 , 5})$ durante el proceso de ataque por cloruros.

En la Figura 138 se ha cuantificado el pico correspondiente a la deshidratación de los aluminatos y silicoaluminatos cálcicos hidratados para las pastas de cemento con distintas sustituciones de FCC. Como se puede observar, una mayor proporción de FCC en la pasta produce una mayor formación de estos compuestos cementantes. Dado que los aluminatos cálcicos hidratados son los responsables de la fijación de los cloruros a través de la formación de cloroaluminatos cálcicos hidratados, se entiende que una mayor proporción de FCC en las muestras consiga fijar una mayor cantidad de cloruros. 


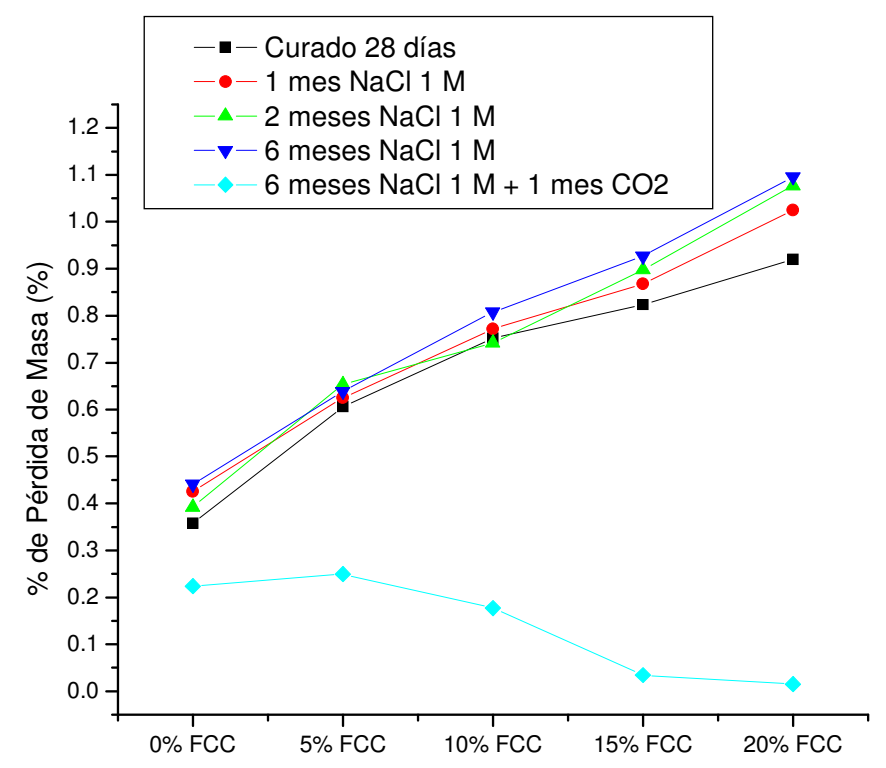

Figura 138. Cuantificación de la pérdida de masa registrada en los termogramas asociada a los CAH-CASH en las pastas de cemento con FCC $(\mathbf{a} / \mathrm{mc} 0,5)$ durante el proceso de ataque por cloruros.

Por último, queda analizar el resultado que produjo el ataque mediante dióxido de carbono posterior al ataque por cloruros. En la Figura 139 se presentan los termogramas obtenidos para las pastas de cemento y FCC tras haber sido curadas durante 28 días, sumergidas en $\mathrm{NaCl} 1 \mathrm{M}$ durante 6 meses y almacenadas en la cámara de carbonatación durante 1 mes. En ella se pueden apreciar claramente cuáles han sido los efectos producidos por la carbonatación acelerada de las pastas.

En primer lugar, como era de esperar, ha desaparecido el pico correspondiente a la descomposición del hidróxido cálcico $\left(550{ }^{\circ} \mathrm{C}\right)$ debido a que el ataque por dióxido de carbono produce una reacción entre ambos que da lugar a la formación de carbonato cálcico. Además se observa una disminución del pico correspondiente a los aluminatos y silicoaluminatos cálcicos hidratados $\left(200^{\circ} \mathrm{C}\right)$, producidos por la captura del calcio de estas fases para la formación adicional de 
carbonato cálcico. Estos dos aspectos ya se habían comentado en capítulos anteriores de este trabajo. Por último, se observa que también han desaparecido los picos correspondientes al cloroaluminato cálcico hidratado $\left(350^{\circ} \mathrm{C}\right)$, por el mecanismo descrito anteriormente: la bajada del $\mathrm{pH}$ de la disolución instersticial debido a la carbonatación produce que se descomponga la sal de Friedel según la Ecuación 32 [162,163]. Este proceso conlleva la liberación al medio de los cloruros que habían sido fijados a la matriz cementante poniendo en grave riesgo el estado de pasivación de las armaduras, ya que a la bajada de $\mathrm{pH}$ se une el aumento de la concentración de cloruros. Si se observa de nuevo la Figura 134, Figura 137 y Figura 138 se pueden ver claramente los resultados de este ataque. En la Figura 134 se aprecia que, para todas las pastas el hidróxido cálcico ha desaparecido; en la Figura 137 se observa que no queda sal de Friedel en las muestras; y por último, en la Figura 138 se pone de manifiesto una clara reducción en las pérdidas de masa debidas a la deshidratación de los aluminatos y silicoaluminatos cálcicos hidratados.

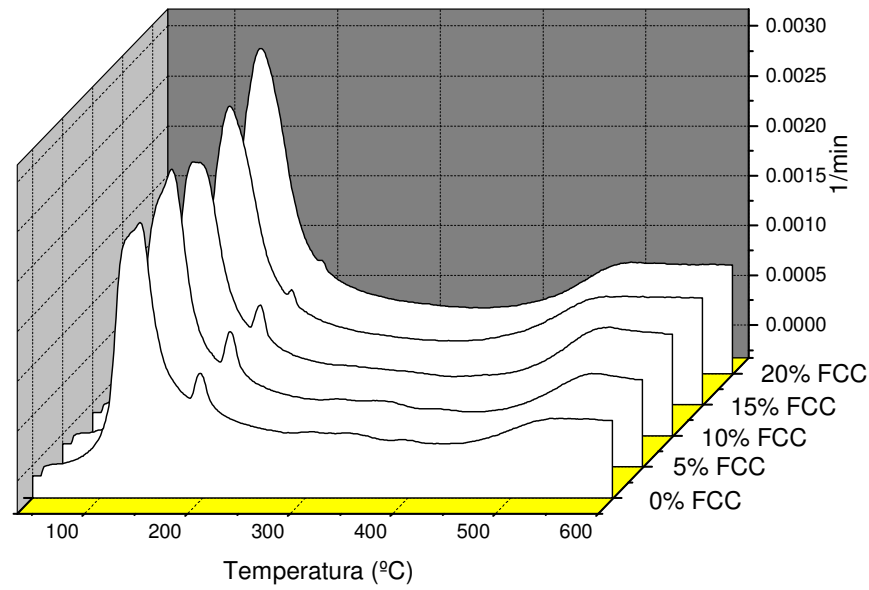

Figura 139. Curva derivada (DTG) de los termogramas para las pastas de cemento y FCC $(\mathrm{a} / \mathrm{mc} 0,5)$ tras 28 días de curado en cámara húmeda, 6 meses de inmersión en $\mathrm{NaCl} 1 \mathrm{M}$ y un mes en cámara de carbonatación acelerada. 
El resultado de esta combinación de procesos, primero el ataque por cloruros y después por dióxido de carbono, se puede anticipar como muy peligroso para un hormigón armado. Por un lado, el dióxido de carbono ha liberado todos los cloruros que se encontraban fijados como sal de Friedel a la disolución intersticial. Por el otro, el dióxido de carbono ha consumido toda la portlandita de la matriz cementante que se encarga de mantener un elevado $\mathrm{pH}$ en el medio intersticial que asegura la correcta pasivación del acero de las armaduras. Estos dos fenómenos elevarían enormemente el riesgo de fallo prematuro de una estructura por efecto de la corrosión de sus armaduras por el ataque combinado del dióxido de carbono y los cloruros.

\subsection{Influencia de los cloruros en la propiedades mecánicas de morteros de cemento-FCC}

En la Figura 140 se muestra la resistencia a flexotracción de probetas de mortero con un $15 \%$ de FCC y sin FCC, en las que se incluyeron distintas cantidades de cloruros en el agua de amasado. En dicha gráfica se puede comprobar que la resistencia a flexotracción de los morteros sin cloruros es superior para el caso del mortero que incorpora un $15 \%$ de FCC. Además, la resistencia a flexotracción de los morteros sin FCC permanece prácticamente invariable para todas las concentraciones de cloruros. Para adiciones de cloruros comprendidas entre el 0,5 y el $2 \%$, la resistencia a flexotracción de los morteros con FCC presenta valores similares a los ofrecidos por los morteros sin FCC. Finalmente, con una adición del 5\% de cloruros la resistencia de los morteros con FCC es algo inferior a la que se observa para el mortero control sin FCC.

Dado que las variaciones que se pueden producir en la matriz cementante sólo podrían ser atribuidas a la formación de sal de Friedel, parece lógico que el mortero con FCC presente más cambios que el mortero sin FCC, dado que aquel sufre una mayor transformación de los constituyentes de la pasta de cemento. No obstante, cabe destacar que adiciones de cloruros de hasta el $2 \%$ con respecto a la masa de cemento, no producen un empeoramiento del mortero con FCC respecto del mortero control. 


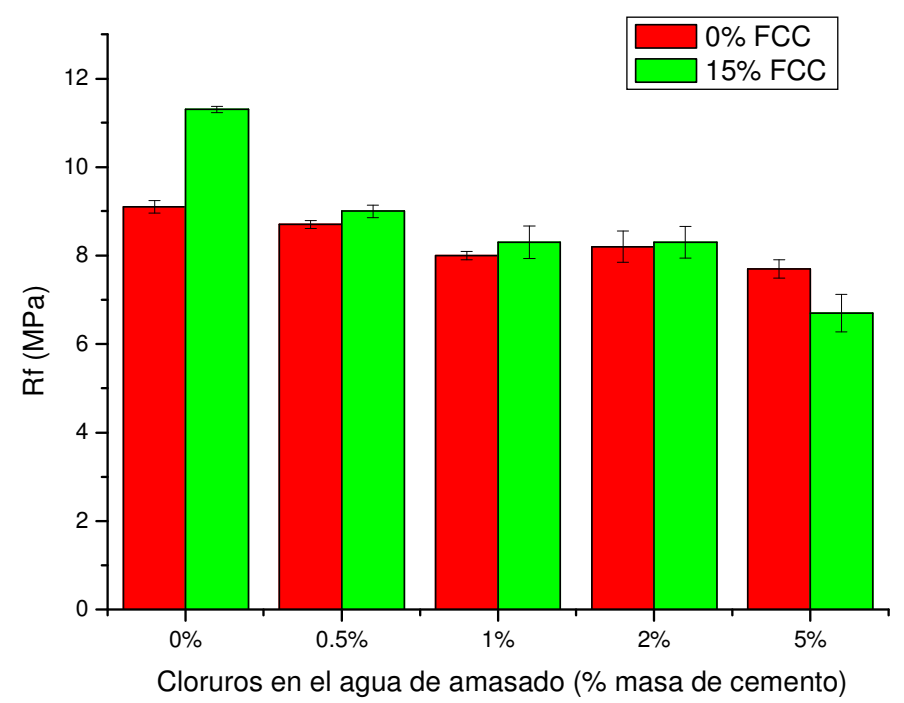

Figura 140. Resistencia a flexotracción de morteros de cemento/FCC con diferentes adiciones de cloruros en el agua de amasado.

En la Figura 141 se muestra la resistencia a compresión de probetas de mortero con un $15 \%$ de FCC y sin FCC, en las que se incluyeron distintas cantidades de cloruros en el agua de amasado. En este caso se observa que la resistencia a compresión de los morteros con un $15 \%$ de FCC no presenta variaciones al incrementar el contenido de cloruros en el agua de amasado. Por otro lado, el mortero sin FCC sufre un leve incremento de la resistencia a compresión al incorporar un $0,5 \%$ de cloruros, permaneciendo invariable después hasta el $5 \%$ de cloruros.

Parece ser, por tanto, que la incorporación de cloruros no afecta de forma negativa a la resistencia a compresión de los morteros con FCC, y se destaca además que para todas las adiciones de cloruros estudiadas, el mortero con un $15 \%$ de FCC ofrece un incremento de resistencia a compresión entre el 10 y el $25 \%$ con respecto al mortero $\sin$ FCC. 


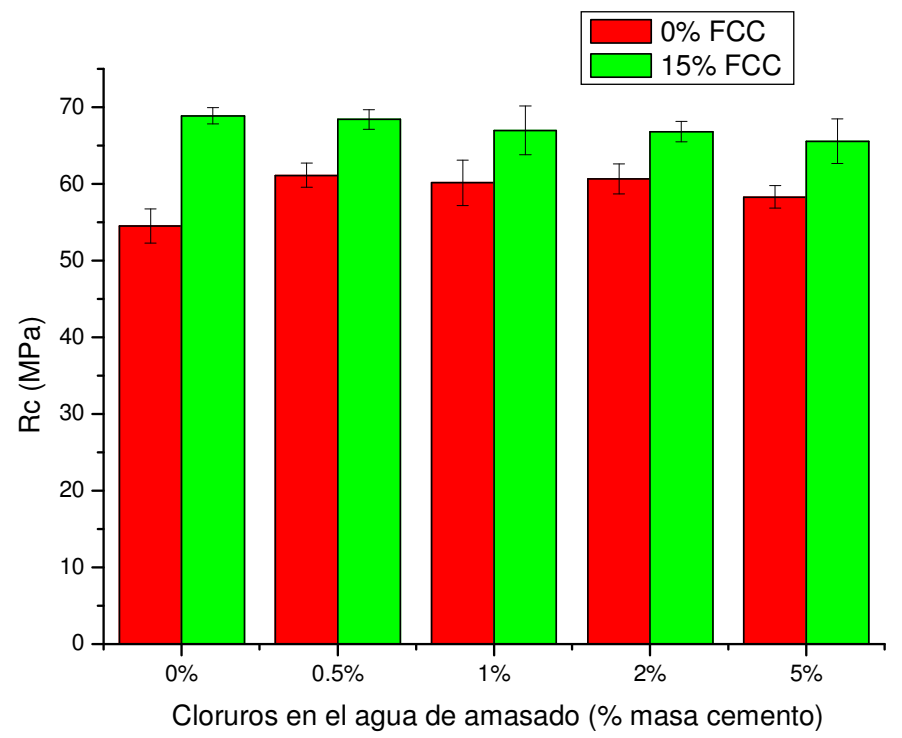

Figura 141. Resistencia a compresión de morteros de cemento/FCC con diferentes adiciones de cloruros en el agua de amasado.

Finalmente, en la Tabla 30 se muestran los valores de resistencias mecánicas representados en la Figura 140 y la Figura 141. El intervalo que se muestra se corresponde con la desviación estándar de los 3 datos obtenidos para cada valor de la resistencia a flexotracción y los 6 correspondientes a cada resistencia a compresión.

\begin{tabular}{||c|c|c|c|c||}
\hline \multirow{2}{*}{$\begin{array}{c}\text { CLORUROS } \\
\text { ADICIONADOS } \\
(\% \text { masa cemento })\end{array}$} & $\mathbf{0 \%}$ FCC & $\mathbf{1 5 \%}$ FCC & 0\% FCC & $\mathbf{1 5 \%}$ FCC \\
\cline { 2 - 5 } & $9,10 \pm 0,14$ & $11,25 \pm 0,07$ & $54,5 \pm 2,2$ & $68,9 \pm 1,1$ \\
\hline $0 \%$ & $8,70 \pm 0,09$ & $9,00 \pm 0,14$ & $61,1 \pm 1,6$ & $68,4 \pm 1,3$ \\
\hline $0,5 \%$ & $8,00 \pm 0,09$ & $8,30 \pm 0,37$ & $60,2 \pm 2,9$ & $67,0 \pm 3,2$ \\
\hline $1 \%$ & $8,15 \pm 0,35$ & $8,25 \pm 0,35$ & $60,7 \pm 1,9$ & $66,8 \pm 1,3$ \\
\hline $2 \%$ & $7,65 \pm 0,21$ & $6,70 \pm 0,42$ & $58,3 \pm 1,4$ & $65,5 \pm 2,9$ \\
\hline $5 \%$ & & &
\end{tabular}

Tabla 30. Resistencias mecánicas de los morteros de cemento/FCC con diferentes adiciones de cloruros incorporados en el agua de amasado. 


\subsection{Conclusiones}

Así pues, del presente estudio se pueden extraer las siguientes conclusiones:

- El ataque por cloruros en mezclas que contienen FCC produce la formación de la sal de Friedel como consecuencia de la reacción de aquéllos con los productos de la reacción puzolánica.

- La formación de la sal de Friedel lleva asociada una disminución de la reserva alcalina ya que por cada dos cloruros que se fijan se necesita un átomo de calcio que se obtiene de la portlandita.

- La formación de la sal del Friedel se produce principalmente durante el primer mes de inmersión en la disolución con cloruros.

- Cuanto mayor es la proporción de FCC en la pasta mayor es la cantidad de sal de Friedel que se forma, y por tanto, mayor es la cantidad de cloruros que se fijan en la matriz cementante. Esto, a priori, mejoraría la resistencia del mortero u hormigón con FCC al ingreso de cloruros.

- La mayor formación de sal de Friedel en las pastas con FCC se debe a que éste aporta gran cantidad de aluminatos y silicoaluminatos cálcicos hidratados.

- Una carbonatación posterior de las pastas produce la descomposición de la sal de Friedel, lo que conlleva la liberación de los cloruros fijados al medio, poniendo en grave riesgo la pasivación de las armaduras.

- Desde el punto mecánico, la formación de sal de Friedel no afecta de forma negativa a los morteros que contienen FCC. 
Efecto del ataque por cloruros en la matriz cementante de los morteros mixtos de cemento-FCC 


\section{Cinética de ingreso de cloruros en morteros mixtos de cemento-FCC}

En el capítulo anterior se han presentado los resultados referentes a los cambios químicos que puede sufrir la matriz cementante mixta de cemento y FCC frente a un ataque por cloruros. Además se han analizado qué cambios introduce el FCC en esta matriz ante el ambiente agresivo que supone un ataque por cloruros. Estos datos resultan muy interesantes a la hora de entender el comportamiento del ingreso de cloruros. Para evaluar cómo afecta la introducción del FCC frente a este fenómeno se han realizado ensayos de migración de cloruros que aceleran mucho el trabajo experimental y permiten comparar de manera muy efectiva la resistencia que oponen los morteros elaborados con diferentes matrices cementantes al ingreso de cloruros hacia su interior. También se han realizado ensayos de porosimetría de intrusión de mercurio y de resistividad. Este capítulo, por tanto, es muy importante desde el punto de vista aplicado ya que valora un fenómeno crucial en estructuras que sufren un ataque por cloruros externos. 


\subsection{Diseño de las experiencias}

Se han elaborado distintos morteros de cemento en los que se ha variado la sustitución de cemento por FCC y la relación a/mc. Las sustituciones empleadas en este estudio han sido 0, 5, 10, 15 y $20 \%$. El FCC fue molido previamente durante $20 \mathrm{~min}$ en un molino de bolas. Por otra parte se han usado las siguientes relaciones a/mc: 0,3 con plastificante, 0,4 con plastificante, 0,5 y 0,7. Para la fabricación de los morteros se ha usado agua destilada para evitar contaminarlos con cloruros. El plastificante usado en los morteros con relación a/mc de 0,3 y 0,4 ha sido Sika Viscocrete en cantidades variables para mantener la consistencia constante. La relación árido/material cementante ha sido $3 / 1$ en todos los casos. Se utilizado árido silíceo normalizado para la fabricación de los morteros. Las probetas fabricadas fueron de tipo cilíndrico con un diámetro de $10 \mathrm{~cm}$ y una altura de $12 \mathrm{~cm}$. Una vez amasadas las probetas se han curado bajo agua durante 28 días antes de ser sometidas a los ensayos de migración. Tras este periodo se cortaron dos discos de la parte central (se han realizado dos replicados de cada mortero) de cada probeta cuyo diámetro era $10 \mathrm{~cm}$ y cuyo espesor era $15 \mathrm{~mm}$, que serían los empleados en los ensayos de migración (Figura 142).

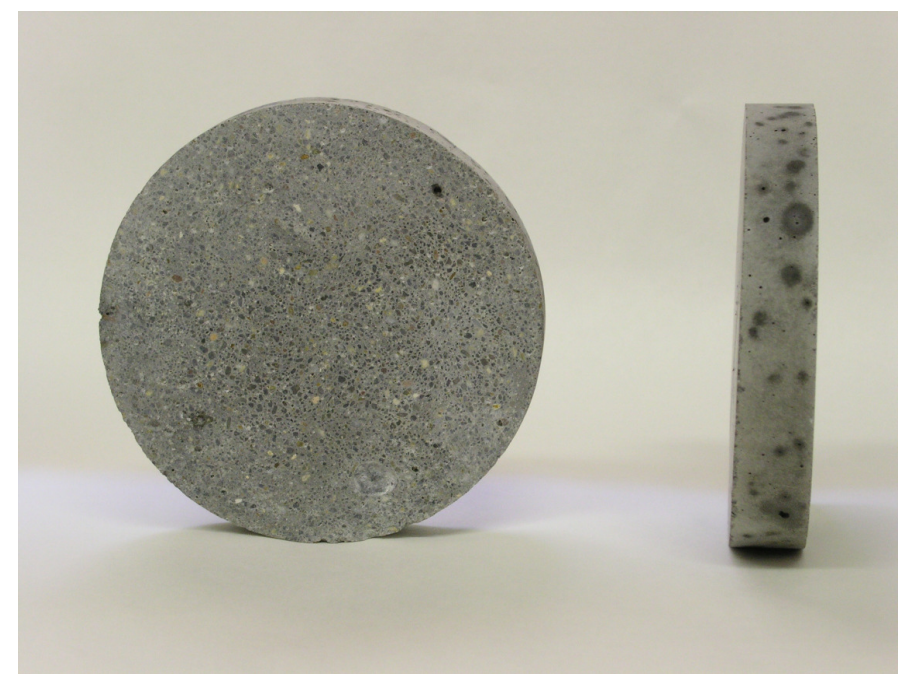

Figura 142. Fotografía de los discos de mortero empleados en los ensayos de migración de cloruros. 
Previamente a ser montados en las células de migración, los discos se saturaron para evitar que existiera aire en los poros. De esta forma se evalúa de forma más precisa el comportamiento del mortero frente al fenómeno de ingreso de cloruros, ya que a través de los poros en los que existe aire no se produce el transporte de los cloruros. Para saturarlos de agua se siguió el siguiente procedimiento [164]: se mantuvieron a vacío durante 3 horas en un desecador al que se conectó una bomba de vacío, a continuación se llenó el desecador de agua sin desconectar el vacío y tras una hora más se apagó la bomba pero manteniendo el vacío en el interior del desecador durante 18 horas más.

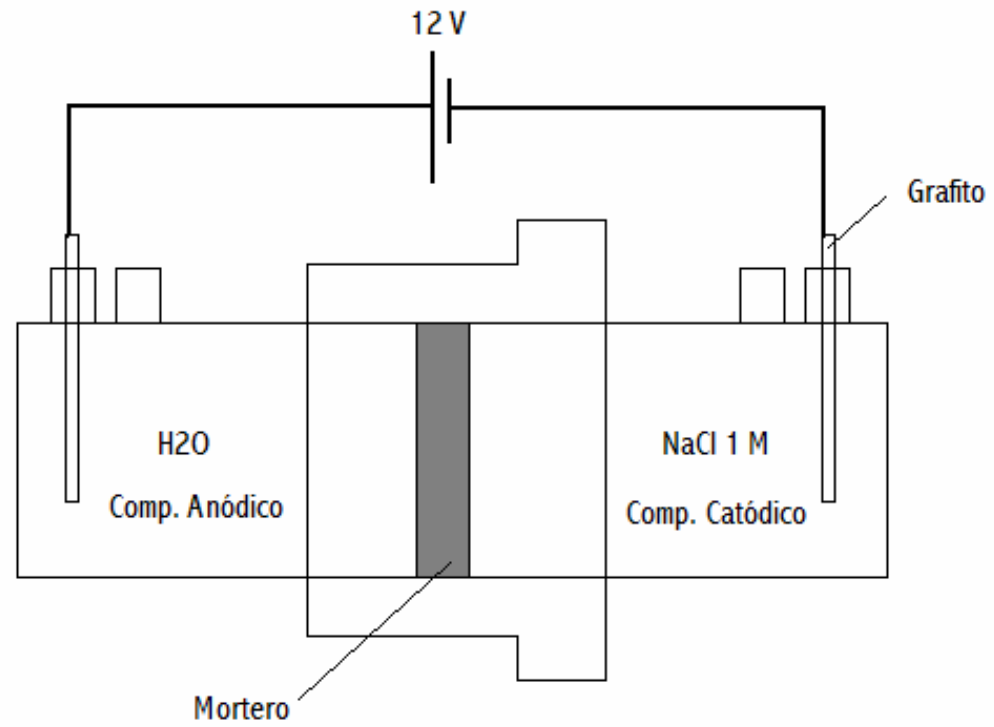

Figura 143. Esquema de la célula empleada en el ensayo de migración de cloruros.

En la Figura 143 se muestra el esquema de la célula de migración empleada en los ensayos, cuyo diseño ha sido utilizado previamente por otros autores [165,166]. El mortero a estudiar se colocó en el centro separando de forma estanca dos compartimentos. Uno de los compartimentos se llenó de agua desionizada (compartimento anódico) y el otro se llenó de una disolución de $\mathrm{NaCl}$ 
$1 \mathrm{M}$ (compartimento catódico). Se introdujo un electrodo de grafito en cada uno de los compartimentos y se aplicó una diferencia de potencial constante de $12 \mathrm{~V}$ mediante una fuente de alimentación de corriente continua, ajustando el polo positivo de la fuente al compartimento anódico y el polo negativo al catódico. De esta forma se fuerza el paso de los iones cloruro a través del mortero desde el compartimento que contiene cloruro sódico hacia el compartimento que contiene agua desionizada [166].

La monitorización del ensayo consistió en seguir la evolución de la conductividad de la disolución del compartimento anódico. Conforme aumenta la concentración de cloruros en esta parte de la célula aumenta la conductividad de dicha disolución. Posteriormente se relacionó la conductividad medida $(C)$ con la concentración de cloruros (Ecuación 33) [166], obteniéndose la curva de la evolución de los mismos durante el ensayo en el compartimento anódico.

\section{Ecuación 33}

$$
\left[\mathrm{Cl}^{-}\right](\mathrm{mM})=-1.71+11,45 \cdot \mathrm{C}(\mathrm{mS} / \mathrm{cm})
$$

Con la gráfica obtenida se puede establecer el coeficiente de difusión no estacionario y el coeficiente de difusión estacionario para el ion cloruro en cada una de las muestras. Para el cálculo de coeficiente de difusión efectivo (estado estacionario) se ha empleado la ecuación modificada de Nernst-Planck:

$$
\text { Ecuación } 34 \quad D_{s}=\frac{J R T x}{z F C_{1} \gamma \Delta \phi}
$$

Donde $D_{s}$ es el coeficiente de difusión en estado estacionario $\left(\mathrm{m}^{2} / \mathrm{s}\right), J$ es flujo de ion cloruro a través de la probeta $\left(\mathrm{mol} / \mathrm{m}^{2} \mathrm{~s}\right), R$ es la constante de los gases ideales $(\mathrm{J} / \mathrm{mol} \cdot \mathrm{K}), T$ es la temperatura $(\mathrm{K}), x$ es el espesor de la probeta $(\mathrm{m}), z$ es la carga del cloruro, $F$ es la constante de Faraday $(96485 \mathrm{C} / \mathrm{mol}), C_{1}$ es la concentración de cloruro en el compartimento catódico $\left(\mathrm{mol} / \mathrm{m}^{3}\right), \gamma$ es el coeficiente de actividad del ion cloruro en el compartimento catódico y $\Delta \Phi$ es el potencial efectivo entre las caras de la probeta en la célula de migración (V.)

Para el cálculo del coeficiente de difusión aparente (estado no estacionario) se ha usado la siguiente expresión: 
Ecuación 35

$$
D_{n s}=\frac{2 x^{2}}{\tau v^{2}}\left[v \operatorname{coth} \frac{v}{2}-2\right] ; \quad v=\frac{z F \Delta \phi}{R T}
$$

Donde $D_{n s}$ es el coeficiente de difusión en estado no estacionario $\left(\mathrm{m}^{2} / \mathrm{s}\right)$ y $\tau$ es el tiempo que tarda en comenzar a aparecer cloruro en el compartimento anódico (s).

Para poder hallar los dos coeficientes de difusión $D_{s}$ y $D_{n s}$ se debe determinar la pendiente de la curva $\left[\mathrm{Cl}^{-}\right]$vs. tiempo (de la cual se deriva el flujo $J$ ) y el tiempo que tarda en iniciarse el incremento de la concentración de cloruro $\tau$, tal y como se muestra esquemáticamente en la Figura 144.

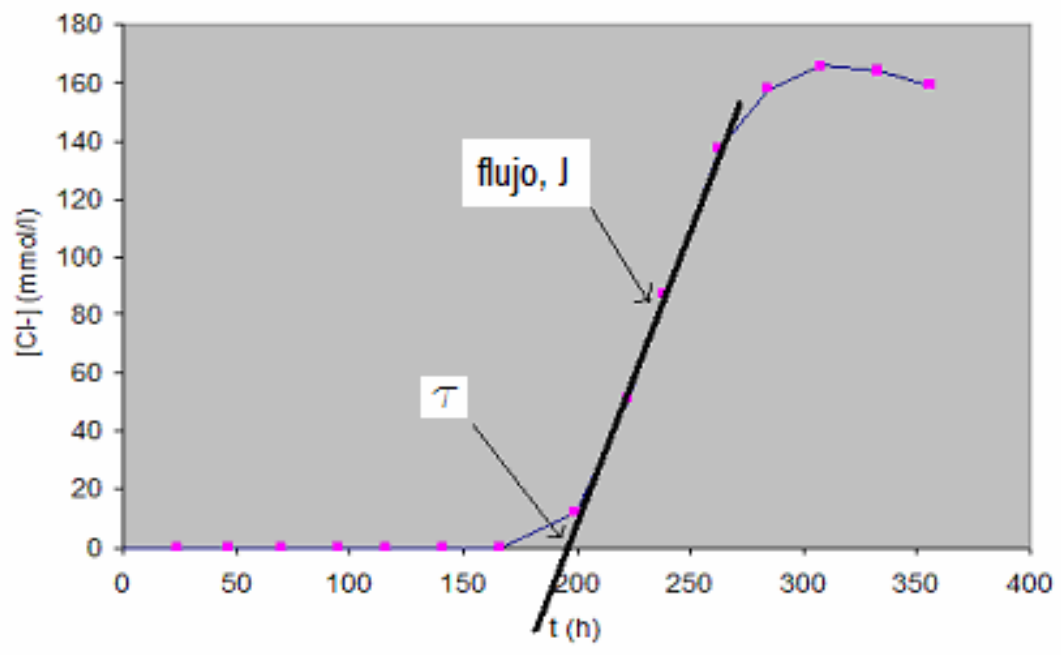

Figura 144. Esquema de una curva típica de evolución de la concentración de cloruros en el compartimento anódico en el ensayo de migración.

También se han realizado porosimetrías de intrusión de mercurio sobre algunos de los morteros usados en este estudio. En concreto, se han analizado cuatro tipos distintos de muestras de mortero: con $0 \%$ y $15 \%$ de FCC, y antes y después del ensayo de migración. De cada tipo se han realizado tres replicados. Las muestras corresponden a trozos de probeta de mortero que fueron extraídos. Las dimensiones de los trozos son aproximadamente de $1 \mathrm{~cm}^{3}$. El 
porosímetro empleado fue un Autopore IV 9500 V1.05 de la empresa Micromeritics Instrument Corporation.

Finalmente también se midió la resistividad eléctrica de los discos de mortero previamente a ser colocados en la célula de migración, mediante un equipo Gecor 8.

\subsection{Cálculo de los coeficientes de difusión de cloruros}

La Figura 145 presenta las curvas de evolución de la concentración de cloruros en el ensayo de migración para todas las relaciones a/mc y dos niveles de sustitución de cemento por $\mathrm{FCC}, 0 \%$ y $15 \%$. Anteriormente hemos comentado que los parámetros clave de este tipo de curvas son la pendiente de la zona de aumento de la concentración de cloruros y tiempo que tarda en empezar a incrementarse dicha concentración. En la Ecuación 34, cuanto mayor sea la pendiente mayor será el coeficiente de difusión en estado estacionario $\left(D_{s}\right)$. Asimismo, cuanto menor sea el tiempo que tarda en empezar a aumentar la concentración, mayor será el coeficiente de difusión en estado no estacionario $\left(\mathrm{D}_{\mathrm{ns}}\right)$ (Ecuación 35). En la Tabla 31 se presentan los datos correspondientes a las curvas de la Figura 145 a partir de los cuales se han calculado los coeficientes de difusión de los cloruros.

Así pues, lo primero que resulta evidente al observar las gráficas de la Figura 145 y los valores de la Tabla 31, es que las pendientes de los morteros con un $15 \%$ de sustitución de cemento por FCC son menores a las respectivas pendientes de los morteros control. Eso va a implicar que el flujo de cloruro a través del mortero también es inferior, tal y como se aprecia en la Tabla 31. Por tanto, los coeficientes de difusión de cloruros en estado estacionario serán menores en el caso de los morteros que tengan esta sustitución. La razón que justifica el descenso de este parámetro se encuentra principalmente en la porosidad. Cuanto más compacto es el mortero más dificultad encuentran los iones como el cloruro para migrar de un compartimento a otro. En condiciones naturales, igualmente la difusión de los iones estará más impedida cuanto más denso sea el mortero o el hormigón. Parece ser, pues, que los morteros con FCC ofrecen una microestructura menos porosa debido a los productos de 
la reacción puzolánica, lo cual hace que estos morteros tengan una mayor resistencia al ingreso de cloruros.
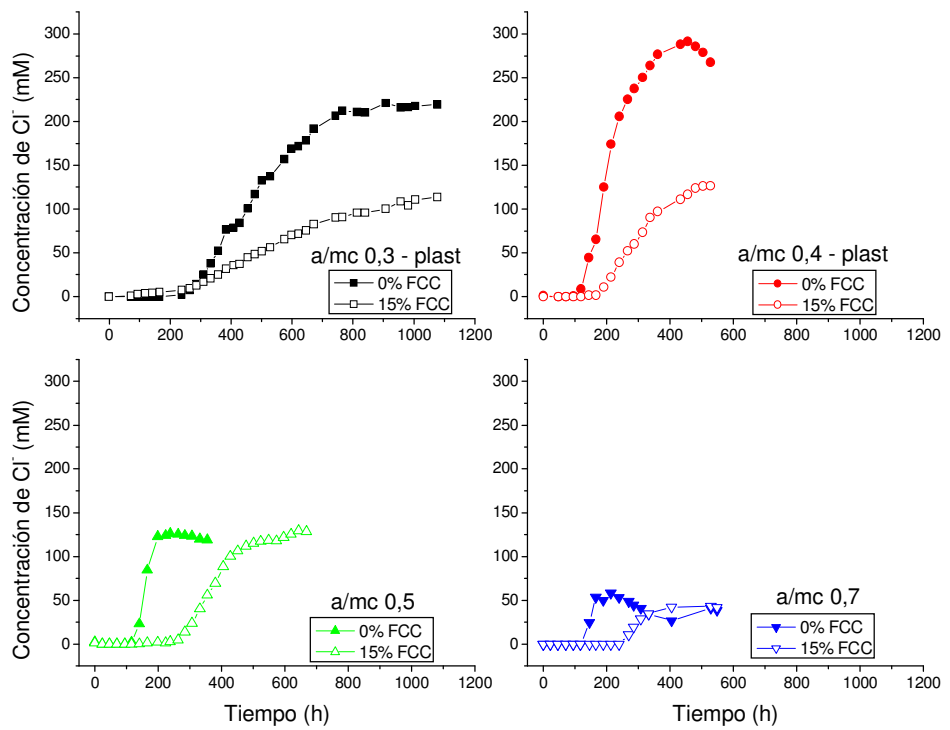

Figura 145. Curvas de evolución de la concentración de cloruros en el compartimento anódico durante los ensayos de migración.

\begin{tabular}{||c|c|c|c|c||}
\hline RELACIÓN a/mc & $\begin{array}{c}\text { FCC } \\
(\boldsymbol{\%})\end{array}$ & $\begin{array}{c}\text { PENDIENTE } \\
(\mathbf{m M} / \mathbf{h})\end{array}$ & $\begin{array}{c}\text { FLUJO } \\
\left(\boldsymbol{\mu m o l} /\left(\mathbf{c m}^{\mathbf{2}} \mathbf{)}\right)\right.\end{array}$ & $\begin{array}{c}\text { TIME LAG, } \boldsymbol{\tau} \\
(\mathbf{h})\end{array}$ \\
\hline \multirow{2}{*}{0,3} & 0 & 0,551 & 8,21 & 240,7 \\
\cline { 2 - 5 } & 15 & 0,183 & 2,76 & 327,7 \\
\hline \multirow{2}{*}{$\begin{array}{c}0,4 \\
\text { (plast.) }\end{array}$} & 0 & 1,615 & 23,34 & 140,1 \\
\cline { 2 - 6 } & 15 & 0,600 & 8,94 & 162,7 \\
\hline \multirow{3}{*}{0,5} & 0 & 1,772 & 22,71 & 156,7 \\
\cline { 2 - 6 } & 15 & 0,618 & 7,68 & 255,5 \\
\hline \multirow{2}{*}{0,7} & 0 & 0,988 & 12,71 & 120,6 \\
\cline { 2 - 6 } & 15 & 0,474 & 6,15 & 225,1 \\
\hline
\end{tabular}

Tabla 31. Parámetros obtenidos de las curvas de migración de cloruros para morteros de cemento con FCC y varias relaciones a/mc. 
Por otro lado, en todos los casos existe un retraso en el comienzo de la aparición de cloruros en compartimento anódico (time lag, $\tau$ ) en los morteros que tienen un $15 \%$ de sustitución de cemento por FCC. Este hecho tiene su origen en la variación que se produce en dos parámetros: la porosidad y la capacidad de fijación de cloruros de la matriz cementante. Como se ha podido observar, los valores de flujo son inferiores para los morteros con FCC, debido a una reducción de la porosidad de los morteros. Es lógico pues, que también se retrase el tiempo que tardan los cloruros en aparecer en el compartimento anódico debido a la reducción de dicha porosidad. Además, en el capítulo anterior se pudo comprobar que la capacidad de fijación de cloruros de las matrices cementantes que incorporan FCC es superior. Este hecho se debía a su mayor contenido en aluminatos y silicoaluminatos cálcicos hidratados que permitían una mayor formación de sal de Friedel. Este factor también produce un retraso en la aparición de los cloruros en el compartimento anódico ya que los cloruros de la vanguardia del frente son fijados como sal de Friedel. Como consecuencia de ello, los coeficientes de difusión de cloruros en estado no estacionario serán inferiores, nuevamente, en los morteros con esta sustitución.

En la Figura 146 se muestran las curvas de evolución de la concentración de cloruros en el compartimento anódico durante los ensayos de migración para los morteros con relación a/mc 0,5. En la Tabla 32 se muestran los parámetros obtenidos de las curvas presentadas en la Figura 146. Si se atienden a los parámetros clave previamente comentados, se observa que a medida que aumenta la sustitución de cemento por FCC se produce una disminución progresiva en el valor de la pendiente debido a la menor porosidad que se obtiene según se aumenta la proporción de FCC en el mortero. Además, se puede observar un retraso en el momento de aparición de los cloruros en el compartimento anódico debido tanto a la menor porosidad que se consigue al aumentar la dosificación de FCC, como a la mayor formación de sal de Friedel que tiene lugar cuando se incrementa la sustitución de cemento por FCC. Esto quiere decir que, tanto el coeficiente de difusión no estacionario, como el estacionario, serán menores conforme se aumenta el porcentaje de sustitución de cemento por FCC. 


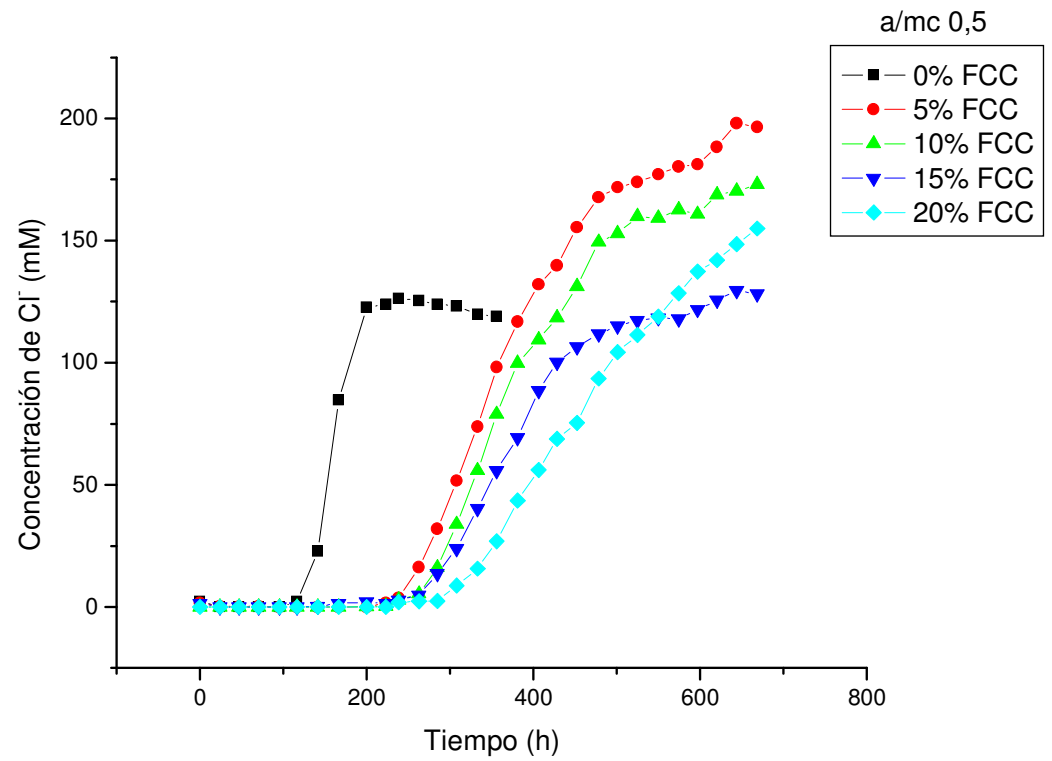

Figura 146. Curvas de evolución de la concentración de cloruros en el compartimento anódico durante los ensayos de migración para una relación a/mc de 0,5 y distintas sustituciones de FCC.

\begin{tabular}{||c|c|c|c|c||}
\hline RELACIÓN a/mc & $\begin{array}{c}\text { FCC } \\
(\boldsymbol{\%})\end{array}$ & $\begin{array}{c}\text { PENDIENTE } \\
(\mathbf{m M} / \mathbf{h})\end{array}$ & $\begin{array}{c}\text { FLUJO } \\
\left(\boldsymbol{\mu m o l} /\left(\mathbf{c m}^{\mathbf{2}} \mathbf{h}\right)\right)\end{array}$ & $\begin{array}{c}\text { TIME LAG, } \boldsymbol{\tau} \\
(\mathbf{h})\end{array}$ \\
\hline \multirow{3}{*}{0,5} & 1,771 & 22,71 & 156,7 \\
\cline { 2 - 6 } & 5 & 0,866 & 11,61 & 257,7 \\
\cline { 2 - 6 } & 10 & 0,882 & 11,57 & 268,0 \\
\cline { 2 - 6 } & 15 & 0,618 & 7,67 & 255,5 \\
\cline { 2 - 6 } & 20 & 0,538 & 6,89 & 277,2 \\
\hline
\end{tabular}

Tabla 32. Parámetros obtenidos de las curvas de migración de cloruros para morteros de cemento con varias sustituciones de FCC y relación a/me de 0,5 .

La Figura 147 presenta las curvas de evolución de la concentración de cloruros, pero en este caso para los morteros con relación a/mc 0,3 con plastificante. En la Tabla 33 se muestran los valores de los parámetros obtenidos para las curvas de la Figura 147. 
El comportamiento que se observa es similar al caso anterior. Conforme se aumenta la sustitución de cemento por FCC, se produce una disminución en el valor de la pendiente y un aumento del tiempo que necesitan los cloruros para atravesar el mortero y aparecer en compartimento anódico. La única diferencia radica, en que la curva perteneciente a un $20 \%$ de sustitución se sitúa entre las curvas del 10 y el $15 \%$, presentando este último el mejor comportamiento. Por tanto en este caso, existe un óptimo situado en el 15\%, debido, probablemente, a que la dificultad en la compactación de estos morteros (que aumenta al aumentar la cantidad de FCC) hace que el mortero con un $20 \%$ de FCC resulte ligeramente más poroso que el mortero con un $15 \%$ de FCC.

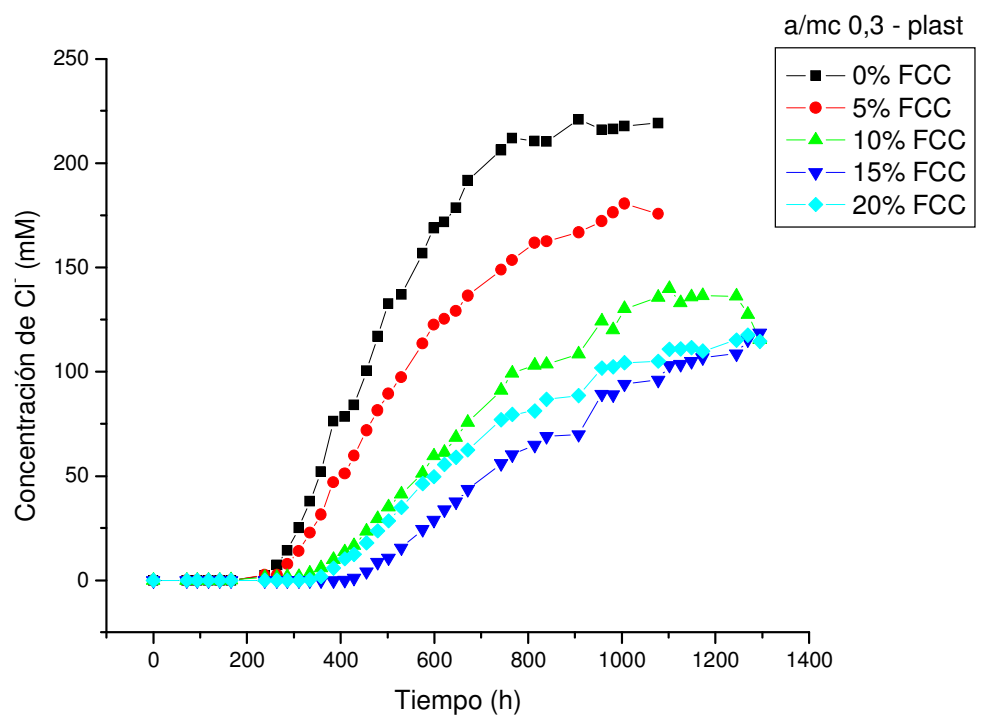

Figura 147. Curvas de evolución de la concentración de cloruros en el compartimento anódico durante los ensayos de migración para una relación a/me de 0,3 con plastificante y distintas sustituciones de FCC. 


\begin{tabular}{|c|c|c|c|c|}
\hline RELACIÓN a/mc & $\begin{array}{l}\text { FCC } \\
(\%)\end{array}$ & $\begin{array}{c}\text { PENDIENTE } \\
(\mathrm{mM} / \mathrm{h})\end{array}$ & $\begin{array}{c}\text { FLUJO } \\
\left(\mu \mathrm{mol} /\left(\mathrm{cm}^{2} \mathbf{h}\right)\right)\end{array}$ & $\begin{array}{c}\text { TIME LAG, } \boldsymbol{\tau} \\
\text { (h) }\end{array}$ \\
\hline \multirow{5}{*}{$\begin{array}{c}0,3 \\
\text { (plast.) }\end{array}$} & 0 & 0,551 & 8,21 & 240,8 \\
\hline & 5 & 0,392 & 5,81 & 270,5 \\
\hline & 10 & 0,232 & 3,45 & 355,2 \\
\hline & 15 & 0,183 & 2,76 & 327,8 \\
\hline & 20 & 0,195 & 2,95 & 380,7 \\
\hline
\end{tabular}

Tabla 33. Parámetros obtenidos de las curvas de migración de cloruros para morteros de cemento con varias sustituciones de $\mathrm{FCC}$ y relación a/me de $\mathbf{0 , 3}$ con plastificante.

En la Figura 148 se presentan los resultados calculados para los coeficientes de difusión de cloruros en estado no estacionario de los morteros estudiados. Se puede observar que a medida que se aumenta el nivel de sustitución de cemento por FCC disminuye este coeficiente. Asimismo, al reducir la relación a/mc también se acusa un descenso en este parámetro.

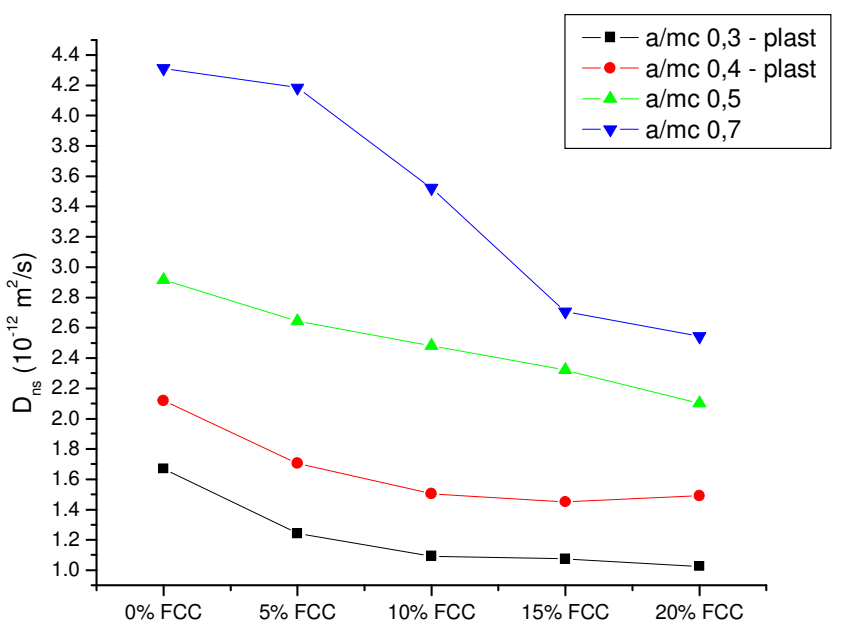

Figura 148. Coeficientes de difusión no estacionarios de los morteros en el ensayo de migración para distintas relaciones a/me y distintas sustituciones de FCC. 
El coeficiente de difusión en estado no estacionario está relacionado, como se ha visto anteriormente, con el flujo de los cloruros que atraviesan el mortero mientras todavía existe alguna capacidad de fijación de cloruros por parte de la matriz cementante. Por ello, los dos parámetros que más influyen en el coeficiente de difusión en estado no estacionario son, la porosidad del mortero y la capacidad de fijación de cloruros [167]. Cuanto mayor sea la porosidad de un mortero, más facilidad existirá en el mismo para ser atravesado por los cloruros. Dado que la porosidad viene determinada principalmente por la relación a/mc, será entonces, este parámetro el que afecte de forma más importante este aspecto. A mayor relación $\mathrm{a} / \mathrm{mc}$, mayor es la porosidad del mortero y mayor es la contribución de este componente en el coeficiente de difusión en estado no estacionario. Otro parámetro importante en este caso es que, como se ha visto en el capítulo 3, el FCC produce una reducción en la porosidad de los morteros, por lo que este factor se une al anterior, lo que produce que al aumentar la sustitución de cemento por FCC también descienda el coeficiente de difusión no estacionario.

Por otro lado, también la capacidad de fijación de cloruros de la matriz cementante tiene influencia en el coeficiente de difusión no estacionario. Esta capacidad de fijación está fundamentalmente determinada por el contenido en aluminatos cálcicos hidratados de la matriz cementante $[158,168,169]$. Estos aluminatos se combinan con los cloruros para formar cloroaluminato cálcico hidratado (sal de Friedel) [158-161]. En el capítulo anterior se observó que, dado que la contribución del FCC a la matriz cementante viene dada principalmente por aluminatos y silicoaluminatos cálcicos hidratados, es fácil entender que un aumento en el nivel de sustitución de cemento por FCC, produce un aumento en la cantidad de aluminatos presentes en la matriz. Por ello, al aumentar la cantidad de FCC se produce una mayor fijación de cloruros en la matriz cementante y se consigue retrasar el avance del frente de cloruros hacia el interior del hormigón, por lo que el coeficiente de difusión no estacionario disminuye al aumentar la sustitución de cemento por FCC.

La Figura 149 presenta los coeficientes de difusión en estado estacionario calculados para los morteros empleados en el estudio. En este caso, el coeficiente de difusión en estado estacionario no está 
afectado por la capacidad de fijación de cloruros, ya que se ha agotado prácticamente en las primeras fases del ensayo. Según avanza el frente de cloruros se va consumiendo la capacidad de fijación de cloruros. Una vez que el frente de cloruros ha atravesado todo el mortero, se han fijado la mayoría de los cloruros que era capaz de aceptar la matriz cementante por lo que la porosidad queda como único parámetro controlador del flujo de cloruros a través del mortero. Ya se ha comentado que la porosidad vendrá determinada por la relación a/mc y por el porcentaje de sustitución de cemento por FCC. Cuanto mayor sea la cantidad de FCC y menor sea la relación a/mc, menor será la porosidad, y por ello, menor debe ser el coeficiente de difusión en estado estacionario. Los resultados obtenidos, pues, concuerdan con la hipótesis en lo referente al nivel de sustitución de cemento por FCC: según aumenta la proporción de FCC, menor es el coeficiente de difusión en estado estacionario. Con respecto a la relación a/mc, se observa que, si bien los menores coeficientes de difusión en estado estacionario los presenta el mortero con relación a/mc 0,3 con plastificante, el resto de relaciones a/mc tienen valores muy similares. Este comportamiento, en principio, no era esperado ya que las propiedades de transporte de los morteros se basan fundamentalmente en la porosidad capilar de los morteros. En lo referente al nivel de sustitución sí es lógico ver la evolución ya comentada debido a que el FCC reduce notablemente la porosidad capilar. No obstante, la porosidad capilar está muy determinada por la relación a/mc, por lo que se esperaría encontrar diferencias más importantes. Por ello, puede que por encima de cierto valor de porosidad capilar, la técnica ya no logre discriminar entre los distintos morteros. Sin embargo, sí que se consigue observar la influencia de la incorporación de FCC para todos ellos. 


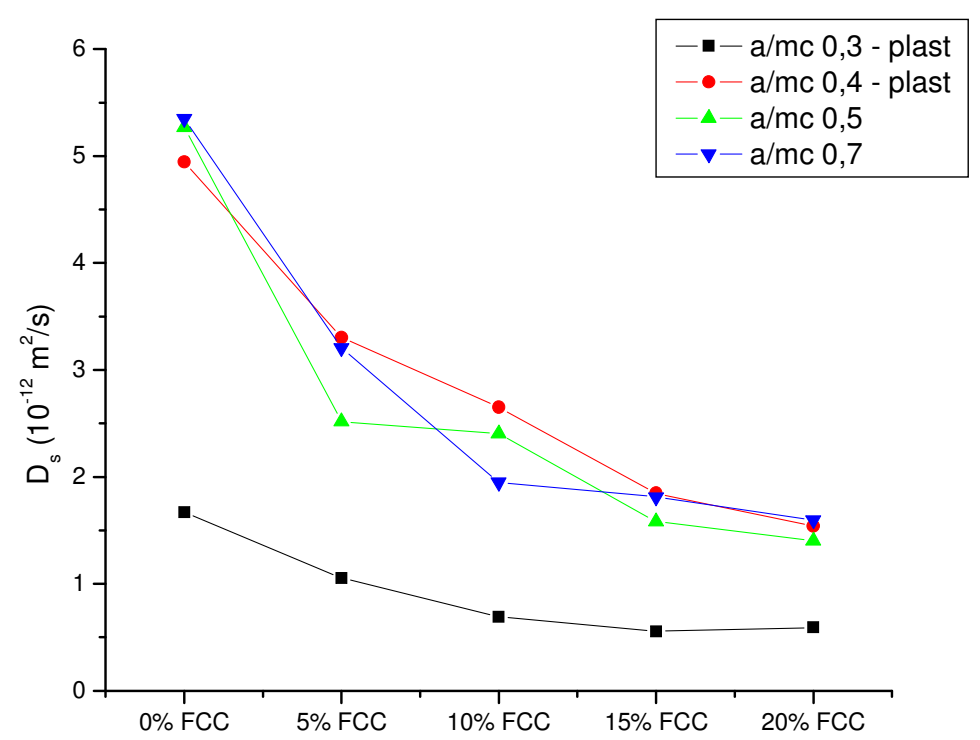

Figura 149. Coeficientes de difusión estacionarios de los morteros en el ensayo de migración para distintas relaciones a/mc y distintas sustituciones de FCC.

En estudios de migración similares realizados con metacaolín se ha podido observar un efecto similar de esta puzolana. Al aumentar la dosificación de metacaolín se producía un descenso acusado tanto del coeficiente de difusión en estado estacionario como del no estacionario $[168,169]$.

A modo de resumen se presentan en la Tabla 34 y la Tabla 35 los valores de los coeficientes de difusión de estado estacionario y no estacionario para los morteros estudiados. 


\begin{tabular}{||c|c|c|c|c||}
\hline $\mathbf{D}_{\mathbf{n s}}\left(\mathbf{x 1 0}{ }^{-12} \mathbf{~ m}^{\mathbf{2}} / \mathbf{s}\right)$ & \multicolumn{4}{|c||}{ Relación a/mc } \\
\hline Sust. FCC & $\mathbf{0 , 3}$ & $\mathbf{0 , 4}$ & $\mathbf{0 , 5}$ & $\mathbf{0 , 7}$ \\
\hline $\mathbf{0 \%}$ & 1,67 & 2,12 & 2,92 & 4,31 \\
\hline $\mathbf{5 \%}$ & 1,24 & 1,70 & 2,64 & 4,19 \\
\hline $\mathbf{1 0 \%}$ & 1,09 & 1,50 & 2,48 & 3,52 \\
\hline $\mathbf{1 5 \%}$ & 1,07 & 1,45 & 2,32 & 2,71 \\
\hline $\mathbf{2 0 \%}$ & 1,03 & 1,49 & 2,10 & 2,54 \\
\hline
\end{tabular}

Tabla 34. Valores de coeficiente de difusión de estado no estacionario ofrecidos por los morteros estudiados.

\begin{tabular}{|c|c|c|c|c||}
\hline \hline $\mathbf{D}_{\mathbf{s}}\left(\mathbf{x 1 0} \mathbf{- 1 2}^{\mathbf{2}} / \mathbf{s}\right)$ & \multicolumn{4}{|c|}{ Relación a/mc } \\
\hline Sust. FCC & $\mathbf{0 , 3}$ & $\mathbf{0 , 4}$ & $\mathbf{0 , 5}$ & $\mathbf{0 , 7}$ \\
\hline $\mathbf{0 \%}$ & 1,67 & 4,94 & 5,27 & 5,35 \\
\hline $\mathbf{5 \%}$ & 1,06 & 3,30 & 2,52 & 3,20 \\
\hline $\mathbf{1 0 \%}$ & 0,69 & 2,65 & 2,40 & 1,95 \\
\hline $\mathbf{1 5 \%}$ & 0,56 & 1,85 & 1,58 & 1,81 \\
\hline $\mathbf{2 0 \%}$ & 0,59 & 1,54 & 1,40 & 1,60 \\
\hline \hline
\end{tabular}

Tabla 35. Valores de coeficiente de difusión de estado estacionario ofrecidos por los morteros estudiados.

\subsection{Caracterización de la red de poros}

Para comprobar que el FCC ofrecía una reducción de la porosidad que entorpecía el avance del frente de cloruros se realizaron porosimetrías de intrusión de mercurio en los morteros con relación a/mc 0,5 y con $0 \%$ y un $15 \%$ de sustitución de cemento por FCC. Se tomaron muestras de los morteros antes y después del ensayo de migración. La Figura 150 presenta las porosimetrías de dichos morteros. En esta gráfica se observan dos cosas importantes. En primer lugar, efectivamente, la incorporación de un $15 \%$ de FCC produce un desplazamiento de los tamaños de poro hacia menores diámetros, como se aprecia en el primer modo de la gráfica. Por otra 
parte, el proceso de ingreso de cloruros no modifica significativamente la distribución de tamaños de poro de los morteros.

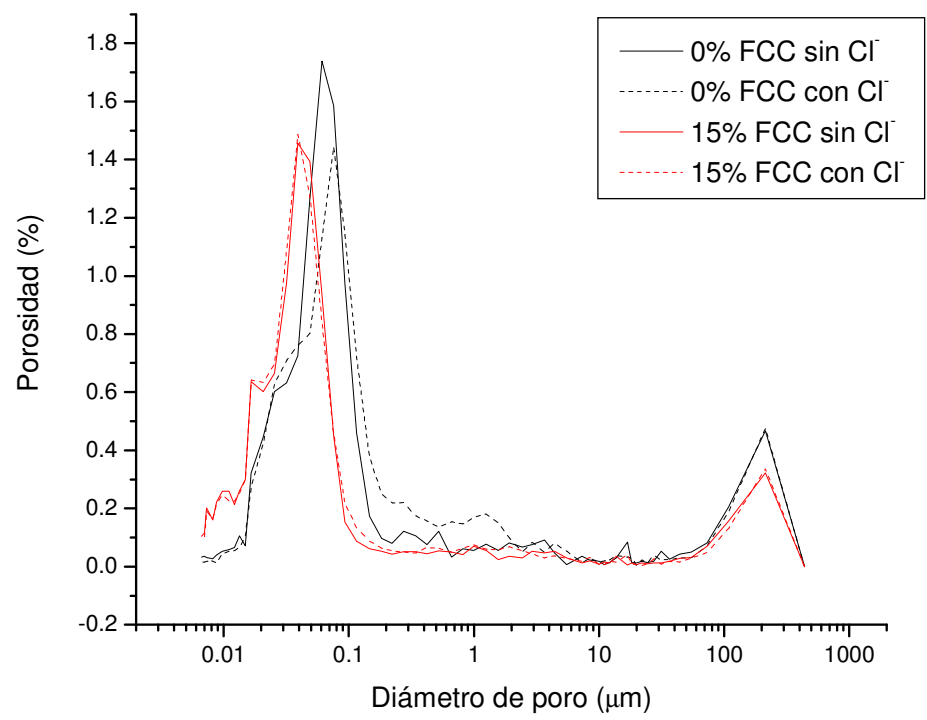

Figura 150. Porosimetrías de intrusión de mercurio de los morteros con y sin FCC realizadas antes y después del ensayo de migración de cloruros. Relación $\mathrm{a} / \mathbf{m c} \mathbf{0 , 5}$.

En los mismos ensayos de porosimetría se calculó la porosidad de los morteros, así como su densidad. En la Figura 151 aparecen los valores de densidad y porosidad de los morteros con relación a/mc 0,5 y sustituciones del 0 y el $15 \%$ de cemento por FCC, antes y después del ensayo de migración. En ella se observa lo ya comentado anteriormente, la incorporación de un 15\% de FCC aumenta ligeramente la densidad y reduce la porosidad. Además, se aprecia que el ingreso de cloruros, a pesar de que no modifica la distribución de tamaños de poro sí ofrece un leve descenso de la densidad y un aumento de la porosidad. Realmente, este último aspecto, se cree que se debe a que se produce cierto ataque sobre la matriz por la disolución del compartimento anódico en la que se genera una gran cantidad de protones que disminuye acusadamente el $\mathrm{pH}$ de dicha disolución. Este fenómeno no es natural, sino que es consecuencia de la metodología del ensayo, por lo que en una difusión natural de 
cloruros no se esperaría que se produjera este aumento de la porosidad.

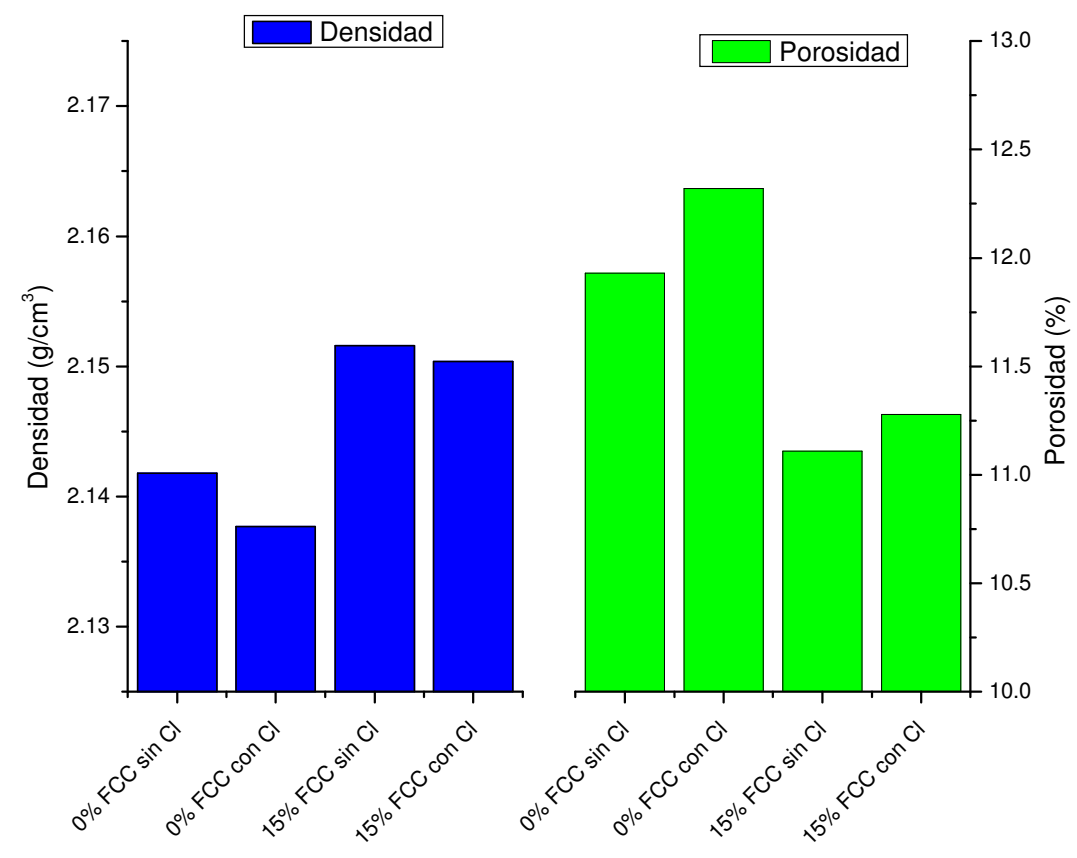

Figura 151. Densidad y porosidad de los morteros con y sin FCC realizadas antes y después del ensayo de migración de cloruros. Relación a/me 0,5.

Los procesos de transporte de sustancias agresivas, como pueden ser los cloruros o el $\mathrm{CO}_{2}$, a través de un mortero u hormigón no se llevan a cabo en todos los poros del hormigón a las mismas velocidades. En los poros de mayor tamaño, los fenómenos de transporte tienen lugar de forma mucho más rápida que en los poros más pequeños. Por ello, a la hora de entender el comportamiento de una determinada matriz frente al ingreso de agentes agresivos como los cloruros, es importante discriminar dentro de la propia porosidad de la matriz, qué parte contribuye a debilitar la resistencia al ingreso de sustancias. Normalmente se establece como criterio que la porosidad de gel, es decir, aquélla con diámetros inferiores a $0,05 \mu \mathrm{m}$, no permite el paso de las sustancias agresivas a una velocidad 
apreciable como para que sea tenida en cuenta. En cambio, la porosidad capilar, o sea, la comprendida entre 0,05 y $3 \mu \mathrm{m}$, es la que más va a afectar a los procesos de transporte [110].

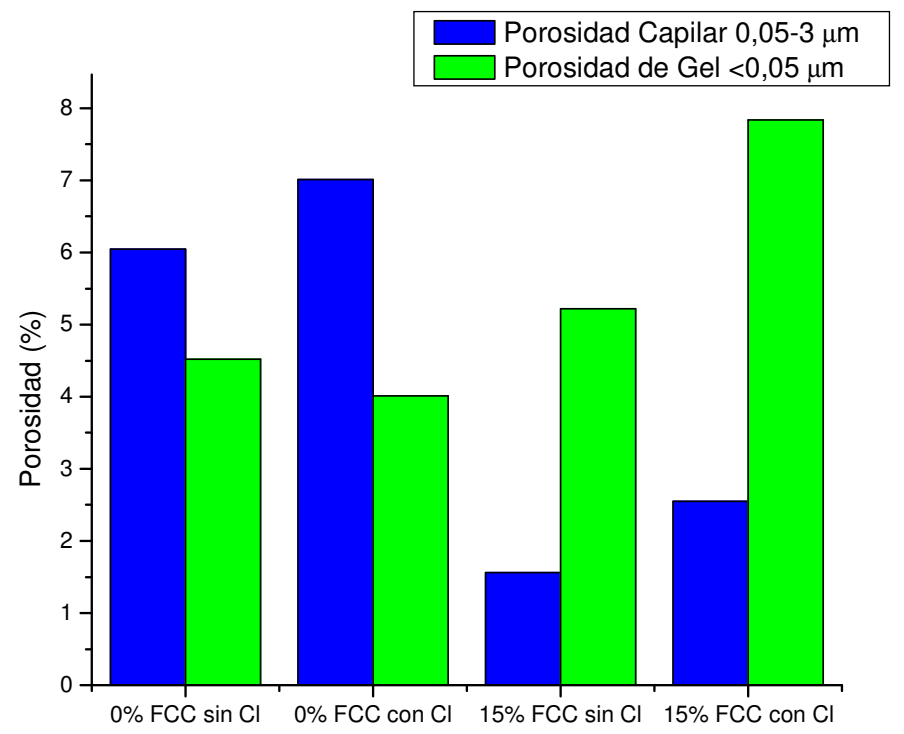

Figura 152. Porosidad capilar $(0,05-3 \mu \mathrm{m})$ y del gel $(<0,05 \mu \mathrm{m})$ de los morteros con y sin FCC, antes y después del ensayo de migración de cloruros. Relación $\mathrm{a} / \mathrm{mc}$ de 0,5 .

La Figura 152 presenta los valores de porosidad de gel y capilar para los morteros con relación a/mc 0,5 y sustituciones del $0 \%$ y el $15 \%$ de cemento por FCC. Se observa que, efectivamente, los morteros sin FCC tienen una mayor proporción de poros en el intervalo de porosidad capilar, mientras que en los morteros con un $15 \%$ de FCC el volumen de poros capilar es mucho menor. Por el contrario, el mortero con FCC presenta más porosidad de gel que el mortero control, pero los cloruros atraviesan estos poros a una velocidad demasiado baja como para que presenten un riesgo. Se comprueba entonces que el aumento de la sustitución de cemento por FCC mejora la porosidad de la matriz cementante en lo que a la resistencia al ingreso de agentes agresivos externos se refiere. 


\subsection{Medidas de resistividad de los morteros}

Por último, en este estudio también se midieron las resistividades de los morteros saturados en agua antes de que se montaran en las células de migración. Una mayor resistencia electrolítica al paso de corriente eléctrica, implica una mayor dificultad para los iones de desplazarse por un medio determinado [170]. Esta resistencia electrolítica estará en mayor medida determinada por el volumen, la conectividad y la tortuosidad de los poros de la matriz cementante por lo que los resultados obtenidos deberían seguir las mismas tendencias que las obtenidas en los cálculos del coeficiente de difusión estacionario. Cuanto menor sea la porosidad de un mortero determinado, mayor resistencia electrolítica al movimiento de iones presenta, y menor debe ser el valor del coeficiente de difusión en estado estacionario para un determinado ion.

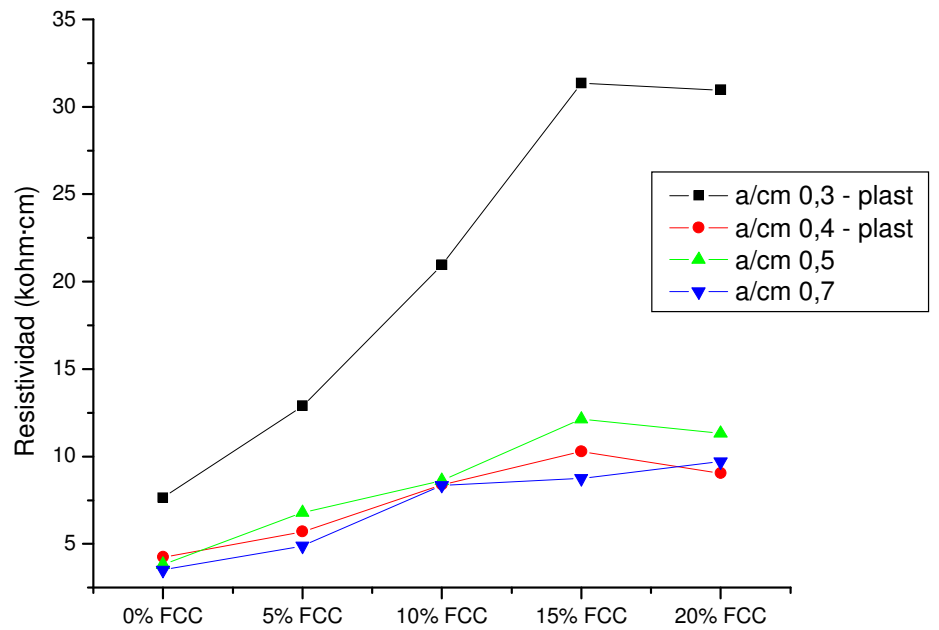

Figura 153. Resistividad de morteros con distintas relaciones a/me y distintas sustituciones de FCC.

En la Figura 153 se presentan los valores de resistividad de los morteros estudiados. Si se compara esta figura con la Figura 149, se aprecia que las tendencias concuerdan perfectamente. El mortero de 
menor relación a/mc presenta los menores valores de coeficiente de difusión de estado estacionario y los mayores valores de resistividad. También se aprecia que al aumentar el porcentaje de sustitución de cemento por FCC se produce una disminución del coeficiente de difusión en estado estacionario y un aumento de la resistividad de los morteros. Por último, los valores de resistividad y de coeficiente de difusión de estado estacionario se agrupan de la misma manera en función de la relación a/mc: 0,3 con plastificante por un lado y el resto agrupados.

En la Figura 154 se han ajustado los valores del coeficiente de difusión de estado estacionario con la resistividad eléctrica de los morteros. Como se puede observar se puede establecer una relación de tipo potencial entre ambos cuya expresión sería la siguiente:

$$
\text { Ecuación } 36 \quad D_{s}=19.641 \rho^{-1.0618}
$$

Donde $D_{s}$ vendría expresado en $\times 10^{-12} \mathrm{~m}^{2} / \mathrm{s}$ y $\rho$ en $\mathrm{kohm} \cdot \mathrm{cm}$. Este ajuste tendría un valor de $\mathrm{R}^{2}$ igual a 0,9473 con los datos utilizados.

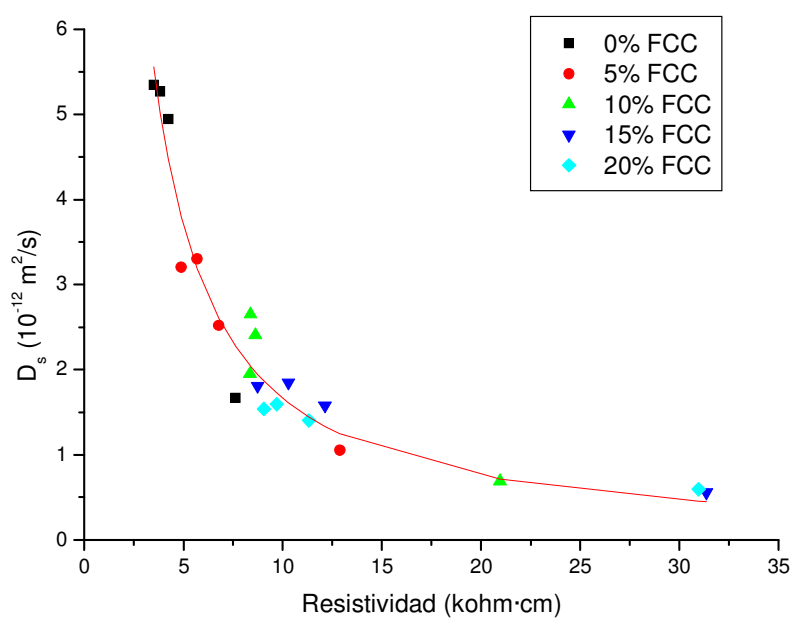

Figura 154. Relación potencial existente entre los valores de coeficiente de difusión de estado estacionario obtenidos con la resistividad eléctrica de los morteros. 
La relación casi inversa entre el coeficiente de difusión de cloruros y la resistividad mostrada en la Ecuación 36 se puede considerar una prueba de la aplicabilidad de la relación NernstEinstein para los morteros que contienen FCC. Esta relación se ha descrito anteriormente que puede ser aplicable a hormigones saturados de agua [165] y hormigones parcialmente saturados de agua [171].

\subsection{Conclusiones}

De los resultados obtenidos en este estudio se han podido extraer las siguientes conclusiones:

- La disminución de la relación a/mc produce una disminución de la porosidad de los morteros, lo que provoca una disminución del coeficiente de difusión en estado no estacionario.

- La sustitución progresiva de cemento por FCC produce una reducción de la porosidad (debido a los productos de la reacción puzolánica) y una mayor capacidad de fijación de cloruros en la matriz cementante (debido a la mayor proporción de aluminatos de calcio hidratados que ofrece a la matriz, los cuales en presencia de cloruros forman la sal de Friedel). Esto conlleva una disminución progresiva del coeficiente de difusión en estado no estacionario.

- El coeficiente de difusión de estado estacionario se ve mejorado al incorporar FCC como consecuencia de la reducción de la porosidad capilar de los morteros como resultado de la formación de productos cementantes adicionales debidos a la reacción puzolánica.

- Existe una relación de tipo potencial entre el coeficiente de difusión de estado estacionario y la resistividad eléctrica de los morteros. Cuanto mayor es la resistividad de los morteros, menor es este coeficiente. 


\section{Estudio de la velocidad de corrosión de aceros embebidos en morteros mixtos de cemento-FCC sometidos a un ataque por cloruros externos}

Una vez analizado cómo se comportan las matrices cementantes frente al ingreso de cloruros desde el exterior, en este capítulo se estudia el fenómeno de corrosión de aceros embebidos en estas matrices. En el capítulo anterior se ha podido observar que la incorporación de FCC a la matriz cementante produce un retraso en la velocidad de avance del frente de cloruros a través de la estructura porosa del mortero. En este capítulo se estudia si este retraso es significativo como para alargar los periodos de iniciación de la corrosión de las armaduras por el efecto de los cloruros externos. 


\subsection{Diseño de las experiencias}

En este estudio se han fabricado probetas similares a las ya utilizadas en el estudio de la corrosión de los aceros frente a un ataque por carbonatación (Figura 114). En este trabajo se han utilizado de nuevo dos electrodos de acero por lo que las medidas que se presentan corresponden a la media de ambos electrodos.

Los morteros elaborados como recubrimiento de los aceros se han realizado con cemento portland tipo CEM I 52,5 R. Se han realizado varias sustituciones de cemento por FCC: 0, 5, 10, 15, $20 \%$. El FCC fue molido previamente en un molido de bolas durante 20 minutos para mejorar sus propiedades puzolánicas. Además se han empleado dos relaciones a/mc, 0,5 y 0,7. El agua de amasado ha sido agua destilada, para evitar la incorporación de cloruros a través de este componente durante el amasado. La relación árido/cemento empleada ha sido 3/1. El árido empleado ha sido árido silíceo normalizado [138]. El procedimiento de amasado ha sido el amasado normalizado de mortero [139]. Las probetas se han compactado mediante el picado manual de las mismas para evitar sacudidas que pudieran mover los electrodos dentro de la probeta.

Una vez amasadas las probetas, se practicaron medidas de corrosión de los aceros desde el día siguiente hasta la finalización del ensayo de forma periódica. Tras el amasado se almacenaron en cámara húmeda $(100 \% \mathrm{HR})$ durante 100 días hasta obtener lecturas de corrosión estables. A continuación se sumergieron parcialmente en una disolución de $\mathrm{NaCl}$ 0,5 M, que simula el agua de mar, durante 125 días. Posteriormente se volvieron a introducir en la cámara húmeda durante 40 días para observar la evolución de los aceros tras el ataque al que fueron sometidos. A continuación se introdujeron las probetas en una cámara de carbonatación $\left(100 \% \mathrm{CO}_{2}, 65 \pm 5 \% \mathrm{HR}[91,124]\right)$ para ver efecto añadido de este agente agresivo sobre la corrosión de los aceros. Por último se guardaron las probetas en una cámara con una humedad relativa del $80 \%$.

Los parámetros de control en los que se ha basado este trabajo han sido el potencial de corrosión (Ecorr) y la intensidad de corrosión (Icorr). Para la medida del potencial de corrosión se ha empleado un 
electrodo saturado de calomelanos como electrodo de referencia. Las medidas de intensidad de corrosión se han llevado a cabo mediante la técnica de resistencia de polarización (Rp) [141] usando un potenciostato EG\&G modelo 362 de Princetone Applied Research. En dicha técnica se han realizado barridos desde $-10 \mathrm{mV}$ hasta $+10 \mathrm{mV}$ alrededor del potencial de corrosión en circuito abierto. La velocidad del barrido ha sido $0,5 \mathrm{mV} / \mathrm{s}$.

Una vez finalizadas todas las etapas del estudio se extrajeron los electrodos de las probetas y se limpiaron mediante una disolución de hexametiltetramina en $\mathrm{HCl} 1 \mathrm{M}$ para eliminar todos los óxidos de hierro adheridos a la superficie de los electrodos y mediante acetona, para eliminar los restos de pegamento de la cinta adhesiva utilizada para limitar el área de electrodo expuesta. Se pesaron los electrodos y se contrastó la pérdida de masa gravimétrica con la pérdida de masa electroquímica. La pérdida de masa gravimétrica se obtiene mediante la diferencia de masa de los electrodos entre el inicio y el final de estudio. La pérdida de masa electroquímica se obtiene a través de la integral de la intensidad de corrosión en función del tiempo, y aplicando la ley de Faraday.

\subsection{Influencia del porcentaje de sustitución de FCC}

En la Figura 155 se presentan las curvas de evolución de la intensidad de corrosión y el potencial de corrosión de los electrodos de acero embebidos en los morteros de cemento con distintas sustituciones de cemento por FCC y una relación a/mc de 0,5. En esta figura se muestran los resultados correspondientes a las tres primeras etapas del estudio. Al igual que se ha realizado en otros capítulos de este trabajo, en las gráficas de Icorr se puede observar una franja que se sitúa entre 0,1 y $0,2 \mu \mathrm{A} / \mathrm{cm}^{2}$ que separa la zona de corrosión activa (parte superior) de la zona de corrosión baja (parte inferior) [143]. Al inicio de las medidas los electrodos presentan valores de Icorr por encima de esta región a consecuencia de que la pasivación de los aceros requiere un tiempo determinado para que se produzca la generación de la capa pasivante sobre toda la superficie de los mismos [157]. Poco a poco los valores de Icorr van cayendo hacia la zona inactiva. Asimismo los potenciales de corrosión se desplazan hacia valores menos negativos, indicando que se está produciendo la 
pasivación de los mismos. Esto tiene lugar para los aceros embebidos en todos los morteros excepto para el que presenta la mayor sustitución de cemento por FCC. En ocasiones anteriores se ha comentado que una sustitución elevada de cemento por FCC produce una elevada demanda de agua y un descenso de la reserva alcalina. Esto produce que la compactación de los morteros sea más difícil y la porosidad resultante de los mismos sea mayor. De ahí que el comportamiento de los aceros del mortero con un $20 \%$ de FCC se separe del resto, ya que este mortero es más poroso. Consecuentemente, existe una mayor difusión de oxígeno, lo que puede hacer que los niveles de corrosión observados sean algo superiores.

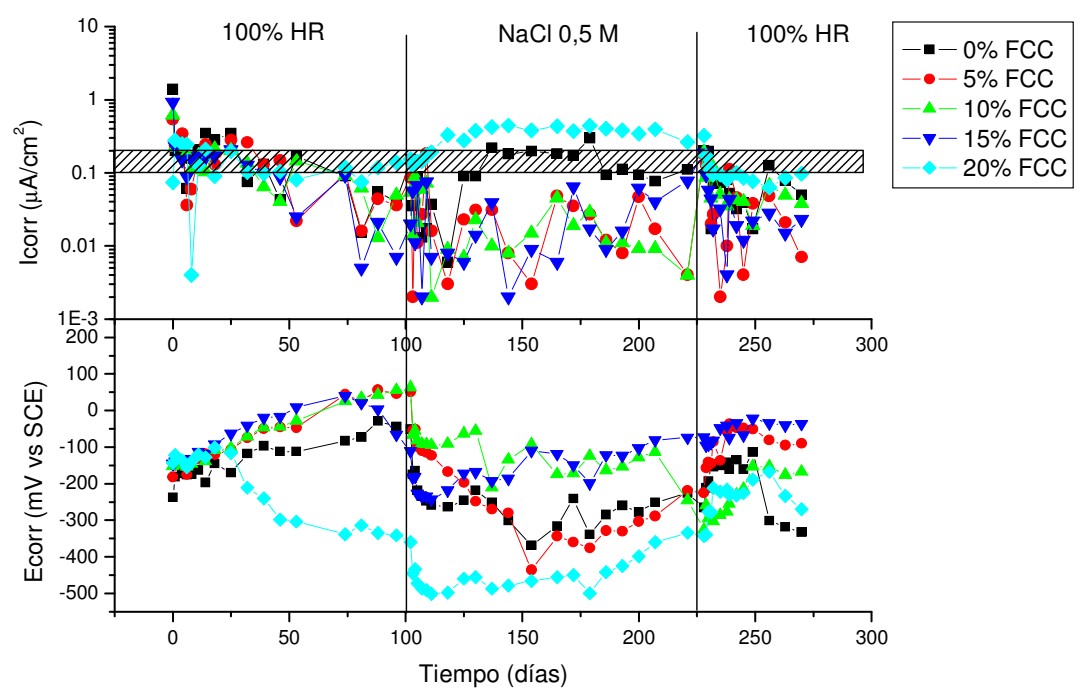

Figura 155. Evolución de la Icorr y Ecorr para los aceros embebidos en morteros con distintas sustituciones de FCC durante el ataque externo de cloruros. Relación a/me de $\mathbf{0 , 5}$.

En la primera etapa, en la que las probetas se mantuvieron en la cámara húmeda, se trataba de desarrollar adecuadamente la matriz cementante antes de someterla al ataque por cloruros. Una vez concluida, se sumergieron parcialmente las probetas en la disolución de $\mathrm{NaCl}$ 0,5 M (Figura 156). En este momento se puede apreciar como 
los potenciales de corrosión presentan un desplazamiento hacia valores más negativos tendentes a propiciar un aumento de la velocidad de corrosión de los aceros. Se puede observar que el potencial más negativo corresponde al mortero con un $20 \%$ de FCC, que como se ha comentado se sitúa fuera de la tendencia general del resto por ser el mortero más poroso. En cuanto al resto de electrodos, en general, se puede decir que cuanto mayor es la sustitución de FCC, mayor es el potencial de corrosión (menos negativo), lo cual lleva a pensar que la cantidad de cloruros que llegan a la superficie del electrodo es menor cuanto mayor es la sustitución de cemento por FCC. Si se observa la parte de la gráfica correspondiente a la Icorr, nuevamente, el comportamiento de los electrodos del mortero con $20 \%$ de FCC se separa del resto, situándose claramente en la zona de corrosión activa. La mayor porosidad del mortero antes comentada, hace que exista una mayor concentración de iones cloruro en la superficie del electrodo de acero lo que produce un incremento en los niveles de corrosión. A continuación, los aceros embebidos en el mortero control sin FCC presentan niveles de corrosión alrededor de la zona límite de corrosión activa. En cuanto a los restantes electrodos, se observa que ninguno de ellos sobrepasa el límite aceptado. En este caso, a pesar de que los cloruros han llegado a la superficie de los electrodos, su concentración no parece ser lo suficientemente elevada para producir una corrosión apreciable. Por ello se pone de manifiesto claramente, que la sustitución de cemento por FCC en cantidades de hasta el $15 \%$ produce una mejora de los niveles de corrosión de los aceros embebidos frente a un ataque por cloruros externos.

En la tercera etapa del experimento, se volvían a introducir las probetas en la cámara húmeda. Los niveles de corrosión se mantienen en los que presentaban en la etapa anterior. Los aceros del mortero con un $20 \%$ disminuyen su velocidad de corrosión debido a que en la cámara húmeda el acceso de oxígeno hacia el interior está más impedido porque los poros se encuentran saturados de agua, de ahí que disminuya la velocidad de corrosión y aumente el potencial de corrosión. 


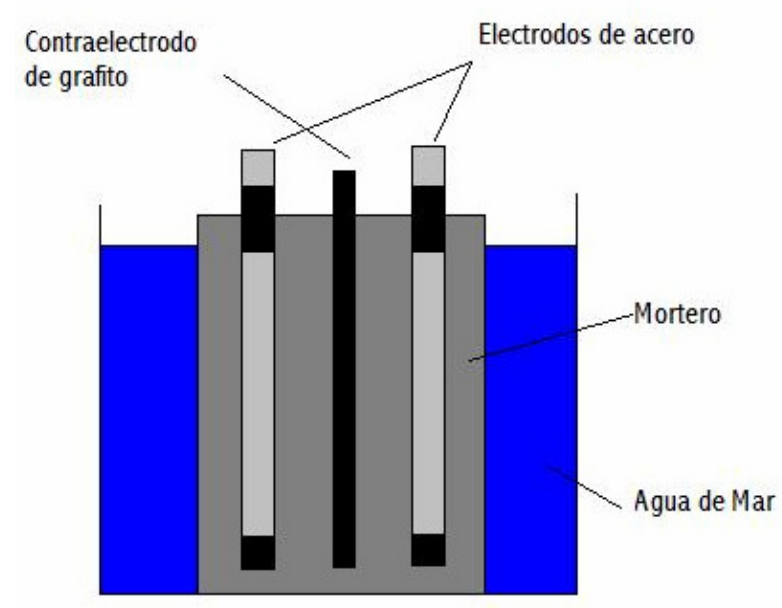

Figura 156. Esquema de la probeta de corrosión en la etapa de ataque por cloruros externos (agua de mar).

\subsection{Influencia de la relación $\mathrm{a} / \mathrm{mc}$}

La Figura 157 muestra la evolución de la intensidad de corrosión y el potencial de corrosión de los aceros embebidos en los morteros de cemento sin FCC y con un 15\% de FCC para dos relaciones a/mc, 0,5 y 0,7 , durante las tres primeras etapas del estudio. En general, las tendencias en los cambios producidos entre una etapa y otra son similares a las comentadas anteriormente.

Se observa que para una determinada sustitución de cemento por FCC el nivel de intensidad de corrosión siempre es superior para el mortero con mayor relación a/mc, debido a que la porosidad de estos morteros es mayor y se facilita el ingreso de cloruros y de oxígeno hacia el interior del mortero. Por otro lado, para ambas relaciones a/mc, los aceros del mortero con un $15 \%$ de FCC presentan una intensidad de corrosión inferior que los equivalentes del mortero control. Esto se puede observar de forma más clara en la curva de evolución de los potenciales de corrosión (ver también Tabla 36). Los aceros de los morteros con menor relación a/mc, para un mismo nivel de sustitución, presentan un potencial de corrosión menos negativo. Asimismo los aceros de los morteros con un 15\% de FCC presentan, para una misma relación a/mc, un potencial de corrosión más elevado. 
El efecto de la incorporación de FCC llega incluso a compensar la mayor porosidad que ofrece una mayor relación a/mc, ya que sitúa el potencial de corrosión del acero del mortero con $15 \%$ y una relación a/mc de 0,7 por encima del potencial del acero del mortero con $0 \%$ de FCC y relación a/mc de 0,5 .

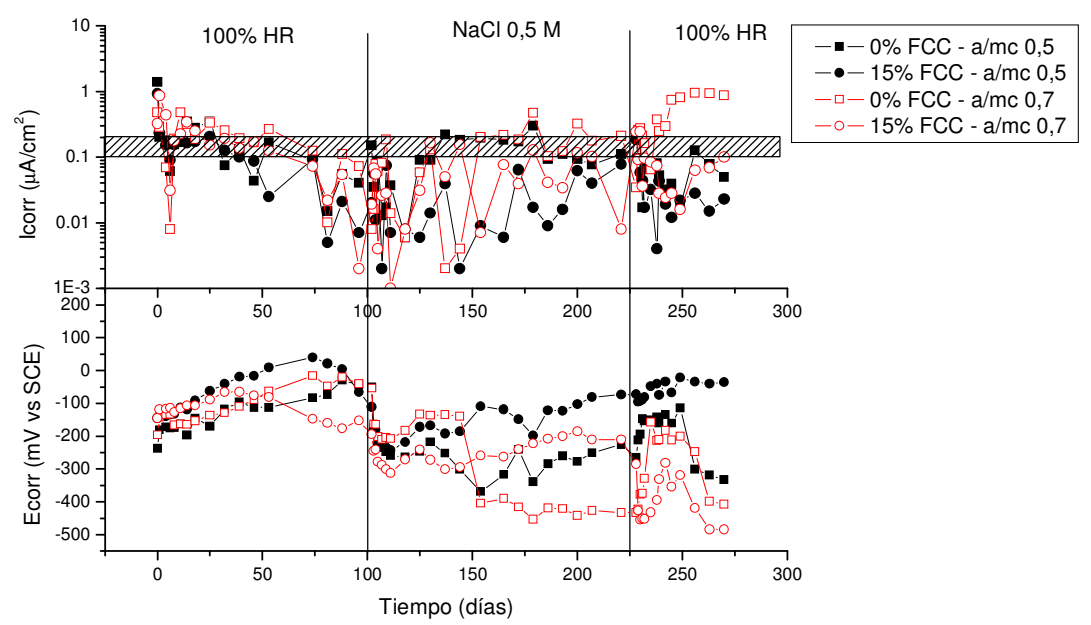

Figura 157. Evolución de la Icorr y Ecorr para los aceros embebidos en morteros con distintas relaciones a/me durante el ataque externo de cloruros.

\begin{tabular}{|c|c|c||}
\hline & \multicolumn{2}{|c||}{ Ecorr en ataque por NaCl 0,5 M (mV vs SCE) } \\
\hline Relación a/mc & $\mathbf{0 \%}$ FCC & $\mathbf{1 5 \%}$ FCC \\
\hline $\mathbf{0 , 5}$ & -283 & -115 \\
\hline $\mathbf{0 , 7}$ & -424 & -228 \\
\hline
\end{tabular}

Tabla 36. Valores de potencial de corrosión estables en el ataque por cloruros externos (agua de mar).

En la etapa final de la Figura 157 se observa como los únicos aceros que presentan una velocidad de corrosión por encima del umbral son los correspondientes a la relación a/mc de 0,7 sin FCC. En este mortero se combinan los dos fenómenos más desfavorables: la elevada porosidad (por la alta relación a/mc) y la menor capacidad de 
fijación de cloruros (por no incorporar FCC). Por ello su velocidad de corrosión es mayor.

\subsection{Influencia de un ataque por carbonatación posterior al ingreso de cloruros}

Tras el ataque por cloruros externos, las probetas se introdujeron en la cámara de carbonatación. En capítulos anteriores se ha mostrado como los cloruros fijados en la matriz cementante se liberan ante un ataque por carbonatación, lo cual puede degenerar en un ataque doblemente peligroso para la corrosión de las armaduras $[162,163]$.

En la Figura 158 se muestra la evolución de la Icorr y la Ecorr de los aceros embebidos en morteros con una relación a/mc de 0,5 , en el ataque por carbonatación posterior al ataque por cloruros. Se aprecia claramente que nada más comenzar la carbonatación la intensidad de corrosión de todos los aceros sufre un incremento acusado, que sitúa el valor de Icorr dentro de la zona límite de corrosión. Análogamente se produce un descenso del potencial de corrosión como consecuencia de la despasivación de las zonas catódicas de los electrodos. Una vez que se colocan los electrodos en un ambiente del $80 \%$ de humedad relativa, debido a la mayor proporción de oxígeno y a que se ha producido la despasivación de los electrodos, se produce un aumento todavía mayor de la velocidad de corrosión de los aceros. En este caso, aunque las diferencias entre los distintos niveles de sustitución son pequeñas, parece claro que el mortero sin FCC presenta una intensidad de corrosión superior. De nuevo, este aumento de la velocidad de corrosión viene acompañado de un descenso de los potenciales de corrosión. 


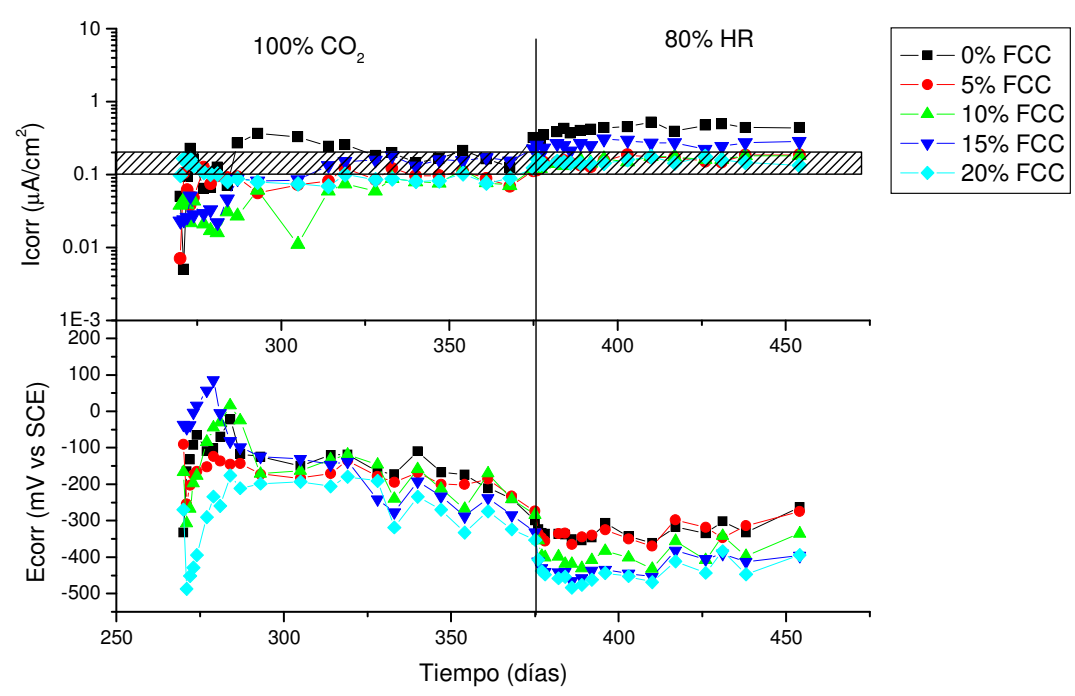

Figura 158. Evolución de la Icorr y Ecorr de los aceros embebidos en los morteros en el ataque de carbonatación posterior al ingreso de cloruros.

Relación a/mc 0,5.

En la Figura 159 se presentan los resultados de Icorr y Ecorr de los aceros embebidos en los morteros durante el ataque por carbonatación posterior al ataque por cloruros, pero para una relación a/mc de 0,7 en este caso. Otra vez se aprecia que la despasivación producida por el $\mathrm{CO}_{2}$ conlleva unos niveles de corrosión muy elevados para todos los aceros. Se puede observar que los niveles de corrosión son un orden de magnitud superior a los registrados para los aceros de los morteros con relación a/mc 0,5. Estos resultados son coherentes, habida cuenta del aumento de la porosidad, y por tanto de permeabilidad, que implica usar una relación a/mc de 0,7 . Como se ha comentado anteriormente, aunque las diferencias son pequeñas, parece que cuanto mayor es el nivel de sustitución, menor es la velocidad de corrosión de los aceros. Igual que en el caso de la relación a/mc 0,5, cuando se almacenaron las probetas en una humedad del $80 \%$ se produjo un aumento mayor en las velocidades de corrosión. El comportamiento de los potenciales de corrosión es el previsto y no se observan diferencias entre los distintos morteros. 


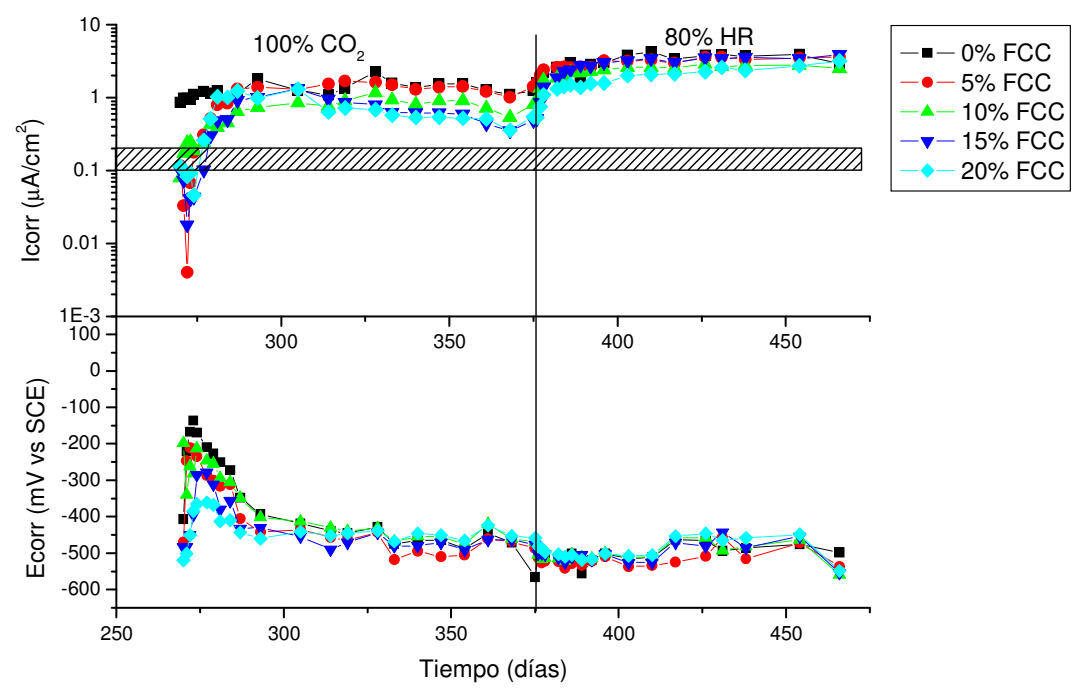

Figura 159. Evolución de la Icorr y Ecorr de los aceros embebidos en los morteros en el ataque de carbonatación posterior al ingreso de cloruros.

Relación a/mc 0,7.

En principio, como se ha comentado, la carbonatación produce la liberación de los cloruros que se habían fijado en la matriz cementante como sal de Friedel. Esto haría que, tras el proceso de carbonatación, los niveles de cloruros en los morteros con FCC sean similares a los de los morteros sin FCC. A pesar de ello, el hecho de que las velocidades de corrosión de los morteros con FCC sean inferiores, viene a demostrar que la reducción que supone la formación adicional de productos cementantes por la reacción puzolánica, sigue siendo una ventaja ofrecida por estos morteros.

Así pues, se observa que la incorporación de FCC mejora los niveles de corrosión de los aceros siempre que no se sobrepase el 15\% de sustitución, nivel en el cual se pone en riesgo la reserva alcalina de los morteros.

\subsection{Comprobación de medidas electroquímicas}

A continuación, en la Figura 160 se muestran algunos ejemplos del estado final de los electrodos tras las 5 etapas de las que constó el 
estudio. Las dos fotografías superiores muestran numerosas picaduras en su superficie, mientras que las inferiores además de las picaduras muestran una corrosión generalizada del electrodo. A simple vista no se aprecia que la incorporación de FCC produzca diferencias en el tipo de corrosión que experimentan los electrodos. Por otro lado, el aumento excesivo de la relación a/mc sí que agudiza el problema de la corrosión de forma muy evidente. Los aceros de los morteros con relación a/mc 0,7 presentaban, además de la corrosión por picaduras una corrosión generalizada bastante avanzada.
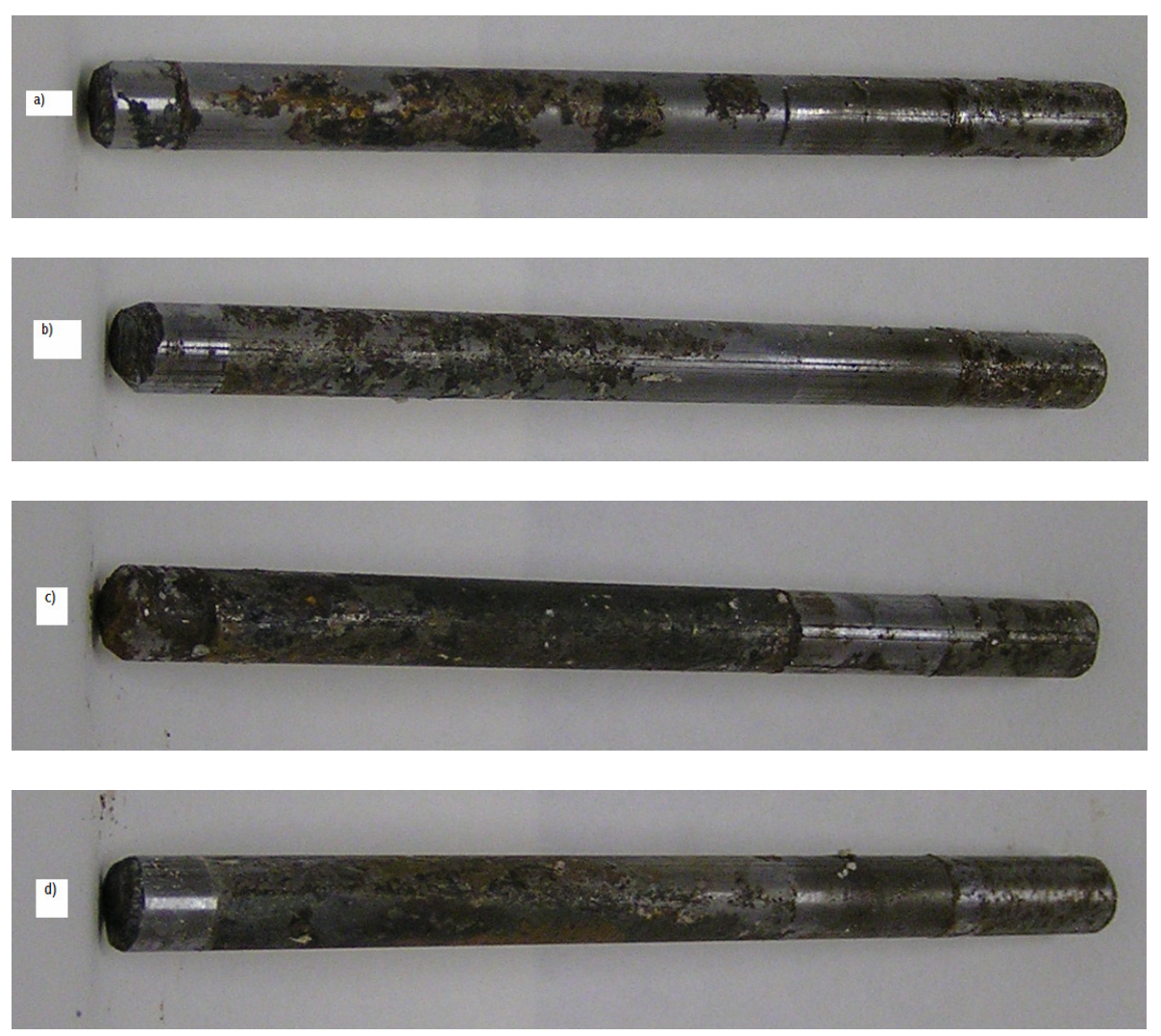

Figura 160. Fotos de los electrodos tras las experiencias. a) $0 \%$ FCC, relación a/mc 0,5; b) $15 \%$ FCC, relación a/mc 0,5; c) $0 \%$ FCC, relación a/mc 0,7; d) $15 \%$ FCC, relación a/mc 0,7.

En la Figura 161 se muestra la comparación de las pérdidas de masa electroquímicas y gravimétricas que se efectuaron tras la 
finalización de los ensayos para comprobar la validez de las medidas electroquímicas realizadas. Se asumen como válidas aquellas medidas electroquímicas que estén dentro de un intervalo situado entre el $50 \mathrm{y}$ $200 \%$ de los valores obtenidos en las pérdidas de masa gravimétricas. Esto es así debido a que la estimación de la constante B en la fórmula de Stern y Geary tiene este factor de error para el sistema acero/hormigón [141,142].

En nuestro caso se puede comprobar cómo todos los valores de las medidas electroquímicas caen dentro del intervalo admitido como válido por lo que se estiman como aceptables aquellas medidas.

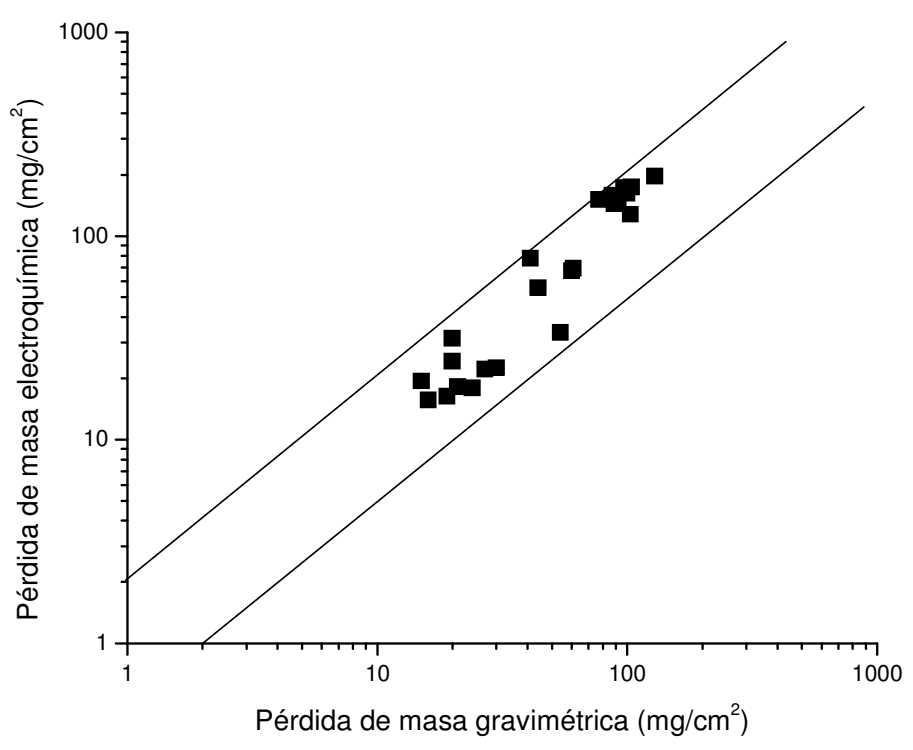

Figura 161. Comparación entre las pérdidas de masa gravimétricas y electroquímicas en los electrodos empleados en el ensayo. 


\subsection{Conclusiones}

Se han podido establecer las siguientes conclusiones a partir de los resultados obtenidos en este apartado de trabajo:

- La sustitución de cemento por FCC no produce un aumento apreciable de la velocidad de corrosión frente a un ataque por cloruros externos, excepto para la sustitución del $20 \%$ en la que la reserva alcalina limita mucho la resistencia a corrosión de los aceros.

- En un ataque por cloruros externos, el empleo de una sustitución de un $15 \%$ de cemento por FCC mejora los niveles de corrosión de los aceros de forma considerable, incluso para relaciones $\mathrm{a} / \mathrm{mc}$ tan elevadas como 0,7 .

- La carbonatación posterior al ataque por cloruros externos produce un aumento significativo de los valores de corrosión debido al propio descenso del $\mathrm{pH}$ del medio intersticial que conlleva, a lo que se une la liberación de los cloruros que se encontraban fijados como sal de Friedel. A pesar de ello, los aceros del mortero con FCC siguen ofreciendo valores de velocidad de corrosión inferiores a los de los aceros del mortero control. 
Estudio de la velocidad de corrosion de aceros embebidos en morteros mixtos de cemento-FCC en un ataque por cloruros externos 


\section{Estudio de la velocidad de corrosión de aceros embebidos en morteros mixtos de cemento-FCC sometidos a un ataque por cloruros internos}

En este capítulo se estudia el efecto que tendría en las propiedades de durabilidad de las armaduras embebidas en morteros mixtos de cemento y FCC, la adición de cloruros en el agua de amasado. La finalidad del mismo es establecer si existe un umbral de cloruros diferente en el caso de usar matrices mixtas de cemento y FCC y de esta forma complementar la información ofrecida en el capítulo anterior, en el cual se trataba de evaluar si existía un retraso en el periodo de iniciación, fundamentalmente. 


\subsection{Diseño de las experiencias}

En este estudio se han fabricado probetas similares a las ya utilizadas en el estudio de la corrosión de los aceros frente a un ataque por carbonatación (Figura 114). En este trabajo se han utilizado de nuevo dos electrodos de acero por lo que las medidas que se presentan corresponden a la media de ambos electrodos.

Los morteros elaborados como recubrimiento de los aceros se han realizado con cemento Portland tipo CEM I 52,5 R. Se han realizado probetas con dos sustituciones de cemento por FCC: 0 y $15 \%$. El FCC fue molido previamente en un molino de bolas durante 20 minutos para mejorar sus propiedades puzolánicas. En este caso se ha empleado una relación a/mc fija e igual a 0,5. Al agua de amasado se le han adicionado distintas cantidades de $\mathrm{NaCl}$ para obtener los siguientes porcentajes de cloruro respecto de la masa de cemento: 0 , 0,5, 1, 2 y 5\%. La relación árido/cemento empleada ha sido 3/1. El árido empleado ha sido árido silíceo normalizado [138]. El procedimiento de amasado ha sido el amasado normalizado de mortero [139]. Las probetas se han compactado mediante el picado manual de las mismas para evitar sacudidas que pudieran mover los electrodos dentro de la probeta.

Una vez amasadas las probetas, se practicaron medidas de corrosión de los aceros desde el día siguiente hasta la finalización del ensayo de forma periódica. Tras el amasado se almacenaron en cámara húmeda $(100 \% \mathrm{HR})$ durante 55 días.

Los parámetros de control en los que se ha basado este trabajo han sido el potencial de corrosión (Ecorr) y la intensidad de corrosión (Icorr). Para la medida del potencial de corrosión se ha empleado un electrodo saturado de calomelanos como electrodo de referencia. Las medidas de intensidad de corrosión se han llevado a cabo mediante la técnica de resistencia de polarización (Rp) [141] usando un potenciostato EG\&G modelo 362 de Princetone Applied Research. En dicha técnica se han realizado barridos desde $-10 \mathrm{mV}$ hasta $+10 \mathrm{mV}$ alrededor del potencial de corrosión en circuito abierto. La velocidad del barrido ha sido $0,5 \mathrm{mV} / \mathrm{s}$. 
Una vez finalizadas todas las etapas del estudio se extrajeron los electrodos de las probetas y se limpiaron mediante una disolución de hexametiltetramina en $\mathrm{HCl} 1 \mathrm{M}$ para eliminar todos los óxidos de hierro adheridos a la superficie de los electrodos, y mediante acetona, para eliminar los restos de pegamento de la cinta adhesiva utilizada para limitar el área de electrodo expuesta. Se pesaron los electrodos y se contrastó la pérdida de masa gravimétrica con la pérdida de masa electroquímica. La pérdida de masa gravimétrica se obtiene mediante la diferencia de masa de los electrodos entre el inicio y el final de estudio. La pérdida de masa electroquímica se obtiene a través de la integral de la intensidad de corrosión en función del tiempo, y aplicando la ley de Faraday.

\subsection{Influencia del nivel de cloruros introducidos en amasado}

La Figura 162 muestra la evolución de Icorr y Ecorr de los aceros embebidos en morteros sin FCC en los que se han adicionado distintos porcentajes de cloruros con respecto a la masa de cemento durante el amasado. Inicialmente se observa que existen unos valores elevados de corrosión debido al proceso de pasivado de los aceros [157]. Estos niveles van cayendo progresivamente hasta situarse en valores estables.

En la parte de la Figura 162 correspondiente al potencial de corrosión se puede observar una clara ordenación de los valores en función de la cantidad de cloruros añadida en el amasado. Cuanto mayor es este porcentaje, más negativo es el potencial de corrosión. Esta tendencia es la esperada, ya que un menor potencial de corrosión indica más tendencia hacia que se produzca la corrosión. Se puede observar cómo los valores de Ecorr se agrupan en valores menos negativos para los aceros embebidos en los morteros con 0 y $0,5 \%$ de cloruro con respecto a la masa de cemento. El valor de Ecorr de los aceros del mortero con $1 \%$ de cloruro presenta un potencial de corrosión ligeramente inferior, a continuación, el potencial de corrosión registrado para los aceros embebidos en el mortero con $2 \%$ de cloruros y finalmente los que más cloruros contienen (5\%). Esto puede ser indicativo de que el umbral de cloruros para este tipo de morteros se sitúa entre el $1 \%$ y el $2 \%$ de cloruro con respecto a la 
masa de cemento. Además el hecho de que no existan diferencias en los potenciales de corrosión de los aceros embebidos en los morteros con $0 \%$ y $0,5 \%$ de cloruros puede ser indicativo de que hasta el $0,5 \%$ de cloruros pueden ser fijados en la matriz cemetante de estos morteros.

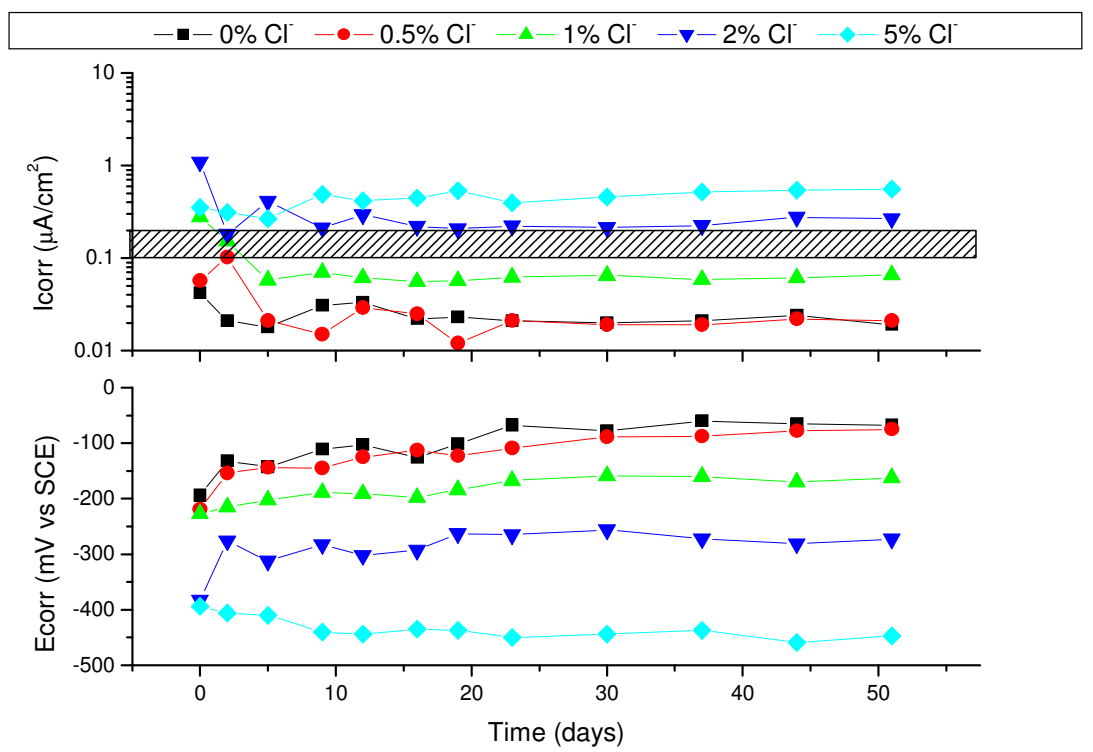

Figura 162. Evolución de la Icorr y la Ecorr de los aceros embebidos en morteros sin FCC para distintos porcentajes de adición de $\mathrm{Cl}^{-}$con respecto a la masa de cemento.

En la parte superior de la Figura 162 también se aprecia cierta ordenación de los valores, siendo, de forma general, los valores de Icorr de los aceros de los morteros con mayor contenido en cloruro los más elevados. Todos los aceros correspondientes a los morteros con concentraciones de $0,0,5$ y $1 \%$ de cloruros con respecto a la masa de cemento se sitúan de forma estable por debajo del umbral de corrosión activa. Por otro lado, los aceros del morteros con un $2 \%$ de cloruros sitúan sus valores de Icorr ligeramente por encima de la zona umbral, lo que indica que el umbral de cloruros que produce una despasivación apreciable de los aceros estaría en valores comprendidos entre el $1 \%$ y el $2 \%$ de cloruros con respecto a la masa 
de cemento. Los aceros de los morteros con 5\% de cloruros presentan velocidades de corrosión claramente en la zona de corrosión activa.

La Figura 163 muestra la evolución de Icorr y Ecorr de los aceros embebidos en morteros, con una sustitución del 15\% de FCC, en los que se han adicionado distintos porcentajes de cloruros con respecto a la masa de cemento durante el amasado. En este caso se vuelve a observar la elevada corrosión de los primeros días del ensayo producida por la pasivación de los aceros.

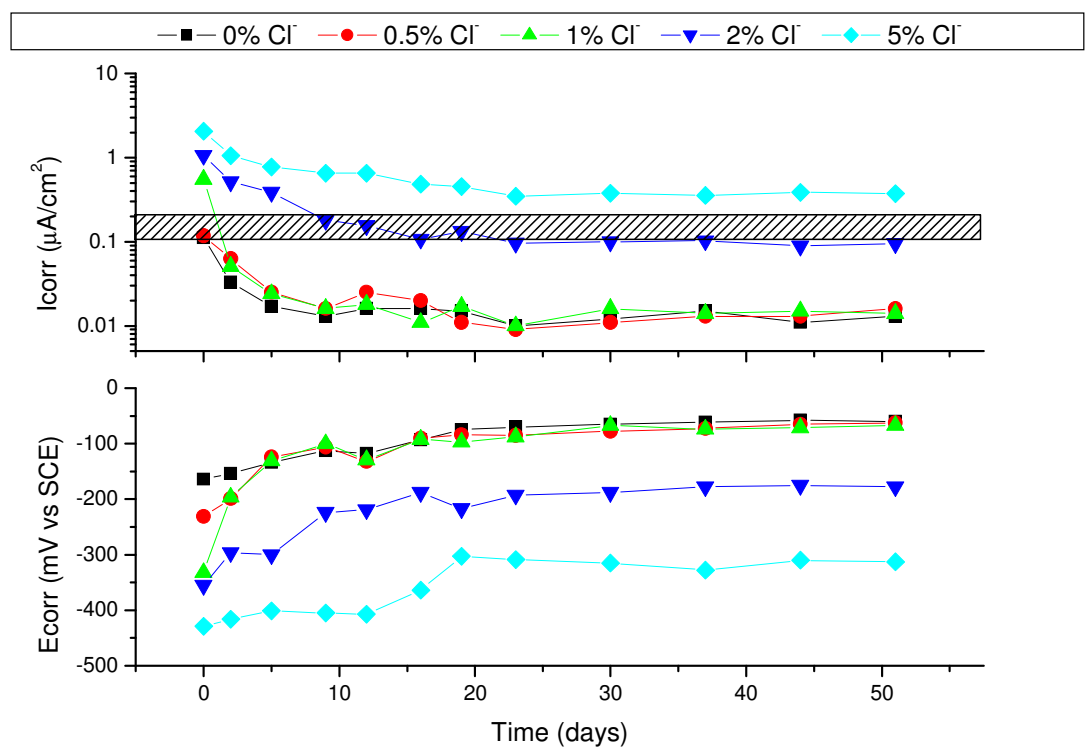

Figura 163. Evolución de la Icorr y la Ecorr de los aceros embebidos en morteros con un 15\% de FCC para distintos porcentajes de adición de $\mathrm{Cl}^{-}$con respecto a la masa de cemento.

El comportamiento de los electrodos embebidos en los morteros con un $15 \%$ de FCC es similar al observado en los aceros del mortero control. Hacia el final del ensayo en parte de la Figura 163 correspondiente a los valores de Ecorr registrados se aprecia que existe una ordenación de valores que coincide con la anterior. Cuanto mayor es la cantidad de cloruros adicionada durante el amasado, más negativos son los potenciales de corrosión, y, por tanto, mayor 
tendencia a corroerse se puede esperar. Además los valores de Ecorr de los aceros embebidos en los morteros con $0 \%, 0,5 \%$ y $1 \%$ presentan comportamientos muy similares ofreciendo los potenciales de corrosión más elevados y prácticamente idénticos. A continuación se situarían los aceros del mortero con $2 \%$ de cloruros, y finalmente, presentado valores mucho más negativos se encontrarían los aceros del mortero con un 5\% de cloruro con respecto a la masa de cemento. A diferencia del caso anterior, los potenciales de los aceros de los morteros con hasta un $1 \%$ de cloruros no presentan diferencias lo que, usando el argumento antes mencionado, puede indicar que esa cantidad de cloruros puede ser fijada a la matriz cementante de los morteros con un $15 \%$ de FCC.

En cuanto a los valores de Icorr presentados en la parte superior de la Figura 163 se puede apreciar que también se ordenan en función del contenido de cloruros adicionado en el amasado. A mayor concentración de cloruros, mayor velocidad de corrosión. En este caso, todos los aceros embebidos en los morteros con $0,0,5$ y $1 \%$ presentan valores de Icorr claramente por debajo del umbral de corrosión activa. Los aceros del mortero con un $2 \%$ de cloruros también se sitúan en la zona de corrosión inactiva pero con valores muy próximos a $0,1 \mu \mathrm{A} / \mathrm{cm}^{2}$. Finalmente, al igual que en el caso anterior, los aceros del mortero con un $5 \%$ de cloruros se sitúan de forma estable en valores de corrosión activos. Parece, pues, que la incorporación de un $15 \%$ de FCC en sustitución de cemento mejora el umbral de cloruros ya que se encontraría en torno al $2 \%$ con respecto a la masa de cemento. Este hecho estaría justificado por los resultados obtenidos en los capítulos anteriores en los que se apunta que la mayor cantidad de aluminatos cálcicos hidratados en la matriz cementante de los morteros con FCC consigue fijar más cantidad de cloruros y, por lo tanto, aumentar el umbral de cloruros tolerables por dicha matriz.

En la Tabla 37 se presentan los valores de velocidad de corrosión y potencial de corrosión medios (una vez estabilizadas las medidas) de los aceros estudiados en este capítulo. En ella se pone de manifiesto claramente que tanto los potenciales de corrosión como las velocidades de corrosión de los aceros embebidos en los morteros con un $15 \%$ de FCC, ofrecen sistemáticamente valores superiores de potencial de corrosión e inferiores de velocidad de corrosión. 


\begin{tabular}{|c|c|c|c|c||}
\hline \multirow{2}{*}{$\begin{array}{c}\text { CONTENIDO DE } \\
\text { CLORUROS } \\
(\% \text { MASA DE CEMENTO) }\end{array}$} & \multicolumn{2}{|c|}{ Icorr $\left(\boldsymbol{\mu A} / \mathbf{c m}^{2}\right)$} & \multicolumn{2}{c|}{ Ecorr $(\mathbf{m V}$ vs SCE) } \\
\cline { 2 - 5 } & $\mathbf{0 \%}$ FCC & $\mathbf{1 5 \%}$ FCC & $\mathbf{0 \%}$ FCC & $\mathbf{1 5 \%}$ FCC \\
\hline $0 \%$ & 0,021 & 0,012 & -68 & -63 \\
\hline $0,5 \%$ & 0,020 & 0,012 & -88 & -73 \\
\hline $1 \%$ & 0,063 & 0,014 & -164 & -73 \\
\hline $2 \%$ & 0,241 & 0,096 & -269 & -182 \\
\hline $5 \%$ & 0,494 & 0,368 & -447 & -315 \\
\hline \hline
\end{tabular}

Tabla 37. Velocidad de corrosión y potencial de corrosión medios de los aceros embebidos en morteros con adición de cloruros en el agua de amasado.

\subsection{Comprobación de las medidas electroquímicas}

En la Figura 164 se muestran las fotografías de algunos de los aceros empleados en este estudio tras la finalización de los ensayos. Los electrodos presentan zonas en las que se ha producido corrosión aunque sólo aparecen claramente picaduras en el electrodo correspondiente al mortero con 15\% de FCC y $2 \%$ de cloruros (Figura $164 d)$. En el caso del mortero con $0 \%$ de FCC y $2 \%$ de cloruros (Figura 164b) también aparecen picaduras, aunque no son tan evidentes. Los aceros correspondientes a los morteros sin cloruros (Figura 164a y Figura 164c) presentan pequeñas manchas de corrosión debidas al proceso de carbonatación que han sufrido y no existen picaduras en los mismos.

Para finalizar, en la Figura 165 se muestra la comparación de las pérdidas de masa electroquímicas y gravimétricas que se efectuaron tras la finalización de los ensayos para comprobar la validez de las medidas electroquímicas realizadas. Se asumen como válidas aquellas medidas electroquímicas que estén dentro de un intervalo situado entre el 50 y $200 \%$ de los valores obtenidos en las pérdidas de masa gravimétricas. Esto es así debido a que la estimación de la constante B en la fórmula de Stern y Geary tiene este factor de error para el sistema acero/hormigón [141,142]. 
Estudio de la velocidad de corrosion de aceros embebidos en morteros mixtos de cemento-FCC en un ataque por cloruros internos
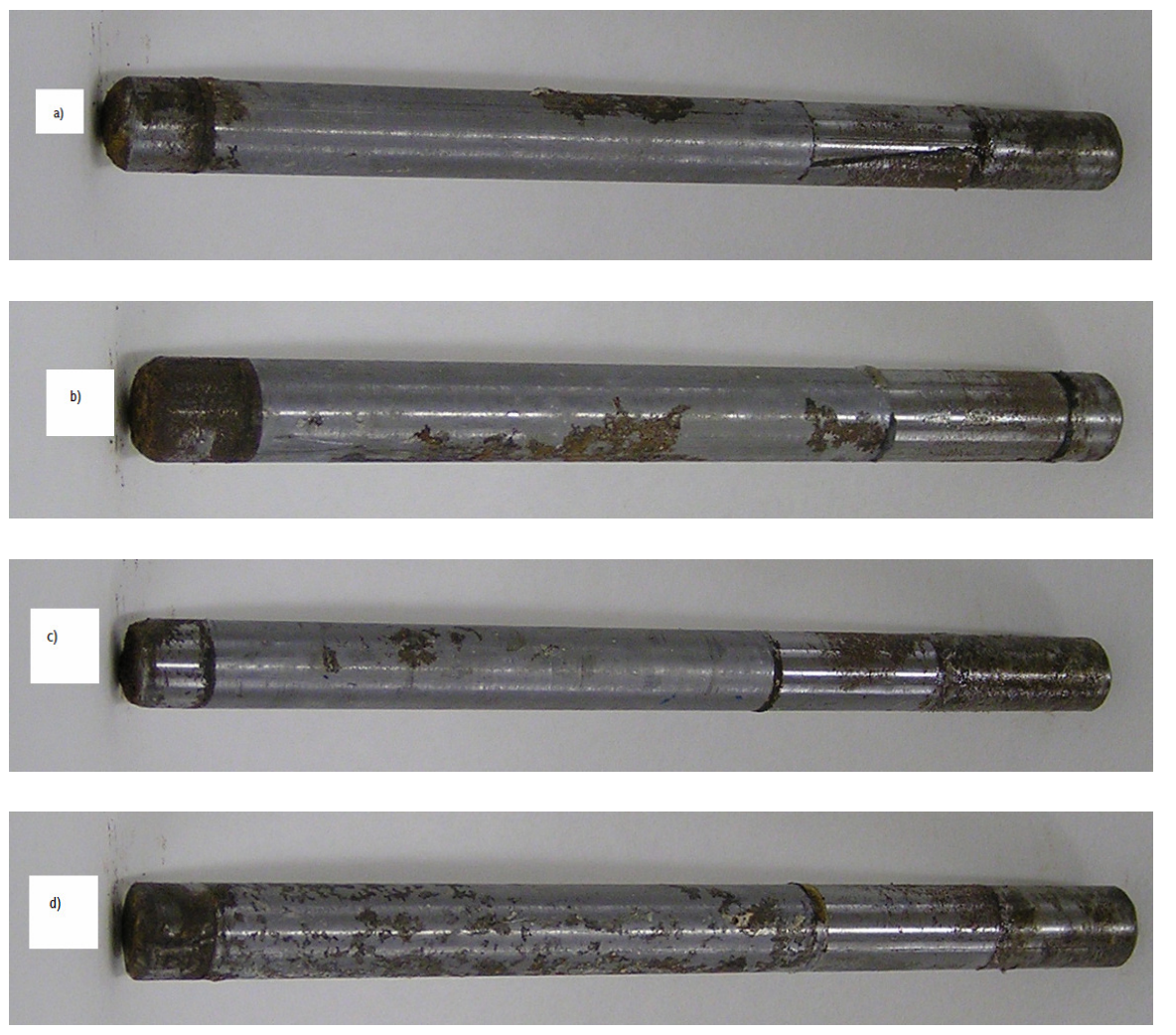

Figura 164. Fotografías de los aceros empleados en el estudio tras la finalización de los ensayos. a) $0 \% \mathrm{FCC}, 0 \% \mathrm{Cl}^{-}$; b) $0 \% \mathrm{FCC}, 2 \% \mathrm{Cl}^{-}$; c) $15 \%$ FCC, $0 \% \mathrm{Cl}^{-}$; d) $15 \% \mathrm{FCC}, 2 \% \mathrm{Cl}^{-}$.

En nuestro caso se puede comprobar cómo todos los valores de las medidas electroquímicas caen dentro del intervalo admitido como válido por lo que se estiman como aceptables aquellas medidas. 


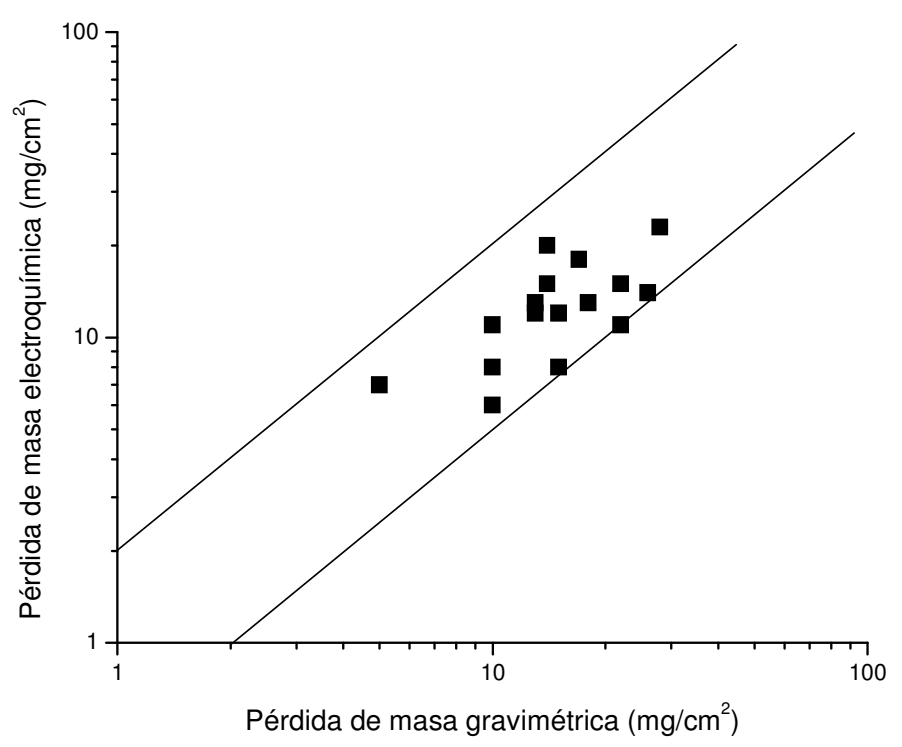

Figura 165. Comparación entre las pérdidas de masa gravimétricas y electroquímicas en los electrodos empleados en el ensayo.

\subsection{Conclusiones}

A tenor de los resultados obtenidos en este estudio se han podido extraer las siguientes conclusiones:

- Se ha podido estimar que para los morteros con un $15 \%$ de FCC el umbral de cloruros se sitúa en un valor cercano al $2 \%$ mientras que para los morteros sin FCC dicho umbral tendría un valor comprendido entre el 1 y el $2 \%$ de cloruros con respecto al peso de material cementante.

- Los valores de potencial de corrosión parecen indicar que el mortero con un $15 \%$ de FCC es capaz de fijar aproximadamente un $1 \%$ de cloruros con respecto a la masa de material cementante, mientras que los morteros sin FCC fijarían en torno al $0,5 \%$ de cloruros. 
- Los valores de velocidad de corrosión son sistemáticamente inferiores para los aceros embebidos en los morteros con $15 \%$ de FCC para cualquier adición de cloruros. Esto indica una clara mejora del comportamiento del recubrimiento que incorpora FCC frente al del mortero sin FCC. 


\section{Efecto del ataque por cloruros en morteros ternarios de cemento-FCC-ceniza volante reforzados con acero}

En este último capítulo de resultados se presentan los obtenidos del estudio de resistencia al ingreso de cloruros y corrosión de armaduras en morteros ternarios de cemento, FCC y ceniza volante. La presencia de ceniza volante en morteros y hormigones mejora la trabajabilidad de los morteros por lo que se puede compensar la alta demanda de agua que ofrece el FCC. Además mediante este tipo de mezclas cementantes se pueden conseguir porcentajes de sustitución de cemento muy elevados, lo que conlleva beneficios medioambientales, a la par que se consigue mejorar las propiedades mecánicas de los productos elaborados y mejorar la microestructura de la matriz cementante. Por otro lado, como ya se estudió anteriormente, usar sustituciones tan elevadas de cemento puede ocasionar una reducción o agotamiento de la reserva alcalina, lo que pondría en peligro la correcta pasivación de las armaduras. 
En este capítulo se estudian las dos vertientes que se han sometido a evaluación a lo largo de este trabajo. Por un lado se ha evaluado la resistencia al ingreso de cloruros de la matriz cementante análogamente a lo realizado en capítulos anteriores. Por el otro, se han efectuado medidas de corrosión de armaduras en probetas sumergidas en disolución de $\mathrm{NaCl}$ 0,5 M, similar al agua de mar.

\subsection{Análisis termogravimétrico de pastas de cemento- FCC-CV}

\subsubsection{Diseño de las experiencias}

Se han elaborado 4 tipos distintos de pastas de cemento en función de la sustitución de cemento por FCC y CV. El cemento utilizado en todas ellas ha sido tipo CEM I 52,5 R. En la Tabla 38 se presentan las proporciones de cemento y puzolana empleadas en las pastas. Para la elaboración de las pastas se empleó agua destilada manteniendo una relación agua/material cementante $(\mathrm{a} / \mathrm{mc})$ de 0,5 .

\begin{tabular}{||c|c|c||}
\hline \hline NOMENCLATURA & \% FCC & \% CV \\
\hline Control & $0 \%$ & $0 \%$ \\
\hline FCC & $15 \%$ & $0 \%$ \\
\hline CV & $0 \%$ & $30 \%$ \\
\hline FCC-CV & $15 \%$ & $30 \%$ \\
\hline
\end{tabular}

Tabla 38. Relación de muestras preparadas en el estudio para análisis termogravimétrico. Porcentajes respecto de la masa de material cementante.

Las pastas se amasaron en contenedores de plástico y se curaron en cámara húmeda (100\% de humedad relativa) durante 28 días. Posteriormente se sumergieron en una disolución de $\mathrm{NaCl}$ de concentración $1 \mathrm{M}$ y se mantuvieron sumergidas durante 6 meses. Tras este periodo, las muestras se almacenaron en una cámara de carbonatación acelerada cuya atmósfera tenía una proporción de $\mathrm{CO}_{2}$ del $100 \%$ y una humedad relativa del $65 \pm 5 \%$ [91,124]. 
Se tomaron muestras de las pastas a distintos tiempos para seguir la evolución de las mismas. En total se efectuaron 5 análisis de cada pasta según la siguiente relación:

- Tras 28 días de curado.

- $\quad$ Tras 28 días de curado y un mes sumergidas en $\mathrm{NaCl} 1 \mathrm{M}$.

- $\quad$ Tras 28 días de curado y 2 meses sumergidas en $\mathrm{NaCl} 1 \mathrm{M}$.

- Tras 28 días de curado y 6 meses sumergidas en $\mathrm{NaCl} 1 \mathrm{M}$.

- Tras 28 días de curado, 6 meses sumergidas en $\mathrm{NaCl} 1 \mathrm{M}$, y un mes en la cámara de carbonatación.

Como muestra para la termogravimetría se tomó de una pequeña porción de las pastas que se pulverizó en un mortero de ágata. A la muestra pulverizada se le eliminó el agua no combinada mediante sucesivos lavados con acetona, tras lo cual se introdujo en una estufa a $60^{\circ} \mathrm{C}$ durante unos $15 \mathrm{~min}$. Finalmente se tamizó cada una de las muestras con un tamiz de $80 \mu \mathrm{m}$. La porción que no se retuvo en el tamiz fue la destinada a introducir en la termobalanza para su ensayo (aproximadamente $30 \mathrm{mg}$ ).

La termobalanza empleada es una Mettler Toledo TGA850 (Figura 42) de brazo horizontal. El ensayo consistió en la aplicación de una rampa de temperatura de $10^{\circ} \mathrm{C} / \mathrm{min}$ hasta $600^{\circ} \mathrm{C}$ que se realizó sobre la muestra en un crisol de aluminio sellado y perforado (Figura 43 dcha.). La atmósfera de este método fue inerte, concretamente nitrógeno con un caudal de $75 \mathrm{ml} / \mathrm{min}$.

\subsubsection{Resultados y discusión}

La Figura 166 muestra las curvas DTG obtenidas para las pastas de cemento-FCC-CV tras los primeros 28 días de curado. En la Tabla 39 se presentan las pérdidas termogravimétricas de los termogramas de la Figura 166. Se pueden observar varias diferencias entre las pastas analizadas. Por un lado, las pastas que contienen un $15 \%$ de FCC son las que mayor cantidad de aluminatos y 
silicoaluminatos cálcicos hidratados producen, como se puede apreciar por el mayor tamaño de los picos correspondientes a estas pastas que aparece sobre $\operatorname{los} 200^{\circ} \mathrm{C}[97,98]$.

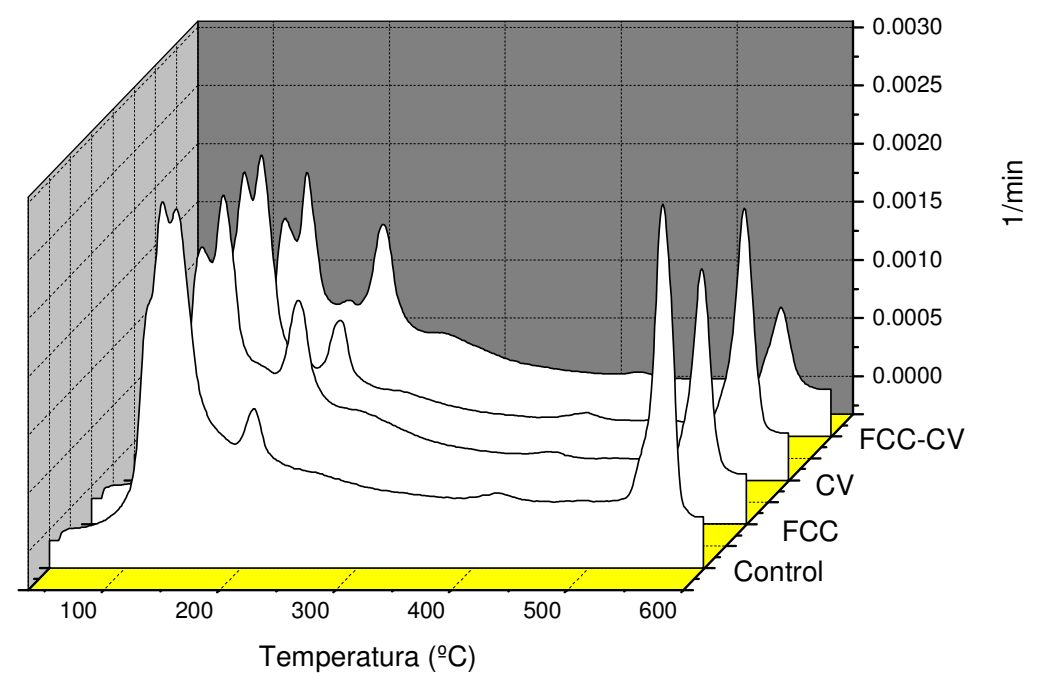

Figura 166. Curvas DTG de las pastas de cemento-FCC-CV tras 28 días de curado. Relación a/mc de 0,5 .

A su vez, también se observa cierto orden en la cantidad de hidróxido cálcico existente en las pastas. Las mayores pérdidas asociadas a este compuesto, que aparecen a unos $550^{\circ} \mathrm{C}$ [82,92-98], las ofrece la pasta Control, seguida de la pasta con un $30 \%$ de $\mathrm{CV}$, la pasta con un $15 \%$ de FCC, y por último la pasta con un $15 \%$ de FCC y un $30 \%$ de CV. Esto viene explicado debido a que conforme aumenta la sustitución de cemento por puzolana se produce, por un lado, menor cantidad de portlandita, y además más portlandita se consume por la puzolana adicionada. Cabe destacar además que a pesar que la sustitución de cemento por $\mathrm{CV}$ es de un $30 \%$, existe más porlandita en la pasta $\mathrm{CV}$ que en la pasta FCC, cuya sustitución es de únicamente un $15 \%$. Esto refleja la mayor actividad puzolánica del FCC, sobretodo a corto plazo. Si se analiza el comportamiento puzolánico desde el punto de vista de la cal fijada, en la Tabla 39 se puede observar que la 
ceniza volante no ha consumido portlandita liberada durante la hidratación del cemento. Sólo las pastas con FCC producen reacción puzolánica como tal. Esto se puede deber a que la ceniza volante puede favorecer las reacciones de hidratación del cemento. Esto hace que se libere más cal a tiempos cortos de la que se encontraría en pastas sin CV [99].

\begin{tabular}{||c|c|c|c|c|c||}
\hline \multicolumn{2}{|c|}{} & \multicolumn{4}{c||}{ PÉRDIDAS (\%) } \\
\hline PASTA & Cal Fijada (\%) & Total & $\mathbf{C a}(\mathbf{O H})_{2}$ & CSH & CAH-CASH \\
\hline Control & 0,00 & 20,59 & 3,11 & 17,12 & 0,36 \\
\hline FCC & 27,75 & 19,90 & 1,91 & 17,17 & 0,82 \\
\hline CV & $-1,52$ & 16,76 & 2,21 & 14,06 & 0,49 \\
\hline FCC-CV & 52,65 & 14,95 & 0,81 & 13,23 & 0,91 \\
\hline
\end{tabular}

Tabla 39. Pérdidas termogravimétricas de las pastas de cemento-FCC-CV tras 28 días de curado. Relación a/me 0,5.

La Figura 167 presenta las curvas DTG de las pastas de cemento-FCC-CV de muestras tomadas tras 6 meses de inmersión en una disolución de $\mathrm{NaCl} 1 \mathrm{M}$. En la Tabla 40 se muestran las pérdidas termogravimétricas de dichas pastas. Se observa que tras este periodo de tiempo, la cantidad de portlandita $\left(550^{\circ} \mathrm{C}\right)$ presente en las pastas con puzolana (ya sea FCC y/o CV) es muy pequeña debido a dos factores: el avance de las reacciones puzolánicas, y la formación de sal de Friedel, que también implica el consumo de portlandita (Ecuación 30 y Ecuación 31).

Además si se observan las magnitudes relativas de los picos correspondientes a las pérdidas de los aluminatos y silicoaluminatos cálcicos hidratados $\left(200^{\circ} \mathrm{C}\right)$, éstas son algo superiores a las obtenidas en las muestras tomadas tras los 28 días de curado (Tabla 39).

Finalmente se puede apreciar que ha aparecido la señal correspondiente a la descomposición del cloroaluminato cálcico hidratado $\left(350{ }^{\circ} \mathrm{C}\right.$ [158]) en todas las pastas como resulta previsible del hecho de adicionar cloruros a una matriz cementante que contiene cierta cantidad de aluminatos de calcio hidratados $[159,161]$. 


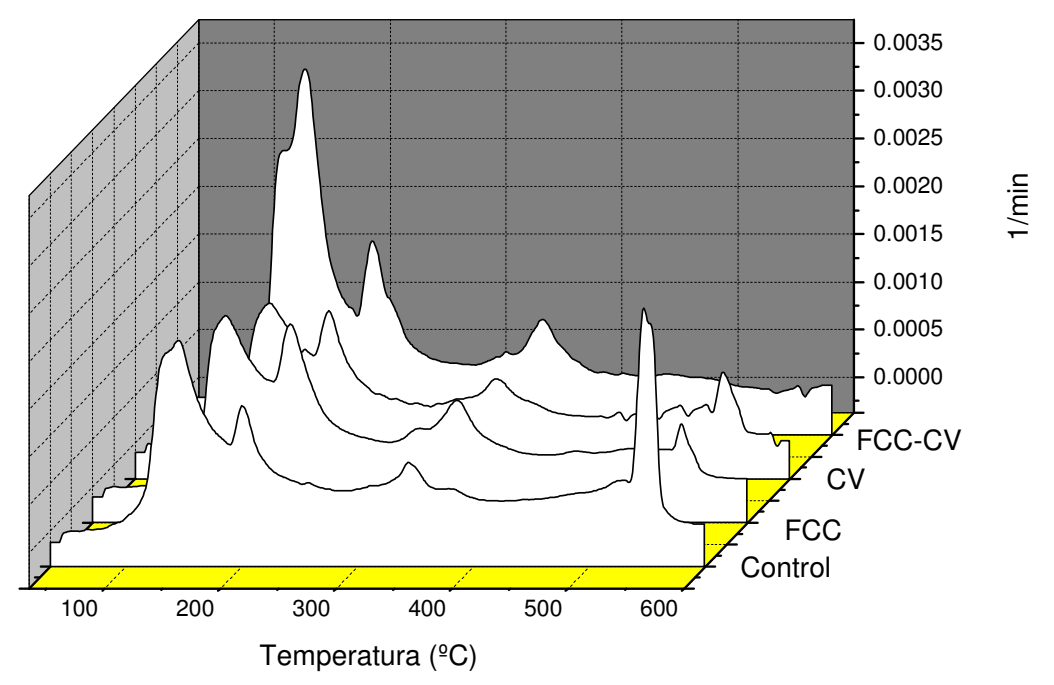

Figura 167. Curvas DTG de las pastas de cemento-FCC-CV tras 28 días de curado y 6 meses de inmersión en NaCl 1 M. Relación a/mc de 0,5.

\begin{tabular}{|c|c|c|c||}
\hline & \multicolumn{3}{|c||}{ PÉRDIDAS (\%) } \\
\hline Pasta & $\mathbf{C a}(\mathbf{O H})_{2}$ & Sal de Friedel & CAH-CASH \\
\hline Control & 2,13 & 0,31 & 0,44 \\
\hline FCC & 0,35 & 0,54 & 0,93 \\
\hline CV & 0,53 & 0,45 & 0,54 \\
\hline FCC-CV & 0,00 & 0,69 & 1,03 \\
\hline
\end{tabular}

Tabla 40. Pérdidas termogravimétricas de las pastas de cemento-FCC-CV tras 28 días de curado y 6 meses de inmersión en NaCl 1 M. Relación a/mc 0,5.

En la Figura 168 se muestran las curvas DTG de las pastas de cemento-FCC-CV tras 6 meses de inmersión en una disolución de $\mathrm{NaCl} 1 \mathrm{M}$ y 1 mes más sometidas a un proceso de carbonatación acelerada. Los cambios más importantes observados en las curvas con respecto las presentadas en la Figura 167 son los siguientes: 
- Desaparición del pico correspondiente a la descomposición del hidróxido cálcico $\left(550^{\circ} \mathrm{C}\right)$, en el caso de que no hubiese sido consumido totalmente por el FCC y la CV, como consecuencia de la reacción del mismo con el $\mathrm{CO}_{2}$ para formar carbonato cálcico.

- Desaparición de la señal correspondiente al cloroaluminato cálcico hidratado $\left(350{ }^{\circ} \mathrm{C}\right)$ debido a que el $\mathrm{CO}_{2}$ captura el calcio de dicho compuesto, lo cual conlleva la liberación de los cloruros que habían sido fijados a la matriz cementante mediante la formación de dicho compuesto $[162,163]$.

- Disminución o desaparición de la señal correspondiente a los aluminatos y silicoaluminatos cálcicos hidratados, que se debe también a la captura del calcio de estas fases por el $\mathrm{CO}_{2}$ produciendo la formación de carbonato cálcico y productos amorfos (óxidos e hidróxidos) de aluminio y silicio [85-89].

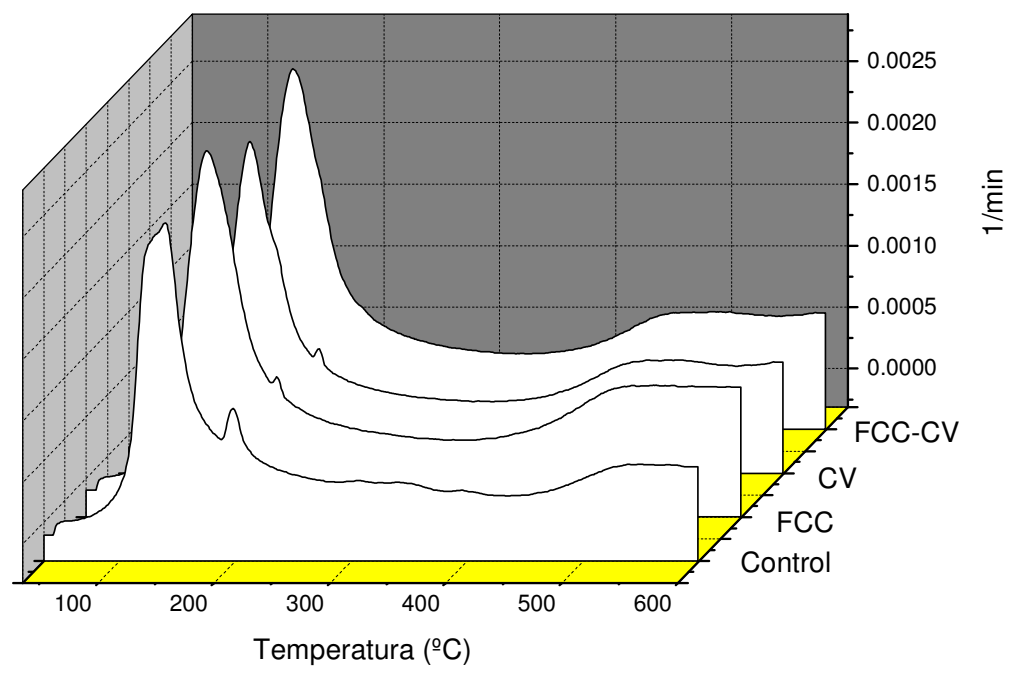

Figura 168. Curvas DTG de las pastas de cemento-FCC-CV tras 28 días de curado, 6 meses de inmersión en NaCl 1 M y 1 mes de carbonatación acelerada. Relación a/me de 0,5 . 
En la Figura 169 se muestra con más detalle la evolución de la cantidad de hidróxido cálcico en las pastas de cemento-FCC-CV durante las experiencias. Como se había señalado anteriormente, la pasta con mayor cantidad de portlandita es la correspondiente a la pasta Control, seguida de la pasta con un $30 \%$ de $\mathrm{CV}$, la pasta con un $15 \%$ de FCC y, por último la pasta con $15 \%$ de FCC y $30 \%$ de CV.

Además en la Figura 169 se puede observar que entre los 28 días de curado y 1 mes de inmersión en $\mathrm{NaCl} 1 \mathrm{M}$, la pasta control sufre un descenso en la cantidad de portlandita, lo que se debe seguramente al consumo de la misma que tiene lugar en la formación de la sal de Friedel. La pasta con un $15 \%$ de FCC presenta un comportamiento similar sólo que la caída entre estas dos muestras es ligeramente superior, debido a que además se puede haber consumido en este periodo de 1 mes una cantidad adicional de hidróxido cálcico por parte del FCC que no había reaccionado totalmente tras los 28 días de curado. En el caso de la muestra con un $30 \%$ de CV la disminución es más progresiva hasta los 6 meses de inmersión ya que la $\mathrm{CV}$ reacciona de forma más lenta con el hidróxido cálcico, lo que hace que la reacción puzolánica del mismo se dilate más en el tiempo. Finalmente, la pasta con un 15\% de FCC y $30 \%$ de CV había agotado todo el hidróxido cálcico suministrado por la hidratación del cemento tras los 28 días de curado y el primer mes de inmersión en la disolución de cloruro sódico debido a la elevada sustitución de cemento por las puzolanas que tiene lugar en esta pasta. También es evidente que tras la carbonatación, no queda ningún resto de portlandita en ninguna de las muestras. 


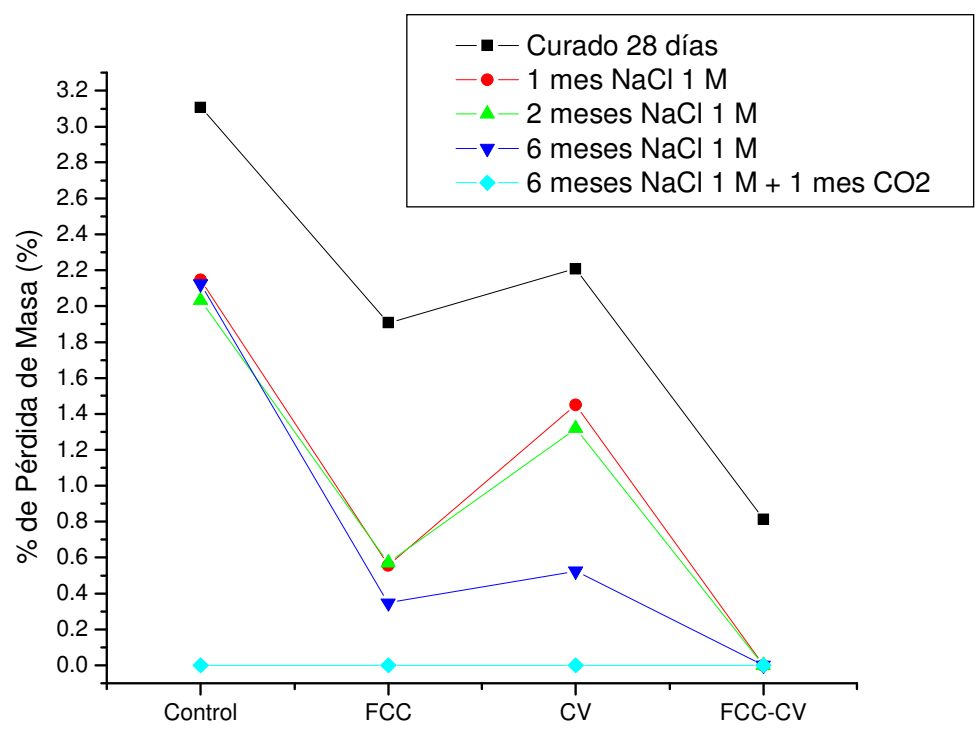

Figura 169. Cuantificación de la pérdida de masa registrada en los termogramas asociada a la portlandita en las pastas de cemento-FCC-CV (a/mc $0,5)$ durante el proceso de ataque por cloruros.

En la Figura 170 se muestran las pérdidas de masa asociadas al cloroaluminato de calcio hidratado presente en las pastas de cementoFCC-CV a lo largo del experimento. Tras los primeros 28 días de curado, no se observa ninguna cantidad de este compuesto ya que todavía no se ha podido formar al no haber puesto en contacto las muestras con la disolución de $\mathrm{NaCl} 1 \mathrm{M}$. Otra característica reseñable es que tras la inmersión inicial de 1 mes en la disolución de $\mathrm{NaCl}$, ya no se produce prácticamente evolución alguna del contenido de cloroaluminato de calcio hidratado. Esto indica que la formación de este compuesto es rápida y avanza al mismo ritmo que el ritmo de avance del frente de ingreso de cloruros. A continuación, se observa que el contenido en cloroaluminato de calcio hidratado se ordena de la siguiente manera: la que más cantidad ha formado es la pasta con $15 \%$ de FCC y $30 \%$ de CV, seguida de la pasta con un $15 \%$ de FCC, la pasta con un $30 \%$ de $\mathrm{CV}$ y, finalmente la pasta Control. Por último, se puede apreciar que el proceso de carbonatación acelerada consigue eliminar la presencia de cloroaluminato de calcio hidratado de todas 
las pastas, liberando los cloruros que se encontraban fijados en la matriz.

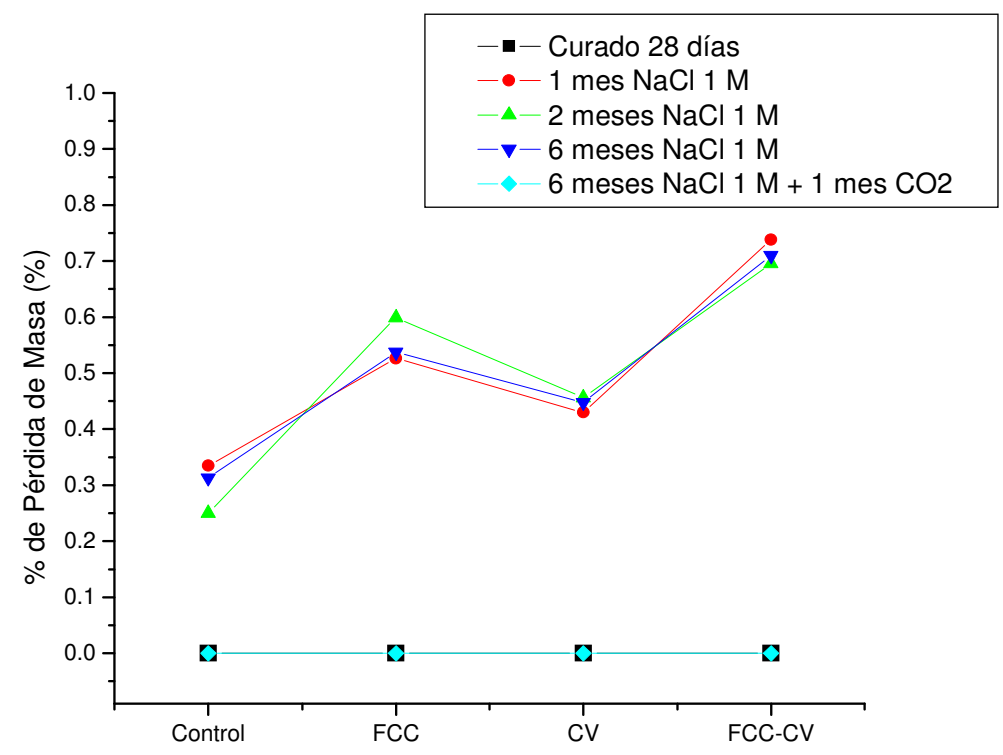

Figura 170. Cuantificación de la pérdida de masa registrada en los termogramas asociada al cloroaluminato de calcio hidratado en las pastas de cemento-FCC-CV $(\mathrm{a} / \mathrm{mc} \mathbf{0 , 5})$ durante el proceso de ataque por cloruros.

La Figura 171 muestra la cuantificación de la pérdida de masa registrada en los termogramas que está asociada a las fases de aluminatos y silicoaluminatos de calcio hidratados presentes en la matriz cementante durante el experimento. Se puede observar que la forma de esta gráfica es muy similar a mostrada en la Figura 170. Esto se debe a que la cantidad que se forma de cloroaluminato cálcico hidratado está relacionada con la cantidad de aluminato cálcico hidratado de la matriz cementante. Cuanto mayor sea la cantidad de aluminatos cálcicos hidratados, mayor formación habrá de sal de Friedel. La mayor proporción de aluminatos que ofrece principalmente el FCC, y en menor medida la $\mathrm{CV}$, enriquecen la matriz cementante en estas fases de aluminatos. Esto propicia una mayor fijación de cloruros por parte de estas matrices, lo que, en 
principio, debe suponer un aumento en el umbral de cloruros tolerable por los morteros u hormigones que incorporen estas puzolanas.

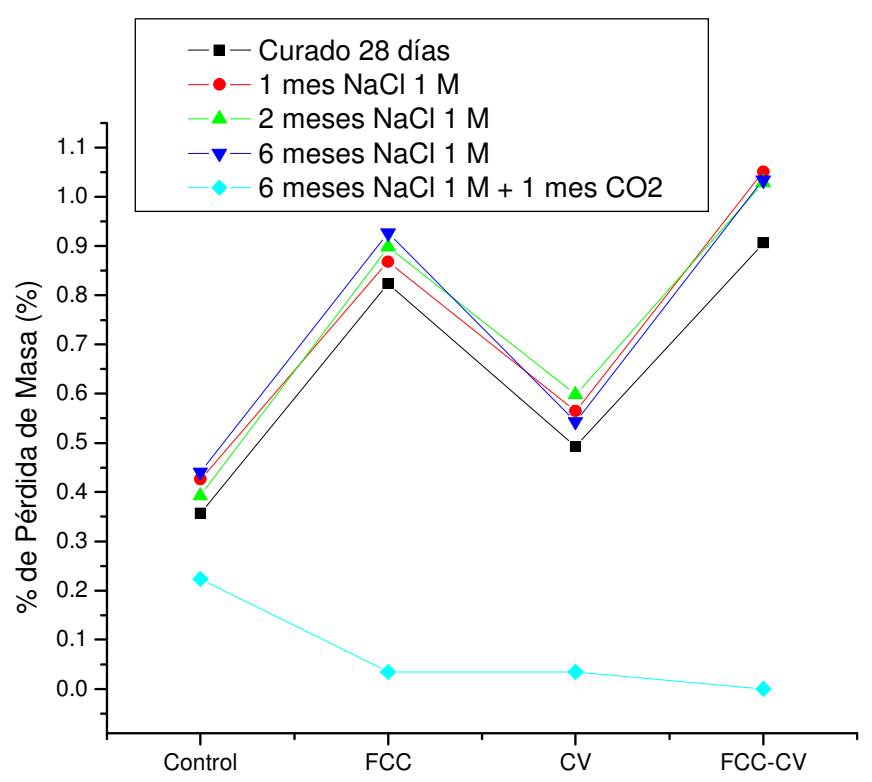

Figura 171. Cuantificación de la pérdida de masa registrada en los termogramas asociada a las las fases de CAH-CASH en las pastas de cementoFCC-CV $(a / m c ~ 0,5)$ durante el proceso de ataque por cloruros.

\subsection{Cinética de ingreso de cloruros en morteros de cemento-FCC-CV}

\subsubsection{Diseño de las experiencias}

Se han elaborado distintos morteros de cemento en los que se ha variado la sustitución de cemento por FCC y/o CV. Las sustituciones empleadas en este estudio son las que figuran en la Tabla 41. Por otra parte se ha usado una relación a/mc: fija e igual a 0,4 . Para la fabricación de los morteros se ha usado agua destilada para evitar contaminarlos con cloruros. El plastificante usado en los morteros ha sido Sika Viscocrete. La relación árido/cemento ha sido 
3/1 en todos los casos. Se utilizado árido silíceo normalizado [138] para la fabricación de los morteros.

\begin{tabular}{||c|c|c|c||}
\hline NOMENCLATURA & $\%$ FCC & $\%$ CV & \% PLASTIFICANTE \\
\hline Control & $0 \%$ & $0 \%$ & $0,5 \%$ \\
\hline FCC Plas & $15 \%$ & $0 \%$ & $1 \%$ \\
\hline CV & $0 \%$ & $30 \%$ & $0 \%$ \\
\hline FCC-CV & $15 \%$ & $30 \%$ & $0 \%$ \\
\hline FCC-CV-Plas & $15 \%$ & $30 \%$ & $0,5 \%$ \\
\hline
\end{tabular}

Tabla 41. Relación de muestras preparadas en el estudio de cinética de ingreso de cloruros. Porcentajes respecto de la masa de material cementante.

El montaje y el desarrollo de las experiencias son idénticos a lo ya anteriormente descrito en la Sección 8.1.

\subsubsection{Resultados y discusión}

La Figura 172 muestra las curvas de evolución de la concentración de cloruros en el compartimento anódico durante los ensayos de migración para los morteros de cemento-FCC-CV, cuya relación a/mc era de 0,4. En primer lugar, se observa que el mortero Control es el que peor comportamiento presenta, ya que es el mortero que más anticipa la aparición de cloruros en el compartimento anódico y además propicia un aumento de la concentración de cloruros más rápido. A continuación se sitúa el mortero con un $30 \%$ de $\mathrm{CV}$, y el mortero con un $15 \%$ de FCC y un $30 \%$ de CV con plastificante. Por último, basándose en las curvas presentadas, el mortero con un $30 \%$ de CV y un $15 \%$ de FCC sin plastificante, y el mortero con un $15 \%$ de FCC con plastificante son los que ofrecen el mejor comportamiento ya que consiguen retrasar más la aparición de los cloruros en el compartimento anódico y además el crecimiento de la concentración de cloruros es el más lento. 


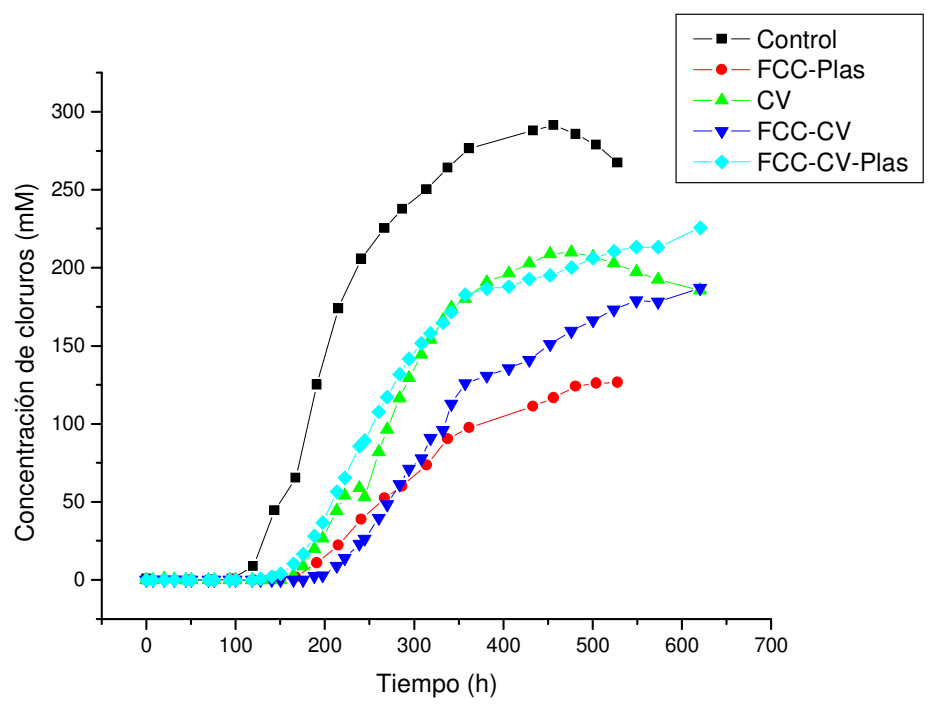

Figura 172. Curvas de evolución de la concentración de cloruros en el compartimento anódico durante los ensayos de migración para los morteros de cemento-FCC-CV. Relación a/me de 0,4 .

En la Tabla 42 se presentan los valores de los parámetros extraídos de las curvas de la Figura 172. En la misma se pueden apreciar cuantitativamente las observaciones antes realizadas. El flujo de ion cloruro se ordena de mayor a menor de acuerdo a la siguiente ordenación: Control > CV > FCC-CV $\approx$ FCC-CV-Plas > FCC-Plas. Por su parte, el tiempo que transcurre hasta que empieza a aparecer ion cloruro en el compartimento anódico se ordena de la siguiente forma: Control < FCC-CV-Plas < FCC-Plas $<$ CV $<$ FCC-CV.

Con estos parámetros se han calculado los valores de coeficiente de difusión de ion cloruro en estado estacionario y no estacionario que se presentan en la Tabla 43. En la misma se puede observar que existen pocas diferencias en el coeficiente de difusión de estado no estacionario, mientras que sí se aprecia que el mortero Control ofrece un coeficiente de difusión de estado estacionario superior al resto, y que el mortero FCC-Plas tiene el menor de todos los calculados. 
Efecto del ataque por cloruros en morteros ternarios de cemento-FCC-ceniza volante reforzados con acero

\begin{tabular}{||c|c|c|c||}
\hline \hline MORTERO & $\begin{array}{c}\text { PENDIENTE } \\
(\mathbf{m M} / \mathbf{h})\end{array}$ & $\begin{array}{c}\text { FLUJO } \\
\left(\boldsymbol{\mu m o l} /\left(\mathbf{c m}^{\mathbf{2}} \mathbf{h}\right)\right)\end{array}$ & $\begin{array}{c}\text { TIME LAG, } \boldsymbol{\tau} \\
(\mathbf{h})\end{array}$ \\
\hline Control & 1,615 & 23,35 & 140,1 \\
\hline FCC-Plas & 0,600 & 8,94 & 162,7 \\
\hline CV & 1,109 & 14,38 & 179,9 \\
\hline FCC-CV & 0,965 & 12,50 & 186,2 \\
\hline FCC-CV-Plas & 1,006 & 12,73 & 144,5 \\
\hline
\end{tabular}

Tabla 42. Parámetros extraídos de las curvas de migración de cloruros de los morteros de cemento-FCC-CV.

\begin{tabular}{|c|c|c||}
\hline MORTERO & $\begin{array}{c}\mathbf{D}_{\mathbf{n s}} \\
\left(\mathbf{1 0}^{-\mathbf{1 2}} \mathbf{~}^{\mathbf{2}} / \mathbf{s}\right)\end{array}$ & $\begin{array}{c}\mathbf{D}_{\mathbf{~}} \\
\left(\mathbf{1 0}^{-\mathbf{1 2}} \mathbf{~}^{\mathbf{2}} / \mathbf{s}\right)\end{array}$ \\
\hline Control & 2,92 & 4,94 \\
\hline FCC-Plas & 2,32 & 1,85 \\
\hline $\mathbf{C V}$ & 2,49 & 3,14 \\
\hline FCC-CV & 2,19 & 2,61 \\
\hline FCC-CV-Plas & 2,81 & 2,61 \\
\hline
\end{tabular}

Tabla 43. Valores de los coeficientes de difusión en estado no estacionario y estado estacionario de los morteros de cemento-FCC-CV.

La Figura 173 presenta los coeficientes de difusión de cloruros en estado estacionario y en estado no estacionario para los morteros ensayados en este estudio. Se puede observar que la ordenación de los valores de cada uno de estos coeficientes coincide con las observaciones realizadas sobre las curvas mostradas en la Figura 172. En el Capítulo 8 se comentó que el coeficiente de difusión en estado no estacionario, $\mathrm{D}_{\mathrm{ns}}$, depende de forma más importante de la porosidad del mortero y de la capacidad de fijación de cloruros de la matriz cementante del mortero [167]. En el apartado anterior se ha mostrado cómo las matrices cementantes que contienen FCC y CV (especialmente FCC), consiguen fijar una mayor cantidad de cloruros, por lo que los morteros que contengan estas puzolanas deben mejorar esta contribución al coeficiente de difusión no estacionario $[158,168,169]$. Además, también se advirtió que la incorporación de 
FCC, mejora la porosidad de los morteros debido a formación de los productos de la reacción puzolánica, por lo que estos morteros también se beneficiarían de este aspecto. Ahora se comprueba que con la CV también se consigue reducir el coeficiente de difusión de estado no estacionario, aunque en menor medida de lo que lo hace el FCC.

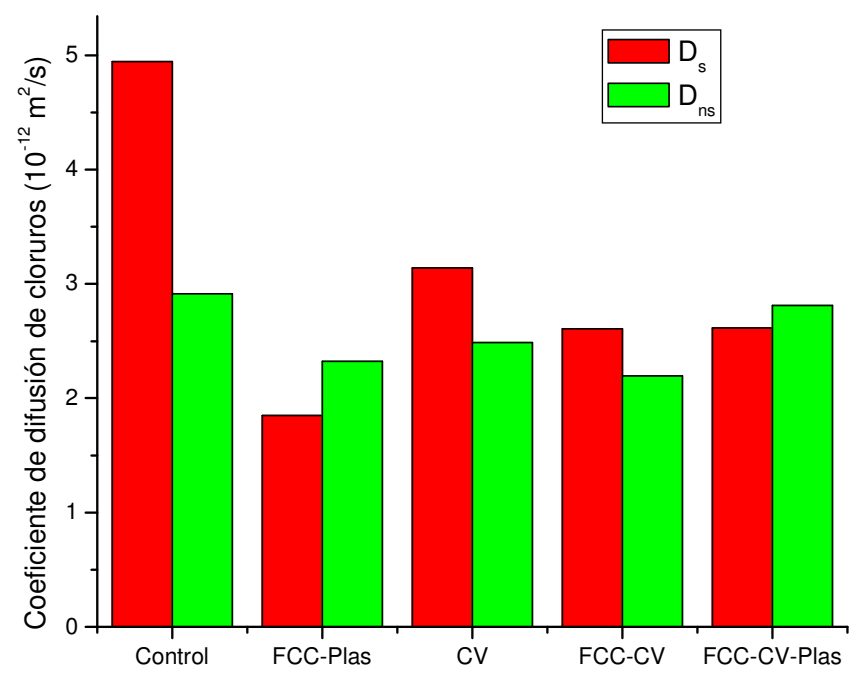

Figura 173. Coeficientes de difusión de estado estacionario y no estacionario de los morteros en el ensayo de migración para los morteros de cemento-FCC-CV.

Atendiendo a los valores de coeficiente de difusión de estado estacionario, $D_{s}$, que se muestran en la Figura 173, también se comprueba que el peor comportamiento lo ofrece el mortero Control, seguido del mortero $\mathrm{CV}$, los morteros con FCC y CV, y finalmente el mortero con FCC. Esto indica que la incorporación de FCC únicamente, mejora la red porosa del mortero en mayor medida de lo que lo haría la $\mathrm{CV}$ o la combinación de FCC y $\mathrm{CV}$, aunque en cualquier caso la mejora que implica el uso de las puzolanas es muy significativa. La actividad puzolánica del FCC es más elevada que la de la CV por lo que es lógico pensar que el FCC produce una mayor reducción de porosidad. Por otro lado, la presencia de la CV puede hacer que no se desarrolle totalmente la reacción puzolánica del FCC, debido a la competencia de ambos por el hidróxido cálcico. Esto 
produce que los morteros que incorporan ambas puzolanas no presenten un comportamiento tan bueno, aunque es evidente, que la combinación de ambas favorece en gran medida la resistencia al ingreso de cloruros de los morteros con casi la mitad de cemento.

\subsection{Corrosión de aceros en morteros de cemento-FCC- CV sometidos a un ataque por cloruros externos}

\subsubsection{Diseño de las experiencias}

En este estudio se han fabricado probetas similares a las ya utilizadas en el estudio de la corrosión de los aceros frente a un ataque por carbonatación (Figura 114). En este trabajo se han utilizado de nuevo dos electrodos de acero por lo que las medidas que se presentan corresponden a la media de ambos electrodos.

Los morteros elaborados como recubrimiento de los aceros se han realizado con cemento Portland tipo CEM I 52,5 R. Las sustituciones cemento por las puzolanas son las mismas que figuran en la Tabla 38. El FCC fue molido previamente en un molido de bolas durante 20 minutos para mejorar sus propiedades puzolánicas. En este caso se ha empleado una relación a/mc fija e igual a 0,5. El agua de amasado ha sido agua destilada, para evitar la incorporación de cloruros a través de este componente durante el amasado. La relación árido/material cementante empleada ha sido 3/1. El árido empleado ha sido árido silíceo normalizado [138]. El procedimiento de amasado ha sido el amasado normalizado de mortero [139]. Las probetas se han compactado mediante el picado manual de las mismas para evitar sacudidas que pudieran mover los electrodos dentro de la probeta.

Una vez amasadas las probetas, se practicaron medidas de corrosión de los aceros desde el día siguiente hasta la finalización del ensayo de forma periódica. Tras el amasado se almacenaron en cámara húmeda $(100 \% \mathrm{HR})$ durante 100 días hasta obtener lecturas de corrosión estables. A continuación se sumergieron parcialmente en una disolución de $\mathrm{NaCl}$ 0,5 M, que simula el agua de mar, durante 125 días (Figura 156). Posteriormente se volvieron a introducir en la cámara húmeda durante 40 días para observar la evolución de los aceros tras el ataque al que fueron sometidos. A continuación se 
introdujeron las probetas en una cámara de carbonatación $\left(100 \% \mathrm{CO}_{2}\right.$, $65 \pm 5 \%$ HR $[91,124])$ para ver efecto añadido de este agente agresivo sobre la corrosión de los aceros. Por último se guardaron las probetas en una cámara con una humedad relativa del $80 \%$.

Los parámetros de control en los que se ha basado este trabajo han sido el potencial de corrosión (Ecorr) y la intensidad de corrosión (Icorr). Para la medida del potencial de corrosión se ha empleado un electrodo saturado de calomelanos como electrodo de referencia. Las medidas de intensidad de corrosión se han llevado a cabo mediante la técnica de resistencia de polarización (Rp) [141] usando un potenciostato EG\&G modelo 362 de Princetone Applied Research. En dicha técnica se han realizado barridos desde $-10 \mathrm{mV}$ hasta $+10 \mathrm{mV}$ alrededor del potencial de corrosión en circuito abierto. La velocidad del barrido ha sido $0,5 \mathrm{mV} / \mathrm{s}$.

Una vez finalizadas todas las etapas del estudio se extrajeron los electrodos de las probetas y se limpiaron mediante una disolución de hexametiltetramina en $\mathrm{HCl} 1 \mathrm{M}$ para eliminar todos los óxidos de hierro adheridos a la superficie de los electrodos y mediante acetona, para eliminar los restos de pegamento de la cinta adhesiva utilizada para limitar el área de electrodo expuesta. Se pesaron los electrodos y se contrastó la pérdida de masa gravimétrica con la pérdida de masa electroquímica. La pérdida de masa gravimétrica se obtiene mediante la diferencia de masa de los electrodos entre el inicio y el final de estudio. La pérdida de masa electroquímica se obtiene a través de la integral de la intensidad de corrosión en función del tiempo, y aplicando la ley de Faraday.

\subsubsection{Resultados y discusión}

La Figura 174 muestra la evolución de la Icorr y la Ecorr de los aceros embebidos en morteros de cemento-FCC-CV durante el ataque por cloruros externos al que fueron sometidas las muestras. En la primera fase se aprecia que inicialmente la velocidad de corrosión de los aceros es elevada debido al proceso de pasivación de los aceros. Progresivamente los valores se reducen hasta situarse por debajo del umbral de corrosión activa. 


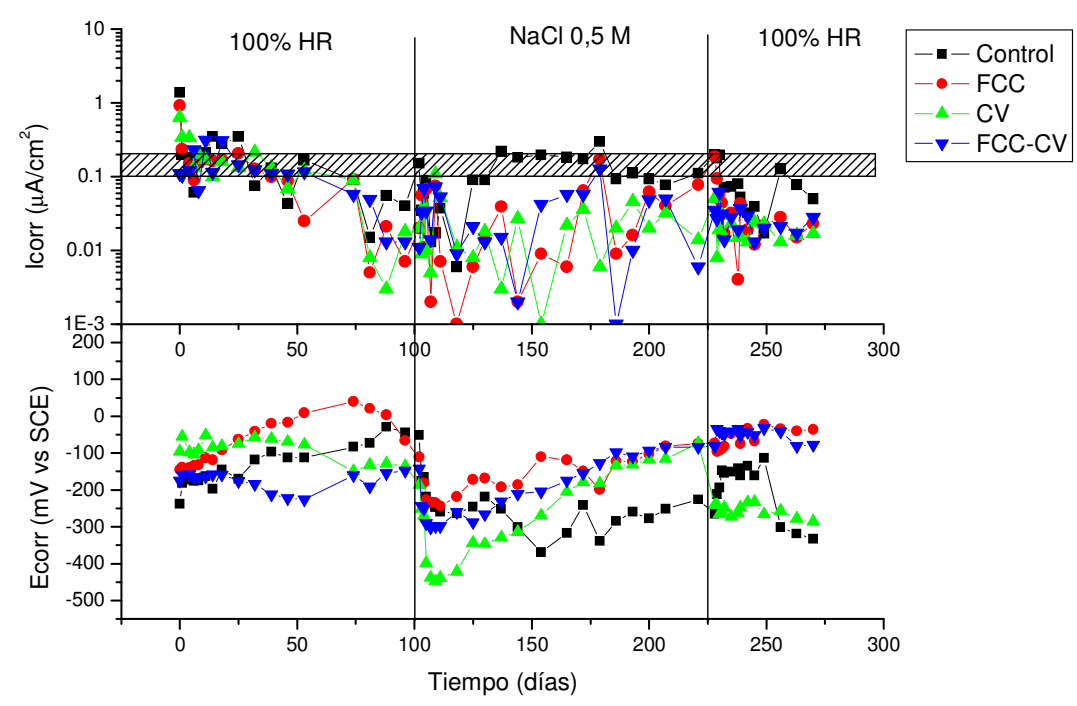

Figura 174. Evolución de la Icorr y la Ecorr de los aceros embebidos en morteros de cemento-FCC-CV durante el ataque por cloruros externos. Relación a/mc de 0,5 .

Durante el ataque por cloruros, las probetas se sumergieron parcialmente en una disolución de $\mathrm{NaCl}$ 0,5 M. En este caso se observa que los perfiles de la velocidad de corrosión presentan los dientes de sierra típicos de un ataque por cloruros que originan picaduras en la superficie del acero. En la parte final de la fase de inmersión en la disolución de cloruros se puede apreciar que el potencial de corrosión más negativo lo ofrece el mortero control, lo que indicaría una mayor tendencia a que se produzca la corrosión. Esto es así de forma que este mortero control mantiene su velocidad de corrosión alrededor del umbral de corrosión activa, superándolo de forma puntual. El resto de morteros presenta valores de potencial de corrosión menos activos y además sus valores son muy coincidentes. En general, los morteros con sustitución de cemento por FCC y/o CV ofrecen valores de velocidad de corrosión inferiores a los del mortero Control pero no se puede discriminar entre ellos ninguno que destaque con respecto a los demás. Los valores de velocidad de corrosión de los morteros con FCC y/o CV permanecen siempre por debajo del umbral de corrosión activa [143]. En la tercera etapa en la que se colocaron 
las probetas en la cámara húmeda, la evolución de los electrodos no experimentó modificaciones significativas con respecto a la etapa anterior.

La Figura 175 muestra la evolución de la Icorr y la Ecorr de los aceros embebidos en morteros de cemento-FCC-CV durante el proceso de carbonatación acelerada al que se sometieron las probetas tras el ataque por cloruros externos. La consecuencia inmediata del proceso de carbonatación es un aumento generalizado de los valores de velocidad de corrosión, que es más pronunciado para el mortero Control y el mortero con un $30 \%$ de CV en las primeras fases, pero que posteriormente son igualados por los morteros con FCC. Este aumento coloca la velocidad de corrosión de los morteros en valores que caen dentro o ligeramente por encima del umbral de corrosión activa. En cuanto a los potenciales de corrosión, al finalizar la etapa de carbonatación acelerada, los aceros que presentan una mayor tendencia a la corrosión son los embebidos en los morteros con un $30 \%$ de CV y con un $15 \%$ de FCC y un $30 \%$ de CV.

Finalmente se colocaron las probetas en una cámara con una humedad relativa del $80 \%$. Esto originó un aumento en la concentración de oxígeno en la superficie de los electrodos que provocó un aumento adicional de la velocidad de corrosión en todos los casos. En esta última etapa, todos los aceros presentaban sus valores de velocidad de corrosión, por encima del umbral de corrosión activa. Los aceros del mortero con un $15 \%$ de FCC fueron los únicos que ofrecieron velocidades de corrosión por debajo de los registrados por el mortero Control. Los morteros que incorporaban ceniza volante (CV y FCC-CV) son los que peor comportamiento han mostrado al final de todo el proceso. Esto se debe a que en estos morteros confluyen dos factores que al parecer debilitan de forma muy importante la protección que ofrecen los aceros. Por un lado la reserva alcalina de los mismos es muy reducida (Figura 169), lo que los hace más vulnerables frente a la carbonatación. Por otro lado, estos morteros consiguen fijar una cantidad importante de cloruros (Figura 170), y dado que su carbonatación es mucho más fácil, también lo es la liberación de los mismos al caer el pH del medio intersticial. Por ello, uniendo ambos factores (facilidad de carbonatación y alta 
concentración de cloruros liberados), la corrosión que experimentan los aceros embebidos en estos morteros es más elevada.

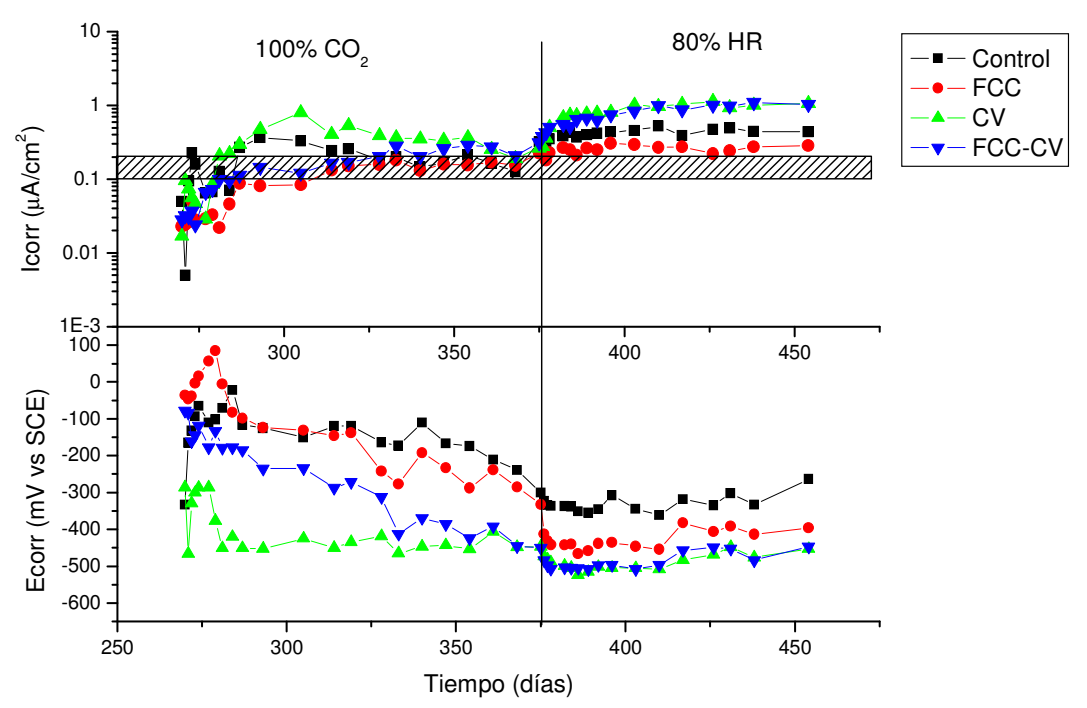

Figura 175. Evolución de la Icorr y la Ecorr de los aceros embebidos en morteros de cemento-FCC-CV durante el proceso de carbonatación acelerada tras el ataque por cloruros externos. Relación a/me de 0,5.

En la Figura 176 se muestra la comparación entre la pérdida de masa electroquímica y la pérdida de masa gravimétrica. En dicha figura se puede comprobar que las medidas de velocidad de corrosión realizadas están dentro de los márgenes de error permitidos para la técnica de resistencia a la polarización. 


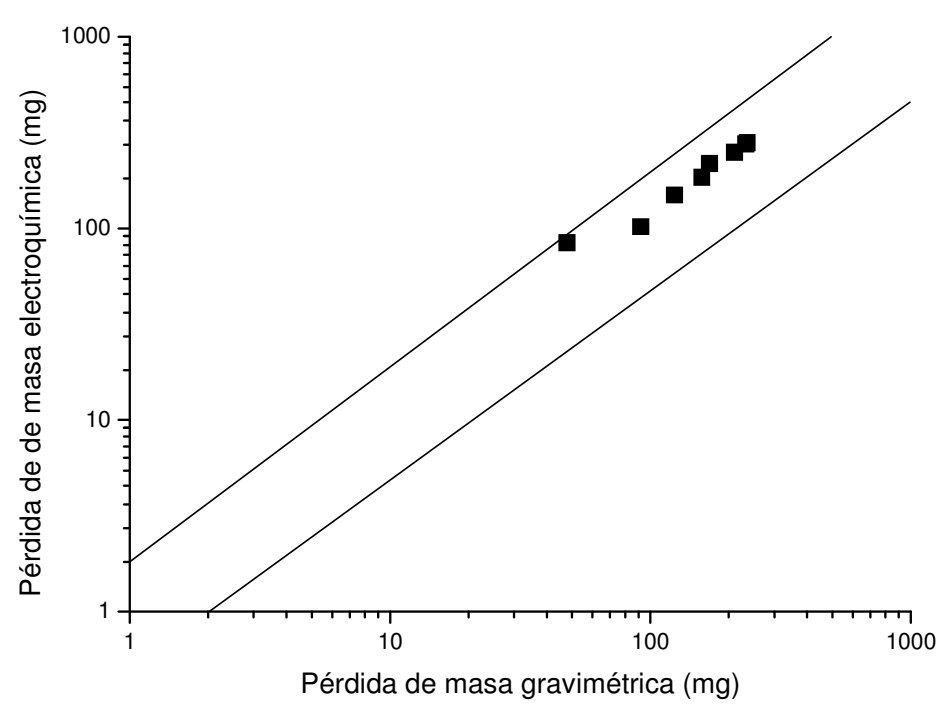

Figura 176. Comparación entre la pérdida de masa gravimétrica y la pérdida de masa electroquímica de los aceros empleados en este estudio.

\subsection{Conclusiones}

Tras los resultados obtenidos en este estudio se pueden extraer las siguientes conclusiones:

- La presencia de FCC en los morteros mejora sensiblemente la capacidad de fijación de cloruros de la matriz cementante mientras que la incorporación de un $30 \%$ de $\mathrm{CV}$ lo hace ligeramente, debido a que el aporte de aluminatos por el FCC es muy superior a la de la CV.

- La mezcla ternaria de cemento Portland-FCC-ceniza volante consigue reducir apreciablemente el coeficiente de difusión de estado estacionario de los morteros (a pesar de contener mucho menos cemento), aunque esta mejora no es tan notable como en el caso de incorporar únicamente FCC.

- Las morteros que incorpan FCC y CV reducen ligeramente los valores de corrosión de los aceros frente a un ataque por 
Efecto del ataque por cloruros en morteros ternarios de cemento-FCC-ceniza volante reforzados con acero

cloruros externos de forma similar a lo que haría la incorporación de FCC ó CV únicamente.

- Un ataque por carbonatación posterior al ataque por cloruros evidencia las carencias de reserva alcalina de los morteros altamente sustituidos (un $30 \%$ y un $45 \%$ ) empleados en el estudio. 


\section{Conclusiones generales}

Una vez evaluada la influencia de la incorporación del FCC en morteros ante los clásicos ataques químicos (carbonatación e ingreso de cloruros) que sufren las estructuras de hormigón armado, se pueden establecer las siguientes conclusiones:

- El FCC es un material puzolánico capaz de aportar productos cementantes adicionales en mezclas de cemento y de cal. Como consecuencia de la reacción puzolánica, se incrementan fundamentalmente las cantidades de aluminatos y silicoaluminatos cálcicos hidratados, produciendo importantes mejoras en la densificación de la microestructura de los morteros.

- Los productos de la reacción puzolánica del FCC son susceptibles de descomponerse por efecto de ataque por carbonatación. A pesar de ello, las mejoras en las propiedades mecánicas que aporta el FCC se siguen manteniendo tras la carbonatación. 
- Frente a un ataque por carbonatación y en el caso de relaciones $\mathrm{a} / \mathrm{mc}$ iguales o superiores a 0,5 el avance del frente de carbonatación en los morteros con FCC es significativamente más rápido, dada la merma de la reserva alcalina que produce la reacción puzolánica. No obstante, para relaciones $\mathrm{a} / \mathrm{mc}$ menores, no existe diferencia de comportamiento con respecto a los morteros de cemento Portland.

- Para morteros con sustitución de cemento por FCC de hasta el $15 \%$ en peso, el parámetro que más influye en el proceso de corrosión de armaduras por carbonatación es la relación a/mc. Para mezclas con relaciones $\mathrm{a} / \mathrm{mc}$ por debajo de 0,5 , la presencia del FCC no produce ningún efecto negativo en la corrosión de armaduras.

- La incorporación progresiva de FCC en los morteros aumenta en la misma medida la capacidad de fijación de cloruros de la matriz cementante. Este hecho, unido a la reducción de la porosidad por efecto de la reacción puzolánica, hacen que los morteros con FCC ofrezcan una cinética de ingreso de cloruros mejorada con respecto a la ofrecida por los morteros de cemento Portland.

- La presencia de FCC en la matriz cementante, permite obtener una importante mejora en los niveles de corrosión de los aceros embebidos en los morteros frente a un ataque por cloruros. Las propiedades del FCC permiten aumentar el umbral de cloruros que provocan una corrosión significativa. La carbonatación posterior al ataque por cloruros no genera una situación más negativa para los sistemas con FCC.

- Frente a un ataque por carbonatación, el uso de mezclas ternarias de cemento/FCC/CV como conglomerantes en morteros en las dosificaciones empleadas en este estudio $(55 / 15 / 30)$, reduce de forma muy importante la resistencia a la carbonatación de los morteros. No obstante, el uso de un plastificante y relaciones $\mathrm{a} / \mathrm{mc}$ bajas puede paliar el aumento en la velocidad de corrosión que se produce, a la vez que se 
estaría reduciendo a casi la mitad el contenido de cemento en el mortero.

- El uso de mezclas ternarias de cemento/FCC/CV en las proporciones empleadas en este trabajo (55/15/30) dificulta el ingreso de cloruros en el mortero. Estas mezclas ternarias, además producen una ligera mejora de los niveles de corrosión de los aceros embebidos en estos morteros.

En resumen, se puede concluir que la sustitución de cemento por FCC ofrece mejoras frente al ataque por carbonatación y frente al ataque por cloruros en relación con la corrosión de armaduras embebidas en morteros. Esta posibilidad de mejora se atribuye a las modificaciones microestructurales en las matrices cementantes. 


\section{Referencias}

1. H.F.W. Taylor, Cement Chemistry, Academic Press Inc., Londres, 1990.

2. A.M. Neville, Properties of Concrete, $4^{\mathrm{a}}$ Edición, Longman Group Limited, Harlow, 1995.

3. P.K. Metha, P.J.M. Monteiro, Concrete: Structure, Properties, and Materials, 2 ${ }^{a}$ Edición, Prentice Hall, 1993.

4. M. Collepardi, The New Concrete, Tintoretto, Villorba (I), 2002.

5. A.M. Neville, J.J. Brooks, Concrete Technology, Longman Scientific and Technical, Harlow, 1990.

6. P. Schiessl (Ed.), Corrosion in Concrete, Rilem Technical Committee 60-CSC, Chapman and Hall, Londres, 1988.

7. T.C. Powers. Structure and physical properties of hardened Portland cement paste. Journal of American Ceramic Society 41 (1958) 1-6. 
8. D. Stauffer, Introduction to Percolation Theory, Taylor \& Francis, Londres, 1985.

9. B. Elsener, D. Flückiger, H. Böhni, "A percolation model for water sorption in porous cementitious materials", en Materials for Buildings and Structures, Euromat, Vol. 6, F.H. Wittmann (Ed.), Wiley-VCH, Weinheim, 163-169, 2000.

10. D.G. Nair, K.S. Jagadish, A. Fraaij. "Reactive pozzolans from rice husk ash: An alternative to cement for rural housing". Cement and Concrete Research 36 (2006) 1062-1071.

11. M. Nehdi, J. Duquette, A. El Damatty. "Performance of rice husk ash produced using a new technology as a mineral admixture in concrete". Cement and Concrete Research 33 (2003) 1203-1210.

12. S.K. Agarwal. "Pozzolanic activity of various siliceous materials". Cement and Concrete Research 36 (2006) 1735-1739.

13. Z.J. Li, Z. Ding. "Property improvement of Portland cement by incorporating with metakaolin and slag". Cement and Concrete Research 33 (2003) 579-584.

14. R.B. Polder, "Simulated de-icing salt exposure of blended cement concrete - chloride penetration", Proc. $2^{\text {nd }}$ International RILEM Workshop Testing and Modelling the Chloride Ingress into Concrete, C. Andrade, J. Kropp, (Eds.), PRO 19, RILEM Publications, 189-202, 2000.

15. CEB, Durable Concrete Structures, Bulletin d'information N.183, Lousanne, 1992.

16. J.M. Frederiksen (Ed.), HETEK, Chloride Penetration into Concrete. State of the Art. Transport Processes, Corrosion Initiation, Test Methods, The Road Directorate, Report No. 53, Copenhagen, 1996.

17. P.B. Bamforth, "Specifications and tests to determine the permeability of concrete", CEMCO-95, XXIII Curso de Estudios 
Mayores de la Construcción, Instituto E. Torroja, CSIC, Madrid, 24-26 Abril 1995.

18. C.L. Page, $\varnothing$. Vennesland. Pore solution composition and chloride binding capacity of silica fume cement pastes. Materials and Structures 16 (1983) 91.

19. J.A. Larbi, A.L.A. Fraay, J.M. Bijen. The chemistry of the pore solution of silica fume-blended cement systems. Cement and Concrete Research 20 (1990) 506-516.

20. J. Tritthart. Chloride binding in cement - II. The influence of the hydroxide concentration in the pore solution of hardened cement paste on chloride binding. Cement and Concrete Research 19 (1989) 586-594.

21. C.L. Page, N.R. Short, A. El Tarras. Diffusion of chloride ions in hardened cement paste. Cement and Concrete Research 11 (1981) 395-406.

22. P.B. Bamforth, J. Chapman-Andrews, "Long term performance of RC elements under UK coastal conditions", Proc. Int. Conf. on Corrosion and Corrosion Protection of Steel in Concrete, R.N. Swamy (Ed.), Sheffield Academic Press, 24-29 Julio 1994, 139156.

23. R.B. Polder, "Laboratory testing of five concrete types for durability in a marine environment", Proc. Fourth Int. Symp. on Corrosion of Reinforcement in Concrete Construction, C.L. Page, P.B. Bamforth, J.W. Figg (Eds.), Society of Chemical Industry, London, 115-123, 1996.

24. Nordtest Standard NT BUILD 443, Accelerated Chloride Penetration, 1995.

25. S.W. Yu, G. Sergi, C.L. Page. Ionic diffusion across an interface between chloride-free and chloride-containing cementitious materials. Magazine of Concrete Research 45 (1993) 257-261. 
26. W. Moore, Physical Chemistry, $4^{\mathrm{a}}$ Edición, Longman, Londres, 1972.

27. D. Bürchler, B. Elsener, H. Böhni, "Electrical resistivity and dielectrical properties of hardened cement paste and mortar", Mater. Res. Soc. Symp. Proc., 1996, 411, 407.

28. L. Tang, L.O. Nilsson. Rapid determination of chloride diffusivity of concrete by applying and electric field. ACI Materials Journal 49 (1992) 49-53.

29. L. Tang. Electrically accelerated methods for determining chloride diffusivity in concrete. Magazine of Concrete Research 48 (1996) 173-179.

30. C. Andrade. Calculation of chloride diffusion coefficients in concrete from ionic migration measurements. Cement and Concrete Research 23 (1993) 724-742.

31. R.B. Polder, W.H.A. Peelen, L. Bertolini, M. Guerrieri, "Corrosion rate of rebars from linear polarization resistance and destructive analysis in blended cement concrete after chloride loading”, $15^{\text {th }}$ International Corrosion Congress, Granada, 22-27 Septiembre 2002 (CD-ROM).

32. R.B. Polder, C. Andrade, B. Elsener, O. Vennesland, J. Gulliker, R. Weydert, M. Raupach. Draft RILEM technical recommendation test methods for on site measurement of resistivity of concrete. Materials and Structures 33 (2000) 603-611.

33. R.B. Polder. Test methods for on site measurement of resistivity of concrete - A RILEM TC-154 technical recommendation. Construction and Building Materials 15 (2001) 125-132.

34. A. Rossi, G. Puddu, B. Elsener, "The surface of iron and $\mathrm{Fe} 10 \mathrm{Cr}$ alloys in alkaline media", Proc. Eurocorr 2001, Riva del Garda, 30 Septiembre - 4 Octubre 2001 (CD-ROM), Associazione Italiana di Metallurgia, Milán. 
35. K. Tutti, Corrosion of Steel in Concrete, Swedish foundation for concrete research, Estocolmo, 1982.

36. R.M. Schroeder, I.L. Muller. Stress corrosion cracking and hydrogen embrittlement susceptibility of an eutectoid steel employed in prestressed concrete. Corrosion Science 45 (2003) 1969-1983.

37. E. Proverbio, P. Longo. Failure mechanisms of high strength steels in bicarbonate solutions under anodic polarization. Corrosion Science 45 (2003) 2017-2030.

38. C. Alonso, C. Andrade, "Life time of rebars in carbonated concrete", en Progress in Understanding and Prevention of Corrosion, J.M. Costa, A.D. Mercer (Eds.), Institute of Materials, Londres, 624, 1994.

39. G. Sergi, Corrosion of Steel in Concrete: Cement Matrix Variables, Tesis Doctoral, Universidad de Aston, Birmingham, 1986.

40. H.J. Wierig, "Long-time studies on the carbonation of concrete under normal outdoor exposure", Rilem Seminar on Durability of Concrete Structures under Normal Outdoor Exposure, Hannover, 26-27 Marzo 1984.

41. L.J. Parrott. Carbonation, moisture and empty pores. Advances in Cement Research 4 (1991/92) 111-118.

42. D.W.S. Ho, R.K. Lewis. Carbonation of concrete and its prediction. Cement and Concrete Research 17 (1987) 489-501.

43. T.K.H. Al-Kadhimi, P. Banfill, S.G. Millard, J.H. Bungey. An accelerated carbonation procedure for studies on concrete. Advances in Cement Research 8 (1996) 47-59.

44. C.L. Page, "Nature and properties of concrete in relation to reinforcement corrosion", in Corrosion of Steel in Concrete, Aachen, 17-19 Febrero 1992. 
45. G.K. Glass, C.L. Page, N.R. Short. Factors affecting the corrosion of steel in carbonated mortars. Corrosion Science 32 (1991) 1283.

46. R.B. Polder, "Cathodic protection of reinforced-concrete structures in the Netherlands - experience and developments", in Corrosion of Reinforcement in Concrete - Monitoring, Prevention and Rehabilitation, Papers from Eurocorr' 97, J. Mietz, B. Elsener, R.B. Polder (Eds.), The European Federation of Corrosion Publication number 25, The Institute of Materials, Londres, 172184, 1998.

47. G. Schuten, J. Leggedoor, R.B. Polder, "Cathodic protection of concrete ground floor elements with mixed in chloride", in Corrosion of Reinforcement in Concrete, Corrosion Mechanisms and Corrosion Protection, Papers from Eurocorr' 99, J. Mietz, R.B. Polder, B. Elsener (Eds.), The European Federation of Corrosion Publication number 31, The Institute of Materials, Londres, 85-92, 2000.

48. P. Pedeferri. Cathodic protection and cathodic prevention. Construction and Building Materials 10 (1996) 391-402.

49. C. Alonso, M. Castellote, C. Andrade, "Dependence of chloride threshold with the electrical potential of reinforcements", Proc. $2^{\text {nd }}$ International RILEM Workshop Testing and Modelling the Chloride Ingress into Concrete, C. Andrade, J. Kropp (Eds.) PRO 19, RILEM Publications, 415-425, 2000.

50. P.R. Vassie, "Reinforcement corrosion and the durability of concrete bridges", Proceedings of the Institution of Civil Engineers, Part 1, Vol. 76, paper 8798, 713, 1984.

51. COST 521, "Determination of chloride threshold in concrete", C. Andrade, in Corrosion of Steel in Reinforced Concrete Structures. Final report, ed. R. Cigna, C. Andrade, U. Nürnberger, R. Polder, R. Weydert, E. Seitz, European Communities EUR 20599, Luxemburgo (2003) p. 100-108. 
52. G.K. Glass, N.R. Buenfeld. Chloride threshold level for corrosion of steel in concrete. Corrosion Science 39 (1997) 1001-1013.

53. C.L. Page, P. Lambert, P.R.W. Vassie. Investigation of reinforcement corrosion: 1 . The pore electrolyte phase in chloridecontaminated concrete. Materials and Structures 24 (1991) 243252.

54. P. Lambert, C.L. Page, P.R.W. Vassie. Investigation of reinforcement corrosion: 2. Electrochemical monitoring of steel in chloride-contaminated concrete. Materials and Structures 24 (1991) 351-358.

55. D.A. Hausmann. Steel corrosion in concrete, how does it occur?. Materials Protection 11 (1967) 19-23.

56. G.K. Glass, N.R. Buenfeld. The inhibitive effects of electrochemical treatment applied to steel in concrete. Corrosion Science 42 (2000) 923-927.

57. C.L. Page, "Advances in understanding and techniques for controlling reinforcement corrosion", $15^{\text {th }}$ International Corrosion Congress, Granada, 22-27 Septiembre 2002.

58. R.B. Polder, J.A. Larbi, "Investigation of concrete exposed to North Seawater submersion for 16 years", Heron (Delft), 1995, 40 (1), 31-56.

59. R.F.M. Bakker, G. Wegen, J. Van der Bijen, "Reinforced concrete, an assessment of the allowable chloride content", Proc. of Canmet/ACI Int. Conf. on Durability of Concrete, Niza, 1994.

60. M.D.A. Thomas. Chloride thresholds in marine concrete. Cement and Concrete Research 26 (1996) 513-519.

61. M. Collepardi, A. Marcialis, R. Turriziani. Penetration of chlorides ions into cement pastes and concretes. Journal of American Ceramic Society 55 (1972) 534-542. 
62. L.O. Nilsson, A. Andersen, L. Tang, P. Utgenannt, "Chloride ingress data form field exposure in a Swedish environment", Proc. $2^{\text {nd }}$ Int. Rilem Workshop Testing and Modelling the Chloride Ingress into Concrete, C. Andrade, J. Kropp (Eds.), París, 11-12 Septiembre 2000, 69-83.

63. A. Lindavall, A. Andersen, L.O. Nilsson, "Chloride ingress data from Danish and Swedish raod bridges exposed to splash from deicing salt", Proc. $2^{\text {nd }}$ Int. Rilem Workshop Testing and Modelling the Chloride Ingress into Concrete, C. Andrade, J. Kropp (Eds.), París, 11-12 Septiembre 2000, 85-103.

64. L. Tang, A. Andersen, "Chloride ingress data form five years field exposure in a Swedish marine environment", Proc. $2^{\text {nd }}$ Int. Rilem Workshop Testing and Modelling the Chloride Ingress into Concrete, C. Andrade, J. Kropp (Eds.), París, 11-12 Septiembre 2000, 105-119.

65. C. Andrade, J.L. Sagrera, M.A. Sanjuán, "Several years study on chloride ion penetration into concrete exposed to Atlantic ocean water", Proc. $2^{\text {nd }}$ Int. Rilem Workshop Testing and Modelling the Chloride Ingress into Concrete, C. Andrade, J. Kropp (Eds.), París, 11-12 Septiembre 2000, 121-134.

66. D. Izquierdo, C. Andrade, O. de Rincón, "Statistical analysis of the diffusion coefficients measured in the piles of Maracaibo's bridge", Proc. $2^{\text {nd }}$ Int. Rilem Workshop Testing and Modelling the Chloride Ingress into Concrete, C. Andrade, J. Kropp (Eds.), París, 11-12 Septiembre 2000, 135-148.

67. C.L. Page, N.R. Short, W.H.R. Holden. The influence of different cements on chloride-induced corrosion of reinforcing steel. Cement and Concrete Research 16 (1986) 79-86.

68. G.K. Glass, C.L. Page, N.R. Short. Factors affecting the corrosion rate of steel in carbonated mortars. Corrosion Science 32 (1991) 1283-1294. 
69. S. Fiore, R.B. Polder, R. Cigna, "Evaluation of the concrete corrosivity by means of resistivity measurements", Proc. Fourth Int. Symp. on Corrosion of Reinforcement in Concrete Construction, C.L. Page, P.B.Bamforth, J.W. Figg (Eds.), Society of Chemical Industry, Cambridge, UK, 1-4 Julio 1996, 273-282.

70. L. Bertolini, R.B. Polder. Factors influencing resistivity of concrete and consequences for corrosion of embedded steel. Materials and Corrosion 38 (1987) 145-157.

71. C. Alonso, C. Andrade, J. González. Relation between resistivity and corrosion rate of reinforcements in carbonated mortar made with several cement types. Cement and Concrete Research 18 (1988) 687-698.

72. R.B. Polder, P.B. Bamforth, M. Basheer, J. Chapman-Andrews, R. Cigna, M.I. Jafar, A. Mazzoni, E. Nolan, H. Wojtas, "Reinforcement corrosion and concrete resistivity state of the arte, laboratory and field results", Proc. Int. Conf. on Corrosion and Corrosion Protection of Steel in Concrete, R.N. Swamy (Ed.), Sheffield Academic Press, 24-29 Julio 1994, 571-580.

73. E. Furimsky. Review of spent refinery catalyst: environment, safety and utilization. Catalysis Today 30 (1996) 223-286.

74. N. Su, Z.-H. Chen, H.-Y. Fang. Reuse of spent catalyst as fine aggregate in cement mortar. Cement \& Concrete Composites 23 (2001) 111-118.

75. N. Su, H.-Y. Fang, Z.-H. Chen, F.-S. Lu. Reuse of waste catalysts from petrochemical industries for cement substitution. Cement and Concret Research 30 (2000) 1773-1783.

76. J. Payá, J. Monzó, M. V. Borrachero. Physical, chemical and mechanical properties of fluid catalytic cracking catalyst residue (FCC) blended cements. Cement and Concrete Research 31 (2001) 57-61.

77. J. Payá, J. Monzó y M. V. Borrachero. Fluid catalytic cracking catalyst residue (FCC). An excellent mineral by-product for 
improving early-strength development of cement mixtures. Cement and Concrete Research 29 (1999) 1773-1779.

78. J. Payá, J. Monzó, M. V. Borrachero, F. Amahjour, I. Girbés, S. Velázquez, L. M. Ordóñez. Advantages in the use of fly ashes in cements containing pozzolanic combustion residues: silica fume, sewage sludge ash, spent fluidized bed catalyst and rice husk ash. Journal of Chemical Technology and Biotechnology 77 (2002) 331-335.

79. B. Pacewska, M. Bukowska, I. Wilinska, M. Swat. Modification of the properties of concrete by a new pozzolan. A waste catalyst form the catalytic process in a fluidized bed. Cement and Concrete Research 32 (2002) 145-152.

80. K.-C. Hsu, Y.-S. Tseng, F.-F. Ku, N. Su. Oil cracking waste catalyst as an active pozzolanic material for superplasticized mortars. Cement and Concrete Research 31 (2001) 1815-1820.

81. J.-H. Wu, W.-L. Wu, K.-C. Hsu. The effect of waste oil-cracking catalyst on the compressive strength of cement pastes and mortars. Cement and Concrete Research 33 (2003) 245-253.

82. J. Payá, J. Monzó, M. V. Borrachero, S. Velázquez. Evaluation of the pozzolanic activity of fluid catalytic cracking residue (FCC). Thermogravimetric analysis studies on FCC-Portland cement pastes. Cement and Concrete Research 33 (2003) 603-609.

83. U. Rattanasak, C. Jaturapitakkul, T. Sudaprasert. Compressive strength and heavy metal leaching behaviour of mortars containing spent catalyst. Waste Management \& Research 19 (2001) 456-464.

84. I. Girbés. "Evaluación del uso de subproductos industriales de carácter puzolánico en conglomerantes de cemento Pórtland. Influencia de su utilización sobre la durabilidad de los materiales". Tesis doctoral, Universidad Politécnica de Valencia, Valencia (2004).

85. F.M. Lea. The Chemistry of Cement and Concrete. Ed. Arnold, London. 
86. S. Zdenek. Carbonization of porous concrete and its main binding components. Cement and Concrete Research 1 (1971) 645-662.

87. S. Kazutaka, N. Tadahiro, I. Suketoshi. Formation and carbonation of C-S-H in water. Cement and Concrete Research 15 (1985) 213224.

88. A.M. Dunster. An investigation of the carbonation of cement paste using trimethylsilylation. Advances in Cement Research 2 (1992) 99-106.

89. P.A. Slegers, P.G. Rouxhet. Carbonation of the hydration products of tricalcium silicate. Cement and Concrete Research 6 (1976) 381-386.

90. RILEM Committee CPC-18. Measurement of hardened concrete carbonation depth. TC14-CPC (1998).

91. Y. Lo, H.M. Lee. Curing effects on carbonation of concrete using a phenolphthalein indicator and Fourier-transform infrared spectroscopy. Building and Environment 37 (2002) 507-514.

92. G. Villain, G. Platret. Two experimental methods to determine carbonation profiles in concrete. ACI Materials Journal 103 (2006) 265-271.

93. M.A. Serry, A.S. Taha, S.A.S El-Jemaly, H. El-Didamony. Metakaolin-lime hydration products. Thermichimica Acta 79 (1984) 103-110.

94. N.J. Saikia, P. Sengupta, P.K. Gogoi, P.C. Borthakur. Hydration behaviour of lime-co-calcined kaolin-petroleum effluent treatment plant sludge. Cement and Concrete Research 32 (2002) 297-302.

95. M. Frías, J. Cabrera. Influence of $\mathrm{MK}$ on the reaction kinetics in $\mathrm{MK} /$ lime and MK-blended cement systems at $20^{\circ} \mathrm{C}$. Cement and Concrete Research 31 (2001) 519-527. 
96. P.S. de Silva, F.P. Glasser. Phase relations in the system CaO$\mathrm{Al}_{2} \mathrm{O}_{3}-\mathrm{SiO}_{2}-\mathrm{H}_{2} \mathrm{O}$ relevant to $\mathrm{MK}$-lime hydration. Cement and Concrete Research 23 (1993) 627-639.

97. J. Payá, J. Monzón, M. V. Borrachero, S. Velázquez. Evaluation of the pozzolanic activity of fluid catalytic cracking catalyst residue. Thermogravimetric analysis studies on FC3R-lime pastes. Cement and Concrete Research 33 (2003) 1085-1091.

98. Application of differential thermal analysis in cement chemistry. V. S. Ramachandran. Ed. Chemical Publishing Company, Inc. New York (1969).

99. F. Amahjour. "Estudio de la reactividad de puzolanas artificiales: Cenizas volantes y humo de sílice, y su reutilización en ingeniería civil". Tesis Doctoral, Universidad Politécnica de Valencia, Valencia (2000).

100. S. Goñi, M. T. Gaztañaga, A. Guerrero. Role of cement type on carbonation attack. Journal of Materials Research 17 (2002) 1834-1842.

101. T. Nishikawa, K. Suzuki, S. Ito. Decomposition of synthesized ettringite by carbonation. Cement and Concrete Research 22 (1992) 6-14.

102. S. Velázquez. Aplicaciones del catalizador de craqueo catalítico usado (FCC) en la preparación de conglomerantes hidráulicos. Estudio de sus propiedades puzolánicas. Tesis doctoral, Universidad Politécnica de Valencia, Valencia, 2002.

103. E.T. Stepkowska, J.L. Pérez Rodríguez, M.J. Sayagués, J.M. Martínez Blanes. Calcite, vaterite and aragonite forming on cement hydration from liquid and gaseous phase. Journal of Thermal Analysis and Calorimetry 73 (2003) 247-269.

104. P.S. de Silva, F.P. Glasser. Phase relations in the system CaO$\mathrm{Al}_{2} \mathrm{O}_{3}-\mathrm{SiO}_{2}-\mathrm{H}_{2} \mathrm{O}$ relevant to metakaolin-calcium hydroxide hydration. Cement and Concrete Research 23 (1993) 627-639. 
105. D.S. Klimesch, A. Ray. Hydrogarnet formation during autoclaving at $180{ }^{\circ} \mathrm{C}$ in unstirred metakaolin-lime-quartz slurries. Cement and Concrete Research 28 (1998) 1109-1117.

106. J. Aguilera, M.T. Blanco Varela, T. Vázquez. Procedure of synthesis of thaumasite. Cement and Concrete Research 31 (2001) 1163-1168.

107. R. Talero. Kinetochemical and morphological differentiation of ettringites by the Le Chatelier-Anstett test. Cement and Concrete Research 32 (2002) 707-717.

108. E.T. Stepkowska, J.L. Pérez Rodríguez, M.C. Jiménez de Haro, M.J. Sayagues. Study of hydration of two cements of different strengths. Journal of Thermal Analysis and Calorimetry 69 (2002) 187-204.

109. Md. A. I. Laskar, R. Kumar, B. Bhattacharjee. Some aspects of evaluation of concrete through mercury intrusion porosimetry. Cement and Concrete Research 27 (1997) 93-105.

110. R.A. Cook, K.C. Hover. Mercury intrusion porosimetry of hardened cement pastes. Cement and Concrete Research 29 (1999) 933-943.

111. M. O'Farrell, S. Wild, B.B. Sabir. Pore size distribution and compressive strength of waste clay brick mortar. Cement \& Concrete Composites 23 (2001) 81-91.

112. J.M. Khatib, S. Wild. Pore size distribution of metakaolin paste. Cement and Concrete Research 26 (1996) 1545-1553.

113. D.P. Bentz, P.E. Stutzman. Evolution of porosity and calcium hydroxide in laboratory concretes containing silica fume. Cement and Concrete Research 24 (1994) 1044-1050.

114. V.T. Ngala, C.L. Page. Effects of carbonation on pore structure and diffusional properties of hydrated cement pastes. Cement and Concrete Research 27 (1997) 995-1007. 
115. J.J. Chang, W. Yeih, R. Huang, C.T. Chen. Suitability of several current used concrete durability indices on evaluationg the corrosion hazard for carbonated concrete. Materials Chemistry and Physics 84 (2004) 71-78.

116. C.A. García González, A. Hidalgo, C. Andrade, M.C. Alonso, J. Fraile, A.M. López Periago, C. Domingo. Modification of composition and microstructure of portland cement pastes as a result of natural and supercritical carbonation procedures. Industrial and Engineering Chemistry Research 45 (2006) 49854992.

117. Ch. Malami, V. Kaloidas, G. Batis, N. Kouloumbi. Carbonation and porosity of mortar specimens with pozzolanic and hydraulic cement admixtures. Cement and Concrete Research 24 (1994) 1444-1454.

118. I. Matsushita, T. Suzuki, T. Moriga, T. Ashida, I. Nakabayashi, J. Metson. XPS study on the carbonation process of $\mathrm{Ca}(\mathrm{OH})_{2}$. Journal of the Ceramic Society of Japan 101 (1993) 725-727.

119. L. Zhang, F.P. Glasser. Investigation of the microstructure and carbonation of CŜA-based concrete removed from service. Cement and Concrete Research 35 (2005) 2252-2260.

120. K. Kobayashi, K. Suzuki, Y. Uno. Carbonation of concrete structures and decomposition of C-S-H. Cement and Concrete Research 24 (1994) 55-61.

121. G. Villain, M. Thiery. Gammadensimetry: A method to determine drying and carbonation profiles in concrete. NDT\&E International 39 (2006) 328-337.

122. Norma UNE-EN 196-1:1996. Métodos de ensayos de cementos. Parte 1: Determinación de resistencias mecánicas.

123. Norma UNE 83-134-90. Áridos para hormigones. Determinación de las densidades, porosidad, coeficiente de absorción y contenido de agua del árido grueso. 
124. L.C. Lange, C.D. Hills, A.B. Poole. The influence of mix parameters and binder choice on the carbonation of cement solidified wastes. Waste Management 16 (1996) 749-756.

125. J. Khunthongkeaw, S. Tangtermsirikul, T. Leelawat. A study on carbonation depth prediction for fly ash concrete. Construction and Building Materials 20 (2006) 744-753.

126. M. A. Sanjuán, C. Andrade, M. Cheyrezy. Concrete carbonation tests in natural and accelerated conditions. Advances in Cement Research 15 (2003) 171-180.

127. P. Sulapha, S.F. Wong, T.H. Wee, S. Swaddiwudhipong. Carbonation of concrete containing mineral admixtures. Journal of Materials in Civil Engineering 15 (2003) 134-143.

128. T.H. Wee, A.K. Suryavanshi, D. Logendran. Pore structure controlling the carbonation of a hardened cement matrix blended with mineral admixture. Advances in Cement Research 11 (1999) 81-95.

129. P. Castro, M.A. Sanjuán, J. Genescá. Carbonation of concretes in the Mexican Gulf. Building and Environment 35 (2000) 145149.

130. T. Uomoto, Y. Takada. Factors affecting concrete carbonation rate. Durability of Building Materials and Components 6 (1993) 1133-1141.

131. Y.H. Loo, M.S. Chin, C.T. Tam, K.C.G. Ong. A carbonation prediction model for accelerated carbonation testing of concrete. Magazine of Concrete Research 46 (1994) 191-200.

132. J. Bai, S. Wild, B. B. Sabir. Sorptivity and strength of aircured and water-cured PC-PFA-MK concrete and the influence of binder composition on carbonation depth. Cement and Concrete Research 32 (2002) 1813-1821. 
133. C. D. Atiş. Accelerated carbonation and testing of concrete made with fly ash. Construction and Building Materials 17 (2003) 147-152.

134. V. G. Papadakis. Effect of supplementary cementing materials on concrete resistance against carbonation and chloride ingress. Cement and Concrete Research 30 (2000) 291-299.

135. M.I. Khan, C.J. Lynsdale. Strength, permeability, and carbonation of high-performance concrete. Cemente and Concrete Research 32 (2002) 123-131.

136. M.N. Haque, H. Al-Khaiat. Carbonation of concrete structures in hot dry coastal regions. Cement and Concrete Composites 19 (1997) 123-129.

137. L. Fernández-Carrasco, F. Puertas, M. T. Blanco-Varela, T. Vázquez. Carbonatación de pastas de cemento de aluminato de calcio. Materiales de Construcción 51 (2001) 127-136.

138. Norma EN 13139:2003, “Áridos para morteros”.

139. Norma EN 1015-2, "Métodos de ensayo de los morteros para albaliñería. Parte 2: Toma de muestra total de los morteros y preparación de los morteros para ensayo".

140. L. García Andión, P. Garcés, E. García Alcocel, F. Cases. Steel corrosion and durability of calcium aluminate cementereinforced mortars. Corrosion 61 (2005) 1004-1010.

141. M. Stern, A.L. Geary, "A theorical analysis of the shape of polarization curves", Journal of Electrochemical Society, 1957, 104, 56-63.

142. W.J. MaCarter, Ø. Vennesland. Sensor systems for use in reinforced concrete structures. Construction and Building Materials 18 (2004) 351-358.

143. C. Andrade, J.A. González. Quantitative measurements of corrosion rate of reinforcing steels embedded in concrete using 
polarization resistance measurements. Wekst. Korros. 29 (1978) 515-523.

144. J.P. Broomfield. Corrosion of steel in concrete. Ed. E\&FN Spon. Londres (1997) 240.

145. S. Ahmad. Reinforcement corrosion in concrete structures, its monitoring and service life prediction - a review. Cement and Concrete Composites 25 (2003) 459-471.

146. J.H. Cahyadi, T. Uomoto. Influence of environmental relative humidity on carbonation of concrete (mathematical modelling). Durability of Bulding Materials and Components 6. Ed. E\&FB Spon (1993) 1142-1151.

147. J. Raupach. Models for the propagation phase of reinforcement corrosion - an overview. Materials and Corrosion 57 (2006) 605613.

148. K. Kobayashi, K. Suttoh. Oxygen diffusivity of various cemetitious materials. Cement and Concrete Research 21 (1991) 273-284.

149. Norma Americana ASTM C876 (1999). Standard test method for half-cell potentials of uncoated reinforcing steel in concrete.

150. O.E. Gjorv. Effect of condensed silica fume on steel corrosion in concrete. ACI Materials Journal 92 (1995) 591-598.

151. J.G. Cabrera, P.A. Claisse, D.N. Hunt. A statistical analysis of the factors which contribute to the corrosion of steel in Portland cement and silica fume concrete. Construction and Building Materials 9 (1995) 105-113.

152. M.F. Montemor, M.P. Cunha, M.G. Ferreira, A.M. Simões. Corrosion behaviour of rebars in fly ash mortar exposed to carbon dioxide and chlorides. Cement and Concrete Composites 24 (2002) 45-53. 
153. J. Tangpagasit, R. Cheerarot, C. Jaturapitakkul, K. Kiattikomol. Packing effect and pozzolanic reaction of fly ash in mortar. Cement and Concrete Research 35 (2005) 1145-1151.

154. S. Goñi, C. Andrade. Synthetic concrete pore solution chemistry and rebar corrosion rate in the presence of chorides. Cement and Concrete Research 20 (1990) 525-539.

155. J. Payá, M.V. Borrachero, J. Monzó, E. Peris Mora, M. Bonilla. Long term mechanical strength behaviour in fly ash/Portland cement mortars prepared using processed ashes. Journal of Chemical Technology and Biotechnology 77 (2002) 336-344.

156. J. Payá, J. Monzó, M.V. Borrachero, E. Peris Mora, F. Amahjour. Mechanical treatment of fly ashes. Part IV. Strength development of ground fly ash-cement mortars cured at different temperatures. Cement and Concrete Research 30 (2000) 543-551.

157. P. Garcés, E. Ga Alcocer, J.J. Martínez Pérez, J. Payá, L. Ga Andión. Effect of sewage sludge ash (SSA) on the mechanical performance and corrosion levels of reinforced Portland cement mortars. Materiales de Construcción 56 (2006) 31-43.

158. N. Saikia, S. Kato, T. Kojima. Thermogravimetric investigation on the chloride binding behaviour of MK-lime paste. Thermochimica Acta 444 (2006) 16-25.

159. A. K. Suryavanshi, J.D. Scantlebury, S.B. Lyon. Mechanism of Friedel's salt formation in cements rich in tricalcium aluminate. Cement and Concrete Research 26 (1996) 717-727.

160. U.A. Birnin-Yauri, F.P. Glasser. Friedel's salt, $\mathrm{Ca}_{2} \mathrm{Al}(\mathrm{OH})_{6}(\mathrm{Cl}, \mathrm{OH}) \cdot 2 \mathrm{H}_{2} \mathrm{O}$ : Its solid solutions and their role in chloride binding. Cement and Concrete Research 28 (1998) 17131723.

161. M.R. Jones, D.E. Macphee, J.A. Chudek, G. Hunter, R. Lannegrand, R. Talero, S. N Scrimgeour. Studies using ${ }^{27}$ Al MAS 
NMR of $\mathrm{AF}_{\mathrm{m}}$ and $\mathrm{AF}_{\mathrm{t}}$ and the formation of Friedel's salt. Cement and Concrete Research 33 (2003) 177-182.

162. S. Goñi, A. Guerrero. Accelerated carbonation of Friedel's salt in calcium aluminate paste. Cement and Concrete Research 33 (2003) 21-26.

163. A.K. Suryavanshi, R.N. Swamy. Stability of Friedel's salt in carbonated concrete structural elements. Cement and Concrete Research 26 (1996) 729-741.

164. Norma Americana ASTM C 1202-91. Standard test method for electrical indication of concrete's ability to resist chloride ion penetration. American Society for Testing Materials (1991).

165. C. Andrade. Calculation of chloride diffusion coefficients in concrete from ionic migration measurements. Cement and Concrete Research 23 (1993) 724-742.

166. M. Castellote, C. Andrade, C. Alonso. Measurements of the steady and non-steady-state chloride diffusion coefficients in a migration test by jeans of monitoring the conductivity in the anolyte chamber. Comparison with natural diffusion tests. Cement and Concrete Research 31 (2001) 1411-1420.

167. C.C. Yang, L.C. Wang. The diffusion characteristic of concrete with mineral admixtures between salt ponding test and accelerated chloride migration test Materials Chemistry and Physics 85 (2004) 266-272.

168. J. Bai, S. Wild, B.B. Sabir. Chloride ingress and strength loss in concrete with different PC-PFA-MK binder compositions exposed to synthetic seawater. Cement and Concrete Research 33 (2003) 353-362.

169. A. Boddy, R.D. Hooton, K.A. Gruber. Long-term testing of the chloride-penetration resistance of concrete containing highreactivity metakaolin. Cement and Concrete Research 31 (2001) 759-765. 
170. D. McPolin, P.A.M. Basheer, A.E. Long, K.T.V. Grattan, T. Sun. Obtaining progressive chloride profiles in cementitious materials. Construction and Building Materials 19 (2005) 666-673.

171. M.A. Climent, G. de Vera, J.F. López, E. Viqueira, C. Andrade. A test method for measuring chloride diffusion coefficients through nonsaturated concrete. Part I: The instantaneous plane source diffusion case. Cement and Concrete Research 32 (2002) 1113-1123. 